\title{
Guidelines for Conceptual \\ Design and Evaluation of Aquifer Thermal Energy Storage
}

October 1980

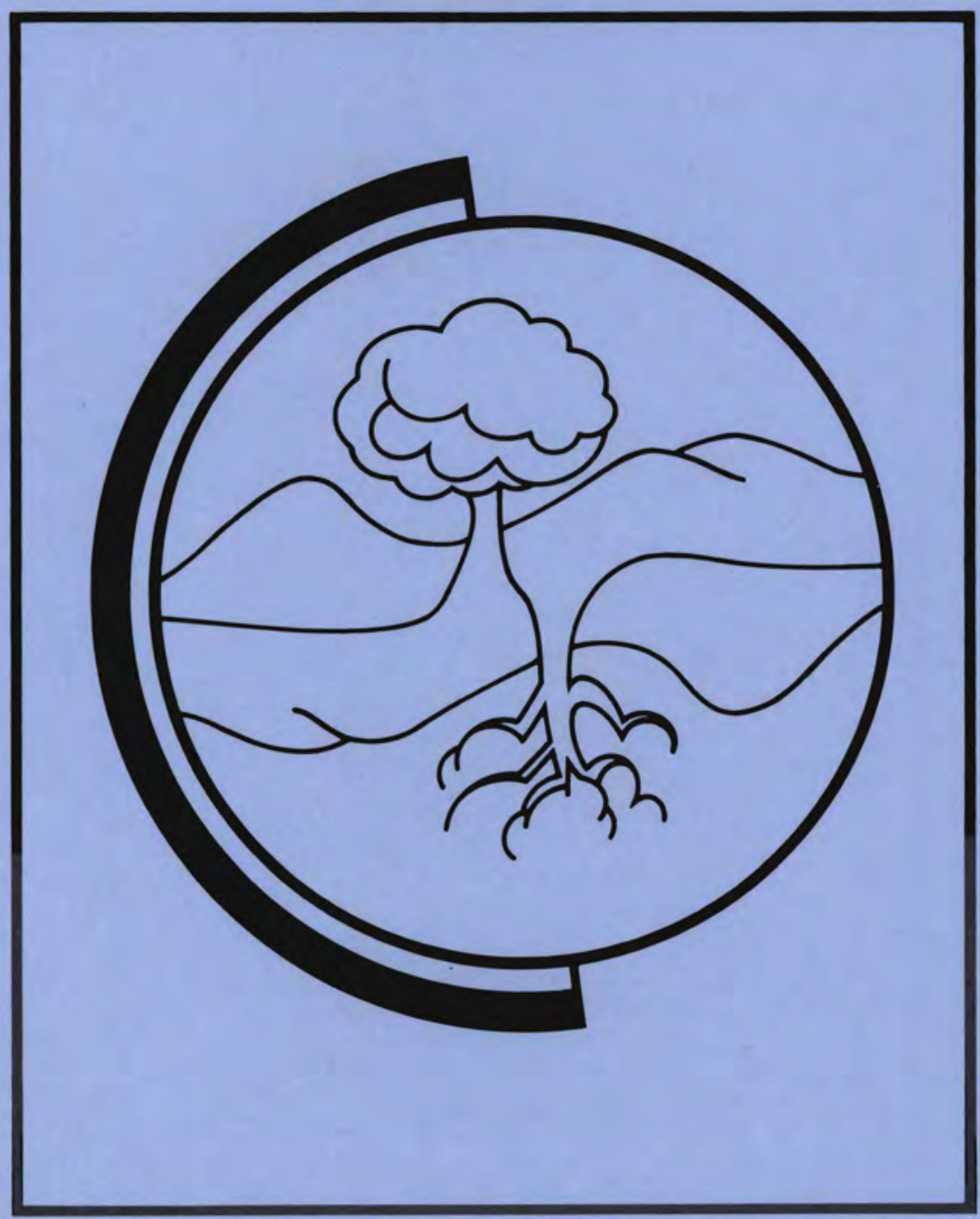

Prepared for Pacific Northwest Laboratory Seasonal Thermal Energy Storage Program under Special Agreement B-67764-A-O

Pacific Northwest Laboratory Operated for the U.S. Department of Energy by Battelle Memorial Institute 


\title{
NOT I C E
}

This report was prepared as an account of work sponsored by the United States Government. Neither the United States nor the Department of Energy, nor any of their employees, nor any of their contractors, subcontractors, or their employees, makes any warranty, express or implied, or assumes any legal liability or responsibility for the accuracy, completeness or usefulness of any information, apparatus, product or process disclosed, or represents that its use would not infringe privately owned rights.

The views, opinions and conclusions contained in this report are those of the contractor and do not necessarily represent those of the United States Government or the United States Department of Energy.

\author{
PACIFIC NORTHWEST LABORATORY \\ operated by \\ BATTELLE \\ for the \\ UNITED STATES DEPARTMENT OF ENERGY \\ Under Contract DE-AC06-76RLO 1830
}

\author{
Printed in the United States of America \\ Available from \\ National Technical Information Service \\ United States Department of Commerce \\ 5285 Port Royal Road \\ Springfield, Virginia 22151
}

Price: Printed Copy $\$$ *: Microfiche $\$ 3.00$

$\begin{array}{cc}\text { *Pages } & \begin{array}{c}\text { NTIS } \\ \text { Selling Pric }\end{array} \\ 001-025 & \$ 4.00 \\ 026-050 & \$ 4.50 \\ 051-075 & \$ 5.25 \\ 076-100 & \$ 6.00 \\ 101-125 & \$ 6.50 \\ 126-150 & \$ 7.25 \\ 151-175 & \$ 8.00 \\ 176-200 & \$ 9.00 \\ 201-225 & \$ 9.25 \\ 226-250 & \$ 9.50 \\ 251-275 & \$ 10.75 \\ 276-300 & \$ 11.00\end{array}$




\author{
GUIDELINES FOR CONCEPTUAL DESIGN \\ AND EVALUATION OF AQUIFER THERMAL \\ ENERGY STORAGE \\ C. F. Meyer \\ W. Hauz \\ TEMPO Center for Advanced Studies \\ General Electric Company \\ Santa Barbara, California
}

October 1980

Prepared for Pacific Northwest Laboratory Seasonal Thermal Energy Storage Program under Special Agreement B-67764-A-0 under U.S. Department of Energy Contract DE-AC06-76RLO 1830

\footnotetext{
- Pacific Northwest Laboratory Richland, Washington 99352
} 


\section{ABSTRACT}

Guidelines are presented for use as a tool by those considering application of a new technology, aquifer thermal energy storage (ATES). The guidelines will assist utilities, municipalities, industries, and other entities in the conceptual design and evaluation of systems employing ATES.

Chapters 1 and 2 are an eight-page executive summary, describing the potential benefits of ATES, giving an overview of the technology and its applications, and providing rules of thumb for quickly judging whether a proposed project has sufficient promise to warrant detailed conceptual design and evaluation.

The balance of the 230-page document discusses the characteristics of sources and end uses of heat and chill which are seasonally mismatched and may benefit from ATES (industrial waste heat, cogeneration, solar heat, and winter chill, for space heating and air conditioning); describes storage and transport subsystems and their expected performance and cost as best these parameters are now known; presents a 10-step methodology for conceptual design of an ATES system and evaluation of its technical and economic feasibility in terms of energy conservation, cost savings, fuel substitution, improved dependability of supply, and abatement of pollution, with examples; and applies the methodology to a hypothetical proposed ATES system, to illustrate its use.

Key words: Air conditioning, Aquifers, Cogeneration, District heating, Energy conservation, Energy transmission, Groundwater, Pollution abatement, Sensible heat storage, Solar energy storage, Space heating, Thermal energy storage, Thermal power plants. 


\section{CONTENTS}

$\begin{array}{lr} & \text { Page } \\ \text { ABSTRACT } & i \mathrm{i} \\ \text { ILLUSTRATIONS } & \text { vi } \\ \text { TABLES } & \mathrm{ix} \\ \text { ACKNOWLEDGMENTS } & \mathrm{x} \\ \text { INTERNATIONAL SYSTEM OF UNITS (SI) } & \mathrm{xi} \\ \text { CHAPTER } & \end{array}$

\begin{tabular}{|cr}
\hline \multicolumn{2}{c}{ EXECUTIVE SUMMARY } \\
\hline INTRODUCTION & $1-1$ \\
Purpose & $1-1$ \\
Overview & $1-1$ \\
Organization of This Volume & $1-3$ \\
2 EARLY SCREENING OF POTENTIAL ATES APPLICATIONS & $2-1$ \\
Summary of Early-Screening Criteria & $2-1$ \\
Mismatch Between Thermal Energy Source & $2-1$ \\
and End Use & $2-2$ \\
High Temperature Water (HTW) Versus Steam & $2-2$ \\
Minimum Feasible Size & $2-3$ \\
Availability of a Suitable Aquifer & $2-4$ \\
Cost of ATES Facilities and Operation &
\end{tabular}

3 INFORMATION NEEDED FOR DESIGNING AN ATES SYSTEM

Sources of Heat and Chill 3-2

Reference-Case Description 3-2

Cases with ATES 3-3

Information Needed 3-3

Importance of Second-Law Considerations 3-4

Industrial Waste Heat 3-5

Renewable Sources 3-6

Cogeneration 3-7

Auxiliary Boilers in ATES Systems 3-13 
Reference-Case Subsystem

Cases with ATES

Information Needed

Above Ground

Below Ground

Heat Storage Well Doublet

Rate of Thermal Energy Storage

Amount of Thermal Energy Storage

Distance to Heat Interface; Well Spacing

Heat Exchanger

Compensating for Temperature Drop

Across Heat Exchanger

Other Aboveground Equipment

Scaling, Corrosion, Fouling, and Well Plugging

Stored Hot Water:

Temperature Loss and Heat Recovery Fraction

Stored Cold Water:

Temperature Rise and Chill Recovery Fraction

Number of Wells Required

Land Area Required

Cost of Wells and Pumping

Special Well Design Features

Thermal Transport Subsystem

Describing the Load and the Thermal Energy Storage

Comparing Source and Load

Quantify Mismatch vs. Time

Select Supply and Storage Temperatures

Estimate ATES Capacity Needed

Estimate ATES Location and Transport

Capacity Needed 


\section{Chapter}

Estimate Losses in ATES and Transport

Page

Estimate ATES Losses

4-11

Estimate Transport Losses

4-12

Adjust Estimates of ATES and Transport Capacity Required

$4-12$

4-15

Develop Operating Schedules

Find Cost and Fuel Consumption Benefits

4-20

Estimate Expected Cost of ATES

4-22

Benefit/Cost Appraisal

$4-23$

Option $9(a)$

4-24

Option $9(b)$

4-24

Option 9(c)

4-25

Utilize Improved Data to Improve the System Evaluation

4-25

5 ECONOMIC ANALYSIS

5-1

Life-Cycle Costing

5-1

Al ternative Methods of Economic Analysis

Required-Revenue Approach

Costs

Fixed Costs

$5-5$

Economic Scenario

$5-8$

Variable Costs

Benefits

$5-12$

One Product Cases

5-12

Multiple Product Outputs

5-13

other Benefits

5-19

Cost Allocation

5-20

6 EVALUATION: AN EXAMPLE

Chosen Application 6-1

Data Gathering 6-3

Sources 6-3

Load Demands 6-3

Concept Definition 6-11

Economic Analys is 6-16 
Chapter

6

Concept C (Existing Situation)

$\underline{\text { Page }}$

Concept A (Reference Case)

$6-16$

Concept B (ATES Case)

$6-17$

6-21

Discussion

$6-22$

Conclusion

$6-25$

APPENDIX

A TECHNICAL ASPECTS OF THERMAL ENERGY STORAGE

IN AQUIFERS

A-1

B AQUIFER TYPES, AVAILABILITY, AND SUITABILITY FOR ATES

B-1

C ECONOMIC ANALYSIS

C-1

D REFERENCES

D-1 


\section{ILLUSTRATIONS}

Figure

Title

Page

3-1 Comparison of overall thermal efficiency of electriconly and cogeneration power plants.

3-2 Comparison of heat sources for a proposed Twin Cities cogeneration-district heating system with and without ATES.

3-3 Projected monthly average service demand - steam, combined East Bank, West Bank, St. Mary's, Fairview, Augsburg.

3-4 Demonstration community steam load duration curve for years 1976-1979.

3-5 Monthly load duration curves for space heat and hot tap water for Twin Cities.

3-6 Annual load duration curve for space heat and hot tap water for Twin Cities.

3-7 Schematic diagram of heat storage well doublet operation.

3-8 Absolute and gauge saturation pressures for water at temperatures from 100 to $200^{\circ} \mathrm{C}\left(212\right.$ to $\left.392^{\circ} \mathrm{F}\right)$, with corresponding head of water at $15^{\circ} \mathrm{C}\left(60^{\circ} \mathrm{F}\right)$.

3-9 Nomograph relating injection or withdrawal temperatures, temperature difference between wells in a doublet, water flow rates, and thermal energy flow rates; (a) in SI units.

(b) in English units.

3-10 Nomograph of radii to thermal and hydraulic interfaces (cylindrical coordinates) versus aquifer thickness and injected volume of water, for assumptions shown.

3-11 Temperature drops across heat exchanger

(a) during heat storage.

(b) during heat withdrawal.

3-12 Heat recovery fraction, per cycle and cumulative. 3-35

3-13 Production temperature of hot water as it is recovered from aquifer storage.

3-14 Heat transferred into pipeline and into warm well during first-cycle production period. 
3-15 Production temperature of chilled water as it is recovered from aquifer storage.

3-16 Annual costs of $300 \mathrm{MW}$ thermal energy transport dual pipeline.

3-17 Optimization of pipe diameter for thermal energy sendout pipe at $300 \mathrm{MW}, 227^{\circ} \mathrm{C}\left(440^{\circ} \mathrm{F}\right)$.

3-18 Average pipeline installation cost for five U.S. cities, concrete culvert design.

5-1 Equivalence factor relating heat cost to electricity cost.

5-2 Costs of conventional versus combined heat and power system.

6-1 Load fluctuations for district heating system.

6-2 Scenario C - spring/fall weekly load cycle plot.

6-3 Scenario C - spring/fall load duration curve.

6-4 Scenario C - summer weekly load cycle plot.

6-5 Scenario $\mathrm{C}$ - summer load duration curve.

6-6 Scenario C - winter weekly load cycle plot.

6-7 Scenario C - winter load duration curve.

6-8 Alternative concepts defined. 


\section{TABLES}

Table

Title

$\underline{\text { Page }}$

3-1 Summary of effects of TES on Scenario A system configuration.

3-10

4-1 Capital costs, savings, and breakeven TES cost (1978 dollars).

4-2 Annual fuel consumption and energy benefits (1978 dollars).

4-3 Combined savings and resultant breakeven annual cost of TES (1978 dollars).

5-1 Economic analys is criteria.

5-2 Fixed cost elements.

5-3 Variable cost elements.

5-4 Fuel price assumptions.

5-5 Levelizing factor for annual costs (for discount rate 0.10$)$.

6-1 Scenario C - winter weekly load cycle and load duration data tabulation.

6-2 Scenario C - monthly peak data.

6-3 Demand scheduling for Concepts $A$ and $B$.

6-4 Determination of peaking energy demand.

$6-19$

6-5 Comparison of Concepts $A$ and $C$.

6-6 Comparison of Concepts $A$ and $B$. 


\section{ACKNOWLEDGMENTS}

The authors wish to acknowledge the advice and support of TEMPO staff members G. Garth Leeth, John W. McKee, Robert C. Hare, and Benjamin J. Berkowitz, and consultant Mark L. Rippberger, in preparing these Guidelines. Chin Fu Tsang and Christine Doughty of Lawrence Berkeley Laboratory have been generous in discussing their latest work and supplying copies of their reports and illustrations.

The encouragement and support of the Seasonal Thermal Energy Storage Program office at Pacific Northwest Laboratory are gratefully acknowledged. Mr. Raymond Wm. Reilly, Technical Administrator for the work, has provided invaluable assistance and guidance.

The original ATES work dating as far back as 1972 which was the genesis of this publication was supported by the General Electric Company and by the Office of Water Research and Technology of the U.S. Department of the Interior. More recent work has been supported by the Electric Power Research Institute and by the Division of Energy Storage Systems and the Office of Advanced Conservation Technologies of the U.S. Department of Energy. 
The International System of Units (SI) is used in this volume, with some non-SI units as recognized by IEEE Std. 268-1976 and ASTM Standard $E$ 380-76ع. English units are shown in parentheses. The number of significant digits shown indicates the accuracy intended.

POWER UNITS

The SI unit of power, both thermal and electrical, is the watt. Where the context does not make clear which energy form is meant, the word "thermal" or "electric" will follow the unit: "A heat input rate of $10 \mathrm{MW}$, "or "An input rate of $10 \mathrm{MW}$ thermal."

\section{ENERGY UNITS}

The SI unit of energy is the joule. However, the watthour and its multiples are accepted as a measure of electrical energy and are so used in this volume. The joule and its multiples are used for thermal energy. Parenthetical conversions show equivalent Btu, and may also show watthours thermal. One wh thermal $=3.413 \mathrm{Btu}=3600 \mathrm{~J}$.

It is usefur to note that, within a few percent, $1 \mathrm{GJ}=1 \mathrm{MBtu}$.

\section{SI MULTIPLIER PREFIXES}

SI prefixes used in this volume.

\begin{tabular}{|cccc|}
\hline Multiplication Factor & & Prefix & Symbol \\
\cline { 2 - 3 } $10^{18}$ & & exa & $\mathrm{E}$ \\
$10^{15}$ & peta & $\mathrm{P}$ \\
$10^{12}$ & tera & $\mathrm{T}$ \\
$10^{9}$ & giga & $\mathrm{G}$ \\
$10^{6}$ & mega & $\mathrm{M}$ \\
$10^{3}$ & kilo & $\mathrm{k}$ \\
\hline
\end{tabular}


CHAPTER 1

INTRODUCTION

PURPOSE

These guidelines have been prepared as a tool for those considering use of a new technology, aquifer thermal energy storage (ATES). The guidelines will assist in the conceptual design and the evaluation of technical and economic feasibility of systems employing ATES.

Use of ATES can correct large-scale mismatches between thermal energy supply and demand - between seasonal loads, such as space heating and air conditioning, and the availability of inexpensive supplies of heat or chill, such as solar heat, byproduct or waste heat, and winter chill. ATES has significant potential for:

- Conserving energy

- Reducing energy costs

- Permitting substitution of coal or nuclear heat for oil and gas

- Improving the dependability of energy supplies

- Abatement of air and water pollution

\section{OVERVIEW}

Aquifers are natural underground porous rock formations, filled with water. Widely occurring, they supply half the drinking water for the United States. They are capable of efficiently storing very large amounts of hot or cold water for long periods of time, at low cost. The water is injected and extracted through wells. While novel as an energy-system component, ATES technology draws upon experience gained from millions of water and oil wells and from ongoing geothermal investigations.

No water is consumed for ATES. A pair or an array of wells is used, with downhole pumps and aboveground heat exchanger and controls. 


\section{EXECUTIVE SUMMARY}

The heat exchanger isolates the groundwater from the pipeline loop that conveys hot or cold water between the thermal energy source and the load. Heat or chill is stored by pumping groundwater from one well, passing it through the heat exchanger to be heated or chilled by pipeline water flowing through the other side of the heat exchanger, and injecting the groundwater back into another well. To withdraw heat or chill, the flow direction in the wells and on both sides of the heat exchanger is reversed.

Little or no interaction is expected with other wells using the same aquifer. In a typical application, stored hot or cold water will have traveled only one or two hundred meters (300 to 600 feet) radially from the well after three or four months of injection. It moves back toward the well when heat or chill is withdrawn from storage.

The water used for storing heat or chill need not be of drinkingwater quality. If necessary, at some additional cost such as using noncorrosive materials, groundwater that is brackish or even saline may be utilized.

The economic maximum storage temperature for hot water will probably be about $150^{\circ} \mathrm{C}\left(300^{\circ} \mathrm{F}\right)$. Because of the rapid increase in vapor pressure of water above this temperature, water at higher temperatures is likely to have an immediate surface use more beneficial than storage; and containing higher pressures requires such deep, tightlyconfined aquifers that the cost of wells may be prohibitive.

The cost of ATES is expected to be about one-tenth that of a large fabricated tank. The storage media (water and rock), the containment (layers of clay or shale), and the insulation (sand and rock) are all provided by the aquifer formation. The only significant capital cost elements are the land, the wells, and surface equipment for handling the hot or cold water. 


\section{EXECUTIVE SUMMARY}

ORGANIZATION OF THIS VOLUME

This chapter provides an overview of ATES technology and its potential benefits. Chapter 2 gives criteria for screening proposed applications of ATES to quickly identify applications for which ATES is not suited.

Chapters 1 and 2 serve as an Executive Summary. They provide a basis for judging whether detailed technical and economic evaluation should be undertaken, as described in Chapters 3 through 5 and illustrated by an example in Chapter 6 .

Appendix A discusses the flow of fluids and heat in aquifers, the design of ATES wel1s, and operational aspects of ATES, in greater detail than is found in the main body. Appendix $B$ describes types of aquifers in the United States and their suitability for ATES. Appen$\operatorname{dix} C$ gives formulas and tables for economic analysis, to supplement Chapter 5 .

Appendix $D$ lists references cited. For bibliographic lists of ATES-related references by subject and author, the reader should contact the Seasonal Thermal Energy Storage Program Office, Battelle Pacific Northwest Laboratory, P.0. Box 999, Richland, Washington 99352. 


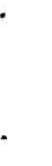


CHAPTER 2

EARLY SCREENING OF POTENTIAL ATES APPLICATIONS

This chapter provides rules of thumb for quickly judging whether a proposed project has sufficient promise to warrant spending the time and effort required for the conceptual design and evaluation described in subsequent chapters.

SUMMARY OF EARLY-SCREENING CRITERIA

- A seasonal mismatch exists.

- High temperature water is a satisfactory heat-transport medium.

- System size is large enough.

- A suitable aquifer may be available.

- The cost of ATES is acceptable.

MISMATCH BETWEEN THERMAL ENERGY SOURCE AND END USE

The first requirement for justifying use of ATES is that a seasonal mismatch exists between the availability and the use of heat or chill.

The source or sources of heat or chill may be seasonal (solar energy, summer-peaking cogeneration of electricity and heat, winter chill); or the use may be seasonal (space heating, food processing, air conditioning); or both. The function of ATES is to buffer seasonal fluctuations in source and/or use, to correct a mismatch and make otherwise-wasted or unused thermal energy sources useful.

ATES is capable of also smoothing short term fluctuations - e.g., diurnally in solar energy systems, weekly in space heat or industry in addition to smoothing seasonal fluctuations. However, other techniques for thermal energy storage, such as fabricated tanks or latent-heat systems, may be better suited than ATES to handle only short term fluctuations. 


\section{EXECUTIVE SUMMARY}

The degree of mismatch is seldom total. Captured waste heat may, for example, be used to heat tap water or process water on a yearround basis, while some of the heat is put into ATES and used later to supplement the capacity of the heat source during the space heating season. Often, although only a fraction of total heat produced would be stored - say, 25 percent - ATES would make it possible to use waste heat for both space heating and year-round loads.

\section{HIGH TEMPERATURE WATER (HTW) VERSUS STEAM}

When an existing end use of heat employs steam and application of ATES is being considered, conversion of end-use equipment to use HTW instead of steam must be evaluated. Using aquifers to store steam is not believed feasible; and, although producing steam from HTW is possible, there are inherent thermodynamic limitations such as the "pinch effect" in heat exchangers which need to be taken into account.

Steam can deliver at a constant temperature most of the thermal energy it carries as latent heat. For HTW to deliver efficiently the thermal energy it carries as sensible heat, there must be a substantial drop in temperature from sendout to return pipeline. However, the energy density per unit volume of HTW is so much higher than that of steam that HTW transport is much less expensive than steam transport, and is feasible for much greater distances. In large district heating systems, this feature has been considered important enough to justify the cost of converting end-use equipment from steam to HTW, or operating parallel steam and HTW systems until the steam-driven equipment is retired. Gaining the economic benefits of ATES may enter into such decisions.

\section{MINIMUM FEASIBLE SIZE}

The fraction of thermal energy input that is lost during seasonal ATES will become unacceptably high if the input volume is too small, because the ratio of surface area to enclosed heat-storage volume will be too small. Seasonal ATES is best suited to multi-megawatt systems. 
Finding the heat recovery fraction that can be expected in a particular aquifer for a specific system configuration requires computer simulation of fluid and heat flow in the aquifer. Based on such simulations and very limited field experience, rough rules of thumb may be suggested:

- If the objective is to recover at least three-fourths of the injected heat after three or four annual cycles of operation the heat input rate to ATES should average at least 3 megawatts $\left(10^{7}\right.$ Btu/hour $)$ for about 90 days; i.e., at least 20 terajoules ( $20 \mathrm{GBtu}, 6 \mathrm{GWH}$ ) of heat should be stored.

- For storing chill, it appears that a rate and amount of energy storage of about one-third that suggested for heat may be acceptable.

More field experience with ATES can be expected to modify these rules of thumb.

\section{AVAILABILITY OF A SUITABLE AQUIFER}

Because ATES is a new technology, unfamiliar to most welldrillers, geologists, and regulatory agencies, only rarely will it be possible to verify through simple inquiries that a suitable aquifer is available. However, if a well-drilling firm or geologist thoroughly familiar with local conditions is quite certain that a suitable aquifer is not available, or if insurmountable regulatory difficulties are encountered, it may be wise to abort the investigation.

The size and hydraulic characteristics of aquifers available at the site or sites of interest - in the area of the heat load and/or the heat source - will set an upper limit on the amount and rate of TES that is physically feasible. A well-drilling firm or geologist should be consulted.

Information needed by the wel1-drilling firm or geologist is found in the basic discussion of heat storage wells in Chapter 3 under "Storage Subsystem," and in Appendix B on types of aquifers and probable suitability of each type for ATES. 


\section{EXECUTIVE SUMMARY}

The question of availability involves not only whether an aquifer exists but also whether it can be used for heat storage purposes.

Local regulations and regulatory agencies may classify heat as a pollutant; special authorization may be required for ATES. Such authorization has been obtained on the basis that heat storage wells are designed to avoid loss of hot water, which is a valuable commodity and not a waste product being disposed of by injection. The possibility of interference between heat storage wells and water supply wells in the same aquifer is negligible if the heat storage wells are located at a generous distance from the supply wells. The appropriate spacing will depend on the size of the wells and the aquifer. One kilometer ( 3000 feet) or more probably is safe. Alternatively, a few tens of meters (yards) of vertical separation between the water supply formation and a separate, tightly confined formation suitable for heat storage well completion may be entirely adequate.

\section{COST OF ATES FACILITIES AND OPERATION}

The element in ATES capital investment cost which may be of most concern is verifying the availability and suitability of an aquifer. If insufficient hydrogeological information is available for estimating the cost and performance of ATES wells, a substantial initial investment in exploratory drilling and testing may be required. The acceptability of this investment will be related to the size of the proposed project. For a large project, the prospective benefits will be large, and the investment can be amortized over many ATES wells if an aquifer is found and is suitable. For a small project, involving only a few wells, the investment may be unacceptable. An estimate of the cost of a surface geophysical survey, exploratory drilling, borehole geophysical measurements, pump tests, and analysis should be obtained if this investment is an important early-decision criterion.

Assuming a suitable aquifer is available, what will ATES facilities cost? A very rough rule of thumb is that the capital investment cost of a pair of wells deep enough to store $150^{\circ} \mathrm{C}\left(300^{\circ} \mathrm{F}\right)$ water, including pumps, heat exchanger, controls, shelter, and a nominal 
amount for land, will be roughly the same as that of a hot-water boiler: about $\$ 55$ per kilowatt thermal, in 1980 dollars. This is a useful comparison because evaluating the application of ATES in a proposed system very often involves considering whether to use ATES or hot-water boilers for peak loads and standby reserve.

The operating costs of an ATES facility should be much lower than for a boiler of equivalent thermal capacity. No oil or gas fuel is required for ATES, only a modest amount of electricity to drive pumps.

The cost comparison will be less favorable if the groundwater is mineralized and can cause significant corrosion and scaling, which will increase the fixed costs by requiring special materials and the operating costs by requiring more frequent shut-down for cleaning and repair. Deep or difficult drilling can also increase well costs. 


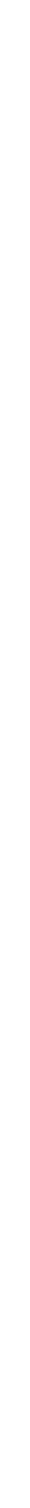


CHAPTER 3

INFORMATION NEEDED FOR DESIGNING AN ATES SYSTEM

To employ the conceptual-design procedure described in the next chapter, information about the four subsystems making up an ATES system will be needed:

- Source or sources of heat or chill: Amount, quality (temperature), cost, and constraints on availability, all versus time. Location.

- End use or uses for heat or chilz: Amount, temperature, and dependability of thermal energy supply required, versus time. Flexibility of requirements. Location. Allowable price or cost of supply (usually that of a reference or alternative supply such as natural gas).

- Storage: Heat exchanger size versus temperature loss and cost. Scaling, corrosion, geochemical problems. Thermal energy and temperature losses during storage. Mitigating measures. Cost of wells, special design features, number required, and spacing.

- Transport: Tradeoffs of pipe size versus pumping power and thickness of insulation versus thermal energy loss. Cost elements and their sensitivity to the choice of operating temperatures and the type and difficulty of installation.

In this chapter, the sources and end uses of heat and chill which are the most promising candidates for profitable use in an ATES system are discussed in general terms, and examples of the information needed to describe them are given. The storage subsystem, needed in any ATES system, is described in some detail, with estimates of performance and cost. The transport subsystem which will be needed in some ATES systems is described in less detail; design parameters are discussed, with examples and cost estimates. 
SOURCES OF HEAT AND CHILL

ATES may be the key in many instances to large-scale use of three inexpensive sources of thermal energy:

- Industrial waste heat

- Solar heat and winter chill (renewable sources)

- Cogeneration.

\section{Reference-Case Description}

As a basis for evaluating the potential benefits of ATES in making feasible the use of inexpensive thermal energy sources, a reference-case system without ATES must be described. The completed reference-case description will inciude the source subsystem, the end use, short-term storage (not ATES), and transport if required. Of interest here is the source subsystem.

It is important that the reference case be a basis for evaluating the net benefits of ATES - not merely the benefits of using captured waste heat, or renewable sources, or cogeneration, unless utilizing these sources is not feasible without seasonal storage; comparison should be between feasible alternatives. For the reference case, the source subsystem must be described as it would be configured or reconfigured if ATES were not employed: the reference may or may not be an existing source.

EXAMPLE A: An industrial plant uses a gas-fired boiler for space heating. Waste heat is available from periodic testing of large engines, but it is not being used because it is not matched in time or magnitude to space heating needs. ATES may make feasible the capture and use of the waste heat for space heating. The referencesource subsystem in this example is the existing gas-fired boiler.

EXAMPLE B: A utility is considering modifying turbines to permit combined production of electricity and heat, for district heating. The proposed system calls for use of auxiliary boilers to meet peak wintertime demands for space heating. The reference-source subsystem is not the existing individual boilers and furnaces which the district heating system would replace, but rather the proposed cogenera- 
tion subsystem for district heating, without ATES and with auxiliary boilers. ATES may make it possible to operate cogeneration turbines at a higher annual capacity factor, storing inexpensive heat to use later during peak load periods and making the boilers unnecessary.

\section{Cases with ATES}

The examples above illustrate not only reference-case source subsystems but cases with ATES. In developing conceptual system designs with ATES, source-related benefits in cost reduction, energy conservation, and fuel substitution will usually be of primary concern. Other benefits to be sought include improved dependability (particularly, no interruptions of gas or oil delivery); burning less fuel, thereby producing offsetting emission credits which make possible plant expansion not otherwise permitted; cooling stack gases to facilitate precipitation of pollutants; and others which will occur to the system designer.

\section{Information Needed}

For both the reference case subsystem and the one or more cases with ATES, projections will be needed of

- Annual energy production, energy units: GJ or MWh

- Monthly production, energy and power units: GJ, MW

- Hour-by-hour production for typical weeks, power units: MW

- Peak hourly production, power units.

If energy is to be produced from more than one source, separate projections should be prepared for each source. Expected temperatures and fluctuations should be indicated.

Energy-production availability may be influenced by seasons of the year. If so, it usually can be typified with three weekly patterns, for winter, summer, and spring/autumn, with extremes indicated by range bars or tabulated data. Other availability constraints might include scheduled maintenance, forced outages, product manufacturing schedules, cloud cover, air quality regulations (emission controls), or fuel supply curtailment. Hour-by-hour 
projections for weeks when such constraints might affect production should be prepared; or the effects may be indicated as range bars on season-typical weekly graphs or as upper and lower bounds in tabulated data.

Flexibility in availability of energy production will be of interest in case more or less thermal energy is needed than is shown in the suggested projections. For example, it may be possible to operate an industrial boiler or cogeneration equipment at a higher capacity factor than has been projected, which could make supplemental heat available at a lower cost than with auxiliary boilers.

Cost information will be of particular interest for obvious reasons. Any potential effects on cost, such as savings through having ATES available to store excess thermal energy during peak output when otherwise the energy would have to be dumped, should be noted. Conversely, cost penalties such as having no storage or transport available when it is being counted on should be noted.

Importance of Second-Law Considerations

The significance of thermodynamics' second-law concept of entropy extends beyond the principle that heat does not flow uphill. Secondlaw analysis of energy quality and availability reveals the maximum amount of useful work or heat, or both, that can be extracted from a source of heat; it is particularly applicable to ATES system conceptualization and evaluation when the proposed heat source involves high temperature, as in a fossil-fueled boiler.

Because combustion temperature in a boiler characteristically is much higher than the temperature of the steam produced, it may be found that only 15 percent of the total input energy has been lost (in an 85-percent efficient boiler), but entropy considerations reveal that energy availability has been decreased by 66 percent. Two possibilities for improving this situation might be considered: carry out the combustion process at a high pressure, expand the products through a gas turbine-generator, then pass the exhaust gases through a waste heat boiler to generate process steam at the same 
pressure and temperature at which the boiler would have produced it; or produce steam from the boiler at higher temperature and pressure than needed for process heat (or space heating), and expand the steam to desired pressure-temperature conditions through a turbogenerator. Assuming a use or a market exists for the electricity generated perhaps an electric utility, required by recent regulatory action to purchase electricity from industrial cogeneration - the energy available from the fuel will be used much more efficiently than when the boiler supplies steam directly at lower pressure-temperature conditions. The tradeoffs of cogeneration investment, operation and maintenance, and of reliability of supply against energy conservation and cost savings, have been examined for many industrial plants. With continually increasing costs of fluid fuels and pressures for fuel substitution, more attention to opportunities for second-law efficiency has become mandatory. (National Energy Act of 1978; NBS Handbook 121, 1977, Chapter 2; Kovach, 1976; Kovacik, 1975; Keenan and others, 1973; Wilson and Hefner, 1973.)

A concept called "exergy" introduced in the Soviet Union and Europe is coming into use in the United States for applying the second law in analysis of energy systems. (Ahern, 1980; Koefoed, 1976.)

Industrial Waste Heat

Having ATES available as a large reservoir for captured waste heat can solve a basic problem which often makes industrial waste heat recovery infeasible: the heat load cannot always absorb the heat which can be captured, forcing the heat recovery equipment to operate at low utilization factor and the facilities for disposing of waste heat to be kept in service.

Case studies of successful systems for industrial waste heat recovery are reported in the Waste Heat Management Guidebook, prepared by the National Bureau of Standards and the Federal Energy Administration (NBS Handbook 121, 1977). Several studies of industrial waste heat recovery and short-term storage for later use have been made under DOE auspices (e.g., Lundberg and Christenson, 1979; 
Katter and Hoskins, 1979; Katter and Peterson, 1978; Glenn, et al, 1976).

Seasonal TES was included in a study of capturing waste heat from the $120^{\circ} \mathrm{C}\left(250^{\circ} \mathrm{F}\right)$ fume-exhaust stream of an aluminum production plant and utilizing it for district heating in a nearby city. Among the alternatives considered for TES were aquifer storage and the use of two insulated steel tanks, each with a capacity of 380,000 cubic meters (100 million gallons). ATES was found to be potentially the lowest cost approach, but not yet sufficiently proven to be included in the system proposed for early implementation. (Katter and Hoskins, 1979; McCabe and Huxtable, 1980.)

\section{Renewable Sources}

SOLAR THERMAL. It has been noted that solar systems in high latitudes could benefit substantially from inexpensive high-capacity seasonal storage. Insolation at high latitudes amounts to about the same energy available annually at lower latitudes, but the intensity is low during the space heating season and high during the summer months.

A workshop on Solar Energy Storage Options, sponsored by the U.S. Department of Energy's Solar Applications Office, was held in March 1979. One workshop panel addressed annual cycle storage for heating and cooling. The modes of storage considered included aquifers, insulated ponds, earth, salt gradient ponds, and tanks. (USDOE, March 1979, Vol. II.)

The design and construction of a solar energy system with seasonal storage is described in a recent report by Finn (1979). It is located at Ingelstad, Sweden ( $57^{\circ} \mathrm{N}$ latitude), to supply space heating for a new 52-unit residential development. A $5000 \mathrm{~m}^{3}(1.3 \mathrm{mil-}$ lion gallon) concrete tank, insulated with one meter of mineral wool, will store up to $1.2 \mathrm{TJ}(335 \mathrm{MWh})$ in water at $95^{\circ} \mathrm{C}\left(200^{\circ} \mathrm{F}\right)$. Several hundred parabolic solar collectors whose area is $1320 \mathrm{~m}^{2}\left(14,200 \mathrm{ft}^{2}\right)$ supply $2.1 \mathrm{TJ}$ (586 MWh) of heat during an average year, to handle 
about half the total space heating energy requirement. A boiler, large enough to carry the entire load, supplies the other half.

ATES has not yet been utilized in solar thermal systems because of the minimum-size requirement (Meyer, 1978) for which rules of thumb were given in Chapter 2. Multimegawatt solar systems for supplying hot water for wintertime space heating have not yet been built, but are being seriously considered (in Canada, for example).

WINTER CHILL. As a source of thermal energy, winter-chilled water is very cheap. However, because the temperature difference between the chilled water and the aquifer ambient is 1 imited, the energy density of storage in aquifers is lower than for hot water. Temperature loss across heat exchangers - the "approach temperature" becomes a governing economic factor. Nonetheless, successful largescale storage of chilled water in aquifers was demonstrated at least as far back as World War II, and experiments continue. (See Appendix $B$, page $B-20$. )

\section{Cogeneration}

Studies indicate that ATES can substantially improve the economics of large-scale cogeneration, further improve the alreadyimpressive gains in the efficiency of fuel-energy utilization, permit substitution of coal or nuclear heat for fluid fuels, and el iminate the need for cooling water or towers. (Meyer, Hausz, et al, 1976; Meyer, 1979.)

COGENERATION BY ELECTRIC UTILITIES. Figure 3-1 illustrates graphically the impressive second-law improvement in efficiency of fuel use which can be achieved by thermal power plants when cogeneration is adopted. A recent Report to the Congress by the Comptrolzer General (USGA0, 1980) identifies this as one of the most important national opportunities for energy conservation and fuel substitution. Power plants discharge more heat as waste than the entire industrial sector consumes as primary energy. The waste heat from conventional power plants is not worth considering for ATES because it is of such 


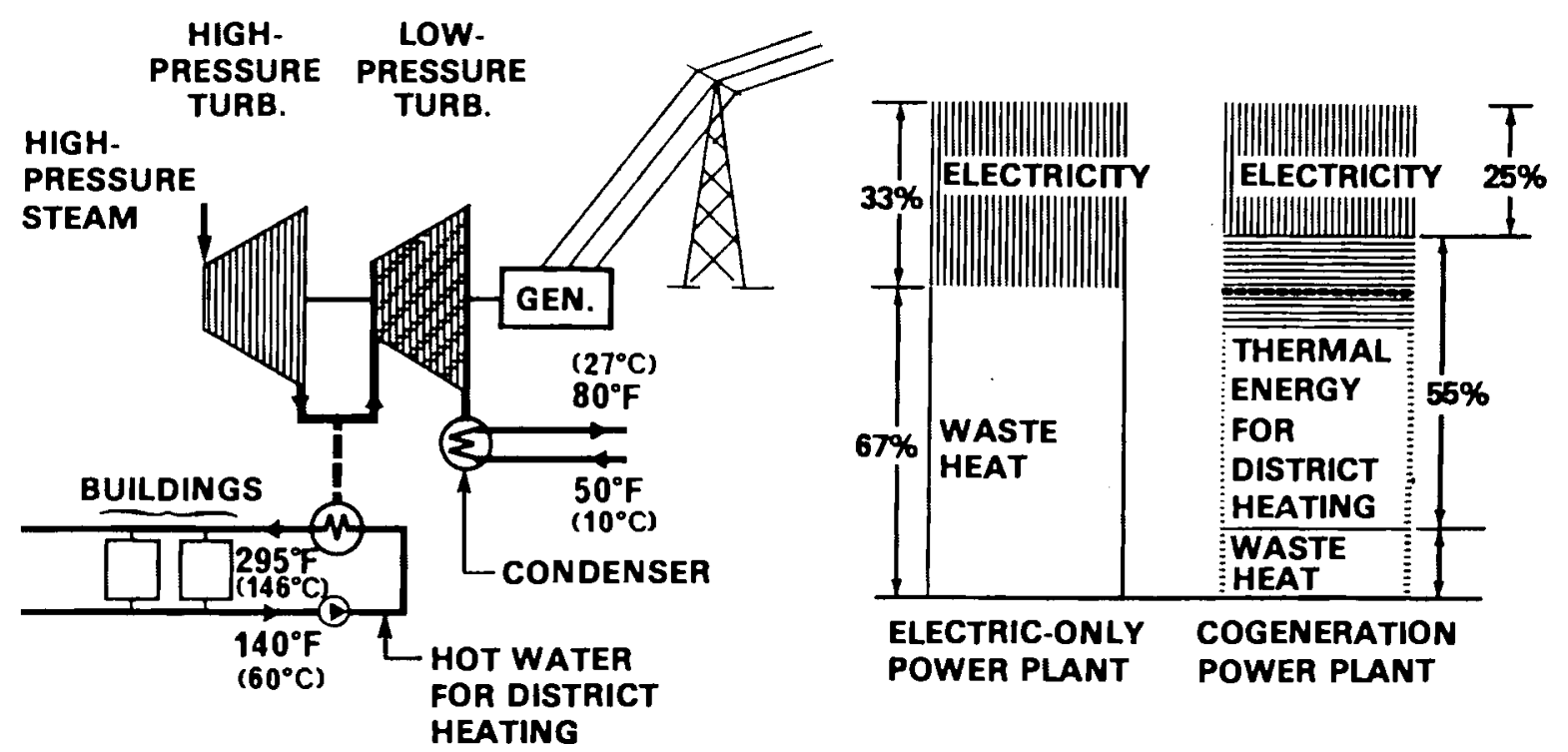

Figure 3-1. Comparison of overall thermal efficiency of electric-only and cogeneration power plants. (Source: Margen, et al, 1979b)

low quality (so little above ambient temperature). Utility plants are carefully designed to extract as much work from steam as possible, to drive electrical generators, before discharging the steam from turbines at as close to ambient temperature as is economically feasible. Some existing equipment can be adapted, some must be replaced, to allow higher temperature steam to be extracted (at some loss in electrical generation) as a heat source for large district heating sys tems.

In response to action of the Minnesota Energy Agency, a large new cogeneration-district heating system has been proposed for the Twin Cities metropolitan area of Minnesota. Hot water would be used, in a closed-loop system. The system as described by Studsvik Energiteknik $A B$ of Sweden does not employ thermal energy storage (Margen, et al, 1979b). In a study supported by DOE/ORNL (as was the Studsvik study), TEMPO evaluated the potential benefits of incorporating ATES into the proposed system (Meyer, 1979). TEMPO's Twin Cities study followed much the same procedure for conceptual design and evaluation that is presented in Chapter 4 of these Guidelines. 
A reference case was at hand - not an existing but a proposed system, whose fuel and energy saving features had already been evaluated. The question was not the benefits of cogeneration for a large district heating system but the added benefits of ATES in the system. Four ATES cases - conceptual designs - were developed and studied. They are summarized in Table $3-1$.

The first of the four ATES cases involved only the replacement of standby and peaking boilers with ATES. This was found to be feasible and beneficial. (It was assumed, throughout the study, that a suitable aquifer was available - exploration and aquifer characterization were not a part of the study.) Flexibility in the availability of additional heat from the several old turbines was then postulated, with rules for operating the turbines at higher capacity factor than in the reference case. Use of different turbines (backpressure machines) was also postulated, on the basis that ATES would make feasible the production of substantial amounts of heat in excess of the demand at the moment, the heat to be stored until needed to meet peak loads. Not only was it found that a much greater mismatch could be buffered, but the size and cost of transmission lines could be significantly reduced by employing ATES at the cogeneration plant as well as at transmission-line nodes where the distribution system is connected.

Figure 3-2 illustrates, on an annual load duration curve for the Twin Cities district heating system, the makeup of the reference system and of TEMPO Case A-3. Note in Case A-3 that all boilers have been replaced with storage and all heat is supplied by less cogeneration capacity operated at a higher capacity factor.

INDUSTRIAL COGENERATION. Perhaps five or six hundred totalenergy systems in the United States, not owned by utilities, generate electricity and heat as joint products to serve industrial or commercial developments. Their aggregate in-plant electrical generation is well under one percent of national generation. However, the National Energy Act of 1978, DOE support in financing the extra risks inherent 
Table 3-1. Summary of effects of TES on Scenario A system configuration.

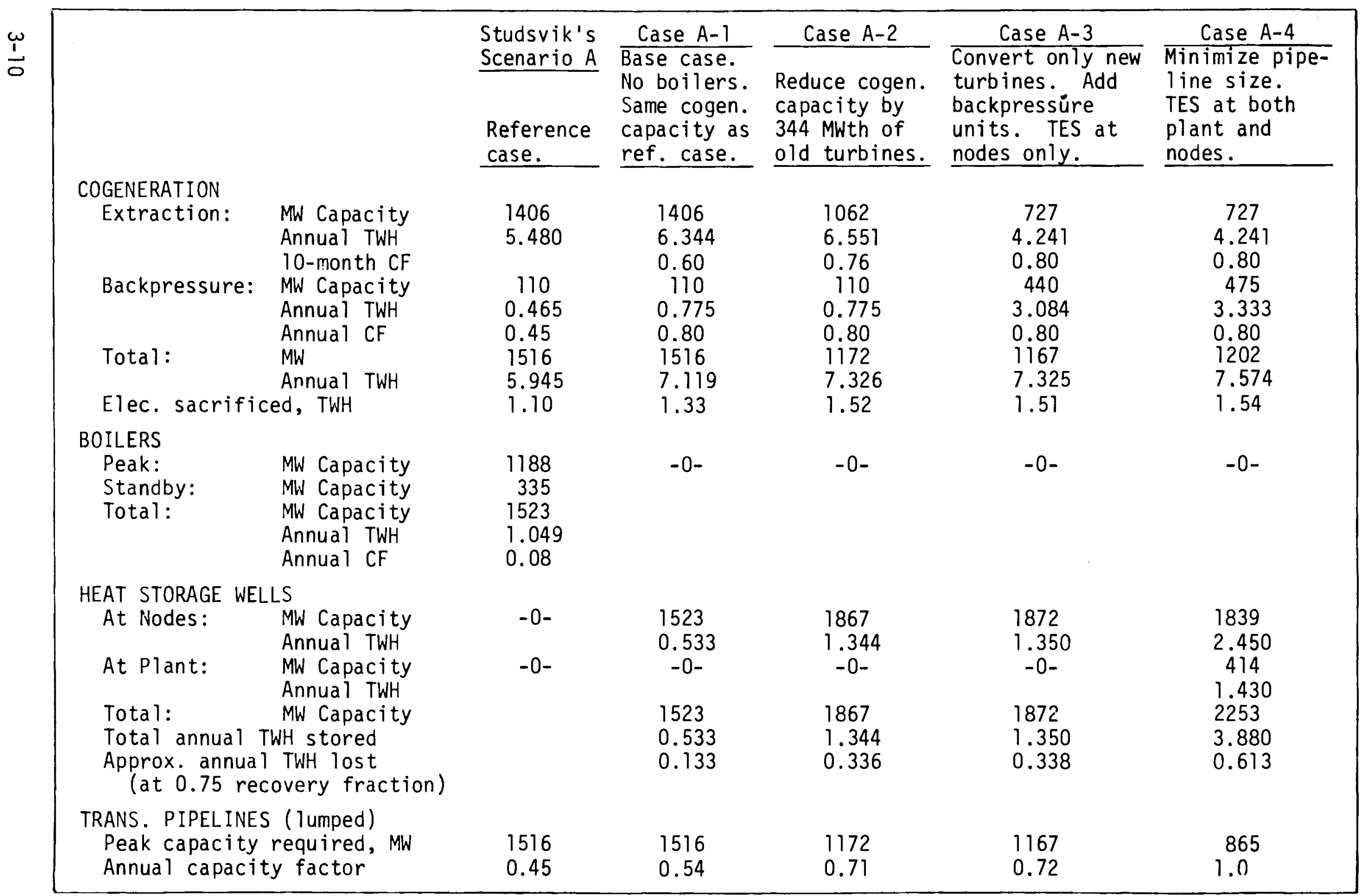



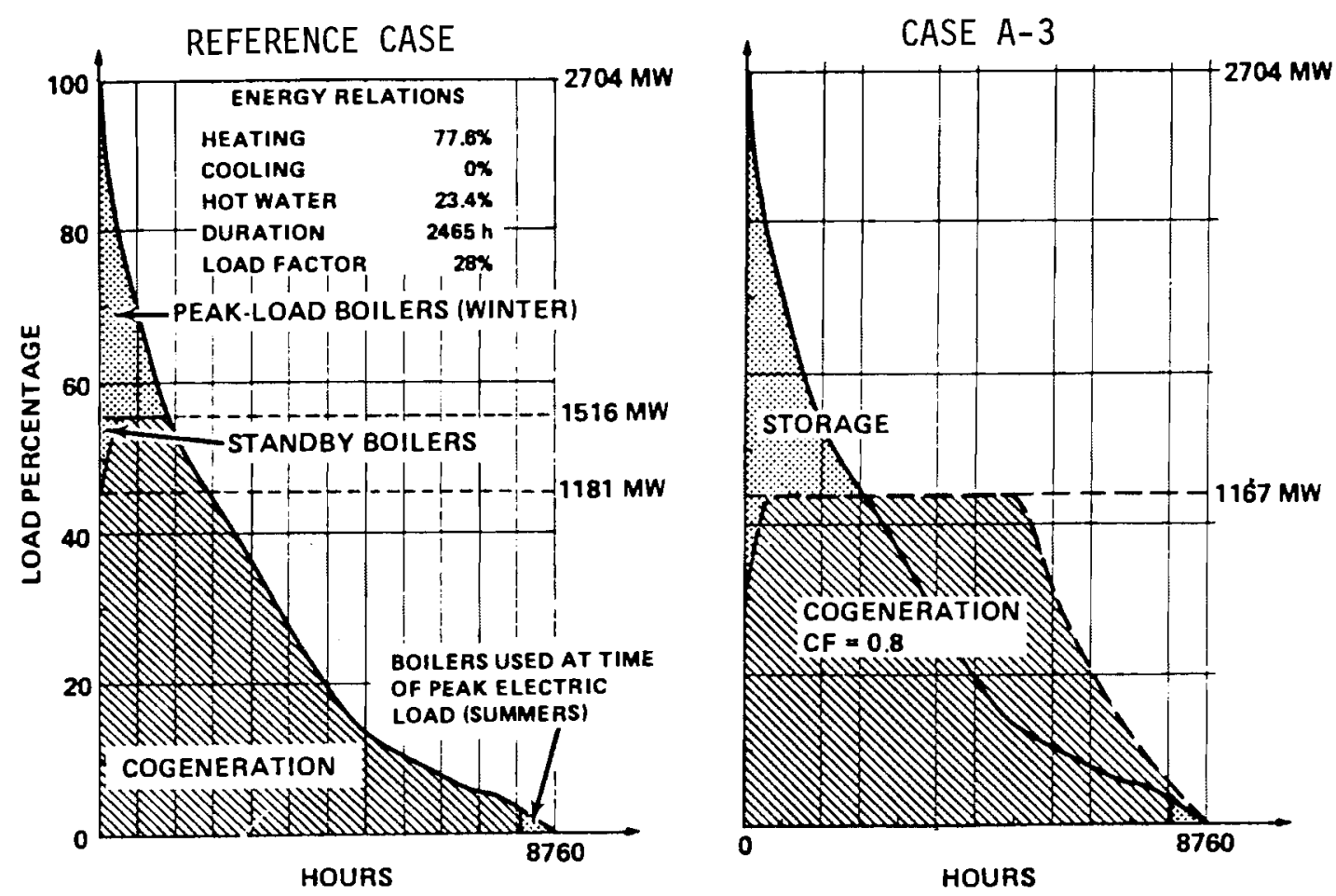

Figure 3-2. Comparison of heat sources for a proposed Twin Cities cogeneration-district heating system with and without ATES. (Source: Meyer, 1979)

in new technology (Savitz, 1977), and actions of State energy agencies and utility commissions, now strongly encourage industrial cogeneration. Of particular interest are the provisions being made to require electric utilities to purchase electrical power generated inplant that is surplus to an industry's needs. ATES can make possible the generation of electricity for sale when its value to the electric utility is greatest - during peak-load periods.

Developing a reference case and ATES cases for industrial applications of cogeneration will be somewhat different from the Twin Cities district-heating example. The major difference is likely to be that space heating has not been included in an existing industrial cogeneration setup, or that plans for cogeneration do not include space heating - only electrical generation and process heat. It then will be necessary to devise provisions for extracting steam for space heating from bottoming turbines, or for capturing waste heat from spent 
process steam when topping turbines are used. Typically, the reference case may be an existing use of dedicated boilers or individual gas-fired heaters for space heating purposes, and only the ATES cases will be concerned with cogeneration as a source for space heating. Without ATES, using cogenerated heat for industrial space heating is unlikely to be economic because the load factor is too low.

HEAT PUMPS FOR PRODUCING CHILL. The heat pumps in wide use in industry today - air conditioners, refrigeration equipment, chillers dispose of waste heat via cooling water or towers, which comes under the category of industrial waste heat discussed earlier. However, reversible heat pumps are again becoming popular for residential use, to air condition in the summer and heat in the winter. A commercial variation, called a heat reclaim chiller by at least one manufacturer (Dunham-Bush), continuously provides two output streams: one of cold water at $5-10^{\circ} \mathrm{C}\left(42-50^{\circ} \mathrm{F}\right)$ for chilling, and a byproduct stream of hot water at $32-66^{\circ} \mathrm{C}\left(90-150^{\circ} \mathrm{F}\right)$. The chiller is driven by an electric motor.

Viewing the heat reclaim chiller as a cogenerator of heat and chill provides the appropriate perspective for serious consideration of large-scale ATES for heat pumps as suggested ten years ago by R.G. Kazmann (1971).

Kazmann's suggestion was to store hot water discharged from heat pumps used for summertime air conditioning and to use the stored water as a source of heat in the winter, materially improving the coefficient of performance of the heat pump in a space-heating mode. In the wintertime, the chill produced by the heat pump might logically be stored in another well, creating a doublet with a hot well and a cold wel1. *

* The National Water Well Association is actively encouraging use of shallow groundwater as a source and a sink for heat pumps for individual residences, which is the same concept on a smaller scale; however, seasonal storage is not the principal thrust of the NWWA program. 
The industrial heat/chill cogenerator begins to approach the size of system needed to make this use of ATES interesting, and is one of very few sources of chill other than natural wintertime temperatures that has been identified.

\section{Auxiliary Boilers in ATES Systems}

To consider boilers in a discussion of heat sources for ATES systems may seem anomalous, in that ATES may often be utilized instead of boilers for peaking and standby purposes.

One reason for listing boilers is that they may already be in place and still serviceable, therefore requiring less capital investment than ATES facilities. (Steam boilers may require addition of an accumulator or a heat exchanger to supply hot water.) In conceptualizing reference and ATES cases, the economy of using existing boilers instead of or in addition to ATES should be considered.

A second reason for listing boilers is that portable boilers often have a role in developing district heating networks, which should be recognized in scenarios for reference and ATES cases. The role of portable boilers is to serve heat loads until extending hotwater pipelines from central sources, and installing ATES facilities, can be economically justified by the size of the load that has been built up. Portable boilers almost always are oil-fired, and keeping them in service in the same location is rarely suggested. Instead, they are moved to new locations where load is to be built, amortized over the period of system build up, and disposed of.

END USES FOR HEAT OR CHILL

ATES can serve as a bridge between seasonal uses for heat or chill - space heating, air conditioning - or between seasonal sources of heat or chill - solar heat, winter cold - or both.

\section{Reference-Case Subsystem}

As with the thermal energy source, a reference-case description will be needed for the load or loads to be supplied, as they would be 
configured or reconfigured if ATES were not employed. The reference case may already exist, or it may be only planned or proposed. Examples are air conditioning which is electrically driven; process heat in a large industrial plant which is to be supplied by captured waste heat; space and tap water heating for a residential/commercial complex, or for an urban area to be served with district heating, from a cogeneration source.

\section{Cases with ATES}

One or more conceptual system designs with ATES will be developed and compared to the reference system cost and energy requirements. To utilize hot water in place of steam or combustion, conversion of existing space heating, process heat, or water heating equipment may be required. Similarly, air conditioning or chilling equipment will require conversion, in some instances, to utilize hot water or winter-chilled water. Converting existing buildings to hot water district heating has been studied by Sundberg and Nyman (1979).

\section{Information Needed}

The basic information required is load versus time. As with the thermal energy sources, projections will be needed for both the reference case and the ATES case, of

- Total annual load in energy units: GJ or MWh

- Monthly load in both energy and power units: GJ, MW

- Hour-by-hour load for typical weeks, in power units: MW

- Peak hourly load, in power units.

Figure 3-3 illustrates a convenient way to summarize monthly load in power units ( $1 \mathrm{lb}$ of steam $/ \mathrm{hr} \approx 1000 \mathrm{Btu} / \mathrm{hr}=293$ watts). A computer program which produces such a graph can also easily compute the monthly and annual load in energy units, and find the peak hourly load. Figure 3-4, from the same source as Figure $3-3$, is a very useful display - an annual load duration curve for actual hourly data in 1976, with projections of expected loads in 1977-1979. 


$$
\text { (1) }
$$




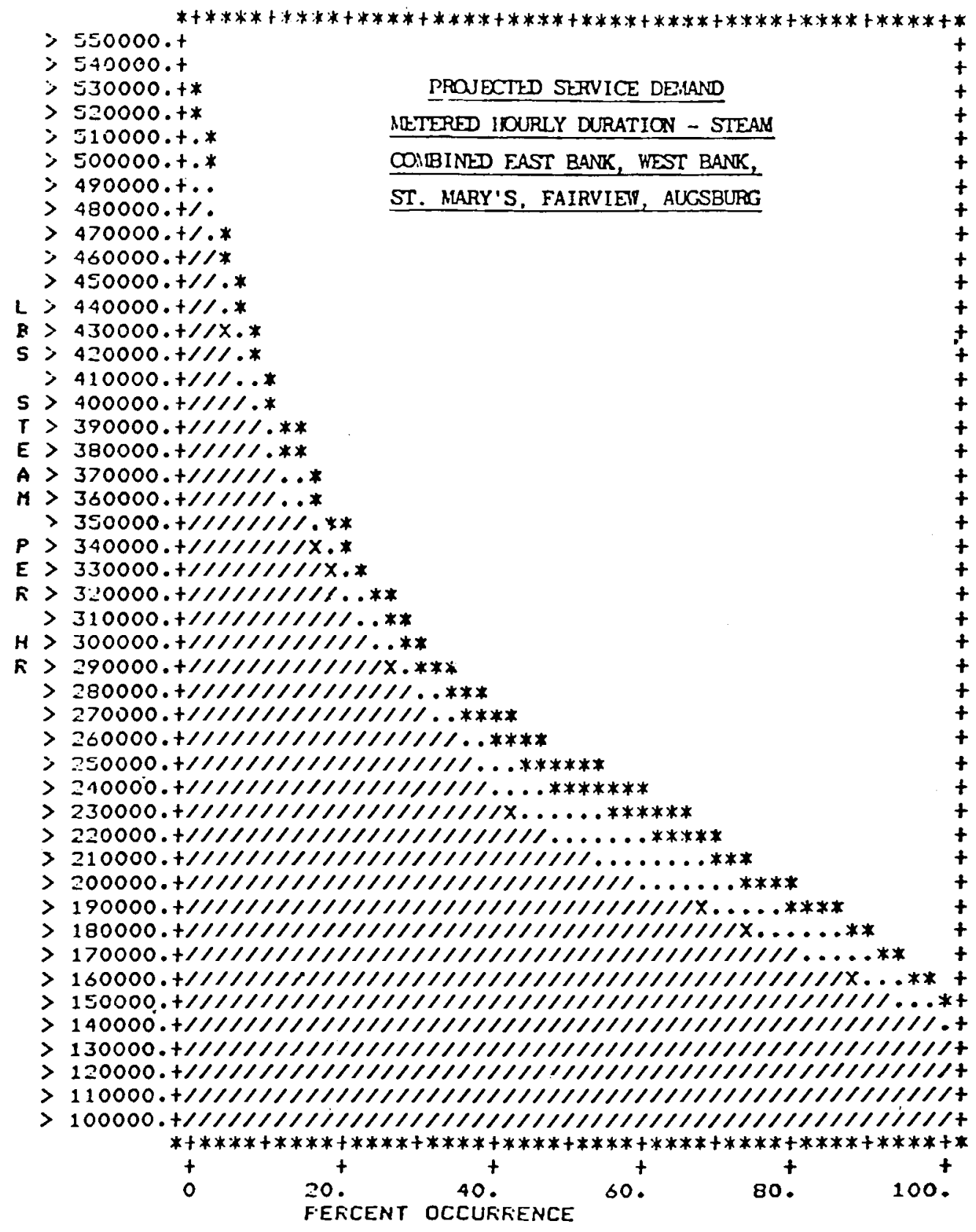

SYMEOL DEFINITION

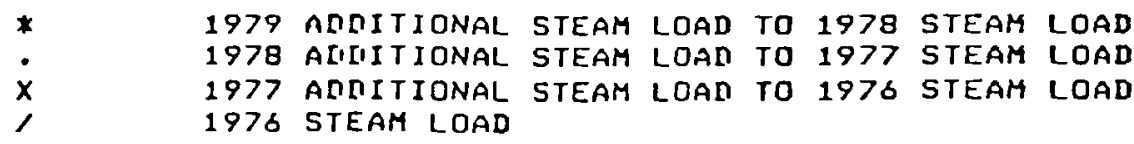

Figure 3-4. Demonstration community steam load duration curve for years 1976-1979. (Source: Soderberg and 0'Gara, 1978) 
If typical and extreme weeks were found from meteorological statistics and combined with knowledge of other factors which cause variations in loads, as many graphs as required to depict typical weeks could be computer-drawn. (For a university campus, for example, times when school is in session or out would be an important factor.)

A different method of presenting load duration curves is shown by Figure 3-5, from which Figure 3-6 is derived. Figure 3-6 gives the annual load factor, 28 percent. This is the ratio of average annual load to peak hourly load during the year. The load duration shown, 2465 hours, is the European practice for stating an equivalent to the load factor. It is the number of hours that equipment would operate at full rated output during the 8760 hours in a year to supply the entire annual load. $(2465 / 8760=0.28$.)

If various loads are to be served (different areas of a city, with some process heat, some space heating, some tap water heating), a diversity factor may be incorporated when the loads are aggregated. For example, in large district heating systems the peak coinciding load may be assumed to be 25 percent less than the total connected load, with space and water heating having different diversity factors.

Temperature requirements and acceptable excursions are of great importance. For space heating, a wide range of hot-water temperatures may be acceptable, permitting temperatures for sendout and return to be optimized for minimum system cost. If process heat loads are involved where severe losses would be incurred if temperature drops below some limit, or the supply fails, these and other such constraints should be noted.

The al lowable price or cost of energy supply normally will be derived from an existing system. The actual cost of natural gas or oil will be known and escalation can be estimated, giving one basis for setting a cost target. Benefits from greater dependability of hot water compared to interruptible gas should be quantified as an allowable increase in cost. The cost target or upper limit will be an important design parameter. 


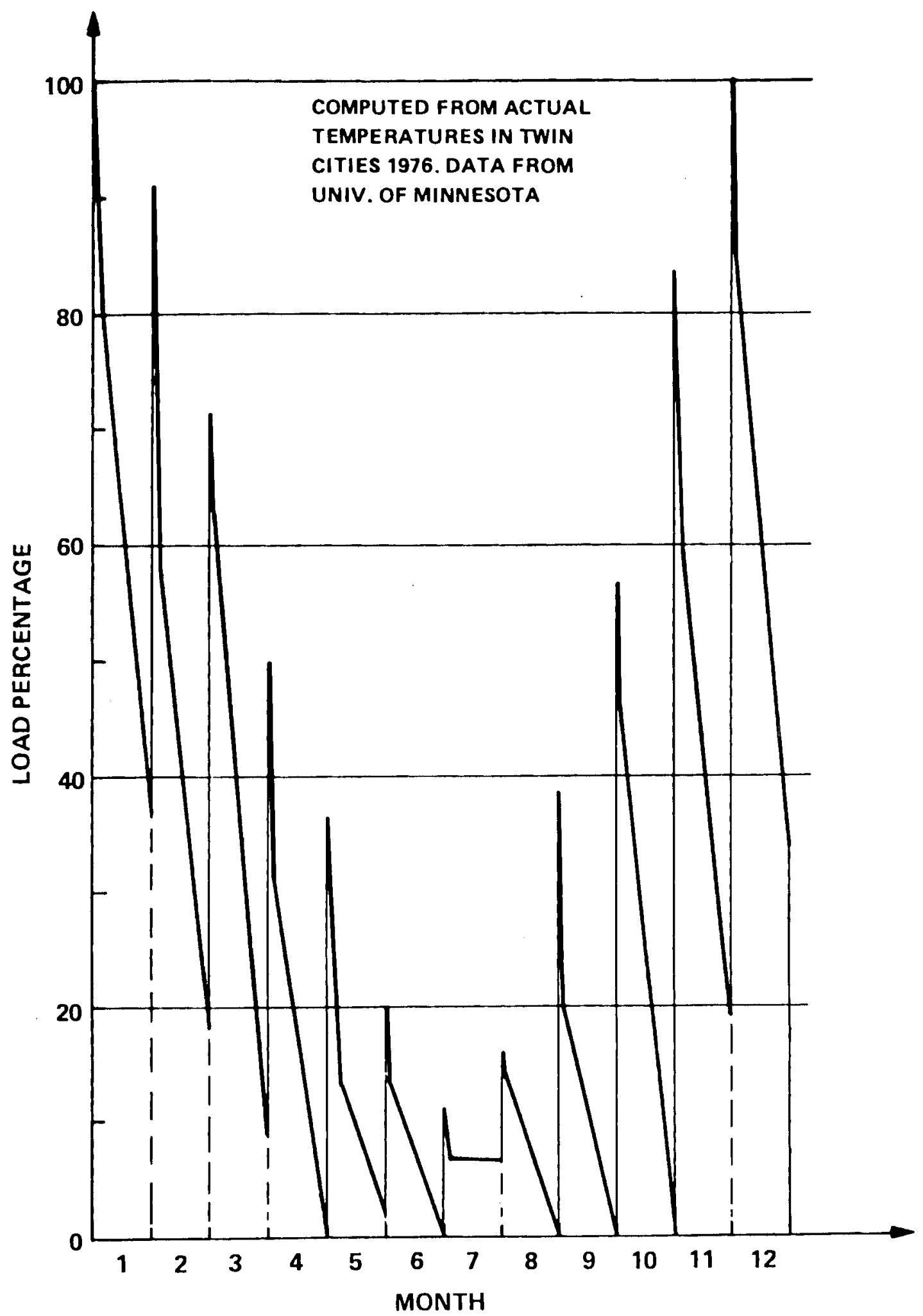

Figure 3-5. Monthly load duration curves for space heat and hot tap water for Twin Cities. (After Margen, et al, 1979b) 


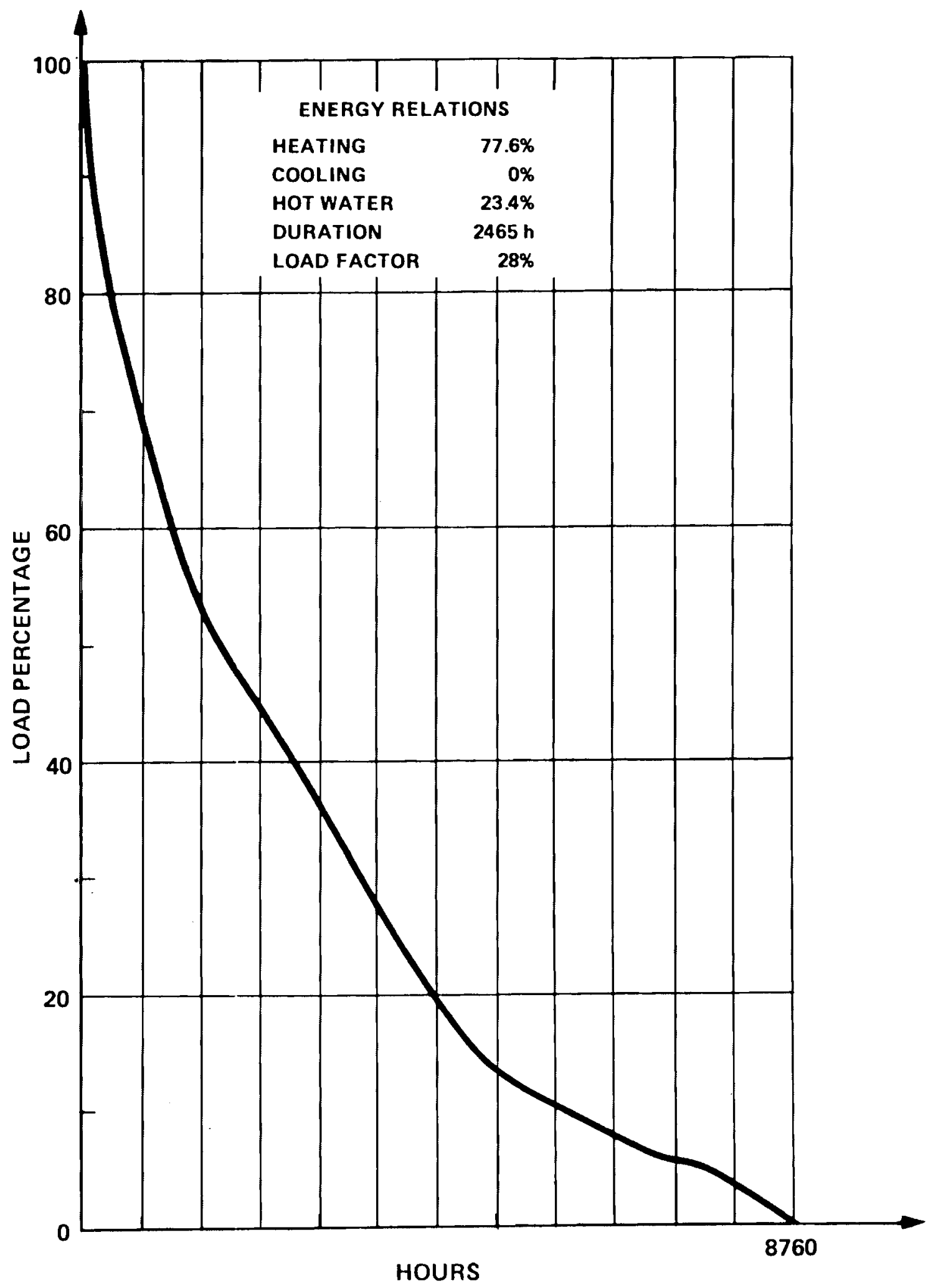

Figure 3-6. Annual load duration curve for space heat and hot tap water for Twin Cities. (After Margen, et al, 1979b) 
STORAGE SUBSYSTEM

Some fraction of the heat or chill produced by the thermal energy source will be diverted to the storage subsystem when production exceeds demand and recovered from the storage subsystem when demand exceeds production. In general, the storage subsystem will be comprised of the following elements:

\section{Above Ground}

- A heat exchanger to keep separate the water quality found in the aquifer from the water quality used in hot water pipelines.

- Valves and piping to control flow.

- Instrumentation, data recording, and controls.

- An enclosed shelter.

- Filtration and/or settling tanks if needed.

Below Ground

- Wells cased and cemented through overlying formations and completed in a confined aquifer.

- Injection tubes and/or valves and packers to control injection, pumps for withdrawal, and remote controls for actuating them.

- Instrumentation in both the hot and warm wells (or cold and cool wells).

- Instrumentation wells between or surrounding the main wells, in some instances.

\section{Heat Storage Well Doublet}

The configuration of the major storage subsystem elements in a basic heat storage well doublet is shown schematically in Figure 3-7. The two wells of the doublet comprise a closed hydraulic system. Water pumped from one well is injected into the companion we11; the net withdrawal is zero.

Heat is stored in the porous rock comprising the aquifer, in the water filling the pores, and in the relatively impervious aquifer cap 


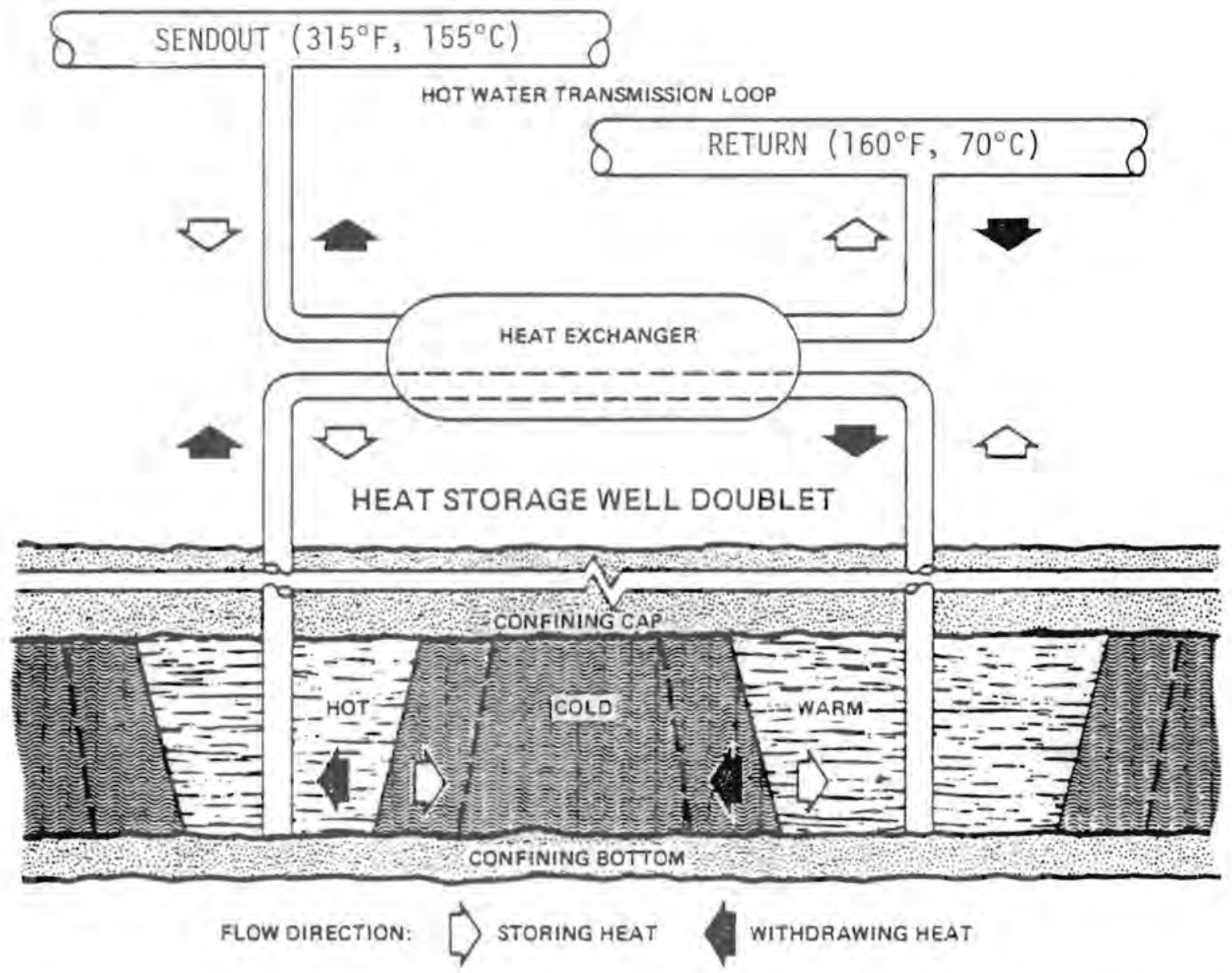

Figure 3-7. Schematic diagram of heat storage well doubTet operation.

and bottom. When heat is to be stored, hot water from the sendout pipeline flows through the counterfiow heat exchanger and to the return pipeline as shown by the open arrows in Figure 3-7. Groundwater is pumped from the warm we11, flows through the heat exchanger where it picks up heat, and is injected into the hot we11. As shown by the open arrows, the thermocline between warm and cold water moves inward toward the warm well, and the thermocline between hot and cold water moves radially outward from the hot wel1. When heat is to be recovered from storage, water flow and thermocline movement are reversed as shown by the solid arrows.

If the stored water is at a temperature above the local boiling point, it must be maintained in its liquid phase by keeping it at all 
times under a pressure higher than its vapor (saturation) pressure. Aquifers which are confined by impermeable formations as shown in Figure 3-7 typically are pressurized. (See Appendix B, "Confined Aquifers".) The amount of pressurization usually increases with depth. In general, the higher above the local boiling point is the temperature of water to be stored, the deeper the aquifer that will be needed.

Figure 3-8 shows the absolute saturation pressure of water from $100^{\circ} \mathrm{C}\left(212^{\circ} \mathrm{F}\right)$ to $200^{\circ} \mathrm{C}\left(392^{\circ} \mathrm{F}\right)$, and the corresponding gauge pressure at sea level - less than absolute pressure by $101 \mathrm{kPa}(14.7 \mathrm{psi})$. When a well is drilled into a confined aquifer, the water level in the well stands above the top of the aquifer at a height, or head, dependent upon the natural pressure in the aquifer (artesian pressure). In Figure 3-8, the vertical scales at the right show the height of a column of water at aquifer temperature (the artesian head) corresponding to the pressure scales on the left. The artesian head required to keep water in its liquid phase at a given temperature can be found directly from the gauge pressure curve for sealevel conditions; for higher altitudes, gauge pressure and required head will be greater.

A reasonable expectation is that a confined aquifer at a depth of 100 to 300 meters ( 350 to 1000 feet), not heavily pumped for other purposes, will have sufficient artesian pressure to exceed the saturation pressure of water at $150^{\circ} \mathrm{C}\left(300^{\circ} \mathrm{F}\right): 375 \mathrm{kPa}$ gauge pressure at sea level (54 psig), corresponding to 38 meters (126 feet) of head at normal aquifer water temperature. Above this temperature, the saturation pressure and required artesian head increase quite rapidly; the difficulty in locating a suitable aquifer, tightly confined, and the expense of well construction, increase accordingly.

The required head as explained above is a minimum requirement in order to maintain water in its liquid phase when the well is shut in - no pumping or injection is taking place. In order to maintain the required pressure when the well is being pumped, the pump must be 


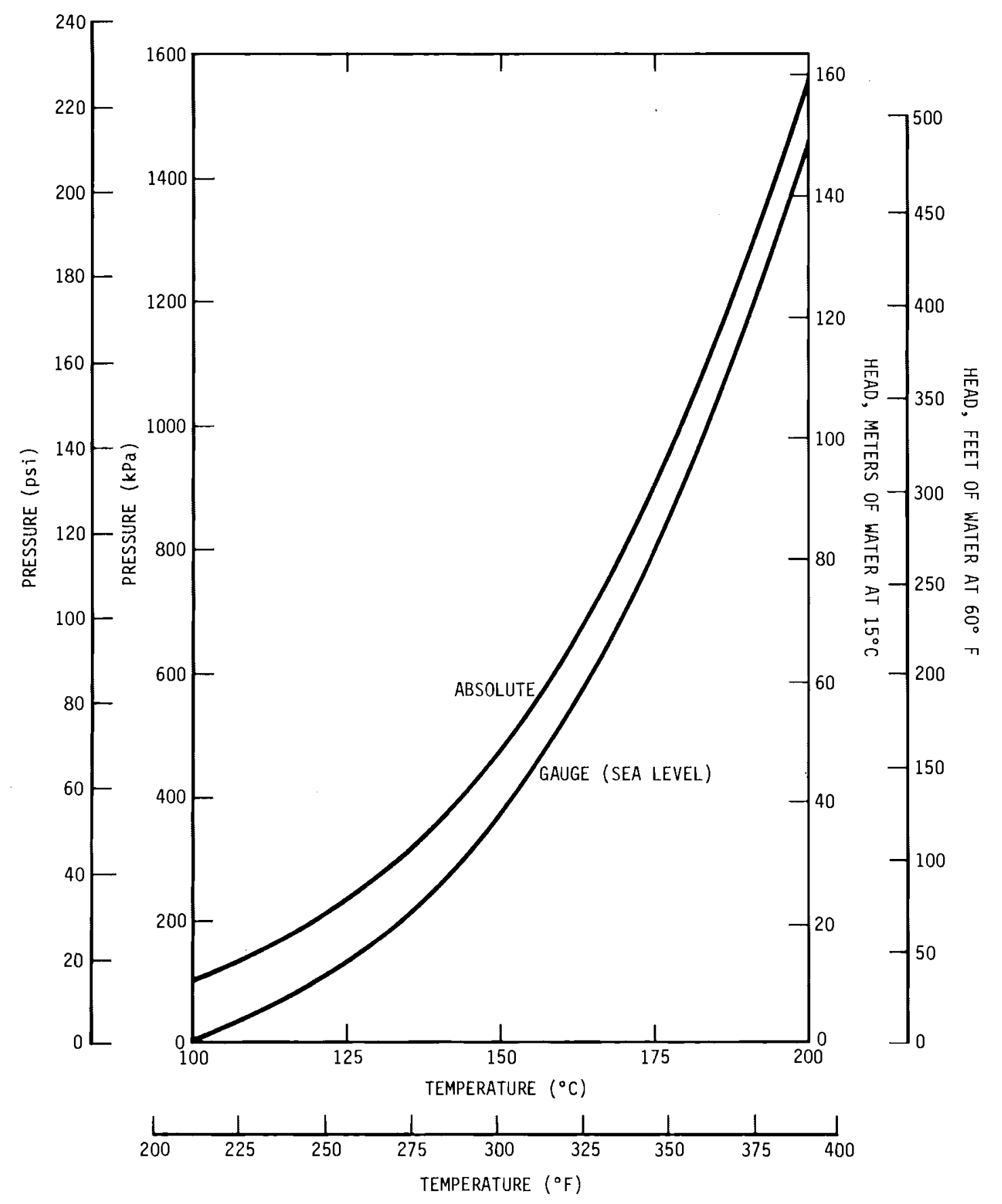

Figure 3-8. Absolute and gauge saturation pressures for water at temperatures from 100 to $200^{\circ} \mathrm{C}\left(212\right.$ to $\left.392^{\circ} \mathrm{F}\right)$, with corresponding head of water at $15^{\circ} \mathrm{C}\left(60^{\circ} \mathrm{F}\right)$. 
set deep enough in the well that the suction produced at the pump's inlet will not cause water pressure to fall below saturation value, or cavitation and pump damage will result.

\section{Rate of Thermal Energy Storage}

The rate at which thermal energy can be stored or withdrawn from storage is determined by the size of the wells, their temperatures, the pumps employed, and the flow parameters of the aquifer. A moderately large heat storage well doublet would have a water production rate of 441 iters per second (700 gpm, 1 million gpd). In Figure 3-9A are two nomographs from which the rate of storage or withdrawal can be found in metric/SI units. Figure 3-9B gives the same information

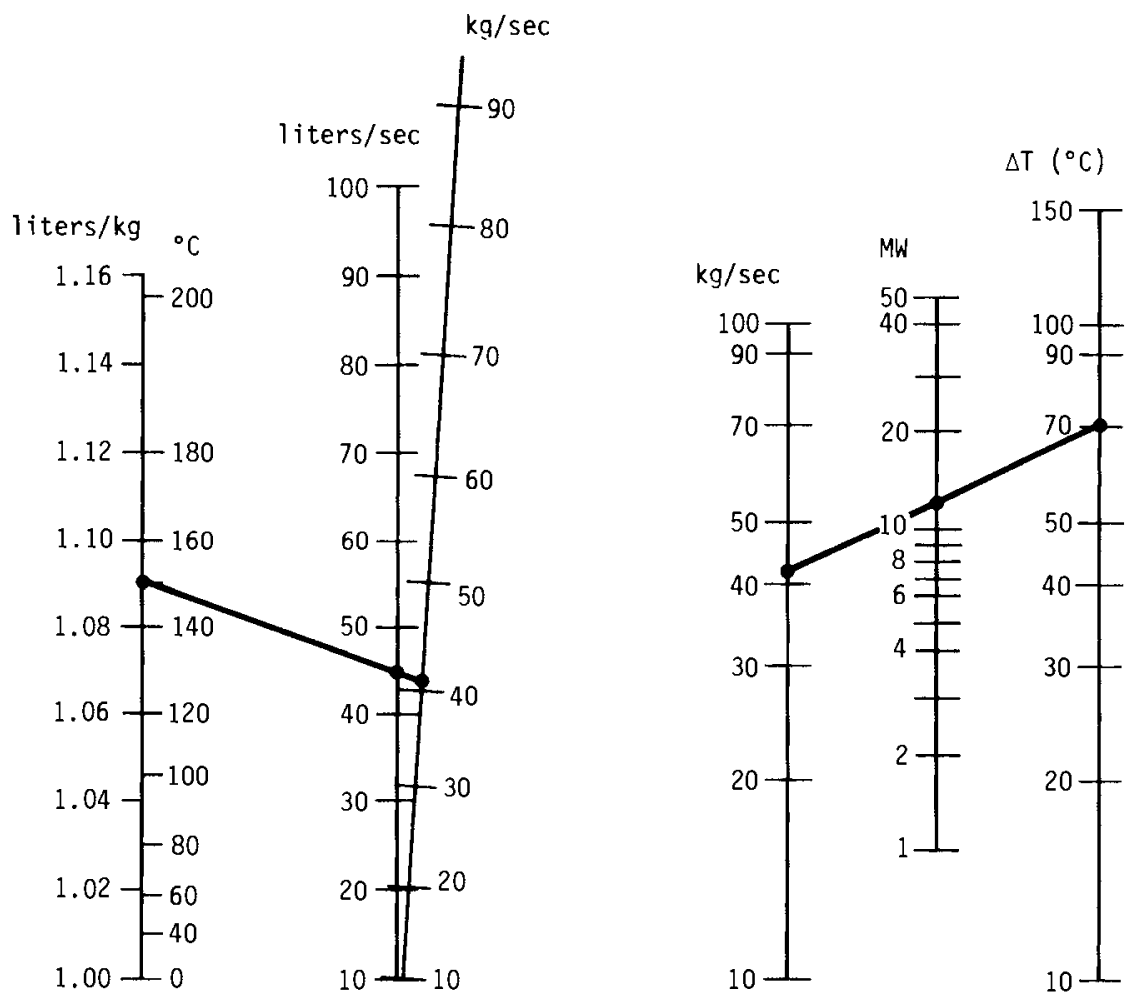

Figure 3-9A. Nomograph relating injection or withdrawal temperatures, temperature difference between wells in a doublet, water flow rates, and thermal energy flow rates; in SI units. 
in English units. The example shown in these nomographs assumes water at a temperature of $150^{\circ} \mathrm{C}\left(300^{\circ} \mathrm{F}\right)$ is to be injected at a rate of 44 liters per second (700 gpm), and that the temperature difference $\Delta \mathrm{T}$ between hot and warm wells is $70^{\circ} \mathrm{C}\left(125^{\circ} \mathrm{F}\right)$. The lefthand portion of the nomograph transforms volume into mass, necessary for energy computations. Water at $44^{\circ} \mathrm{C}\left(300^{\circ} \mathrm{F}\right)$ being 9 percent less dense $(1.09 \mathrm{l} / \mathrm{kg})$ than at $4^{\circ} \mathrm{C}(1.00 \mathrm{l} / \mathrm{kg})$, the mass flow rate is 40.4 $\mathrm{kg} / \mathrm{sec}$ or 320,000 pounds per hour. Transferring the mass flow rate to the righthand portion of the nomograph and drawing a line to the $70^{\circ} \mathrm{C}\left(125^{\circ} \mathrm{F}\right)$ value of $\Delta \mathrm{T}$ shows the rate of thermal energy storage to be $11.7 \mathrm{MW}$ (40 MBtu/hr).

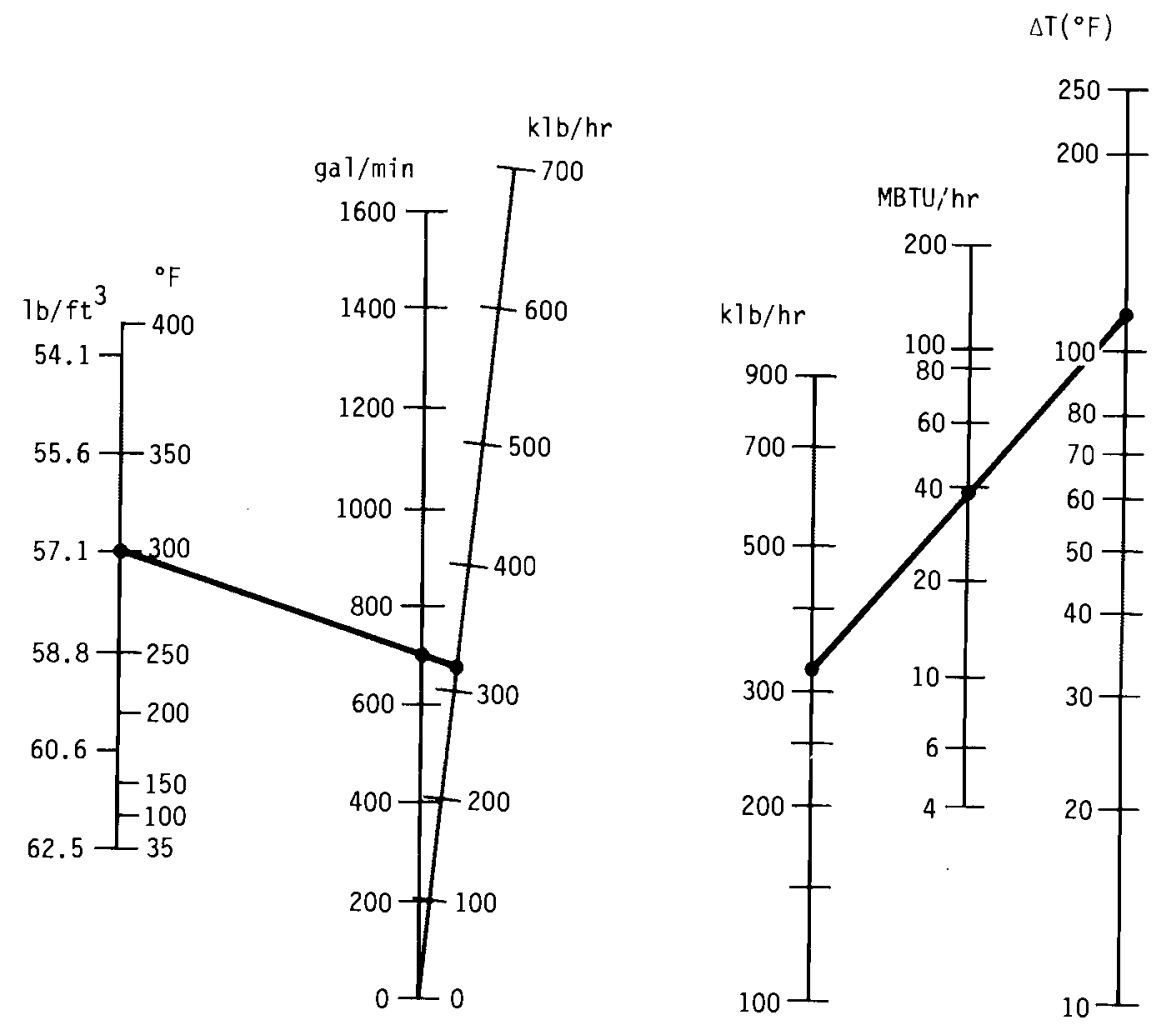

Figure 3-9B. Nomograph relating injection or withdrawal temperatures, temperature difference between wells in a doublet, water flow rates, and thermal energy flow rates; in English units. 
Amount of Thermal Energy Storage

To find the amount of thermal energy stored in an aquifer requires only that the energy storage rate, found from Figure 3-9, be multiplied by the time duration of injection. If the energy storage rate changes with time, as is likely, the sum of the amount stored during each time increment is needed: basically, the area under a graph of energy storage rate versus time, for the total period of interest. Using the example of Figure 3-9, and assuming for simplicity that the thermal energy storage rate is a constant 11 MW for 120 days, the total energy stored is 114 terajoules ( $32 \mathrm{GWh}, 108 \mathrm{GBtu}$ ) in a total water volume of about $0.46 \times 10^{6} \mathrm{~m}^{3}$ (120 million gallons). One extremely large or two very large and expensive insulated tanks would be required to store this amount of hot water. However, aquifers with equivalent storage capacity are very common. An urban water supply well may pump water from an aquifer at this rate for decades. The enormous amount of storage space in aquifers is illustrated by the estimate of the U.S. Geological Survey (1972) that at least 20 times more water is stored underground than in lakes and rivers.

Distance to Heat Interface; Well Spacing

As hot water moves away from the injection well through the porous rock of the matrix, it heats the matrix. Water that has delivered its heat to the matrix will rapidly cool and approach the matrix temperature. A heat interface, or thermocline, will develop. After injection has proceeded for some time, temperature along a path radial from the injection well will be very nearly the same as the injected water until the thermocline is reached. At the thermocline, the temperature of water and matrix will drop abruptly. The distance from the injection well to the thermocline will be determined by the temperature and volume of the injected water, the thickness of the aquifer, the porosity of the rock, and the relative heat capacities of water and matrix. The distance from the injection well to the hydraulic interface between native and injected water will be determined by the injected water volume and the thickness and effective porosity of the aquifer. 
Figure 3-10 shows the radii from the injection well to the thermocline and to the hydraulic interface, assuming a cylindrical shape and specific aquifer and water parameters. The radius $r_{\text {th }}$ found from Figure 3-10 will approximate the average distance from the well to a tilted thermocline. Using the example of Figure 3-9, an injection

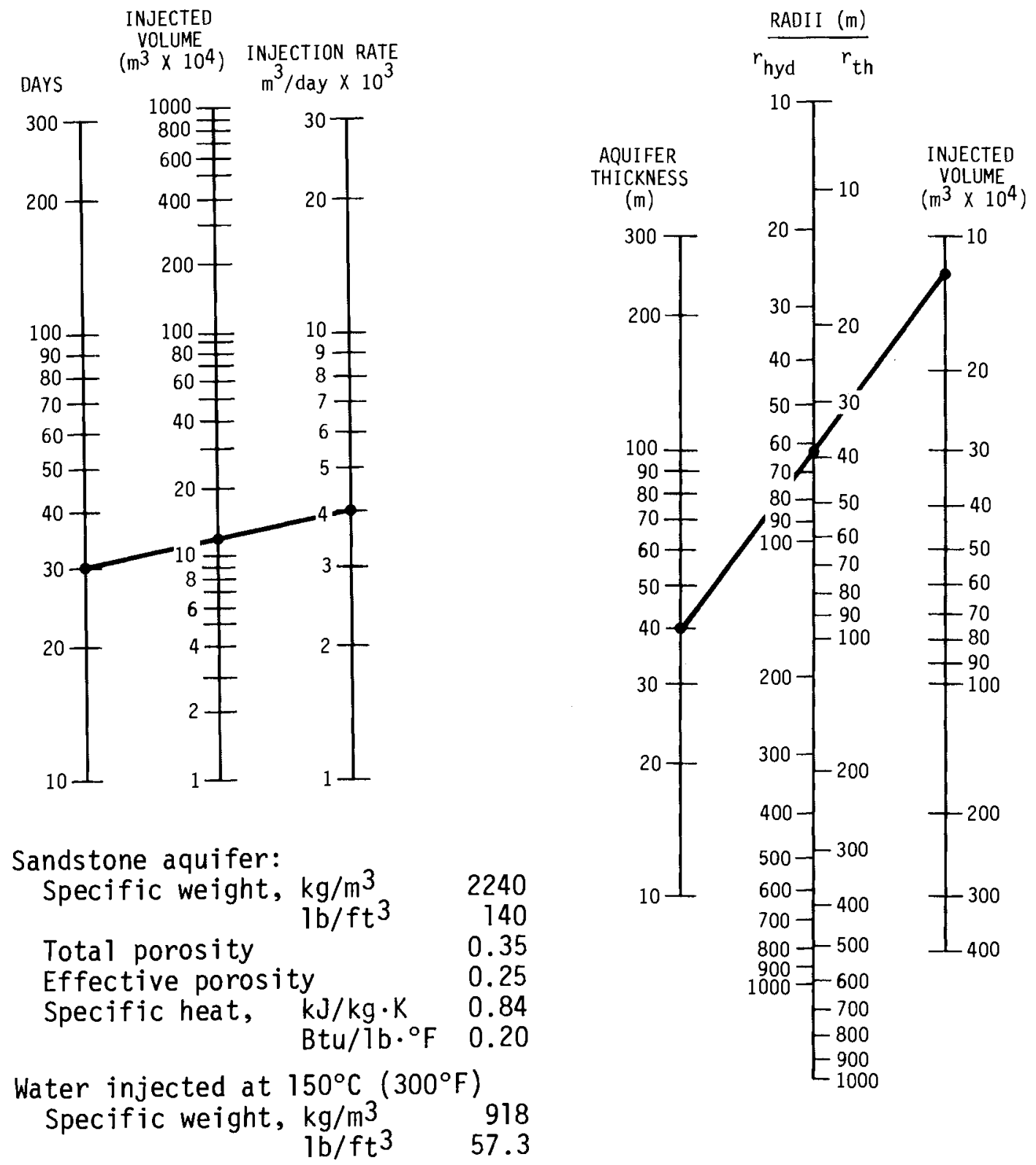

Figure 3-10. Nomograph of radii to thermal and hydraulic interfaces (cylindrical coordinates) versus aquifer thickness and injected volume of water, for assumptions shown. 
rate of 44 liters per second is $3800 \mathrm{~m}^{3}$ ( 1 million gallons) per day. In 30 days the injected volume is $114 \times 10^{3} \mathrm{~m}^{3}$. For an aquifer thickness of 40 meters ( 130 feet), the radius to the thermocline is seen to be about $37 \mathrm{~m}(120 \mathrm{ft})$, and to the hydraulic interface about $61 \mathrm{~m}(200 \mathrm{ft})$. (The equations for Figure 3-10 are given in Appen$\operatorname{dix}$ A.)

To estimate the spacing required between wells to avoid breakthrough, a rule of thumb is to multiply by three the maximum expected thermal radius (distance from hot well to thermocline). In the example given above, suppose the maximum expected injection is 44 liters per second for 120 days. The thermal radius would become about $75 \mathrm{~m}$ $(240 \mathrm{ft})$. The minimum suggested spacing between wells would be $(3 \times 75=) 225 \mathrm{~m}(740 \mathrm{ft})$. (Breakthrough is discussed further in Appendix A.)

\section{Heat Exchanger}

The heat exchanger isolates the groundwater from the treated water used in the hot water transmission loop. This permits operating the transport and well systems at independent pressure and flow conditions, prevents contamination of groundwater, and keeps possible corrosion and scaling effects of mineralized groundwater out of the transport system.

Figures 3-11A and 3-11B show the effect of the temperature drop from input to output side of the heat exchanger (the approach temperature). (To reduce clutter in Figure 3-11, temperatures are shown only in Fahrenheit degrees.) Allowing for some fouling, an approach temperature of $15^{\circ} \mathrm{F}$ is assumed. The nominal sendout-pipel ine temperature is assumed to be $315^{\circ} \mathrm{F}$. Subtracting the approach temperature, water at $300^{\circ} \mathrm{F}$ is injected into the hot well (Figure 3-11A). The nominal return-pipeline temperature is assumed to be $160^{\circ} \mathrm{F}$; during withdrawal (Figure $3-11 \mathrm{~B}$ ), water at $175^{\circ} \mathrm{F}$ is injected into the warm well. This establishes the temperature difference between warm and hot wells as $(300-175=) 125^{\circ} \mathrm{F}$. 


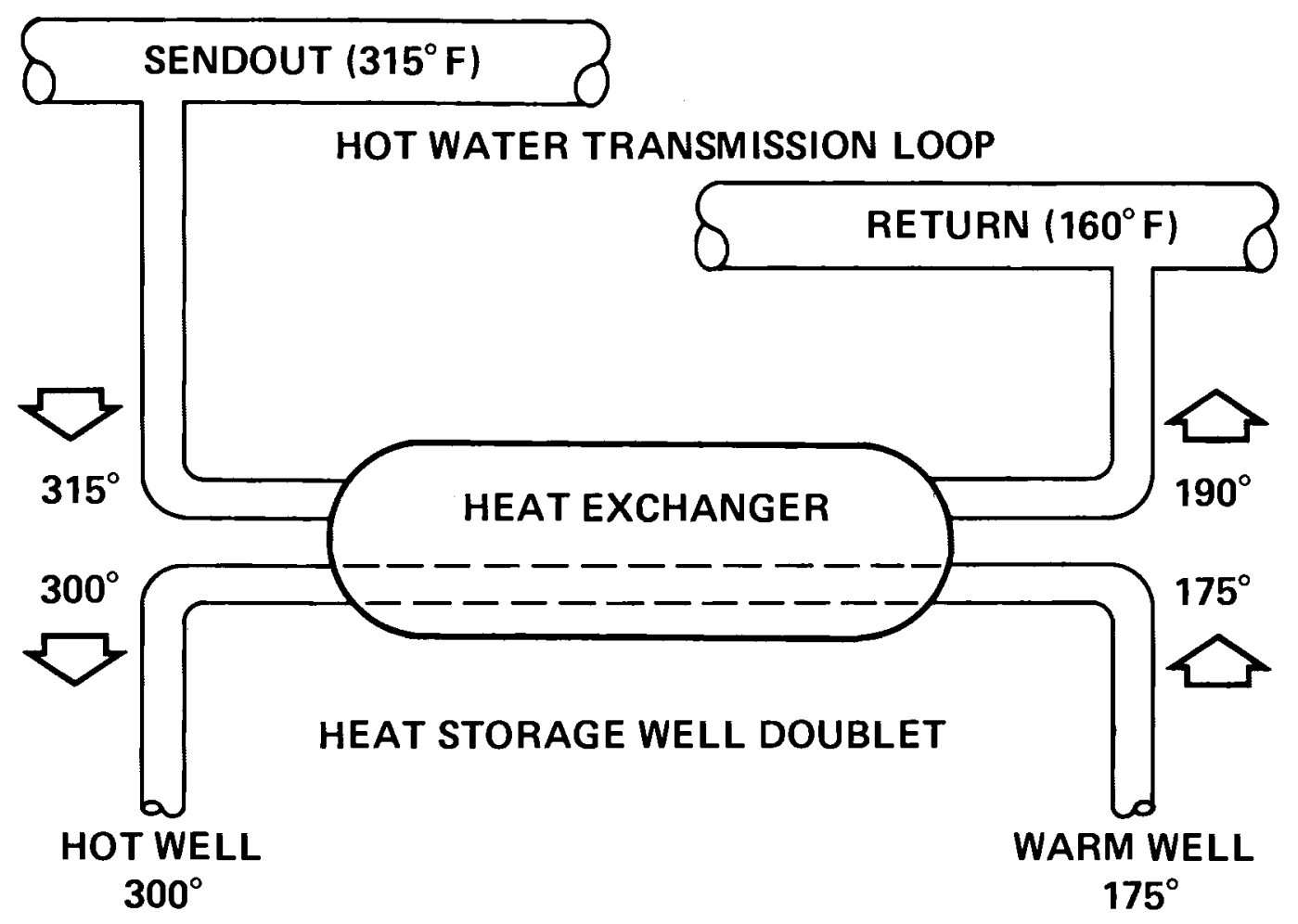

Figure 3-11A. Temperature drops across heat exchanger during heat storage.

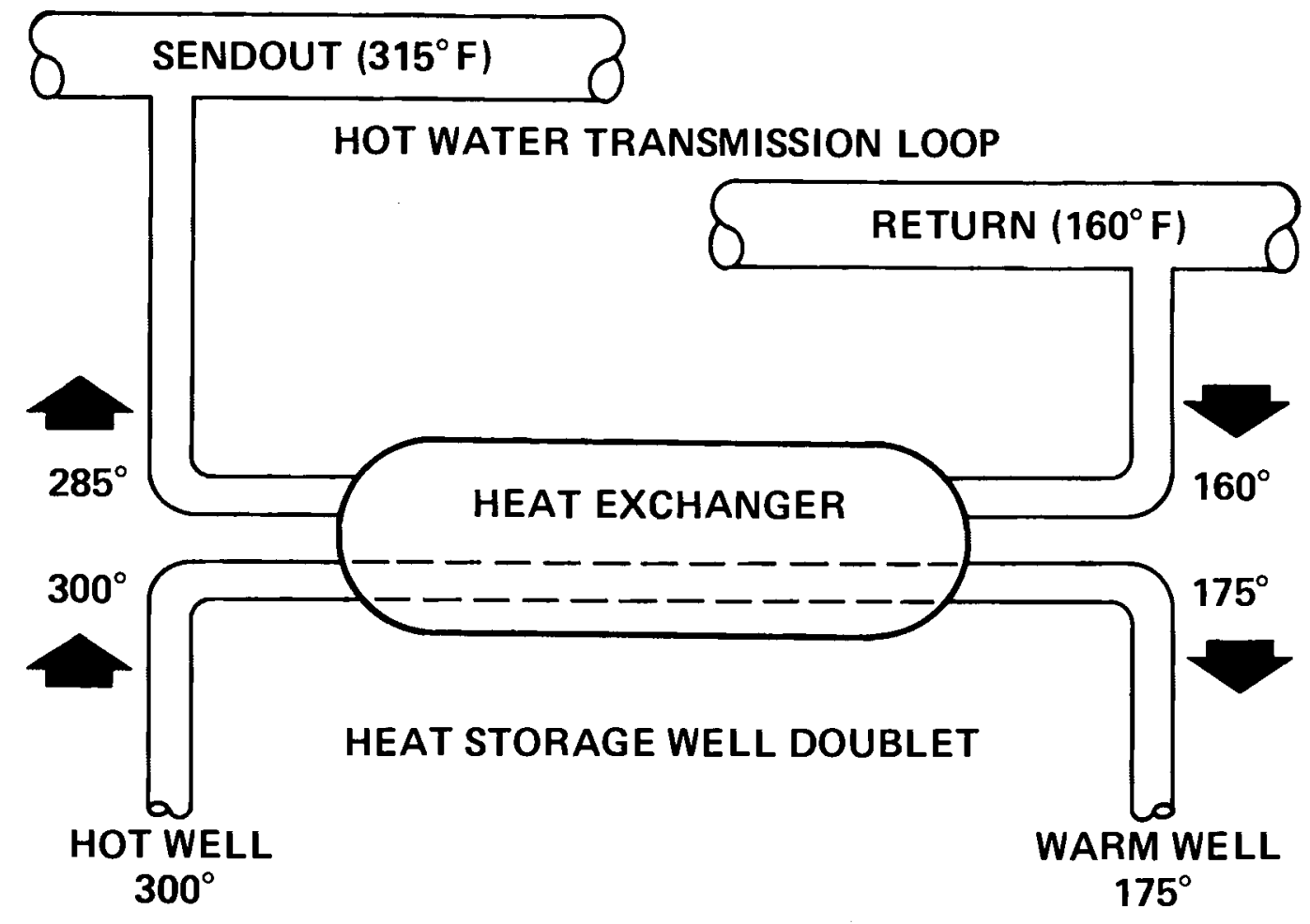

Figure 3-11B. Temperature drops across heat exchanger during heat withdrawal. 
The effect of approach temperature as seen by the pipeline loop can now be noted. During withdrawal, the not well raises the temperature of water going to the sendout pipeline to only $285^{\circ} \mathrm{F}$, lower than the nominal temperature by twice the approach temperature. During storage, water is sent to the return pipeline at $190^{\circ} \mathrm{F}$, higher than the nominal temperature by twice the approach temperature. The useful $\Delta T$ in withdrawing heat is $\left(285-160 \Rightarrow 125^{\circ} \mathrm{F}\right.$, and in injecting heat is $(315-190=) 125^{\circ} \mathrm{F}-$ significantly less than the $\left(315-160 \Rightarrow 155^{\circ} \mathrm{F}\right.$ useful $\Delta \mathrm{T}$ between sendout and return pipelines.

While the temperature drops $\left(\mathrm{T}_{1}-\mathrm{T}_{3}\right)$ and $\left(\mathrm{T}_{2}-\mathrm{T}_{4}\right)$ do not represent a loss of energy, they represent a degradation of the energy; the approach temperature should be made as low as is economically feasible.

For the countercurrent heat exchanger shown in Figure 3-11, where $\left(T_{1}-T_{3}\right)$ and $\left(T_{2}-T_{4}\right)$ are equal, the heat transfer rate through the heat exchanger is

$$
q=U \cdot A \cdot\left(T_{1}-T_{3}\right)
$$

where $A$ is the surface area of the heat exchanger tubes, and $U$ is the overall heat transfer coefficient. The heat exchanger cost is roughly proportional to area $A$; a compromise must be made between cost and the reduction of $\left(T_{1}-T_{3}\right)$.

The overall heat transfer coefficient $U$ represents the composite of the thermal resistance in the layers through which the heat is transferred: the resistance drop through the metal tube is small but that through the slow moving liquid boundary-layer films on the inside and outside is not. For pure water on both primary and secondary, a rule of thumb is that $U=2200 \mathrm{~W} / \mathrm{m}^{2} \cdot \mathrm{K}\left(400 \mathrm{Btu} / \mathrm{hr} \cdot \mathrm{ft}^{2} \cdot{ }^{\circ} \mathrm{F}\right.$ (range 250-500)). For impure water where scale or slime may build up and increase the resistance to heat flow, a fouling coefficient must be used in design. As the fouling may build up without limit (hard water scale can completely clog a pipe) the fouling coefficient chosen is a design margin. Each time it is exceeded, it is time to 
clean the scale or slime from the tubes. A plant design handbook (Peters and Timmerhaus, 1968) suggests a fouling coefficient of $1700 \mathrm{~W} / \mathrm{m}^{2} \cdot \mathrm{K}\left(300 \mathrm{Btu} / \mathrm{hr} \cdot \mathrm{ft}^{2} \cdot{ }^{\circ} \mathrm{F}\right)$ for brine. To get a new value of $\mathrm{U}$ including this, $\frac{1}{2200}+\frac{1}{1700}=\frac{1}{970}$ or $U_{\text {equiv }}=970 \mathrm{~W} / \mathrm{m}^{2} \cdot \mathrm{K}$ $\left(170 \mathrm{Btu} / \mathrm{hr} \cdot \mathrm{ft}^{2} \cdot{ }^{\circ} \mathrm{F}\right)$.

To illustrate design considerations for these numbers assume thermal energy is to be stored at a rate $q=10 \mathrm{MW}$ (34 million Btu/hr) and $\left(\mathrm{T}_{1}-\mathrm{T}_{3}\right)$ is not to exceed $10^{\circ} \mathrm{C}\left(18^{\circ} \mathrm{F}\right)$. The heat exchange area in the tubes must be

$$
A=q / U \cdot \Delta T=10 \cdot 10^{6} /(970 \cdot 10)=1030 \mathrm{~m}^{2}\left(11000 \mathrm{ft}^{2}\right)
$$

A rule-of-thumb estimator for heat exchanger costs in mid-1980 dollars for this application is 10 to 20 dollars per square foot (100 to $220 \$ / \mathrm{m}^{2}$ ) for the equipment with about another 10 to $15 \mathrm{dol}$ lars per square foot (110 to $\left.160 \$ / \mathrm{m}^{2}\right)$ for installation, including valves, piping, instruments, foundation, and the associated labor. The lower figure per square foot is for plain steel, probably inadequate in corrosion resistance for brackish water. The upper figure represents a higher grade stainless steel than may be necessary in all cases. Using $\$ 16$ per square foot $\left(170 \$ / \mathrm{m}^{2}\right)$ plus $\$ 12$ per square foot $\left(130 \$ / \mathrm{m}^{2}\right)$ for installation gives $\$ 308,000$ as the estimated installed cost for the above heat exchanger, in mid-1980 dollars.

This represents direct costs of $31 \$ / \mathrm{kW}$. If it were necessary to reduce the approach temperature $\left(T_{1}-T_{3}\right)$ to $5^{\circ} \mathrm{C}\left(9^{\circ} \mathrm{F}\right)$ the cost would double. However, note that the fouling factor provides a margin of safety. When first operated, or just after removing fouling by periodic maintenance, the factor $U$ is 2200 rather than 970 , so $\left(T_{1}-T_{3}\right)$ can be $4.5^{\circ} \mathrm{C}\left(8^{\circ} \mathrm{F}\right)$.

The buildup rate of scale or other fouling is an uncertainty for every application and aquifer. To counter it, multiple heat exchangers should be used, such as four $280 \mathrm{~m}^{2}$ ( $3000 \mathrm{ft}^{2}$ ) modules, so that one can be shut down for cleaning without serious effect on charging or discharging of storage. Pump capacity should be adequate 
to send the full flow through three units while the fourth is being cleaned. If possible, cleaning should be scheduled between injection and production periods, when the wells are shut in.

In the above example for heat storage, the primary loop $\Delta T$ is $86^{\circ} \mathrm{C}\left(155^{\circ} \mathrm{F}\right)$. When storing chill, the $\Delta T$ is seldom more than $20^{\circ} \mathrm{C}$ $\left(36^{\circ} \mathrm{F}\right)$. Tolerable temperature drop will be much smaller so more heat exchanger area will be required as well as frequent cleaning to maintain a high $U$. Scaling by chemical deposits may be less severe than with hot water but organic fouling is more likely than with hot water. It may be feasible to use groundwater for cooling directly, rather than through a heat exchanger (Angus and Williams, 1980).

Compensating for Temperature Drop Across Heat Exchanger.

The system may be designed to accommodate the lower sendout temperature obtained when heat is being recovered from storage, by providing for increasing the flow rate at end-use equipment so that the needed amount of heat can be delivered at a smaller $\Delta T$. If a primary heat source (e.g., cogeneration) is also delivering hot water at nominal temperature through the sendout pipeline, as is often the case, blending will reduce the temperature drop that needs to be accommodated.

If the expected temperature drop cannot be accommodated, various means of mitigating it can be considered:

- Larger heat exchanger or more frequent tube cleaning.

- Trim heat; add supplementary heat to the primary or secondary at the storage heat exchanger.

- Using a higher sendout temperature during storage charging.

- Novel heat exchanger designs. *

\footnotetext{
"Keller (1980) and Cole and Allen (1979) discuss a fluidized-bed heat exchanger for geothermal brines which minimizes corrosion and scale formation. Alfa-Laval advertises turbulent-flow heat-plate exchangers with self-scrubbing action which have temperature approaches as low as $2^{\circ} \mathrm{F}$.
} 
- Compare variable-temperature (seasonally) constant-flow operation modes with constant-temperature variable-flow modes and intermediate schemes, for an optimum.

Other Aboveground Equipment

The required piping, valves, and controls, as well as foundation and shelter, are customarily included in the on-site labor and materials of installation. The direct cost or installed cost used above, $31 \$ / \mathrm{kW}$, includes them.

In addition to master valves and pumps to control the flow in the hot water transmission loop and the storage loop, individual valves on each heat exchanger (if multiples are used) are needed to facilitate maintenance.

Scaling, Corrosion, Fouling, and Well Plugging

Heating water from an aquifer and injecting it back into the aquifer is expected to cause some geochemical effects. Both increased solubility of some chemical constituents and precipitation of others are among the possibilities. Biological effects also remain to be fully explored. Growth of biota may be either inhibited or encouraged, depending on water temperature and species present. Corrosion may range from minor to so severe as to require special, expensive materials, as in geothermal installations.

Scale deposits in the well bore and on aboveground equipment may occur due to both heating and cooling the groundwater. The solubility of some chemical constituents such as calcite (calcium carbonate) and dolomite (calcium magnesium carbonate) decreases with increasing temperature. Other constituents (silica) have the more usual characteristic of increased solubility with increasing temperature. Geochemical reactions can be predicted by analysis of aquifer material and the groundwater it contains - at least to the extent of suggesting suitable and unsuitable materials and procedures.

Biological fouling may occur. It is more likely at low than at high temperatures. Reversing the direction of flow, as will be 
routine in an ATES doublet, may provide easy opportunity to dose the well with additives in accordance with conventional water-well practice.

Precipitates formed during heating or cooling which do not adhere as scale, or which break away during cleaning, can potentially cause plugging of wells during injection. (Van Note, et al, 1978.) Provision for removal of particular matter may be required: settling tanks, sand and charcoal beds, micropore filters, centrifugal separators, flocculation, clarifiers. Environmental regulations may prohibit or limit the use of additives.

Additional discussion of geochemical and biological effects may be found in Appendix A. Advice of geochemists and water-treatment specialists should be sought for specific recommendations.

Stored Hot Water:

Temperature Loss and Heat Recovery Fraction

In addition to the temperature drop across the heat exchanger, a temperature loss will occur as water is produced from storage. Unlike the temperature drop across the heat exchanger, the temperature loss of recovered hot water is associated with a loss of thermal energy, during storage.

Somewhat as with root cellars and ice caves, natural rocks and sand insulate the hot water stored in an aquifer. Early studies suggested that three-fourths or more of the stored heat would be recoverable after six months or longer (Meyer, Todd, and Hare, 1972).

The fraction of stored heat that is lost for a given storage temperature will depend on the ratio of surface area, through which heat escapes, to the enclosed volume where the heat is contained. The ratio of surface area to enclosed volume decreases for larger volumes; hence heat loss will be higher for small scale than for large scale storage. This effect sets a lower bound on the applications of aquifer TES (Meyer, 1978, P-785). Heat loss increases, of course, as the storage temperature increases. 
More heat will be lost during early cycles of injection-storagerecovery than during later cycles when the aquifer matrix and confining layers have been prewarmed. This effect is sketched in Figure 3-12. After stored hot water has been extracted until the temperature of the water being withdrawn has dropped to whatever temperature is considered the lowest that is useful in the system, some fraction of the injected heat will remain behind - in Figure 3-12 about 30 percent after the first cycle. The heat that stays in the aquifer and confining layers improves the recovery fraction for the next cycle. In the example plotted here, the recovery fraction levels off at about 80 percent after four or five cycles. Other situations will give higher or lower recovery fractions.

The best basis currently available for predicting or explaining heat recovery efficiency and temperature loss during recovery of hot water from storage is judged to be Lawrence Berkeley Laboratory computer simulations, together with results from the two field experiments in the United States: heat storage and recovery, by Auburn University, and storage and recovery of winter-chilled water, by

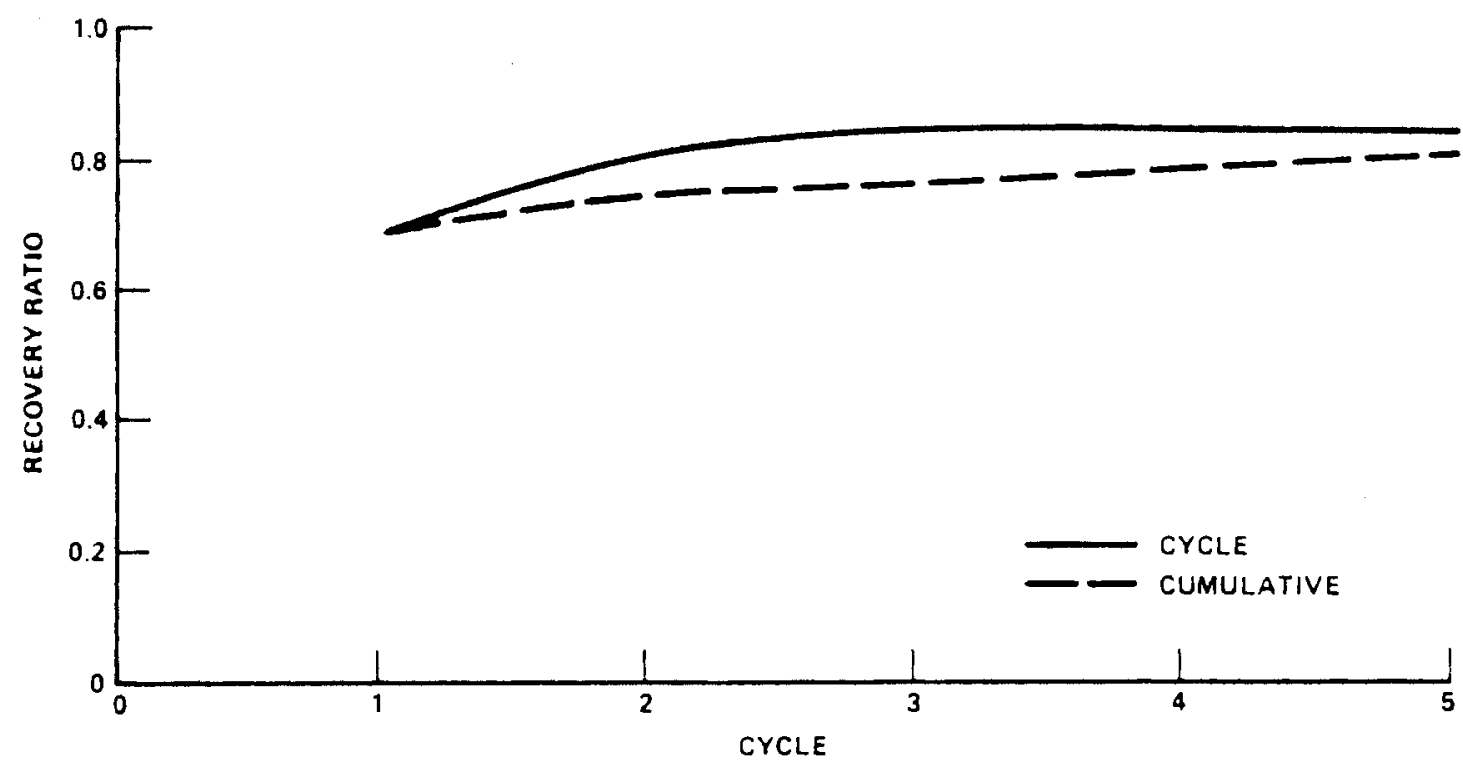

Figure 3-12. Heat recovery fraction, per cycle and cumulative. 
Texas A\&M University. Recovery of 80 percent or more of the injected heat, after a few cycles, continues to be the expectation.

As results are obtained from the DOE/PNL ATES Demonstration Program (Minor, 1980) and from work ongoing in other countries, a better data base will become available and the state of knowledge will be further improved.

TEMPERATURE LOSS. When recovery of stored heat begins, the temperature of water pumped from the hot well will at first be approximately the same as the injection temperature. As hot water pumping continues, the water temperature will drop as water that has been cooled by loss of heat into the aquifer and its confining layers begins to enter the well. Eventually, depending upon the system application, the water will not be hot enough to be useful and pumping will be stopped.

MITIGATION. As with temperature drop across the heat exchanger, designing the system for increased flow when it is needed, and use of blending to reduce the temperature drop, are possibly the best ways to accommodate the temperature losses associated with ATES. Sending out higher temperature water when ATES is being charged, so that recovery temperatures will be higher, is another mitigating measure to consider. A third is to add a small source of trim heat to raise the temperature of water entering the sendout pipe from the heat exchanger and hold it within a useful range for longer periods of time.

ESTIMATING TEMPERATURE LOSS VERSUS TIME. To predict temperature joss versus time as hot water is produced from storage requires using a computer model to simulate the injection, storage, and production of hot water, in an aquifer of known hydraulic and thermal characteristics. Tsang, Witherspoon, Buscheck, and others at DOE's Lawrence Berkeley Laboratory (LBL) have published a number of reports on results of computer simulations, validated in some cases against field data, which illustrate temperature loss versus time. 
The results of one LBL simulation are shown in Figure 3-13.

These results may be used to estimate temperature loss during production for aquifers of comparable (Zow) permeability and thermal characteristics, with similar schedules of injection-storage-productionrest. The LBL simulation illustrated is for an annual cycle of a single well - a distant doublet. It assumes a relatively low permeability aquifer $\left(10^{-9} \mathrm{~cm}^{2}, 0.1\right.$ darcy ${ }^{*}$ at an ambient temperature $T_{0}$ of $20^{\circ} \mathrm{C}\left(68^{\circ} \mathrm{F}\right)$, into which $10^{6}$ kilograms per day $(180 \mathrm{gpm})$ of water at a temperature $T_{\text {in }}$ of $120^{\circ} \mathrm{C}\left(248^{\circ} \mathrm{F}\right)$ is injected for 90 days.

(This is a heat injection rate of $5.7 \mathrm{MW}$ (19 MBtu/hour) referenced to $20^{\circ} \mathrm{C}$; in 90 days, total heat injection is 44 terajoules ( $42 \mathrm{GBtu}$, 12 GWh).) Regional groundwater flow is assumed negligible. Buoyancy effects are included. Following the 90-day injection period is a 90day storage period, during which the wells are shut in. Then the 90day production period commences, to be followed by a 90 -day rest period when the wells are again shut in. (Tsang, et al, 1978.)

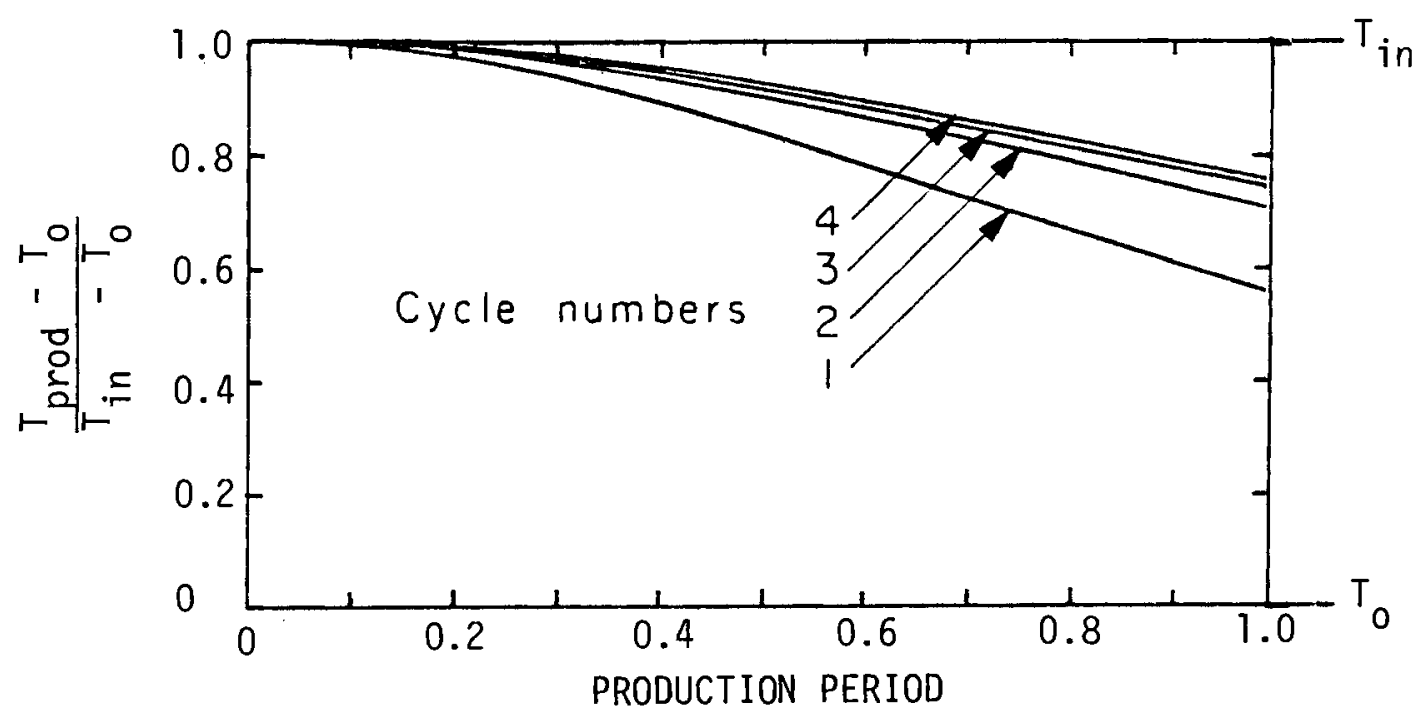

Figure 3-13. Production temperature of hot water as it is recovered from aquifer storage.

(After Tsang, et al, 1978, Figure 10)

$\bar{*}$ Typical of sandstone or silty sand. 
From other LBL simulation runs for comparable aquifers, it appears that the production temperature ( $T_{\text {prod }}$ ) curves shown in Figure 3-13 are reasonably applicable for injection temperatures $T_{\text {in }}$ considerably higher than $120^{\circ} \mathrm{C}$, and for essentially any period of production provided the injection, storage, and rest periods are equal to the production period - e.g., 10 days or 120 days instead of 90 days for each period. (Tsang, et al, 1978, and personal communication with Dr. Tsang.)

If hot water is produced for the full nominal production period, a rule of thumb suggested (for comparable aquifers) by Figure 3-13 is that the production temperature $T_{\text {prod }}$ will drop during the first cycle of production to about midway between the injection temperature $T_{i n}$ and the ambient temperature $T_{0}$ of the native groundwater: i.e., ( $\left.T_{\text {prod }}-T_{0}\right) / T_{\text {in }}-T_{0}$ ) is 0.5 to 0.6 . If $T_{\text {in }}$ is $120^{\circ} \mathrm{C}\left(248^{\circ} \mathrm{F}\right)$ and $T_{0}$ is $20^{\circ} \mathrm{C}\left(68^{\circ} \mathrm{F}\right), T_{\text {prod }}$ at the end of the first full production period would be about $75^{\circ} \mathrm{C}\left(165^{\circ} \mathrm{F}\right)$.

If the drop in $T_{\text {prod }}$ associated with a full production period is too large to be acceptable (the water is not hot enough to be useful), production may be halted when $T_{\text {prod }}$ reaches whatever limit is set by system application requirements. For example, during the first half of the first production period, $T_{\text {prod }}$ drops less than 20 percent of $\left(T_{\text {in }}-T_{0}\right)$; for a $T_{\text {in }}$ of $120^{\circ} \mathrm{C}$ and a $T_{0}$ of $20^{\circ} \mathrm{C}, T_{\text {prod }}$ would be a few degrees above $100^{\circ} \mathrm{C}\left(212^{\circ} \mathrm{F}\right)$.

During successive cycles, $T_{\text {prod }}$ drops more slowly and not as far as during the first cycle of production. This is because the heat left behind keeps the aquifer and confining layers warm, and successive cycles then yield a higher heat recovery fraction (ratio of heat extracted to heat injected). The amount of heat not recovered in a given cycle is proportional to the "loss area" between the Tprod curve for that cycle and the top of the figure - the injection temperature $T_{\text {in }}$.

During the fourth cycle, the rule of thumb deduced is that $T_{\text {prod }}$ drops only about half as rapidly and half as much as during the first 
cycle. For a full nominal production period, the loss would be about 20 to 25 percent of $\left(T_{\text {in }}-T_{0}\right)$; for a half-period, less than 10 percent.

HEAT RECOVERY FRACTION. The production temperature loss is directly related to the heat recovery fraction (heat extracted/heat injected). The useful heat recovery fraction needs to be carefully defined as reference temperatures change, particularly that of the warm well.

As explained earlier in this chapter, the amount of heat injected is determined by the water flow rate and heat capacity, the injection time period, and the $\Delta T$ across the heat exchanger loop connecting the two wells: initially, $T_{\text {in }}{ }^{-T_{w}}$, where $T_{\text {in }}$ is the injection temperature and $T_{W}$ is the warm-well temperature.

Only during the first cycle of injection will $T_{w}$ equal $T_{0}$. During the first cycle, the injected heat (the $44 \mathrm{TJ}$ mentioned in describing LBL's assumptions) is proportional to the entire area of Figure 3-13 and the hot-well heat recovery fraction is proportional to the entire area minus the "loss area" between $T_{\text {prod }}$ and the top of the figure, $T_{\text {in }}$. However, a portion of the heat recovered from the hot well is not delivered to the pipeline system but instead is injected into the warm we11. This portion, as shown in Figure $3-14$, is proportional to the area between $T_{W}$ and $T_{0}$, since $T_{W}$ is the injection temperature for the warm well.

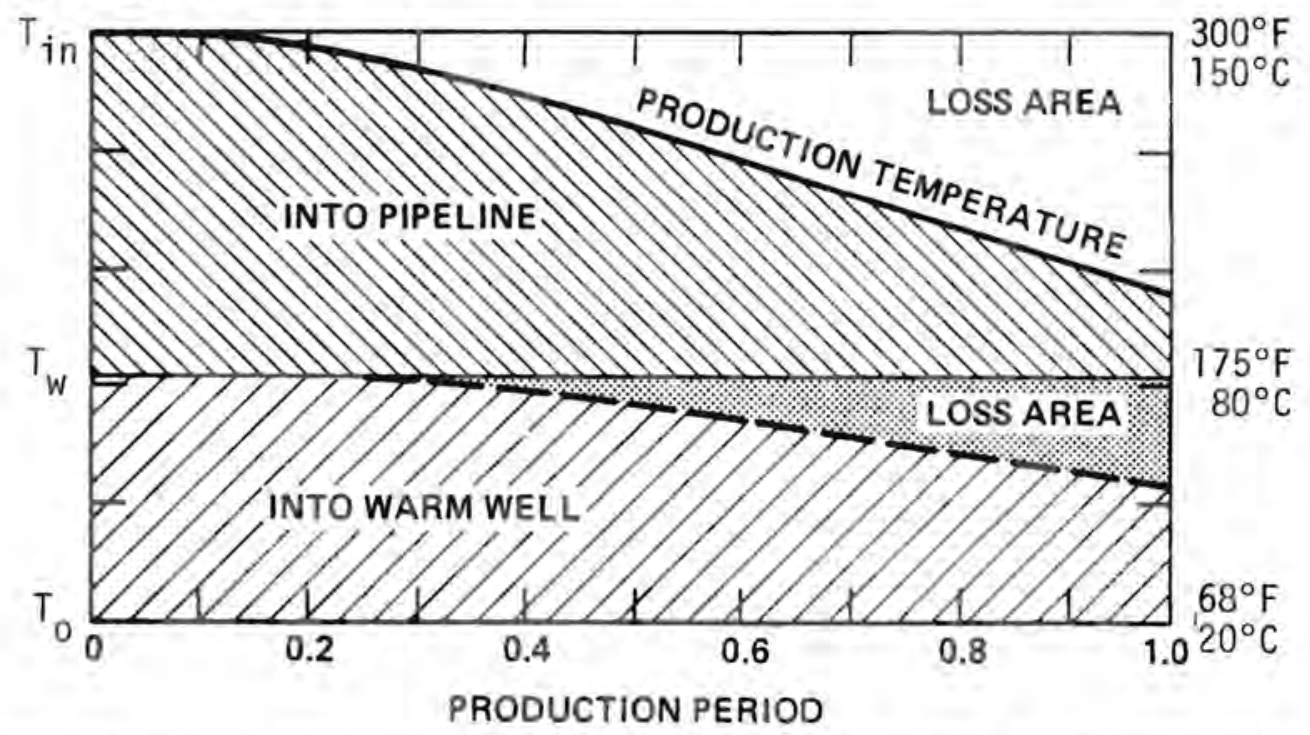

Figure 3-14, Heat transferred into pipeline and into warm wel1 during first-cycle production period. 
Using as an example the temperatures shown on the righthand vertical scale of Figure $3-14$, and assuming $15^{\circ} \mathrm{F}\left(8^{\circ} \mathrm{C}\right)$ drop across the heat exchanger, $\mathrm{T}_{W}$ will be $80^{\circ} \mathrm{C}\left(175^{\circ} \mathrm{F}\right)$ during withdrawal of stored hot water. The heat not delivered to the pipeline but instead transferred to the warm well is about 40 percent of total heat produced from the hot well. The usefuz recovery fraction during the first period of production is then less than 50 percent instead of the heat recovery of about 80 percent found from the ratio of total heat extracted to heat injected.

During the second period of injection, water from the warm well will at first be supplied at a $T_{w}$ temperature of $80^{\circ} \mathrm{C}$, dropping by the end of the injection period to about $55^{\circ} \mathrm{C}$ as shown by the dashed line in Figure 3-14. The amount of heat required to bring the hot well to "fully charged" is proportional to the area between the dashed line and the top of the figure, $T_{i r}$. This amount of heat is substantially less than was required to fully charge the hot well during the first cycle with water heated from $T_{0}\left(20^{\circ} \mathrm{C}\right)$, and continues to decrease with successive cycles as the "loss area" for the warm well shrinks. Consequently, the net heat recovery fraction increases with successive cycles because both the hot-well and the warm-well loss areas shrink.

CAVEAT. The foregoing is intended only to provide a basic understanding of temperature drop during production and how it is related to heat recovery. Aquifer conditions and schedules of injection-storage-production-rest will almost certainly be different in practice from those assumed for Figure 3-13, giving results which may be much less favorable with regard to viability of a potential application of ATES. For example, in aquifers with relatively high permeability, buoyancy can cause a large vertical movement of the injected water and lead to a substantially smaller heat recovery fraction. Buoyant movement of injected water will increase as the temperature difference $\left(T_{\text {in }}-T_{0}\right)$ and the length of the cycle increase. Factors which influence heat recovery fraction and their effects are reviewed in Appendix $A$. 
Stored Cold Water:

Temperature Rise and Chill Recovery Fraction

Analogous to the foregoing discussion of temperature drop and heat-recovery fraction of stored hot water as it is recovered from storage is the temperature rise and recovery fraction of chilled water as it is recovered.

There are three major dissimilarities between storing heat and chill. The first is that buoyancy forces are smaller and tend to cause chilled water to sink rather than to rise (making use of unconfined aquifers more likely to be feasible for storing chilled water than for storing heated water).

The second dissimilarity is the smaller difference attainable between the injection temperature and the aquifer ambient temperature. The normal temperature of shallow groundwater corresponds to the mean annual air temperature, ranging in the United States from about $2.8^{\circ} \mathrm{C}\left(37^{\circ} \mathrm{F}\right)$ in northern Minnesota to $25^{\circ} \mathrm{C}\left(77^{\circ} \mathrm{F}\right)$ at the southern tip of Florida. (Geraghty, et al, 1973.) Geothermal heat adds roughly $1{ }^{\circ} \mathrm{C}$ per 30 meters of depth below land surface. The lowest possible injection temperature being limited by the freezing point of water, the maximum difference between injection and ambient temperatures can seldom be as much as $20^{\circ} \mathrm{C}\left(36^{\circ} \mathrm{F}\right)$. This is an important limitation on the density of chill storage and its economic attractiveness.

The third dissimilarity to be noted is that there is never the need to contain the vapor pressure of chilled water which occurs with water injected at temperatures above the boiling point; this basis for selecting confined aquifers for ATES does not apply for storing chill. However, problems of infiltration of surface water and high regional flow rates in shallow aquifers probably will make confined aquifers more suitable.

ESTIMATING TEMPERATURE RISE VERSUS TIME. Figure 3-15, also from LBL computer simulation vork (Tsang, 1978), is based on aquifer characteristics and operating schedules similar to those assumed for 


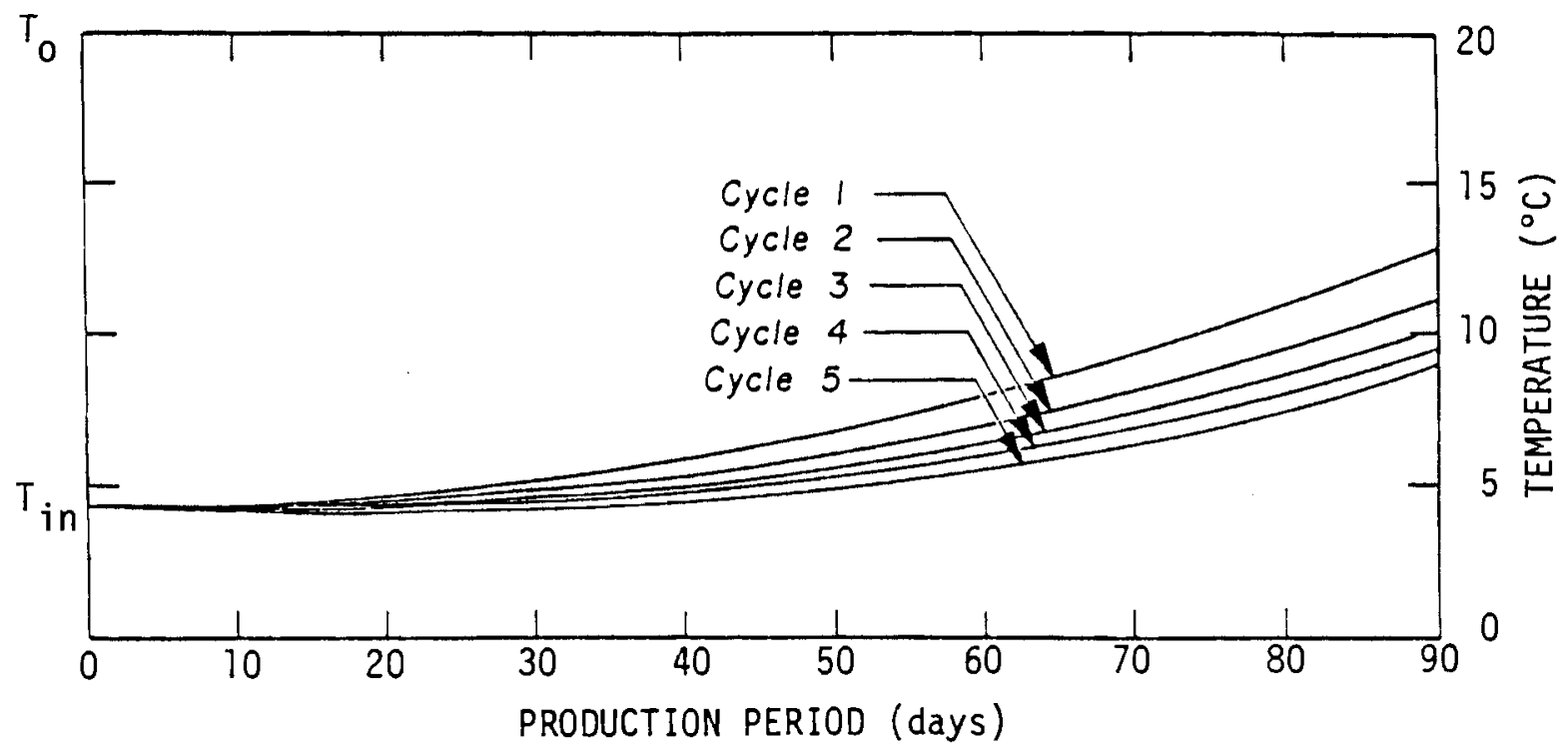

Figure 3-15. Production temperature of chilled water as it is recovered from aquifer storage. (Source: Tsang, 1978)

Figure 3-13. A similar caveat applies to using the results for estimating temperature rise, in other aquifers for other applications: the aquifers must be comparable and the injection-storage-productionrest schedule must be similar.

In Figure 3-15 the vertical scale is not normalized but instead shows the specific temperatures used for the simulation ( $T_{\text {in }}=4^{\circ} \mathrm{C}$, $T_{0}=20^{\circ} \mathrm{C}$ ), because of the small degree of flexibility available in choosing $T_{i n}$. The abscissa scale is the production period simulated. It may be adjusted for other cycle lengths under the same requirements for equal periods that were explained for Figure 3-13, for hot water.

The same water flow rate, $10^{6}$ kilograms per day (180 gpm), was used by LBL in simulations of storing heat and of storing chill. Because the $\Delta T$ between injection and ambient temperatures was so much less for chill than for heat storage, the rate of chill injection simulated was about one-sixth the rate of heat injection: $\sim 1 \mathrm{MW}$ vs. $5.7 \mathrm{MW}$. The total chill stored in 90 days would be about 7 TJ (7 GBtu, 2 GWH). 
CONCLUSIONS REGARDING CHILL RECOVERY FRACTION AND TEMPERATURE RISE. Based on the results of a field experiment in Texas (Reddell, Davison, and Harris, 1980; Minor, 1980), it appears that winterchilling of water in spray ponds and injecting it into high-permeability aquifers is feasible and inexpensive. It also appears that a confined aquifer with low or neutralized regional flow would be a better choice for the next stage of experimentation and demonstration, to avoid the severe effects of high rates of rainfall infiltration and regional flow experienced in Texas.

In the absence of hard data, the LBL simulation of temperature rise portrayed in Figure 3-15 is the best estimate of what may be expected in a confined Zow-permeability aquifer. The effects of higher permeabilities should not be as significant as with hot water, because the buoyancy forces and effects are smaller and viscosity differences are negligible for the temperature ranges involved.

The chill recovery fraction, for the reasons just stated, should be at least as good for storing cold water as for storing hot water. LBL simulations of storage in a confined aquifer suggest recovery of 75 to 80 percent or more after a few cycles. (Tsang, 1978, and recent personal communication with Dr. Tsang.)

Number of Wells Required

The number of wells required at each ATES location will be determined by:

- Water flow rate and storage capacity achievable in the aquifer,

- Total power-related ATES capacity required (maximum charge or discharge rate, whichever is higher),

- Minimum temperature difference across the transmission loop or between hot and warm or cold and cool wells, during charge or during discharge (whichever governs), and

- Operating temperatures of hot and warm wells. 
Finding the ATES capacity required will be discussed in Chapter 4 , together with selection of system operating temperatures. The charge or discharge rate in MW of a given well or array of wells is, of course, simply the product of mass flow rate of water times the useful temperature change, with appropriate conversion to state the result in MW. (Figure 3-9.) of interest here is effect on flow rate of the operating temperature of the wells.

The flow of groundwater through an aquifer, for a given head gradient, is shown by Darcy's Law to be proportional to density and inversely proportional to viscosity (Todd, 1959, p 51). Over the temperature range from $20^{\circ} \mathrm{C}\left(68^{\circ} \mathrm{F}\right)$ to $150^{\circ} \mathrm{C}\left(300^{\circ} \mathrm{F}\right)$, density of water decreases by 8.7 percent and viscosity decreases by a factor of 5.4. In terms of well capacity, density and viscosity changes indicate that a well yielding $1900 \mathrm{~m}^{3}$ (500,000 gallons) of water per day from a aquifer whose native temperature is $20^{\circ} \mathrm{C}$ may be capable of yielding about $3800 \mathrm{~m}^{3}$ (one million gallons) per day at $60^{\circ} \mathrm{C}$ $\left(140^{\circ} \mathrm{F}\right)$ - the approximate temperature of the warm well - and over $7600 \mathrm{~m}^{3}$ (two million gallons) per day at $150^{\circ} \mathrm{C}\left(300^{\circ} \mathrm{F}\right)$ - the approximate temperature of the hot well. Barring serious geochemical problems, ${ }^{*}$ and if pumps, pipes, heat exchangers, and control valves are sized accordingly, it becomes possible to use one hot well per pair of warm wells when more than one doublet is required. For example, one warm well might be required per $12 \mathrm{MW}$ thermal capacity of ATES, one hot well per $24 \mathrm{MW}$. With the wells arranged in circular or linear arrays to establish proper flow conditions, the required

\footnotetext{
* Field experience and laboratory analysis have shown a degradation of 50 to 100 percent in permeability to liquid water of silica sand and sandstone when the temperature is increased from $20^{\circ} \mathrm{C}$ to less than $200^{\circ} \mathrm{C}$. Potential causes for the permeability changes are being investigated. (Stottlemyre and Cooley, 1980.) Other geochemical effects which reduce injectivity of wells have been experienced and identified as due to clay swelling and dispersion, outgassing, suspended solids, hydrothermal reactions, oxidation reactions, fluidfluid incompatibility, and fluid-rock incompatibility. (Stottlemyre, Smith, and Erikson, 1979; Warner and Lehr, 1977.)
} 
number of wells would be 25 percent fewer than if doublets were employed.

\section{Land Area Required}

The actual land area required by a wel1, even with a heat exchanger and associated controls and shelter, is quite small - perhaps $1000 \mathrm{~m}^{2}$. Urban water supply wells often are located in parking lots or narrow rights of way. Whether such small plots of land for each well are adequate for roads, parking, and other civil works is not within the scope of this volume. Similarly, the question will not be addressed here of whether ownership of the land overlying the body of injected hot water, and a buffer zone as well, is necessary in order to protect the stored commodity against taking by others. Related considerations may include possibility of migration of hot water to nearby water wells and whether this could constitute a nuisance or trespass. (Reilly, 1980.)

\section{Cost of Wells and Pumping}

The cost of wells, completed and equipped, is determined by local geology, depth, flow rate and special features required, and prevailing labor and material costs. It therefore is site- and applicationspecific. For a rough estimate of the cost of a doublet, the following rules of thumb may be used for conventional water wells (USDOE, March 1979, Vol. II, p 63):*

Doublet cost, $\$ / \mathrm{kW}$

$$
\begin{aligned}
& =\frac{(0.2 \pm 20 \%) \times \text { well depth }(\mathrm{m})}{\text { Water } \Delta T\left({ }^{\circ} \mathrm{C}\right) \times \text { flow rate }\left(\mathrm{m}^{3} / \mathrm{sec}\right) \times \text { storage efficiency }} \\
& =\frac{(1700 \pm 20 \%) \times \text { well depth }(\mathrm{ft})}{\text { Water } \Delta T\left({ }^{\circ} \mathrm{F}\right) \times \text { flow rate }(\mathrm{gal} / \mathrm{min}) \times \text { storage efficiency }}
\end{aligned}
$$

\footnotetext{
* The National Water Well Association, 500 West Wilson Bridge Road, Worthington, Ohio 43805, has recently conducted a national survey of well costs. NWWA can provide estimates of regional well costs and supply names of well-drilling firms, geologists, and hydrologists in a given locale as possible sources of site-specific information.
} 


$$
\begin{aligned}
& \text { Pumping cost, } \$ / 10^{6} \text { Btu } \\
& \cong \frac{0.22 \times \$ / k \text { Whe } \times \text { pumping head }(\mathrm{m})}{\text { Water } \Delta T\left({ }^{\circ} \mathrm{C}\right) \times \text { storage efficiency }} \\
& \cong \frac{0.12 \times \$ / k \text { Whe } \times \text { pumping head }(\mathrm{ft})}{\text { Water } \Delta \mathrm{T}\left({ }^{\circ} \mathrm{F}\right) \times \text { storage efficiency }}
\end{aligned}
$$

Equation 3-3 gives the cost of the two wells required for a doublet. The cost of a conventional water well is assumed to be $\$ 100$ to $\$ 150$ per foot ( $\$ 30$ to $\$ 45$ per meter) of depth, in mid-1980 dollars. Storage efficiency is the heat or chill recovery fraction.

The variation of \pm 20 percent should cover most situations up to about $70^{\circ} \mathrm{C}\left(160^{\circ} \mathrm{F}\right)$ operating temperature. Above $70^{\circ} \mathrm{C}$, for the hot we11, the cost may exceed the high-side estimate because special materials and pumps may be required. Other special design features such as adjustable flow rates, injection tubes, and downhole valves, discussed below, are not included. The cost of special features can only be estimated by completing a preliminary design of the wells and obtaining bids or estimates for construction.

In equation $3-4$, pumping costs, the term $\$ / k W_{e}$ refers to the cost of electricity to operate the pumps; if other prime movers are to be employed, the appropriate cost should be used. Pumping head includes both the distance that water must be lifted and the pressure, in meters or feet of water, to be maintained at the wellhead by the downhole pump.

\section{Special Well Design Features}

During production of hot water, it is very unlikely that the natural artesian pressure of the storage aquifer will be sufficient to produce the desired pressure and flow rate at the well head. As in geothermal systems, downhole pumps will be required, set far enough below the drawdown level to maintain downhole pressure at sufficient NPSH (net positive suction head - absolute pressure at the pump inlet in feet of liquid, plus the velocity head, minus the 
vapor pressure of the fluid at the pumping temperature) and discharging so that appropriate well-head pressure will be maintained at the desired flow rate. Both submersible and line-shaft pumps are available which will operate at temperatures up to at least $150^{\circ} \mathrm{C}\left(300^{\circ} \mathrm{F}\right)$, albeit at higher cost than standard water-well pumps. They are used, for example, to produce flow rates of 50 liters per second (800 gpm) from hydrothermal reservoirs in Idaho.

Few water wells are designed for variable flow rates. Usually, the pump operates at its best efficiency point until a tank or reservoir is filled, then is shut off. For ATES purposes, both the injection and production rates of wells will need to vary. If a number of doublets or an array of wells are used, the necessary flow and injection rates may be approximated, in steps, by operating wells at reasonably close to rated flow or turning them off. When only one doublet is to be used for ATES, pump manufacturers should be contacted for assistance in specifying a pump or set of pumps capable of operating over as wide a flow range as possible at acceptable efficiency and cost.

Particularly if ATES is used for smoothing daily fluctuations, a given well may be cycled from injection to production mode daily. Experience with supply wells and with injection wells is extensive, but designing a well to switch quickly from one mode to the other is a new requirement. A conventional injection well may be periodically pumped, for redevelopment, but a temporary pump is lowered when needed. Production wells often are converted to injection wells by removing the pump.

Injecting and producing cold water presumably will be much simpler than for hot water. Thermal stresses in well and pump are inherently much lower because of the limited difference between aquifer ambient and injection temperatures. There are no requirements for maintaining a minimum pressure. Geochemical problems should be fewer. Only biological fouling would appear to be potentially a more severe problem with cold than with hot water. 
For injection, it appears unlikely that either hot or cold water can be injected as backflow through a downhole pump. Whether the desired flow rate can be attained is one question. Of more importance is that pump manufacturers indicate the pump would be damaged by backflow because of lack of bearing lubrication and other problems (e.g., clearances); backflow preventers often are installed to protect pumps.

An alternative path for injection is through the annulus between the well casing and the production string. This approach, unless surface-actuated downhole packers with valves, or other equipment not now available is developed to restrict flow, would result in entrainment of air by the cascading water and possible plugging of the aquifer. Hot water would flash to steam if near or above the boiling point, and would impose thermal stresses in the casing which could cause buckling, joint failure, or rupture of the external cement sealing the casing.

The most promising approach appears to be use of an injection tube in the well, extending to below the pump setting. The casing size would have to be larger than usual, to accommodate both the production and the injection strings. Injection tubes can be designed to provide flow conditions that prevent cascading and flashing. At zero or reduced flow rates, a surface-actuated downhole valve would be desirable to prevent flashing of hot water in the tube and we11, and to prevent entrance of air and subsequent cascading of either hot or cold water. The injection string should be designed and installed to accommodate thermal stresses while protecting the casing and its cement against unacceptable changes in temperature. Maintaining a constant circulation of hot water by operating the downhole pump even when the well is shut in has been suggested, to avoid temperature cycling, but the electricity consumed could be an appreciable expense even at low pumping rates, in view of the inefficiency of pumps when operated at off-design pumping rates. 
A fallback position in lieu of designing a combined productioninjection well is to drill two wells spaced as closely as practicable, using one for injection and the other for withdrawal. It would then take two pairs of wells to comprise a doublet.

Plugging is always a potential problem with injection wells. Carefully engineered gravel pack, screens, and possibly downhole reaming to enlarge the effective well radius should be the practice.

\section{THERMAL TRANSPORT SUBSYSTEM}

If the sources, the end uses, and the ATES facilities are in widely separated locations, transport of the thermal energy (heat or chill) is necessary. In some applications the subsystems are essentially in the same building and all pipes for transport may be above ground, attached to walls or ceilings. In other cases they are in buildings of the same complex - an industrial plant, a residential/ commercial complex under one ownership, a university, or a military base. Utilities for such applications are often in a common tunnel between buildings. In other cases, as in urban district heating applications, the sources may be separated by many kilometers from load centers. Here large scale transmission is needed followed by a smaller scale distribution system fanning out to individual customers.

The conceptual design aspects of large scale transport can be described with examples from a recent study on thermal energy storage and transport (Hausz, 1979a, 1979b). The design of a thermal transport system many kilometers long requires an optimization on the one hand of pipe size used versus pumping power required, and on the other an optimization of the thickness of the insulation used versus the thermal energy lost through the insulation. All of these are related to each other and to the scale of thermal power being transported and the properties of the transport medium. An iterative optimization is required; Hausz (1979a) describes a computer program devised for this purpose.

Various media of transport were compared. Figure 3-16 shows the reported results for high temperature water (HTW), steam, an oil or 


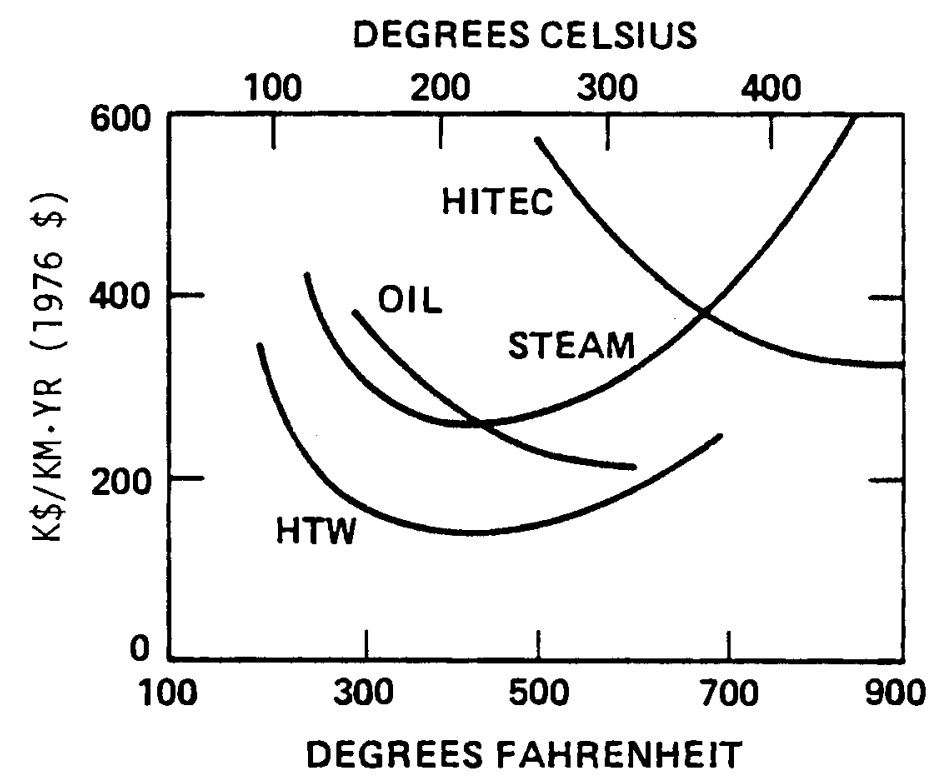

Figure 3-16. Annual costs of $300 \mathrm{MW}$ thermal energy transport dual pipeline.

organic medium called Caloria, and a molten salt called HITEC (mixed sodium and potassium nitrates and nitrites). Over a wide range of temperature, HTW was superior to all the other media in annual costs per kilometer $(\mathrm{k} \$ / \mathrm{km} \cdot \mathrm{yr})$. In all cases a closed loop transport system was used, with the sendout temperature as indicated and the return temperature in every case $80^{\circ} \mathrm{C}\left(175^{\circ} \mathrm{F}\right)$. The power transport rate was $300 \mathrm{MW}$ thermal.

The shape of the curves, particularly that for HTW, serves to illustrate some of the design considerations. For HTW and steam, the sendout pipe must stand rapidly increasing pressures as the temperature increases. The pipe wall must be thicker to withstand the pressure; high temperature also reduces the rated yield strength of pipe, further increasing required wall thickness. Balancing this in part, as the $\Delta T$ between sendout and return temperature increases the HTW flow decreases for the same power, $300 \mathrm{MW}$; smaller diameter pipe can be used on both sendout and return pipes.

As the sendout temperature is lowered, approaching the return temperature, the required flow rate for a given power level rises 
rapidly. The pipe size required increases, causing the increase shown in costs at low temperatures.

The minimum cost for transmission is at about $200^{\circ} \mathrm{C}\left(400^{\circ} \mathrm{F}\right)$. It is a broad minimum representing the interplay of the cost elements. Near the minimum the sendout pipe represents 65 percent of the cost and the return pipe 35 percent. The investment cost items - pipes, pumps, and insulation - represent respectively 45, 6, and 23 percent; the operating costs - pumping power and heat loss - represent 8 and 18 percent. In this example $610 \mathrm{~mm}$ (24-inch) 0.D. pipe with $6.4 \mathrm{~mm}$ (0.25-inch) wall was used for both pipes, with $100 \mathrm{~mm}$ (4 inches) of insulation on the sendout and $25 \mathrm{~mm}$ ( 1 inch) on the return pipe.

As an illustration of the cost sensitivity to design parameters, as shown in Figure $3-17$, use of $510 \mathrm{~mm}$ (20-inch) sendout pipe instead of $610 \mathrm{~mm}$ (24-inch) pipe will double the pump and power cost while reducing the pipe cost and the insulation and heat loss costs each about 17 percent. Going to a $760 \mathrm{~mm}$ (30-inch) sendout pipe increases pipe cost 38 percent and insulation and loss costs by 24 percent while reducing pump and power costs by 62 percent.

In the source reports (Hausz, 1979a, 1979b) economic analys is was reported in mid-1976 dollars. For mid-1980 dollars a multiplier of 1.4 is appropriate. Over a reasonable range of power-transmission capacity, 100 to $1000 \mathrm{MW}$, the annual cost per $\mathrm{km}$ varies as the square root of power capacity. More precisely, a match of the computed pipeline costs versus power at one temperature has a constant term, a square root term, and a linear term. At lower power levels the constant term begins to dominate. A suggested match for estimates down to $50 \mathrm{MW}$ is $(10.1 \sqrt{\mathrm{P}}+22) \mathrm{k} \$ / \mathrm{km} \cdot \mathrm{yr}$ in 1980 dollars. For other temperatures, at $300 \mathrm{MW}$, use Figure 3-16 for scaling.

This analysis was based on the assumption of buried, protected pipes in a common trench, in rural areas where breaking and replacing paving is a minimum and where pipe code standards permit design to a higher fraction of yield strength than in heavily populated areas. 


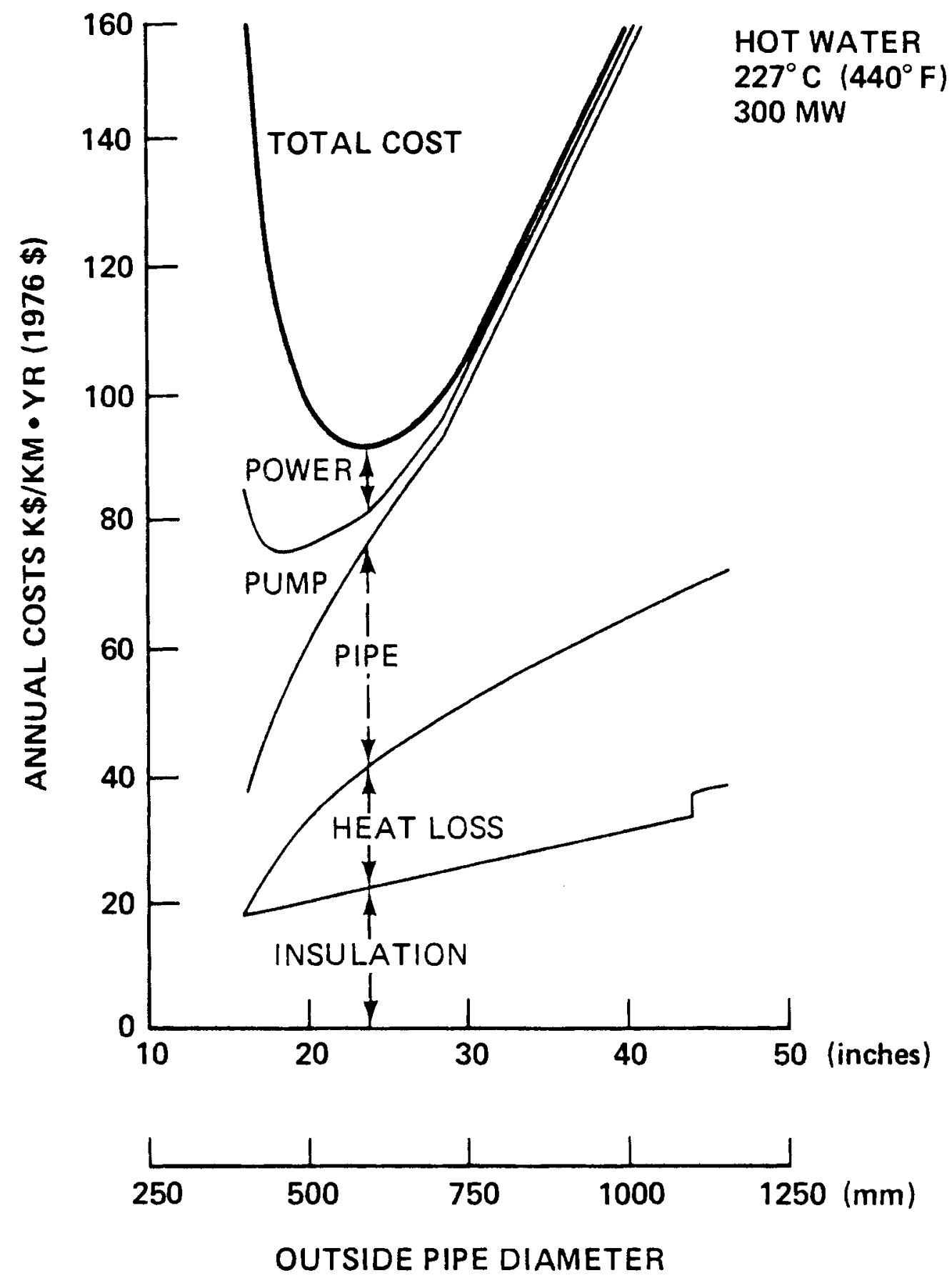

Figure 3-17. Optimization of pipe diameter for thermal energy sendout pipe at $300 \mathrm{MW}, 227^{\circ} \mathrm{C}\left(440^{\circ} \mathrm{F}\right)$.

(Source: Hausz, 1979a, p 4-16) 
For smaller pipe sizes and for urban pipe installations another recent reference gives rules-of-thumb (01iker, 1979). Considering distribution subsystems of large and medium diameter piping, and small diameter interconnection service to valves inside the end user's property, much useful information is given in this reference.

Figure 3-18 summarizes installed costs per foot (in 1979 dollars) for pipe sizes of $25 \mathrm{~mm}$ (10-inch) to $610 \mathrm{~mm}$ (24-inch) diameter in a concrete culvert configuration. * The average for five urban areas is given, for both installation under the street and installation under sidewalks. Installation under the sidewalk is generally about 40 to $60 \$ / \mathrm{ft}$ less since the installation can be shallower because there is less loading than in the street, and also there are fewer interferences to be avoided. ${ }^{+}$A range bar is shown at $500 \mathrm{~mm}$ (20inch) pipe with street installation and a $300 \mathrm{~mm}$ (12-inch) pipe with sidewalk installation, to show the range of the five cities compared. In both cases the tops of the range bar represent Boston; the bottoms, Baltimore.

One cannot compare directly the previously cited annual costs per $\mathrm{km}$ for rural transmission of HTW and the urban transport in installed cost per foot. The former includes the operating costs of pumping power and heat loss, is in 1976 dollars, and annualizes the investment costs. The latter includes only initial installed and overhead costs, and is in 1979 dollars. Converting both to mid-1980 dollars and putting rural transmission cost on the same basis as 0liker's capital cost gives, for a $610 \mathrm{~mm}$ (24-inch) pipe subsystem, $\$ 810$ per

\footnotetext{
* Both sendout and return pipes are insulated, covered with a waterproof layer, and suspended in a concrete trough with removable concrete cover. Sandfill above, below, and on the sides aids drainage, to prevent water entry into the culvert. A drain pipe below the culvert may be used in difficult areas to dispose of seasonal groundwater.

†nterferences include other utilities using the space under streets and sidewalks including electric, telephone, gas, water, sewer, etc.
} 


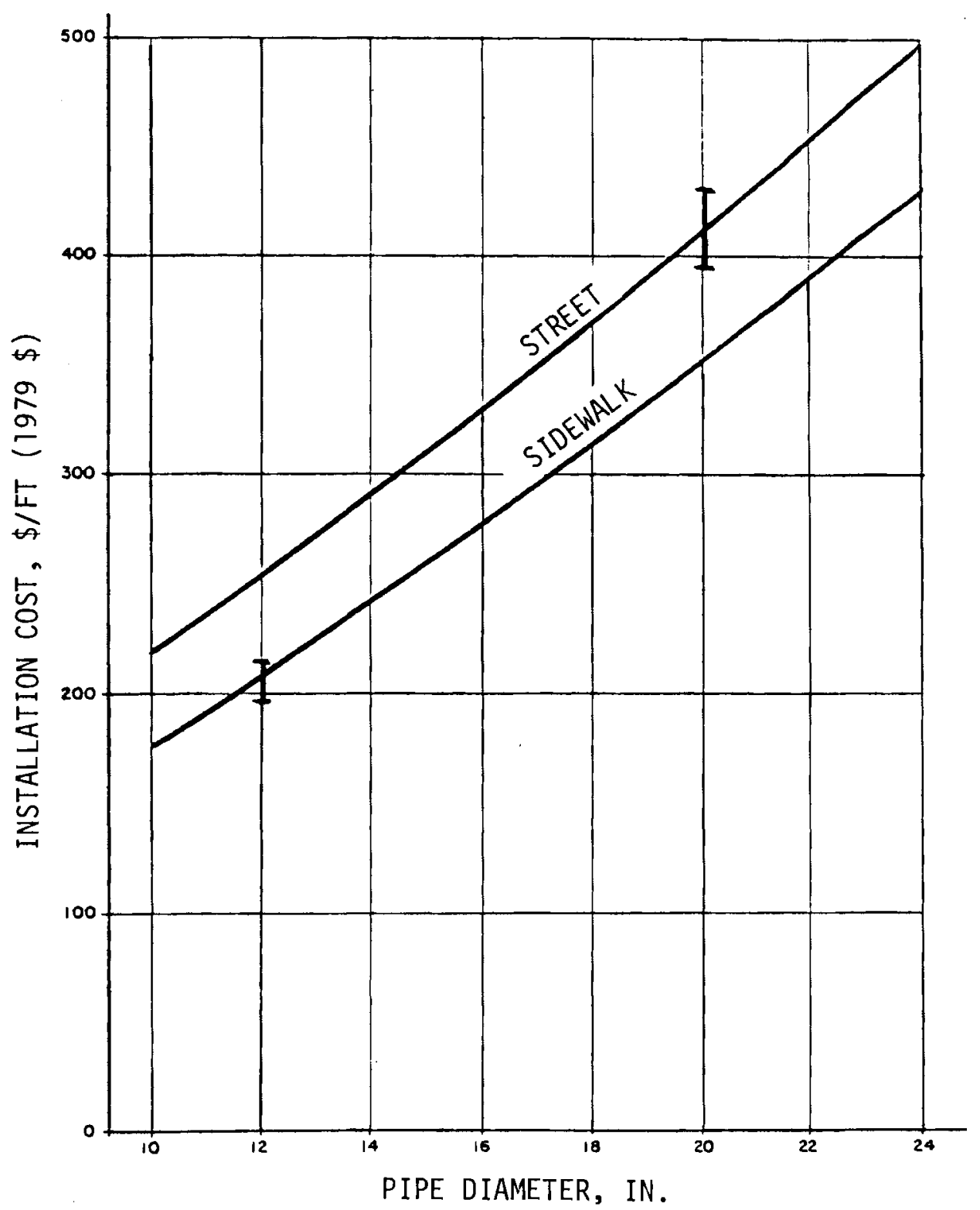

Figure 3-18. Average piping installation cost for five U.S. cities, concrete culvert design. (Source: 01iker, 1979) 
meter $(\$ 250 / \mathrm{ft})$ for transmission and $\$ 1800$ per meter $(\$ 560 / \mathrm{ft})$ for the average urban street installation, or 2.2 times as much.

01 iker indicates the cost components in his estimated cost - 37 percent for pipes and fittings, 8 percent for insulation, and 6.4 percent for valves and expansion joints, with a total for the mechanical work of 62 percent. The civil work of pavement breaking and excavation, 7 percent, formwork and concrete, 16 percent, and backfill and replacement, 5 percent, total 38 percent, including overhead. The pipe and insulation costs should be similar in rural and urban applications except for stronger pipe for a higher safety factor; valves, expansion joints, and manholes are much less frequent per kilometer in the rural case. The requirements for pavement breaking and repavement, and the slow pace, including hand excavation where there are interferences, makes the urban case more expensive. 01 iker notes that the costs per foot are much greater at intersections than for the city blocks $-1300 \$ / \mathrm{m}(400 \$ / \mathrm{ft})$ for the blocks and $4900 \$ / \mathrm{m}(1500 \$ / \mathrm{ft})$ for the 14 percent of the length in the intersections. 

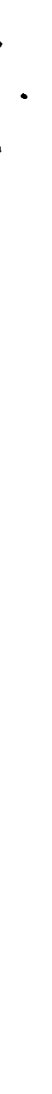


\section{CHAPTER 4}

METHODOLOGY FOR CONCEPTUAL DESIGN OF AN ATES SYSTEM

Broadly, the objective in conceptual design of an ATES system is to postulate and evaluate the use of ATES in correcting a seasonal mismatch between thermal energy demand and supply, in order to reduce cost, to conserve energy, to permit substitution of available fuels for scarce or unreliable sources, or a combination of these. This implies that a reference demand-supply system exists or is being planned. This is assumed to be the case.

The step by step methodology suggested in this chapter also assumes that the ATES system design objective - management's reason for considering ATES - has been defined, albeit in broad-brush fashion, in order to screen the prospective application of ATES as suggested in Chapter 2. No explicit suggestions are made for the review and revision of the design objective that may become desirable as the potential benefits of an ATES system are recognized during the conceptual design process.

That a conceptual design is to be developed, not a final nor even a preliminary design, should be kept clearly in mind. The methodological steps given here would be much the same for later design stages: even in the conceptual stage a reasonably complete understanding of the system elements and costs involved should be developed, to avoid later, unpleasant surprises. But the level of detail and degree of accuracy implied here is only that needed for conceptual design purposes.

SUMMARY OF STEPS IN A CONCEPTUAL DESIGN

A summary of steps will be given first, followed by a discussion of each step. 
Whether the first step is to consider the energy source or the load is immaterial to the methodology. Descriptions of each must be developed and brought together to find ATES and related requirements and develop an operating strategy. Arbitrarily, describing the load is shown as the first step.

1. Describe expected thermal energy load as a function of time.

2. Describe prospective energy source as a function of time.

3. Compare source and load:

a. Quantify mismatch as a function of time.

b. Select supply and storage temperatures.

c. Estimate ATES capacity needed.

d. Estimate ATES location and transport capacity needed.

4. Estimate losses in ATES and transport. Add these to the thermal load to find the annual total energy demand, production required, and maximum hourly peak. Adjust estimates of ATES and transport capacity needed.

5. Develop operating schedules for production, transport, ATES charge, and ATES discharge, to supply the demand.

a. Evaluate effect of temperature drop across ATES heat exchangers.

b. Evaluate effect of temperature loss as stored water is wi thdrawn.

c. Plan for mitigation of temperature losses as appropriate (blending, add trim heat, increase supply temperature during storage).

d. Iterate earlier steps to incorporate mitigation.

6. Evaluate the potential benefits of ATES: Assume ATES at zero cost. Subtract the other costs and the fuel consumption of the system using ATES from those of the reference system without ATES. The difference is the breakeven cost and the fuel savings of ATES. If the difference is negative, ATES is not beneficial for the proposed application.

7. Repeat above procedure to develop alternative conceptual ATES system designs covering variations of interest in energy sources, uses, and ATES employment. 
8. Make rough estimate of the expected cost of ATES facilities and their operation.

9. If the prospective benefits found in step 6 are

a. Substantially less than the expected cost of ATES facilities (including exploratory drilling and aquifer testing, if needed): Defer or abandon investigation.

b. Substantially greater than the expected cost of ATES facilities: Proceed with exploratory drilling and aquifer testing if needed, or utilize existing information if available, to ascertain hydrogeological and geochemical parameters of candidate aquifers. Prepare preliminary design of ATES facilities to develop budgetary estimate of performance and cost.

c. Roughly equal to the expected cost of ATES facilities: Evaluate secondary benefits (environmental, reliability, fuel substitution) and disbenefits (regulatory problems, risk that no suitable aquifer will be available). Decide whether secondary benefits outweigh disbenefits sufficiently to justify proceeding as in step 9 (b).

10. If step $9(\mathrm{~b})$ is performed, use the improved performance and cost data to repeat steps 4 through 9 .

It will be noted from the above summary and the discussion which follows that estimating the cost of ATES facilities and their operation is deferred until it has been established (steps 1 through 7) that ATES has potential benefits in terms of cost and fuel consumption. This sequence is suggested so that relatively well-known system design procedures and components can be dealt with before undertaking the more speculative steps of preliminary ATES facility design and predictions of cost and performance. If seasonal storage is not sufficiently promising, time and expense will be saved. 
DESCRIBING THE LOAD AND THE THERMAL ENERGY SOURCE

Chapter 3 covers the required descriptions of expected end use and sources of thermal energy.

COMPARING SOURCE AND LOAD

Step 3 in the conceptual design methodology is to compare source and load in order to quantify mismatch, select supply and storage temperatures, and estimate ATES and transport capacity needed.

Quantify Mismatch vs. Time

ANNUAL. Total annual mismatch will have been given some thought during the early screening procedure of Chapter 2. It is obvious, but important, that an ATES facility cannot generate energy. The ATES facility in an ATES system stores energy and returns part of it to smooth fluctuations in supply and demand. The energy source or sources in an ATES system must supply the end-use energy load plus all system losses including those in the ATES facility.

If the prospective energy source or sources for which descriptions have been developed cannot dependably produce an output which exceeds the expected annual load, by whatever amount is needed to supply system losses (to be found later), either the load must be reduced or the source augmented. Conversely, if more energy can be dependably produced than the load and system losses require, additional load may be sought (e.g., thermal energy may be offered for sale), or the source capacity may be reduced, or advantage may be taken of the flexibility afforded by reserve capacity.

MONTHLY. For each monthly time period, the load requirements and the energy production capability on both a power and energy basis should be tabulated and compared. Either the load or the supply may be the independent variable: a given load is to be supplied by an alternative source (cogeneration), or a new source of energy is to be developed (waste incineration) and loads are sought for it. To avoid undue complexity in explanation, it will be assumed in most of what follows that the load is known or postulated as the inde- 
pendent variable, and the energy supply and ATES are to be fitted to the load. The reverse case can be analyzed with much the same procedure.

The over- or under-supply of thermal energy and power (GJ and MW) for each month are found from the above comparison, giving an initial quantification of mismatch. The energy to be stored in or withdrawn from ATES month-by-month is the principal output of this comparison at this point.

Worst-case analysis - highest load, lowest production - will eventually be required in many instances. Average or nominal conditions are more appropriate assumptions until the entire design procedure has been completed at least once, to establish a reasonable probability of technical and economic feasibility.

PEAK. The power capacity required to meet load peaks is a key factor in determining how much ATES and transport capacity will be needed. By definition of seasonal mismatch, the energy source will not be able to supply the peak power demand.

The peak hourly load is given by annual or monthly load duration curves. The difference between peak load and energy production capacity available at the hours of peak load is found from the more detailed information on the load and source as a function of time, called for in Chapter 3.

In contrast to electrical supply systems which can fail to meet peak demand for only fractions of a second without causing severe problems, failure of a hot water supply system to meet maximum demand for space or tap water heating for an hour is not considered a problem. Buildings and hot water tanks have adequate thermal inertia. (Certain process heat or chill loads may require a supply with more stiffness.)

The heat source may have inherent peaks in output which require quantification because they will require storage capacity. Examples are solar collectors, and backpressure steam turbines which cogener- 
ate heat as electricity is generated to meet electrical system demands.

Select Supply and Storage Temperatures

Selection of the supply and the storage temperature is one of the most important aspects of designing an ATES system.

It may appear that the descriptions of the source and the load should fairly well determine supply and storage temperatures. But design of an ATES system is very unlike specifying the steam pressure and temperature to be delivered by a boiler to satisfy a nearby load. A considerably more complex set of constraints and opportunities applies. In particular, the conventional approach to selection of sendout temperature for a district heating system without seasonal storage is very unlikely to be appropriate for a system with seasonal storage.

Considerations in selecting supply and storage temperatures include the following:

a. UPPER TEMPERATURE LIMIT. Hydrogeological considerations suggest that the storage temperature be lower than the local boiling point; but this limitation would negate the use of ATES in many large systems whose sendout temperature is higher than water's boiling point. The economic maximum storage temperature for hot water will probably be about $150^{\circ} \mathrm{C}\left(300^{\circ} \mathrm{F}\right)$. Because of its rapid increase in vapor pressure above this temperature (discussed in Chapter 3 and illustrated in Figure 3-8), water at higher temperatures is likely to have an immediate surface use more beneficial than storage; and containing higher pressures would require such deep, tightly-confined, pressurized aquifers that the cost of wells may be prohibitive. Problems with scaling, corrosion, and well plugging may be expected to become more severe with higher temperatures. Water well pumps are usually not rated for operation at above about $70^{\circ} \mathrm{C}\left(160^{\circ} \mathrm{F}\right)$. Relatively inexpensive geothermal well pumps are believed 
capable of reliable operation at $150^{\circ} \mathrm{C}\left(300^{\circ} \mathrm{F}\right)$, but special, expensive designs probably would be required for much higher temperatures.

b. BENEFITS OF HIGH TEMPERATURES. Basically, energy density is greater and less HTW must be stored, pumped, and transported as temperature increases - more precisely, as temperature difference between sendout and return increases. If higher temperature allows greater temperature loss across heat exchangers to be tolerated, less heat-exchange area is required and cost decreases. High supply temperature during periods of injection of HTW into ATES can make possible the recovery of higher temperature water from storage, mitigating the effect of temperature losses across the heat exchanger and during withdrawal from storage. Well productivity (specific capacity) and injectivity will, in general, increase at higher operating temperatures because the viscosity of water decreases substantially.

c. SECOND-LAW CONSIDERATIONS. For most effective use of fuel energy, the maximum possible amount of work or heat, or both, should be extracted and used. Therefore, the supply temperature should be no higher than required by the load. A good example is cogeneration: Steam should be extracted from the turbine at the lowest possible temperature, so that the maximum amount of shaft work can be developed before the remaining thermal energy in the steam is used for heating purposes. In fact, the extraction should be in two or three stages, to build up from return temperature to sendout temperature in steps. Second-law considerations may justify relatively extensive modifications in the end-use equipment (steam radiators) or in the source equipment (boilers supplying process heat). However, economic considerations cannot be ignored and may often justify second-law inefficiencies - e.g., capturing heat from high-temperature stack gases for lowtemperature space heating is better than discarding it. 
d. CONTRAST WITH CONVENTIONAL DISTRICT HEATING SYSTEM TEMPERA-

TURES. In conventional hot-water district heating systems (found principally in Europe, not in the United States), the amount of heat delivered is adjusted by changing the temperature of the hot water. The flow rate is essentially constant. However, if annual-cycle ATES facilities are incorporated into the system, heat must be stored during off-peak-load periods, and at temperatures comparable to the delivery temperature required when ATES is discharged during subsequent peak-load periods. This implies variable flow at constant year-round temperature. Some loads, such as industrial process heat, absorption-cycle air conditioning, and tap water heating, may be more effectively served by a constanttemperature system. In general, the entire philosophy of district heating system design and operation should be reexamined when ATES is incorporated.

e. RETURN TEMPERATURE. Taking into account only the difficulties associated with high storage temperatures, it is best to choose as low a return temperature as is consistent with load requirements: the supply and storage temperatures can be reduced as the return temperature is reduced. This tandem reduction also has other beneficial effects, such as reducing the loss of electricity production when steam is extracted for heating purposes in cogeneration systems. (See Figure 5-1; also, Orchard and Robinson, 1979; Hausz, 1979a.)

Even though so many tradeoffs are involved in selecting optimum supply and storage temperatures for different applications, the choice is not necessarily difficult. When all the factors involved are identified and weighted, it may be obvious. 


\section{Estimate ATES Capacity Needed}

The power-related TES capacity required is equal to the maximum rate of thermal energy storage or the maximum rate of withdrawal, whichever is larger.

In a system whose design objective is to satisfy a given seasonal load by supplying energy from a relatively uniform year-round source, the peak load will govern. As a first approximation, the ATES capacity needed equals the difference (mismatch) between the peak load and the maximum dependable output of the energy source at the time of peak load. Simply put, the energy source supplies as much as it can, and withdrawal from ATES supplies the rest.

In a system whose design objective is to utilize to maximum advantage a source of waste or renewable energy which may peak sharply at times, to satisfy a relatively uniform heat load, the peak energy output will govern. The ATES capacity needed will be approximately equal to the difference (mismatch) between peak energy output and the thermal load. When energy output exceeds the load, ATES stores the unused output.

Most systems are not as simple as the two examples given. It is only necessary for a first approximation to make as reasonable a guess as possible at whether the charge or discharge rate of ATES will govern, and what that rate will be.

For later, closer approximations the dependable capacity of the energy source needs to be taken into account: the availability of the energy source at the time of peak load. Full rated output from one or several sources cannot safely be assumed, because of the possibility of forced outage. One rule of thumb is to assume that the largest single source will be down for maintenance or repair at the time of peak load. A more conservative rule of thumb used by some electric utilities, with a number of generating stations, is to 
assume both the largest and next largest units are down at the time of maximum demand.

Energy production equipment scheduled for retirement sometimes is retained and kept in readiness for standby or peaking service. ATES may permit such equipment to be retired; conversely, it may be more economical to keep the equipment in service and provide less ATES capacity.

The reliability of supply required by the load will govern the philosophy adopted. Obviously, high reliability can be costly. When design alternatives are being compared, the reliability of each alternative should be essentially the same; or, appropriate allowance for the cost of higher reliability should be made in the comparison.

Estimate ATES Location and Transport Capacity Needed

The transport capacity needed will be determined by peak thermal energy production, peak demand, and location of source, load, and ATES location, as follows:

a. Energy production, load, and ATES collocated within a few hundred meters: Consider pipes, etc. as part of ATES facility; transport need not be treated as a separate subsystem.

b. Energy production at one location, load at another, separated by a kilometer or more. Transport is required, as follows: - If load peaks require smoothing, ATES is located near load. Transport capacity equals maximum production level from energy source. (Transport of peak load is avoided.)

- If production peaks require smoothing and load does not, ATES is located near source. Transport capacity equals maximum demand. (Transport of production peaks is avoided.)

- If both production and load peaks require smoothing, ATES may be located at both source and load. TES and transport capacity must be found by iteration.

c. One or more energy production locations, with load dispersed over a wide area; e.g., the district heating system diagramed in Figure 4-1. 


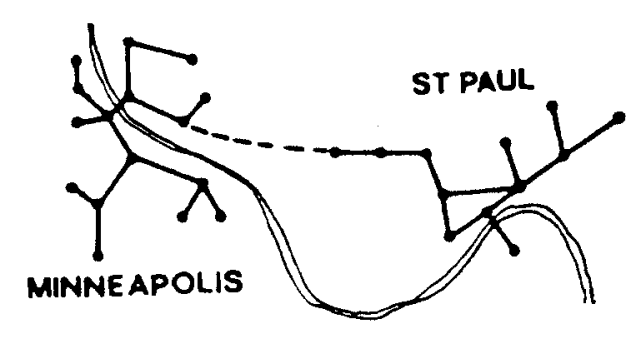

Figure 4-1. Proposed hot water transmission network for Minneapolis-St. Paul district heating system. (Source: Studsvik)

In an urban or other large district heating system, transport includes both transmission and distribution. The distribution pipes connected to individual loads are, of course, sized to carry peak load. As distribution pipelines converge toward transmission-line nodes, indicated by dots in Figure 4-1, they need not be sized to carry the total connected load but only the peak coinciding load. Fully aggregated at the generating stations, the peak coinciding load is approximately 80 percent of the total connected load.

If either peaking boilers or ATES wells are sited at each of the 29 nodes shown in Figure 4-1, the expensive transmission pipelines need be only large enough to transport the maximum thermal output from the generating stations, rather than the peak coinciding load. Depending on the load factor, the maximum output from the generating stations may be less than 60 percent of the peak coinciding load.

\section{ESTIMATE LOSSES IN ATES AND TRANSPORT}

Step 4 in the conceptual design methodology is to estimate losses in ATES and transport; add these to the thermal load to find the annual total energy demand, the production required, and the maximum hourly peak; and adjust estimates of ATES and transport capacity needed. 
Est imate ATES Losses

From the Chapter 3 discussion of the storage subsystem, it is clear that (1) the ATES losses cannot be predicted accurately, and (2) the losses will be highest during the first cycle and decrease significantly thereafter.

In the absence of an indication that difficult problems may be expected because of the characteristics of available aquifers, it is suggested that a nominal loss of 25 percent of heat stored be used. To explore sensitivity to this assumption, losses of 15 and 35 percent may also be carried through the analysis. This was done in a study of the benefits of ATES in a large urban district heating system (Meyer, 1979). For the first pass through the conceptual design methodology, it is suggested that only the nominal loss be used, with sensitivity checking deferred until a reasonable probability of technical and economic feasibility has been established.

That the first-cycle heat recovery efficiency will be lower than subsequent cycles may need to be taken into account in cash flow and payback analyses, as well as in evaluating the amount of heat production required and deciding whether a temporary supplemental source should be considered.

A convenient way to add ATES losses to the load is to increase on a month-by-month basis the amount of energy to be stored in ATES, as found in the tabulation prepared in Step 3 . If the heat recovery fraction is 0.75 , the amount stored should be divided by 0.75 . The amount that needs to be withdrawn from storage, month-by-month, wi11 not be affected; the total energy stored for the year times the heat recovery efficiency will equal the energy withdrawn. (See Table 6-3 for an example of this procedure.)

\section{Estimate Transport Losses}

The equation for thermal energy flow rate through cylindrical insulation surrounding a cylindrical pipeline is:

$$
H_{0}=\frac{\pi 0_{3} \cdot\left(T_{P}-T_{0}\right)}{\frac{0_{3} \cdot \ln \left(0_{3} / 0_{2}\right)}{2 \cdot K_{1}}+S_{1}} \mathrm{~kW} / \mathrm{m} \text { or Btu/hr. ft }
$$


where

$0_{3}=$ insulation outer diameter

$0_{2}=$ insulation inner diameter

$T_{P}=$ pipe temperature

$T_{0}=$ ambient temperature

$\mathrm{K}_{1}=$ thermal conductivity of insulation

$S_{1}=$ thermal resistance of convective film outside insulation

For pipelines buried in the ground directly or in various culvert configurations, the geometry can become complex and more variables may need to be taken into account. Some simplifying assumptions, on the conservative side, are discussed by Hausz (1979a). He suggests for the resistance $S_{1}$ in an air film the value $0.12 \mathrm{~m}^{2} \cdot \mathrm{K} / \mathrm{W}$ $\left(0.68 \mathrm{hr} \cdot \mathrm{ft}^{2} \cdot{ }^{\circ} \mathrm{F} / \mathrm{Btu}\right)$, or, for a meter of wet earth surrounding the pipeline, $\mathrm{S}_{1}=0.78 \mathrm{~m}^{2} \cdot \mathrm{K} / \mathrm{W}\left(4.4 \mathrm{hr} \cdot \mathrm{ft}^{2} \cdot{ }^{\circ} \mathrm{F} / \mathrm{Btu}\right)$.

The amount of insulation which is economically justifiable to limit thermal energy loss from pipelines depends largely on the unit value of the thermal energy. The need for iterative optimization of pipe size, pumping power, insulation type and thickness, and thermal energy loss was covered in Chapter 3, and component pipeline costs found by such an optimization were shown (Figures 3-16, 3-17).

The optimization discussed in Chapter 3 is for a dual $610 \mathrm{~mm}$ (24 inch) point-to-point aboveground pipeline 50 kilometers ( 30 miles) long, designed for $300 \mathrm{MW}$ thermal capacity, with no TES. Sendout temperature is $227^{\circ} \mathrm{C}\left(440^{\circ} \mathrm{F}\right)$, return temperature is $81^{\circ} \mathrm{C}\left(178^{\circ} \mathrm{F}\right)$. The optimized heat loss rate was found to be $24 \mathrm{MW}$, or 8 percent of rated thermal power through the pipeline. For constant-temperature pipeline operation and at an annual capacity factor of 0.75 , the energy loss is then $(8 / 0.75=) 10$ to 11 percent of annual energy production. Using these pipeline loss estimates, the end-user peak hourly load would be increased by 8 percent to find peak hourly demand, and the annual total energy load would be increased by 10 or 11 percent to include pipeline 1osses. As has been seen, ATES losses will also increase the annual energy demand but should not add to the peak hourly demand. 
A second example of the results of computer optimization of pipeline design may be found in an ORNL/Studsvik report on a proposed district heating system for the Twin Cities (Margen, et al, 1979b). The consumer load is about $2600 \mathrm{MW}$, dispersed over the Minneapol isSt. Paul metropolitan area. The two major heat sources are a cogeneration station in Minneapolis and one in St. Paul. The transmission network was diagrammed in Figure 4-1. The total length of dual transmission pipeline is about 50 kilometers ( 30 miles), with diameters ranging from $150 \mathrm{~mm}$ ( 6 inches) to $900 \mathrm{~mm}$ (36 inches). The maximum heat load for these sizes is $14 \mathrm{MW}$ and $890 \mathrm{MW}$ respectively, at a sendout temperature of $146^{\circ} \mathrm{C}\left(295^{\circ} \mathrm{F}\right)$ and return temperature of $60^{\circ} \mathrm{C}\left(140^{\circ} \mathrm{F}\right)$. About half of the pipelines are in tunnels, the other half in culverts. The distribution system connects to the 29 nodes of the transmission system via heat exchangers, and operates at $130^{\circ} \mathrm{C}$ $\left(266^{\circ} \mathrm{F}\right)$ sendout, $60^{\circ} \mathrm{C}\left(140^{\circ} \mathrm{F}\right)$ return. Results obtained from Studsvik's proprietary computer program indicate the heat loss rate for the entire system is about $88 \mathrm{MW}$, or 3.3 percent of peak load, which increases the peak hourly demand to about $2700 \mathrm{MW}$. The system would operate at constant temperature year-round at a capacity factor of 25 to 30 percent, making the annual pipeline energy loss about 11 or 12 percent of consumer load.

An interesting difference between the two examples is the heat loss rate. In the first example, it was 8 percent for a single pipeline $50 \mathrm{~km}$ long. In the second example, the loss is 3.3 percent for a complex network with $50 \mathrm{~km}$ of transmission pipelines which account for much less than half of the total loss - more than 90 percent is in the distribution system. While the assumption of tunnels or concrete culverts rather than aboveground or direct buried pipe explains part of the difference, the mix of sizes in the latter case makes further comparison difficult. However, the interesting point is that more than 2:1 difference in calculating insulation and losses makes only a small difference - less than 5 percentage points - in the hourly peak demand. By happenstance, the annual pipeline energy losses are almost the same percentage of annual load, in the two examples, because of the difference in capacity factors. 
It is worth noting that, in small pipelines, pumping power used to overcome friction losses may exceed thermal power loss through the pipeline walls (Hausz, 1979a). Aamot and Phetteplace (1976) suggest that precautions should be taken to insure that this situation does not raise the water temperature so much that two-phase flow occurs and, possibly, pressure exceeds pipeline strength.

Adjust Estimates of ATES and Transport Capacity Required

At this point, the ATES power-related capacity needed for the load peak will no longer be correct, if transport losses are appreciable. Transport losses add to the original peak load. Additional ATES capacity will be needed to supply the total demand if ATES capacity is discharge-limited. (Since ATES will not be charged during peak loads, but will be discharging to help meet peak load, the ATES itself does not add to peak load.)

Depending upon the procedure used to find transport losses, it may be necessary at this point to increase pipeline capacity to accomodate the transport losses, and possibly to do another iteration to recalculate losses and adjust capacity. Computerized approaches for optimizing pipeline parameters usually design the pipeline to deliver a specified load, which takes care of this step.

Upon completion of this step, the month-by-month energy demands and the production required to supply them (with ATES), the energy into and out of storage each month, and the power-related ATES capacity required), have been found. Loss during storage has been accounted for. Transport capacity required and associated losses have been found. The total amount of energy to be stored has also been found.

\section{DEVELOP OPERATING SCHEDULES}

The fifth step is to develop operating schedules for production, transport, ATES charge, and ATES discharge. This step becomes systemspecific. The input data needed to perform it will be contained in the descriptions of end use and thermal sources prepared in accord- 
ance with Chapter 3. In particular, the hour-by-hour information on typical weeks, together with information on flexibilities and constraints, will be used.

The effects of temperature drop across the ATES heat exchangers and the temperature loss as stored water is produced should be evaluated. The ATES system design should accommodate them, if feasible. If mitigation is required, various measures have been discussed in Chapter 3.

In order to reduce thermal energy losses during storage, the period of storage should be minimized when possible. In a study of utilizing ATES in conjunction with cogeneration as a heat source for the large district heating system proposed for the Twin Cities in Minnesota, discussed in Chapter 3, cogeneration was scheduled to minimize storage time. Within the constraints on capacity factor of the cogeneration machines, including maintenance, outages, and electrical system peak-load periods, heat output from the machines was scheduled to provide maximum storage rates during months just preceding the months of high heat demand. Maximum transmission to load during months of high demand was also scheduled, to reduce size and cost of the transmission system. System configurations were summarized in Table 3-1.

Figure 4-2 shows use of ATES solely to displace peaking and standby boilers; the cogeneration capacity and configuration were not changed. The need for storage, month by month, is shown by the difference between heat load and production (top third of the figure). The capacity factors for extraction and backpressure turbines, shown in the center of the figure, illustrate that the most efficient source of heat - backpressure machines - was chosen for the largest amount of heat production, and during a period of time just preceding the wintertime heat load. The amount of heat stored and the length of time it is in storage are thus kept to a minimum. 

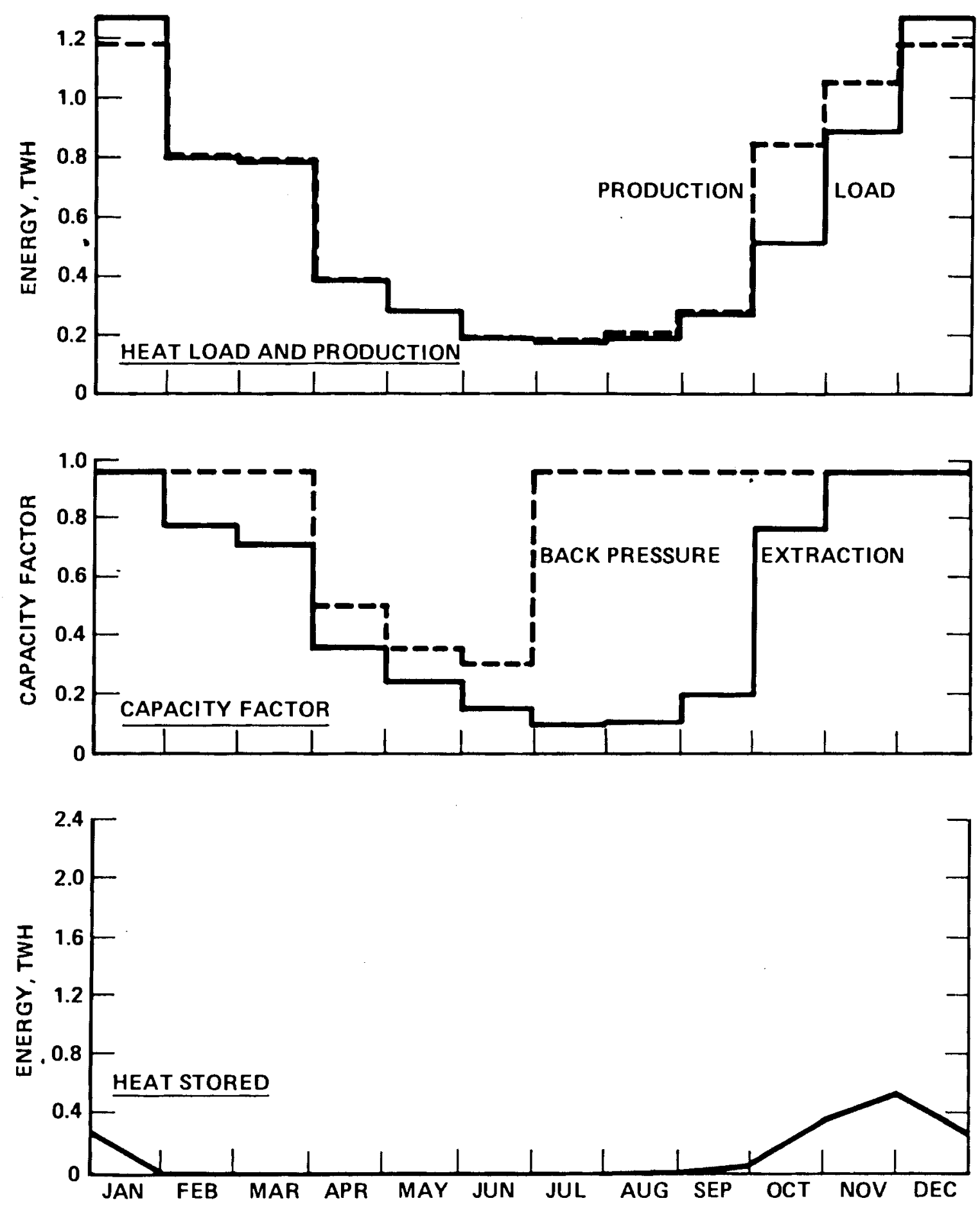

Figure 4-2. Case A-1 - 1516 MW cogeneration capacity. 1523 MW TES at nodes.

(Source: Meyer, 1979) 
Figure 4-3 shows maximum use of ATES, at transmission nodes and at cogeneration sites, to operate cogeneration equipment and transmission lines at their maximum allowable capacity factor. The charging rate of ATES (upward slope of the "Heat Stored" curve) determined the ATES capacity required in this case. The hot-water transmission pipeline capacity required was reduced, through use of ATES, from $1516 \mathrm{MW}$ to $865 \mathrm{MW}$. 

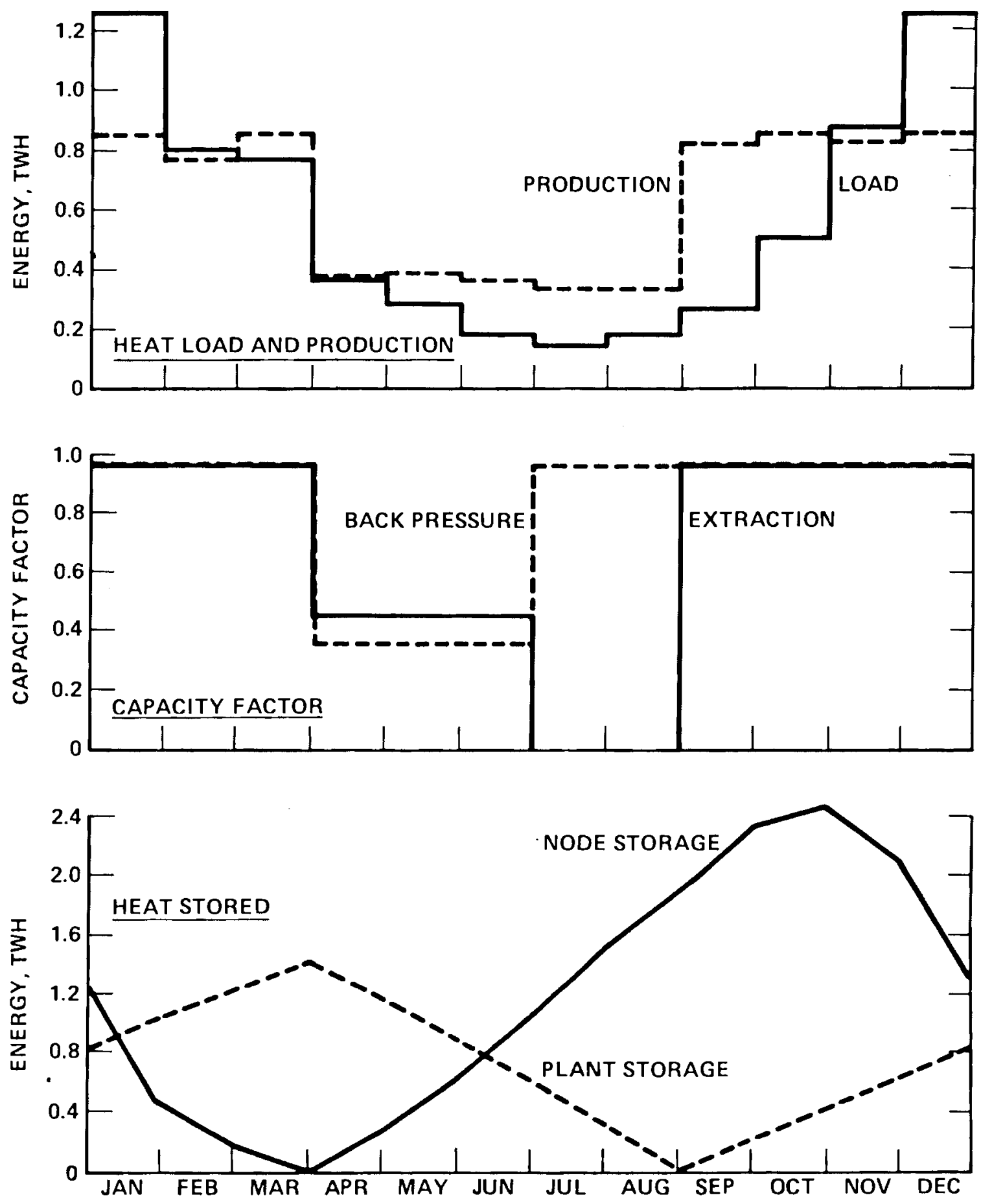

Figure 4-3. Case A-4 -

Minimize pipeline size; recovery fraction is 0.75 . Cogeneration capacity, 1202 MW; 727 MW extraction, 475 MW backpressure. TES: 414 MW at plant, 1839 MW at nodes. Pipeline: $865 \mathrm{Mk}$. (Source: Meyer 1979) 
FIND COST AND FUEL CONSUMPTION BENEFITS

Step 6 is to estimate fixed and variable costs and fuel consumption of ATES cases, at zero cost for ATES, and to subtract them from those of the reference system. Of principal interest is the difference in cost and fuel consumption, rather than specific total amounts, to find the potential benefits of ATES.

Methodology for economic analysis is given in Chapter 5.

Fuel consumption is, of course, system-specific. It can be found from the preceding steps. Note that comparison of fuel consumption rather than energy consumption is suggested. The intent is that both the amount of energy and the fuel used to supply it should be compared. If coal or nuclear energy can be substituted for fluid fuels, the substitution may be considered an important energyconservation measure even if total energy consumed should increase which it may, due to ATES losses.

At the completion of Step 6 , the cost and fuel benefits of using ATES for at least one ATES case will have been found. Step 7 will be performed if more than one ATES case is to be studied, possibly because the first case indicates inadequate benefits.

As an example of how the results of Steps 6 and 7 may be displayed and compared, three tables are reproduced from the Twin Cities study by TEMPO (Meyer, 1979).

Table 4-1. Capital costs, savings, and breakeven TES cost (1978 dollars).

\begin{tabular}{|c|c|c|c|c|c|c|c|c|c|c|c|c|}
\hline & \multicolumn{2}{|c|}{ Boilers } & \multicolumn{4}{|c|}{ Cogeneration } & \multicolumn{2}{|c|}{ Pipel ine } & \multirow{2}{*}{$\begin{array}{c}\text { Total } \\
\$ M\end{array}$} & \multirow{2}{*}{$\begin{array}{l}\begin{array}{c}\text { Cost } \\
\text { Saved }\end{array} \\
\qquad \$ M\end{array}$} & \multicolumn{2}{|c|}{ TES } \\
\hline & MW & $\$ M$ & $\frac{\text { Extra }}{\text { MN }}$ & $\frac{i o n}{\$ M}$ & $\frac{\text { Backpres }}{\text { WW }}$ & $\frac{\text { sure }}{\$ M}$ & MN & SM & & & $\underset{M W}{\text { Capacity, }}$ & $\begin{array}{l}\text { Break- } \\
\text { even, } \\
\$ / \mathrm{kWt}\end{array}$ \\
\hline Reference Case & 1523 & 66 & 1406 & 55 & 110 & 0 & 1516 & 105 & 226 & Ref & -0 & \\
\hline Case $A-1$ & $-0-$ & -0 & 1406 & 55 & 110 & 0 & 1516 & 105 & 160 & 66 & 1523 & 43 \\
\hline Case A-2 & $-0-$ & $-0-$ & 1062 & 42 & 110 & 0 & 1172 & 92 & 134 & 92 & 1867 & 49 \\
\hline Case A-3 & $-0-$ & $-0-$ & 727 & 14 & $440\left\{\begin{array}{l}110 \\
330\end{array}\right.$ & $\begin{array}{r}0 \\
10\end{array}$ & 1167 & 92 & 116 & 110 & 1872 & 59 \\
\hline Case A-4 & $-0-$ & $-0-$ & 727 & 14 & $475\left\{\begin{array}{l}110 \\
375\end{array}\right.$ & $\begin{array}{c}0 \\
11.3\end{array}$ & 865 & 79 & 104 & 122 & 2253 & 54 \\
\hline
\end{tabular}


Table 4-2. Annual fuel consumption and energy benefits (1978 dollars).

\begin{tabular}{|c|c|c|c|c|c|c|c|c|c|c|c|c|c|}
\hline & (1) & $(2)$ & (3) & (4) & (5) & (6) & (7) & (8) & (9) & $(10)$ & (11) & (12) & (13) \\
\hline & $\begin{array}{l}\text { Electric } \\
\text { Generation } \\
\text { Sacrificed }\end{array}$ & \multicolumn{2}{|c|}{$\begin{array}{l}\text { Coal } \\
\text { to replace } \\
\text { Electricity }\end{array}$} & \multicolumn{2}{|c|}{$\begin{array}{l}0 i l \\
\text { to fire } \\
\text { Boilers }\end{array}$} & \multicolumn{2}{|c|}{$\begin{array}{c}\text { Gas } \\
\text { not } \\
\text { Consumed }\end{array}$} & \multicolumn{4}{|c|}{ Net Eneray Sayinos } & \multicolumn{2}{|c|}{ Cost Savings } \\
\hline & TWH & TWH & \$N & TWH & $\$$ & TWH & $\$ M$ & TWH & $10^{6 m B t u}$ & MBOE & $\overline{\mathscr{q}}$ & $\$ M$ & $\Delta, \$ M$ \\
\hline Reference System & 1.10 & 2.75 & 11.1 & 1.20 & 18.1 & 9.23 & 160.7 & 5.28 & 18.0 & 2.83 & Ref & 131 & Ref \\
\hline Case $A-1$ & 1.33 & 3.20 & 12.9 & $-0-$ & $-0-$ & 9.23 & 160.7 & 6.03 & 20.6 & 3.22 & 14 & 148 & 16 \\
\hline Case $A-2$ & 1.52 & 3.72 & $15 . n$ & $-0-$ & $-0-$ & 9.23 & 160.7 & 5.43 & 18.5 & 2.91 & 3 & 145 & 14 \\
\hline Case $A-3$ & 1.51 & 3.16 & $14 . n$ & $-0-$ & $-0-$ & 9.23 & 160.7 & 5.46 & 18.6 & 2.92 & 3 & 145 & 14 \\
\hline Case $A-4$ & 1.54 & 3.53 & 14.2 & $-0-$ & $-0-$ & 9.23 & 160.7 & 5.37 & 18.3 & 2.87 & 2 & 145 & 14 \\
\hline
\end{tabular}

Table 4-3. Combined savings and resultant breakeven annual cost of TES (1978 dollars).

\begin{tabular}{|c|c|c|c|c|c|c|c|}
\hline & \multicolumn{2}{|c|}{$\begin{array}{c}\text { Capital Costs Saved } \\
\text { Due to TES }\end{array}$} & \multirow{3}{*}{$\begin{array}{l}\begin{array}{c}\text { Fuel Cost Savings } \\
\text { Due to TES }\end{array} \\
\$ M / y r\end{array}$} & \multicolumn{4}{|c|}{ Breakeven Annual Cost of TFS } \\
\hline & \multirow{2}{*}{$\begin{array}{l}\text { Municipal } \\
\frac{\text { Financingt }}{\$ M / y r}\end{array}$} & \multirow{2}{*}{$\frac{\begin{array}{c}\text { Private } \\
\text { Financing }\end{array}}{\$ M / y r}$} & & \multicolumn{2}{|c|}{ Municipal Financing } & \multicolumn{2}{|c|}{ Private Financing } \\
\hline & & & & $\$ M / y r$ & $\begin{array}{c}\$ / y r \text { per kW } \\
\text { of TES Capacity }\end{array}$ & $\$ M / y r$ & $\begin{array}{c}\$ / y r \text { per kW } \\
\text { of TES capacity }\end{array}$ \\
\hline Case A-1 & 7.9 & 11.9 & 16 & 23.9 & 15.7 & 27.9 & 18.3 \\
\hline Case $A-2$ & 11.0 & 16.6 & 14 & 25.0 & 13.4 & 30.6 & 16.4 \\
\hline Case A-3 & 13.2 & 19.8 & 14 & 27.2 & 14.5 & 33.8 & 18.1 \\
\hline Case $A-4$ & 14.6 & 22.0 & 14 & 28.6 & 12.7 & 36.0 & 16.0 \\
\hline
\end{tabular}

Table 4-1 shows, for the reference case and the four conceptual designs, the capital costs (and the MW capacity) of boilers, cogeneration equipment, and transmission pipelines. The MW savings were shown earlier in these Guidelines, in Table 3-1. These savings are translated into capital cost savings in Table 4-1, and the total is shown. The cost savings divided by the ATES capacity required then gives the breakeven cost of TES in $\$ / \mathrm{kW}$ thermal. This is one basis for deciding whether to pursue further evaluation of ATES - exploratory drilling, refining of cost estimates, placing a dollar value on secondary benefits of reduced environmental problems. 
Table 4-2 gives fuel consumption benefits in energy units and in dollar value. Column 1, Electric Generation Sacrificed, denotes the reduction in electric generation because steam is extracted for heating (see Figure 5-1). The electricity must be generated elsewhere, for which columns 2 and 3 show the fuel and cost involved. Columns 4 and 5 show that ATES displaces oil which otherwise would have been burned by auxiliary boilers in the reference system. Columns 6 and 7 show that the systems with and without ATES displace the same residential furnaces and boilers - there is no net effect. The net energy savings are then shown, in columns 8, 9, and 10, and the corresponding cost savings in columns 12 and 13, all compared to the reference case.

Table 4-3 combines capital and fuel cost savings to find an annualized breakeven cost of TES for two types of financing - municipal and private. Both the total dollar savings for the systems and the effect of annualizing these with a fixed charge rate are shown.

\section{EST IMATE EXPECTED COST OF ATES}

Step 8 will be performed if one or more cases with ATES show positive breakeven (i.e., allowable) costs for ATES facilities. A very rough estimate is that ATES will cost $\$ 25$ to $\$ 75$ per thermal $\mathrm{kW}$ in mid-1980 dollars. A better estimate of the expected cost of local ATES facilities should be made. A starting point is "Cost of Wells and Pumping," in Chapter 3. Not only the depth and size of a well but its locale within the United States will have a substantial effect on costs.

Local well-drillers or hydrogeologists should be contacted for information on aquifers which may be available: depths, yield of wells, aquifer thickness and areal extent, artesian pressure, water quality, location and purpose of wells within a kilometer or two of proposed sites for heat storage wells.

Figure 3-8 shows the artesian pressure required for the sendout temperature contemplated in the system being evaluated. As noted, higher storage temperatures imply deeper wells and greater expense. 
From information on well yield obtained from the well-driller or hydrogeologist, together with the postulated operating temperatures of the ATES system, the energy flow rate for a doublet well can be found from the nomographs of Figure 3-9. If water temperatures are well above boiling, the flow rate may be higher than normal well yields at natural aquifer temperatures, because the viscosity will be lower. Conservatism at this stage suggests using normal well yields, particularly since injection wells tend in general to accept water at a slower rate than can be pumped from them.

Comparing the energy flow rate with the ATES capacity required indicates how many wells will be needed. Rough cost estimates for designing and constructing the wells may then be obtained, keeping in mind the unusual dual-function requirements for switching quickly and often between injection and pumping.

If groundwater in an aquifer is believed to be heavily mineralized - say, more than 50 grams per liter - special materials to resist corrosion and scaling will be needed for the well and the aboveground equipment. Well plugging during injection is likely to be a problem. To cope with severe problems from heavily mineralized water, special geothermal technology may be applicable if it can be justified on economic grounds.

If no suitable aquifers are known to be available, the possibility of geophysical surveying and exploratory drilling may have to be considered. Local firms can supply rough estimates of these costs. Analysis of core and water samples to evaluate aquifer parameters and geochemical suitability may be expected to require specialized knowledge and equipment.

BENEFIT/COST APPRAISAL

Step 9 suggests three options, covering a range of situations and actions. 
Option 9(a)

If anticipated costs, difficulties, or uncertainties make the prospective benefits from ATES substantially less than expected costs, the investigation presumably should be deferred or abandoned.

Option 9(b)

If prospective benefits substantially exceed the expected cost of ATES facilities, the next steps toward locating and evaluating an aquifer should be taken. If adequate information is available on hydrogeological and geochemical parameters of a candidate aquifer a somewhat unusual situation - preliminary design of ATES facilities can be undertaken.

Ideally, arrangements should be made for preliminary computer modeling of water flow and heat transfer in the aquifer, to predict storage and recovery performance. Use of partially-penetrating wells, or completion of wells in specific portions of the aquifer formation, may be suggested by modeling. Pumping (interference) tests at the site will be needed, sooner or later, to refine initial modeling estimates.

Preliminary mechanical design of the well can be undertaken if modeling indicates performance will be adequate for system purposes. The special design features enumerated in Chapter 3 must be taken into account.

If adequate hydrogeological and geochemical information on the candidate aquifer is not available, exploratory drilling and aquifer testing will be needed - possibly, surface geophysical surveys, if aquifer locations are uncertain. These rather expensive ventures should be undertaken only after consultation with those who will perform the chemical and physical analyses and the computer modeling of water and heat flow, so that the field test program can be designed to produce specific data at minimum cost. 


\section{Option 9(c)}

The third option of step 9 covers the indeterminate situation in which prospective benefits are roughly equal to expected cost of ATES facilities. It is suggested that secondary benefits and disbenefits be evaluated, in order to decide whether energy conservation, fuel substitution, reliability of supply, pollution abatement, regulatory problems, risk of not finding a suitable aquifer, and other considerations may tip the decision toward continuing the investigation, deferring it, or abandoning it.

UTILIZE IMPROVED DATA TO IMPROVE THE SYSTEM EVALUATION

Step 10 suggests that the improved performance and cost data obtained from undertaking the second option of step 9 be used for another iteration through the design and evaluation procedures. New possibilities for more effective use of ATES may come to light; conversely, expected benefits may have to be trimmed in view of new data. 


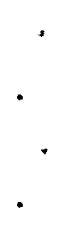


CHAPTER 5

ECONOMIC ANALYSIS

After technical performance and direct cost of systems with and without ATES have been found, comprehensive and self-consistent economic analysis is required in order to evaluate and compare them.

\section{LIFE-CYCLE COSTING}

For valid comparison of concepts with high capital costs and low fuel costs to concepts with lower capital costs and higher fuel costs, al1 costs over the entire life of the equipment or system should be considered.

Life-cycle costing uses estimates or scenarios of future cost variations, year by year. This implies assumptions about general inflation and about net escalation of particular costs such as fuel which may increase faster than general inflation. The cost of capital, or time value of money, is a function of inflation and of the source of financing - the debt/equity mix. Clearly, these assumptions have a strong bearing on 1 ife-cycle costs, per-unit energy costs, and the comparative merit of different system concepts.

A11 revenues and other benefits, year by year, should be considered. The net balance of benefits over costs is then a measure of merit for comparison of alternative concepts, together with per-unit cost of energy.

The "required-revenue" approach which will be described is one in common use by the electric utility industry for life-cycle costing to evaluate and compare alternative energy systems which may differ significantly in their makeup; e.g., solar and geothermal power plants. 
Entities other than utilities who may consider use of ATES industry, municipalities, large commercial/residential complexes are accustomed to their own financial criteria and methods of analysis, and will employ them. Before the required-revenue approach is described, some alternative methods will be discussed briefly to point out that the time value of money and life-cycle costs and benefits are not considered in some methods.

\section{ALTERNATIVE METHODS OF ECONOMIC ANALYSIS}

Four widely employed methods of economic analysis are shown in Table 5-1.

Table 5-1. Economic analysis criteria.

1. Payout Time: Years required for cash earnings/savings to equal capital investment.

2. Rate of Return on Investment (ROI): Ratio of net profit after depreciation and taxes to average outstanding investment.

3. Present Worth Method (PW): Ratio of discounted earnings over life cycle to initial investment.

4. Discounted Cash Flow (DCF): Find the discount rate that makes present worth of all cash flows, in and out, equal zero.

Source: Park, 1973.

The payout time or payback method computes year-by-year cash flow to find when cumulative net revenues equal the investment cost. Usually, no discounting of future returns is considered, nor are revenues over the whole life cycle considered. The method may be useful where cash flow problems dominate other criteria.

The ROI method also does not include discounting of future costs and revenues. Over the project life, operating expense, depreciation, and taxes are subtracted from annual income to find net profit. Depreciation is considered as capital available for reuse, so is no longer charged to the project. The ratio of the cumulative profit over the book life to the average investment is the ROI. 
The PW method, using the expected or acceptable rate of return on investment, compares the amount by which life-cycle benefits exceed costs. The required-revenue approach is a special form of the PW method.

In the DCF method, instead of fixing the discount rate and then comparing costs and benefits as in the PW method, the economic analysis is iterated to find the discount rate for which life-cycle costs and benefits are equal. The alternative with the highest discounted cash flow rate is preferred. This criterion does not compare the cost of energy in alternative systems.

While one or more of the methods listed may be useful or necessary to a particular organization before an investment decision is made, the required-revenue approach should also be used for the reasons already noted and because it is most likely to be acceptable to regulatory agencies if governmental regulation is involved.

\section{REQUIRED-REVENUE APPROACH}

The Electric Power Research Institute (EPRI) is faced with the need to standardize economic analysis of significantly different energy systems, so that they can be properly compared. This need has been met by preparing a Technical Assessment Guide, often called "TAG". The most recently updated edition, listed in Appendix D, was published in 1979.

The TAG methodology is the required-revenue approach, for when all costs over the entire life cycle of a generating plant or other project are considered, the revenues accrued over the system lifetime from this plant or project must at least equal the costs. The measure of merit of alternatives is the difference between revenues and costs or, by normalizing, the difference between unit revenues and unit costs; for example, in dollars per megawatt hour ( $\$ / M W h$ is numerically the same as mills per $\mathrm{kWh}$ ).

The TAG requires consideration of all costs, before and during the operating lifetime of the system concept being considered. It 
requires that the time value of money be considered, i.e., that a dollar in hand now is worth more than a dollar received at a future date, both because of the basic return available from safe investment of the dollar and because of the dilution of value through inflation. This time value of money can be expressed as a discount rate incorporating both real interest and an expected inflation over the system lifetime. Future values of both costs and revenues are discounted back to a base year, say the year of initial operation of the system. This discounting is the multiplying of the future value by $1 /(1+r)^{n}$ where $r$ is the discount rate and $n$ is the time difference in years from the base year; the result is the present worth of the future value. For years prior to the base year (i.e., during construction), $n$ is negative. The present worth of costs and revenues up to year $N$, the system lifetime, must be combined to find the total present worth of the costs and of the revenues.

For the users of this methodology other than utilities there may be some differences in terminology used but the basic concept should be readily applicable. For instance, revenues may be generalized to benefits, which may include savings or earnings or more subjective benefits, harder to quantify, such as reliability of fuel supply, reduced use of non-renewable fuels, or reduced environmental pollution.

Equations and tables more extensive than given here may be found in Appendix C.

\section{COSTS}

Cost elements can be separated into categories. Investment costs and operating costs is one separation; fixed costs and variable costs is another. The latter is more suitable for economic analysis of concepts over their life cycle; the former has its own distinct uses, as in tax accounting.

Fixed costs are those essentially independent of the level of output of a plant or a system. Logically, most costs related to 
investments for capital equipment will continue, independent of output as a fraction of the rated or maximum capacity.

Variable costs are those dependent on, usually directly proportional to, the fraction of maximum output capacity produced in a period, such as a year or over the lifetime of the system. This fraction is called the capacity factor (CF). Fuels and other expendable materials are in this class. For plants making a physical product, the input material costs are variable costs. So is operating and maintenance labor.

The distinction between fixed and variable costs is important in this economic methodology because either energy sources or energy end uses are assumed to be constrained to less than the maximum or rated value so are operating at a capacity factor less than unity. ATES, if it can improve the CF of major pieces of equipment, may reduce the required investment.

\section{Fixed Costs}

Table 5-2 shows the major categories of fixed costs usually considered in analysis, and in architect/engineer firms' classifications of costs. The total investment cost is principally the initial investments preceding the start of system operation, although other periodic investments such as replacements are included. These can a11 be expressed on a comparable basis in terms of their present worth in the initial year of operation.

Some rules of thumb on the installed cost, often called the direct cost of subsystem components, were given in earlier chapters. They include not only the purchased major equipments but also al1 the labor and miscellaneous material required to insta11 them - concrete, steel, piping, paint, etc. There are overhead costs, in planning, managing, inspecting, and providing various services, that are generally not directly chargeable to particular subsystems. These are called indirect costs; they are often estimated as a fraction of direct costs, e.g., 35 percent. The combination of direct and indirect costs is called base costs. Other costs which the owner must 
Table 5-2. Fixed cost elements.

\section{FIXED COSTS}

Total Investment Cost

Direct costs (installed cost)

Equipment cost (delivered)

Site materials

Site labor

Indirect costs

Construction services

Home office engineering and service

Field office engineering and service

Other owner's costs

Contingency

Consultants

Site selection, fees, and permits

Spare parts inventory

Escalation and interest during construction

Salvage value (negative cost)

\section{Annual Costs}

Interest and depreciation

Federal and State income taxes

Property taxes, insurance, etc.

Fixed operating and maintenance costs

pay that are not a part of the construction phase must be considered and estimates made for a realistic economic analysis. Some examples are given in Table 5-2.

Contingency is a prudent inclusion that depends on the estimated risk of unforeseen costs or events. It must be a personal judgment. Ten to 15 percent is often used. For a high risk project 25 percent might be used.

The cost of studies and consultants and the time and effort required to meet all requirements for permits may be considered an investment cost. Providing an inventory of spare parts, to reduce delays if failures occur, is another initial investment. While the salvage value at the end of the project is properly a deductible cost, the present worth of the salvage value is often negligible for a long life project. 
In major projects where the construction phase may last several years, much of the investment cost is incurred before the year of initial operation (base year), when revenues begin. The present worth in the base year of these early costs is found by using negative values of $n$ in the discounting procedure as described on page $5-4$.

There are other fixed costs that continue over the life of the project and may occur annually or more frequently. These include Federal and State income taxes, property taxes, insurance, expenses such as supervision, management, accounting, building maintenance, etc. that are independent of capacity factor. These may be considered as a stream of annual costs over the lifetime of the project.

Such annual costs can be converted, using the discounting formula on page 5-4, into their equivalent in present worth to be on a comparable basis to combine with the investment cost. Alternatively, the investment cost can be transformed into a uniform stream of annual costs of equivalent present worth. This latter is the approach frequently used, and preferred by the TAG. The factor used to convert an investment $I$ into $N$ equal annual payments, representing interest and a sinking fund to return the principal (or interest and depreciation) is called the capital recovery factor (CRF) and is, when the discount rate is $r$ :

$$
C R F=r /\left(1-(1+r)^{-N}\right)
$$

Some tables of the CRF and related financial parameters for various values of $r$ and $N$ are given in Appendix $C$. As an example to be used herein, for $r=0.1$ (10 percent) and $N=10,20$, and 30 years, the CRF is $0.1627,0.1175$, and 0.1061 respectively.

FIXED CHARGE RATE. Since most of the annual fixed cost components are roughly directly proportional to the investment, they can all be combined into one stream of $\mathrm{N}$ uniform annual payments by combining their present worth with the investment and then applying the CRF to the combination. This can be done by multiplying the invest- 
ment by a different factor appropriately larger than the CRF. This factor to convert all fixed costs to a uniform cost stream is called the Fixed Charge Rate (FCR). To be most useful it incorporates not only the lifetime $N$, the discount rate $r$, the indicated taxes and insurance, but also various tax accounting allowances that may apply, such as accelerated depreciation rates and investment tax credits. It may also incorporate an estimated fixed operating and maintenance (O\&M) cost component.

The FCR will vary with all these components. As an approximate value compatible with a discount rate of 10 percent and investorowned utility practice, the TAG suggests 0.18 . Information on the derivation of this value is in Appendix $C$.

\section{Economic Scenario}

The discount rate used is not arbitrary but represents the analyst's perception of likely economic parameters over the life of the project. Since the time value of money depends on inflation, some value of inflation must be assumed. What it will actually be over a 20- or 30-year period is completely uncertain, but extremes such as zero are very unlikely. The TAG assumes, as we will here, that general inflation continues at a constant rate of 6 percent a year indefinitely. Particular cost components such as fuels may escalate at a rate higher or lower than general inflation, as will be discussed.

The discount rate is analogous to interest, but in the general case represents the "weighted cost of capital" of a mix of several modes of financing at different risk levels. Interest on bonds at 8 percent, return on equity for preferred stock of 8.5 percent, and return on equity for common stcck of 13.5 percent are assumed as compatible with a constant 6 percent inflation rate. The TAG assumes a typical utility mix of 50 percent debt (bonds), 15 percent preferred stock, and 35 percent common stock. The weighted average of these is 10 percent. 
Federal and State income tax rate is assumed to be 50 percent, so the before-tax return on equity must be twice that indicated above. The resulting FCR used in the TAG is 0.18 when $N=30$.

For users other than investor-owned utilities, the economic scenario may be very different. Industry may have a debt to equity ratio of 0.2 rather than 1.0 assumed above, and the risk level may make the minimum acceptable return on equity greater than 13.5 percent. The value of 1 ifetime $\mathrm{N}$ to be used may be five years rather than 20 or 30 , because of the risk of technical or market obsolescence rather than physical lifetime. On the other hand, municipalities may be 100 percent debt financed, have no taxes to include, and accept long physical 1 ifetimes such as 40-50 years. If a user cannot readily determine a scenario discount rate and FCR, it is suggested that comparisons be made both at an 18 percent FCR and a higher value (e.g., 30 percent for industry) or a lower value (e.g., 12 percent FCR for municipalities). The sensitivity of the comparison of alternatives to these parameters will thus be tested.

Variable Costs

Variable costs, proportional to capacity factor (CF) are all annual cost streams over the life of the project (Table 5-3). They include fuels and other input materials needed to produce the outputs. For example, for use of coal as a fuel, with scrubbers to reduce pollution, lime and water inputs proportional to CF are required.

Table 5-3. Variable cost elements.

VARIABLE COSTS

Purchased Fuel and Electricity

Other Input Materials

(water, process inputs, etc.)

Operating and Maintenance Costs 
The operating labor and the amount of maintenance required are generally assumed to be also proportional to the CF.

For each year in the cost stream the cost elements are the product of what would be required for maximum output capacity and the CF. This is an approximation, since the efficiency may vary with CF; for example, in a power plant, so that input (e.g., fuel) and output (e.g., electricity) are not strictly proportional.

Cost per unit of fuel can be expected to escalate with time. It is expected that oil, gas, coal, and nuclear fuels will all escalate faster than general inflation, i.e., the net escalation is positive. The year to year fluctuation is uncertain; assumptions must be made of an expected average rate of escalation, as with general inflation, which is then used as though the escalation rate is constant over the lifetime of the project. The TAG assumes the net escalation of coal prices to be from 0.8 percent to 2 percent, for the several regions of the country. As a rule of thumb 1.5 percent net escalation $(7.5$ percent total) will be used here. $0 i 1$ is expected to be not as regionally sensitive and to have a net escalation of 2 percent ( 8 percent total). Nuclear fuel (without reprocessing) has an expected net escalation rate of 2.5 percent ( 8.5 percent total).

Table 5-4 includes these TAG assumed net escalation rates and a suggested mid-1980 value for each fuel. A different initial value in 1980 dollars, to take account of actual costs at the time of analysis and regional differences, can readily be substituted. Natural gas is included in the table but not in the TAG. As gas can reasonably be expected to approach or exceed oil in cost ultimately a high net escalation rate is assumed.

Table 5-4. Fuel price assumptions.

\begin{tabular}{|lcc|}
\hline \multicolumn{1}{c}{ Fuel } & $\begin{array}{c}\text { Mid-Point 1980 } \\
(\$ / G J(\sim / \text { MBtu })\end{array}$ & $\begin{array}{c}\text { Net Escalation Rate } \\
\% \text { per year }\end{array}$ \\
\cline { 1 - 1 } Coal & 1.50 & 1.5 \\
$0 i 1-$ Residual & 5.00 & 2.0 \\
Oil - Distillate & 6.00 & 2.0 \\
Gas & 2.50 & 5.0 \\
Nuclear & 0.55 & 2.5 \\
\hline
\end{tabular}


LEVELIZING ANNUAL COSTS. Just as it was assumed convenient to express investment costs and annual fixed costs as a uniform or levelized annual stream of $N$ payments, it will be convenient to convert the fuel cost, and other variable annual costs, from cost streams escalating at rates from 7.5 to 11 percent, to levelized cost streams. By this means, analysis can be done with one set of numbers, and not on a year-by-year basis. The procedure is to convert the escalating cost stream into a present worth in the base year, then convert back to a levelized stream of uniform payments using the appropriate CRF $(r, N)$. The procedure is explained in Appendix C; Table 5-5 gives the levelizing factor LF by which the base year fuel cost is to be multiplied to get the uniform annual cost.

Table 5-5. Levelizing factor for annual costs (for discount rate 0.10 ).

\begin{tabular}{|c|c|c|c|c|c|}
\hline$N($ years $) \longrightarrow$ & 5 & 10 & 15 & 20 & 30 \\
\hline Net Escalation (\%) & \multicolumn{5}{|c|}{$\operatorname{LF}(N, e, r)$} \\
\hline 0 & 1.18 & 1.34 & 1.49 & 1.63 & 1.89 \\
\hline 1.0 & 1.22 & 1.41 & 1.60 & 1.79 & 2.15 \\
\hline 1.5 & 1.24 & 1.44 & 1.66 & 1.88 & 2.30 \\
\hline 2.0 & 1.25 & 1.48 & 1.72 & 1.97 & 2.46 \\
\hline 2.5 & 1.27 & 1.52 & 1.79 & 2.07 & 2.64 \\
\hline 5.0 & 1.37 & 1.74 & 2.17 & 2.67 & 3.84 \\
\hline
\end{tabular}

For example, if two alternatives, an oil-fired boiler with 80 percent efficiency and a coal-fired boiler with efficiency 70 percent, are both required to produce an output of $100 \mathrm{TJ}\left(\sim 10^{5} \mathrm{MBtu}\right)$ per year, the annual cost of fuel for each, assuming 1980 start of operation and 20-year 1ife, would be:

- OIL

$5 \$ / G J \times 10^{5} \times 1 / 0.80=\$ 625,000$ in the year 1980

$\operatorname{LF}(20,0.02,0.10)=1.97$

Levelized annual cost $=625,000 \times 1.97=\$ 1,230,000$ 
- $C O A L$

$1.50 \$ / G J \times 10^{5} \times 1 / 0.70=\$ 214,000$ in the year 1980

$\operatorname{LF}(20,0.015,0.10)=1.88$

Levelized annual cost $=214,000 \times 1.88=\$ 403,000$

\section{BENEFITS}

In the specific case considered by the TAG for an electric utility, all costs - fixed and variable - must be liquidated by the revenues received from the sale of electricity year-by-year over the book life of the system. For some other cases, revenues may not be the word normally used, e.g., for an industry that purchases electricity and/or heat, savings may be the preferred word. Other benefits may accrue and be important such as increased net earnings, reliability of supply, tradeoffs with pollution or energy conservation requirements on new construction, etc. To the extent that all of these can be quantified in absolute or relative terms (comparing alternatives), they should be included on the righthand side of an equation:

$$
\sum \text { costs }=<\sum_{\text {Benefits }}
$$

With the left side (costs) in levelized terms the right side should similarly be expressed in levelized annual benefits.

\section{One Product Cases}

The simplest case to treat is the one where only thermal energy, heat or chill, is involved. Among such cases, some will have a specific annual demand (with fluctuations within the year) which is currently met by purchase or by equipment already in operation, with known costs. In such cases, the right side is a reference case, and only the alternatives including ATES need be compared to find the least costly.

The reference benefits are determined by the peak demand, the capacity factor of the demand and the levelized annual cost per unit demand (e.g., \$/GJ). Naturally, an escalation scenario for these benefits must be assumed. If they are the purchase price of heat to 
meet the demand, escalation will depend on the fuel used, and the relative share in this price of fuel-related-costs and other costs escalating at the general inflation rate.

It will be noted that the above procedure is essentially the equivalent of using the annual costs of a reference system on the right side as the target for comparison with alternative systems, including ATES, on the left side. When there is no reference system, or when alternative systems differ in the amount of energy produced, or where system alternatives of different scale size are to be compared, the suggested approach is to compare the costs of each alternative on the left with the benefits on the right determined by some consistent method. To make alternatives of different scales more easily comparable, the right side is expressed as a product: the rated energy output capacity times the capacity factor (annual average output divided by peak output) times an assumed "fair," reference, or arbitrary price per unit of energy $(\$ / G J)$. It is then possible to divide both sides of the equation by the product of peak output and the capacity factor, to express both sides in unit costs and price ( $\$ / G \mathrm{~J})$. The alternative that has the lowest unit energy cost, if lower than the reference or target price, is usually preferred.

Two points should be noted:

- The capacity factor of the benefits defined above is usually not the same as that of some cost elements on the left. In fact, a major purpose of ATES is to make possible the use of some major capital cost elements at a higher capacity factor than is possible without storage.

- By keeping separate the peak and average output, or peak capacity and CF, sensitivity studies of the effects of varying these parameters are more easily done.

\section{Multiple Product Outputs}

In many ATES systems there will be two or more outputs that may be varied semi-independently, i.e., are not in a constant ratio. 
Examples are heat and chill, heat at two or more temperatures, and heat and electricity. In principle there can be other physical products that are energy dependent, i.e., may vary in quantity in some tradeoff with the ATES system parameters. The heat-plus-electricity case, or cogeneration, is probably the most common one, and will be used as an example.

The thermodynamic benefits of cogeneration are well known. Instead of generating electricity at maximum efficiencies of 30 to 35 percent and rejecting the other 65 to 70 percent of the fuel energy at temperatures not usable for other purposes, some of the thermal energy is extracted from the electric generation cycle at temperatures high enough to be useful. For each GJ or MWh of heat extracted, there will of course be a reduction in the amount of electricity generated. The magnitude of this effect is shown in Figure 5-1. The equivalence factor $F_{e}$ is the ratio of the electricity lost to the heat extracted (both in the same units). It is a function of temperature, since more work has been extracted from the steam cycle before extraction if done at lower temperature. The graph should be considered illustrative since it was done by analysis of two specific large power plants for another study (Hausz, 1979a; Hausz, 1979b). The two plants were a high sulfur coal (HSC) plant, $800 \mathrm{MW}_{\mathrm{e}}$, supercritical; and a light water reactor (LWR), $1100 \mathrm{MW}_{\mathrm{e}}$, with saturated steam output at $283^{\circ} \mathrm{C}\left(541^{\circ} \mathrm{F}\right)$. The extracted steam was converted in heat exchangers to sendout HTW at the temperature of the abscissa from a return temperature as shown, of $77^{\circ} \mathrm{C}$ and $81^{\circ} \mathrm{C}$ respectively. Other studies in the literature, including European district heating reports, showed the same trend, with a scatter of points around the lines shown.

At temperatures as $10 \mathrm{w}$ as $100^{\circ} \mathrm{C}, 10 \mathrm{MWh}$ of heat can be extracted with the loss of only 1 MWh of electricity. Cogeneration systems can be designed to extract only part of the steam so that some of the steam energy is still rejected to a cooling tower. They can also be designed as noncondensing or backpressure turbines, in which 


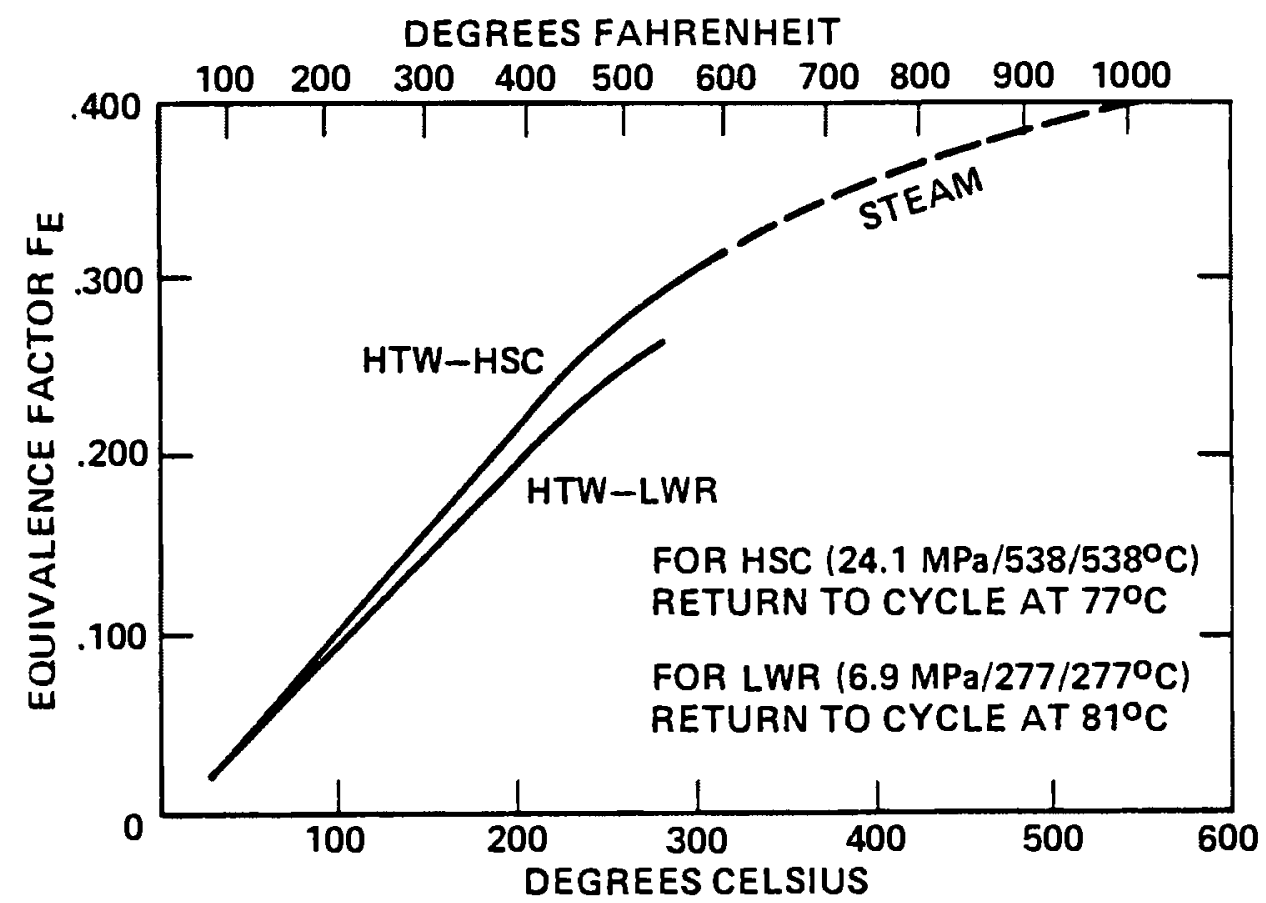

Figure 5-1. Equivalence factor relating heat cost to electricity cost. (Hausz, 1979b)

all steam condensation energy goes into the HTW loop, in several temperature stages for maximum efficiency. In the latter case, electric plus heat generating efficiency can be as high as the boiler efficiency, over 80 percent for the HSC plant and almost 100 percent for the LWR plant. When consideration is given to the fact that the alternative method of thermal energy supply is with small boilers of lower than 80 percent efficiency, energy savings anomalously equivalent to efficiencies over 100 percent can occur.

The yearly output of heat and of electricity can each be expressed, as for the single output case, as the product of its maximum capacity annual output and a capacity factor. Each can be multiplied by a reference price, for electricity and for heat, and combined to find the total revenues or benefits. This can be compared to the costs side of the equation to determine which alternative ATES concept gives the least cost for the same benefits. 
More generally, it may be desirable to find values of the price of electricity $E$ and the price of heat $H$ that would give benefits equal to cost as in Equation 5-3:

$$
\text { Fixed Costs + Variable Costs }=Q_{E} \times E+Q_{H} \times H
$$

where $Q_{E}$ and $Q_{H}$ are the annual energy outputs. Eventually it may be desirable to allocate costs to electricity generation and to heat production. It is suggested that this controversial task be avoided by use of the joint-product diagram illustrated in Figure 5-2 for comparison of alternative concepts.

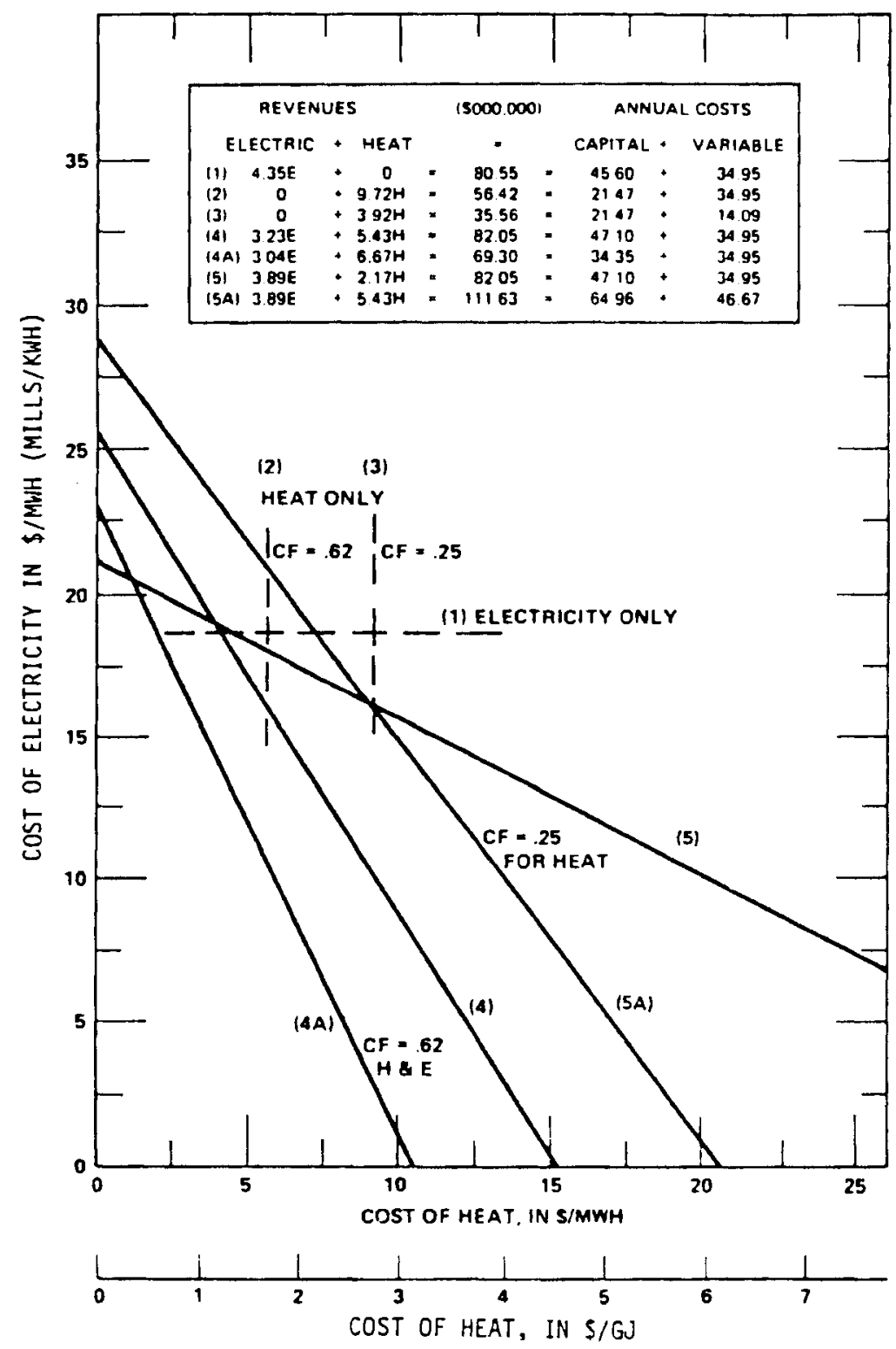

Figure 5-2. Costs of conventional versus combined heat and power system. (Hausz, 1977) 
If the mode of system operation determines the costs and the energy quantities $Q_{E}$ and $Q_{H}$, there are still many combinations of the relative prices $E$ and $H$ that satisfy the equation. In fact, it is a linear equation in these two variables that can be plotted as shown in Figure 5-2. The ordinate is the price of electricity $E$ in $\$ / M W h$. The abscissa as shown is the price of heat $H$ in $\$ / M W h$. An equivalent scale in $\$ / G J$ (roughly the same as $\$ / m i l l i o n ~ B t u$ ) is also shown. Any point on the line shown satisfies the equation.

While conventions, or regulatory or other constraints, may determine the method of deciding which point should be selected, it is useful to consider the joint-products curve in analys is of the sensitivity to different variables, and the comparison of concepts or modes of use.

Figure 5-2 shows how various cases and concepts can be conveniently compared. The equations for each case are given in the box. Modes of operation of an 800 MW coal-fired plant are being compared. Case 1 is for conventional production of electricity only. The revenues from electricity are involved so dashed line (1) represents the cost of electricity, E. The work for this figure was done in 1974 dollars, without fuel cost levelizing, so numerical values won't match earlier figures. A separate or supplementary coal-fired boiler producing heat alone gives a cost-of-heat, $H$, for operation at $C F=0.62$ in (2) and $C F=0.25$ in (3).

Modifying the turbine set for district heating by providing four temperatures of steam extraction to heat water from $66^{\circ} \mathrm{C}\left(150^{\circ} \mathrm{F}\right)$ to $177^{\circ} \mathrm{C}\left(350^{\circ} \mathrm{F}\right)$, producing $1000 \mathrm{MW}$ as $\mathrm{HTW}$, reduces the electric output to $590 \mathrm{MW}$. Capital costs are increased and both heat and electricity produce revenue as shown in (4). While both heat and electricity are produced at $\mathrm{CF}=0.62$ in this case, the capability to still produce $800 \mathrm{MW}$ electric and no heat is retained.

There could be capital cost reductions by making the turbine set noncondensing, producing up to $1200 \mathrm{MW}$ of HTW and $560 \mathrm{MW}$ electric. Cooling towers are eliminated and the low pressure turbine and 
alternator are reduced in size and cost. The flexibility to decouple heat and electricity production is lost. The savings are indicated by $(4 A)$.

Notice that in both (4) and (4A) there is a part of the 1 ine that is to the left of and below the intersection of 1 ines (1) and (2). Both heat and electricity are produced at lower cost by cogeneration than by separate production of electricity and heat. The capital cost savings of noncondensing operation in (4A) increases the range of "viable" alternative pricings. Selection of which point should be used within the range is discussed in the section "Cost Allocation."

Of course a major part of the rationale for heating or cooling applications is the relatively short duration of peak loads for space heating and space cooling. The demand for heat (or cooling) may have an annual capacity factor of 0.25 or less.

The case presented by (5) is that where $\mathrm{CF}=0.62$ for electricity and 0.25 for heat. This implies the condensing operation of case (4) with more electricity and less heat produced during the off-peak seasons. Note in the table that the quantities of electricity and heat are intermediate between cases (1) and (4). As more electricity is produced for the same annual costs, the cost of electricity, E, is less at the left where $H$ is taken as zero. Similarly since less heat is produced for the same annual costs, the cost of heat, $\mathrm{H}$, is higher than in case (4) for points to the right of (3), the separate production cost of heat at $C F=0.25$.

Case (5A) indicates that if separate peaking boilers are added to satisfy the total heat demand of (4), the capital and variable costs are increased; the line $(5 \mathrm{~A})$ is roughly parallel to (4) but passes through the intersection of (3) and (5).

The cost of an ATES subsystem is not included in the cases in Figure 5-2. An increased cost on the left side of Equation 5-2 will shift a joint-products cost curve upwards to the right, with the same slope. The losses of heat in storage reduce $Q_{H}$ which will move the 
intercept at the $\mathrm{H}$ axis (all costs charged to heat) further to the right without changing the $E$ axis intercept. As cases (4) or (4A) with ATES added can meet the demands of cases (5) or ( $5 A$ ) (CF $=0.25$ for heat), lines displaced from (4) and (4A) by the ATES costs can be compared with (5) and (5A) for their region of superiority.

While for three or more products the joint-products curve becomes more difficult to formulate, it may be useful to use a third product price as the parameter for a family of parallel lines.

\section{Other Benefits}

Benefits other than increased revenues, or the equivalent in reduced costs, are often difficult to quantify at all, or particularly to quantify in economic terms. Some of the benefits are very real in terms of an impact on the feasibility of implementing a project, or in terms of the national interest. Briefly, some approaches will be mentioned.

Rules to prohibit use of natural gas by industry or make its supply interruptible have been suggested. The risk of this occurring and the concomitant costs of rapid conversion to more expensive fuel sources, or the costs of temporary shutdowns of a plant with loss of income, can be roughly estimated. If ATES decreases or eliminates the risks these costs can be included as a benefit or as a reduction in the cost side of Equation 5-2.

Reductions in pollution control costs can be included. These are usually proportional to the peak capacity of the source, which ATES may reduce.

The Federal Environmental Protection Agency and various States have considered or authorized pollution offsets, or energy conservation offsets. For example, a reduction in pollution emissions from one part of a plant may facilitate obtaining permits to expand another part of a plant if the resulting new emissions are less than the reductions and if air quality standards are met. Credit for reduced emissions from a cogeneration system including ATES can be 
expressed in part in terms of the increased costs for alternative ways of meeting the air quality standards.

Desired reliability of a system often requires redundancy (e.g., three units each of one-half peak capacity) or reserve standby capacity. ATES may mitigate the need for such equipment if there are multiple well-pairs in the system.

Use of coal and nuclear power instead of imported oil is in the national interest - for security of supply, improved national defense, and increased economic stability. While difficult to translate into benefits to a single project, the increased market potential for heat supplied by coal or nuclear centralized sources instead of dispersed oil-burning units in areas where coal is not permissible can be considered. Both the comparative economics of the fuels and the incentives that may be provided by the local planning and taxing authorities can increase the benefits.

\section{COST ALLOCATION}

Much attention is paid in the literature to the question of allocation of costs to electricity and heat where these are joint products (United Engineers, 1979; Ernst \& Ernst, 1978; Kidder Peabody \& Co., 1979). Basically, the problem is to select a point on the joint-products cost curve. As Ernst \& Ernst (1978) indicate, "... allocation is unnecessary to feasibility decisions, because such decisions should be made only on the basis of incremental cost data. The relevant incremental costs can be determined in all cases without reference to an allocation."

The motivation for cost-allocation is institutional, rather than technical or economic. Regulatory constraints, market considerations, financing methods, and policies may make a cost allocation necessary before a system can be implemented.

Some cost elements, fixed and variable, are clearly chargeable to electricity generation only, e.g., the condenser and cooling towers, alternator, switchgear, and distribution. Some cost elements 
are clearly chargeable only to heat, such as the fixed and variable costs of peaking boilers, heat exchangers, and thermal transport systems. Some costs serve both functions, such as the steam supply, fuel, and plant facilities. The principal problem is the allocation of the latter class of costs.

One aspect of the problem is the division of the benefits of cost savings among the ultimate users of the heat, power, and other joint products. When the generator and the user of all products is one entity the problem should be minimal, except perhaps for tax or financing advantages. Where either heat or power are exported to multiple users, regulatory requirements enter in the case of utilities, and the market elasticity for the several products in the case of industry.

United Engineers (1979) describe in detail eight methods of cost allocation. In an example costs range from $(E=13.78 \$ / \mathrm{MWh}$; $H=2.33 \$ / G J)$ to $(E=19.07 \$ / M W h ; H=1.2 \$ / G J)$ where the cost of separate generation is $(E=19.06 \$ / M W h ; H=2.09 \$ / G J)$. Most but not all of the methods give results that price both products within the range where each is less than the cost of separate generation.

One common method for utility decisionmaking is to assume the cost of electricity is the same as that of separate generation, and examine the resulting cost of heat for market viability. Since a low generation cost of heat permits higher distribution costs, the available market is increased. On the other hand, industries primarily interested in process heat, but considering cogeneration, consider the cost of heat as unchanged but examine the incremental "heat chargeable to power" to determine the cost of cogenerated electricity as compared to purchased electricity.

Kidder and Peabody (1979) examine in detail many of the institutional and financial alternatives when a large project involves multiple parties in the investment and operation as well as multiple end users, some of whom are also investors. Complex financing methods may prove advantageous to balance the benefits to all participants. 
While the tendency may be to include ATES and its associated components as clearly part of the heat generation system, the cost of electricity may also be benefited. Cost allocation considerations should play a minimal role in initial comparison of concepts and in decisions of economic viability. 
CHAPTER 6

EVALUATION: AN EXAMPLE

This chapter will attempt to integrate the preceding chapters, or "put it all together" with a step-by-step example. A single example cannot cover all options and problems; it is only illustrative. The application and data used are fictitious, but numbers used are believed to be reasonable, considering the uncertainties in any future planning in an immature technology.

\section{CHOSEN APPLICATION}

The example describes an application by the United Electric Co. in an unnamed midwestern city of about 500,000 population: The utility in 1979 had on-1 ine electric generation capacity rated at $7.1 \mathrm{GW}$, produced 35.5 TWh for an approximate annual load factor of 0.57 . This utility also has a district heating system in the downtown area distributing steam to about 500 commercial and industrial customers. The annual output of steam was $2.1 \mathrm{PJ}$ (580 GWh, 1800 million pounds of steam), at an average rate of $66 \mathrm{MW}$ and a peak hourly sendout of 300 MW in 1979.

The principal fuel used in the five largest electric generating units, totaling $5.7 \mathrm{GW}$, is high-sulfur midwestern coal in all but the newest one which was designed for low-sulfur Western coal. The utility requires expansion during the 1980s and would like to install over ten years a $500 \mathrm{MW}$ or two $300 \mathrm{MW}$ mid-range cycling coal plants at a site that now contains two small older units, rated 70 MW and 55 MW (electric) which currently burn oil or natural gas (interruptible) for summer peaking, operating only about 1000 hours a year.

The district heating system also burns oil as its principal fuel, consuming 3.5 PJ (about half a million barrels) annually. 
The State Energy Commission has required, as a precondition for permits on the new electric generation desired, that the United Electric Co. consider cogeneration, conversion from oil to coal wherever possible, and reduction of emissions by use of low-sulfur coal.

The desired plant site is located $25 \mathrm{~km}$ from the downtown district heating system, which cannot convert to coal. There is a dense commercial/light industrial/residential area called Panalville about one-third the way between the plant site and downtown. Space heating and tap water heating in this area are served by individual sources, about two-thirds oil and one-third natural gas.

Among the concepts the United Electric Co. decides to analyze is supplying district heating to Panalville by cogeneration using some combination of the present units and the desired new units at the plant site. There are many variants and options from which this example must select one or two as illustrations of the method of analysis. They include:

- Use extraction turbine design in new coal-fired plant to provide district heating to Panalville. Use no ATES. Steam from the oil-fired boilers of the existing (55 and $70 \mathrm{MW}$ ) units can be used as thermal energy backup for reliable operation of the DH system.

- Same as above but with ATES, less backup needed.

- Convert existing 70 and $55 \mathrm{MW}$ units to non-condensing operation for added DH capacity (with and without ATES).

- Extend DH transmission to downtown as a second phase, to displace part or all the oil consumption there. Convert steam end uses to HTW end uses wherever possible. Consider ATES both at Panaiville and downtown.

- Supply industrial customers in Panalville with higher temperature HTW for wider range of applications. Use blending of sendout and return water to serve residences at a safe temperature. 
Clearly, the first two of these are the initial phase to consider and most relevant to screening concepts for ATES applicability.

\section{DATA GATHERING}

While this example is hypothetical, the best available numbers have been used. For convenience they come from a variety of unrelated sources so further identifying this midwest city is not relevant.

Data must be gathered on the source(s), the load(s), the transport needs, and the mismatch which ATES might mitigate.

\section{Sources}

The sources of heat considered are the existing boilers for 70 and $55 \mathrm{MW}_{\mathrm{e}}$ units, and a new $300 \mathrm{MW}_{\mathrm{e}}$ coal-fired unit with extraction turbine (several stages of extraction for efficiency). Temperature of HTW may be designed to be whatever is optimum, up to about $200^{\circ} \mathrm{C}$ $\left(400^{\circ} \mathrm{F}\right)$. The two small units are old and when used for peaking have had a heat rate of $4.1 \mathrm{~J}_{\mathrm{t}} / \mathrm{J}_{\mathrm{e}}(14,000 \mathrm{Btu} / \mathrm{kWh})$; thus their fuel input is $512 \mathrm{MW}$, and at 85 percent boiler efficiency up to $435 \mathrm{MW}$ of steam or HTW can be available. The proposed new cycling coal plant with 300 MW electrical output can be expected to have a heat rate of $3.03 \mathrm{~J}_{\mathrm{t}} / \mathrm{J} \mathrm{e}(10,300 \mathrm{Btu} / \mathrm{kWh})$ and a boiler efficiency of 88 percent. A rating of $16.6 \mathrm{MPa} / 538^{\circ} \mathrm{C} / 538^{\circ} \mathrm{C}$ (i.e., $1000^{\circ} \mathrm{F}$, single reheat, 2400 psig) could give the cogeneration performance shown in Figure 5-1; per $M W$ of heat extracted, the loss of electric output at $100^{\circ} \mathrm{C}$, $150^{\circ} \mathrm{C}$, and $200^{\circ} \mathrm{C}$ sendout temperature is $0.10,0.15$, and 0.21 . It should be feasible to extract $150 \mathrm{MW}$ at $100^{\circ} \mathrm{C}, 200$ and $300 \mathrm{MW}$ at $150^{\circ} \mathrm{C}$ and $200^{\circ} \mathrm{C}$ without exceeding turbine design limits.

\section{Load Demands}

THERMAL. Survey of Pana?ville population and load density shows a variation in thermal peak loads from 10 to $70 \mathrm{MW} / \mathrm{km}^{2}$. There is $1.5 \mathrm{~km}^{2}$ with a load of $55 \mathrm{MW} / \mathrm{km}^{2}, 4$ more at $40 \mathrm{MW} / \mathrm{km}^{2}$, and 15 more at over $25 \mathrm{MW} / \mathrm{km}^{2}$. In any application, there is uncertainty as to what the market will be until the benefits to the many distinct customers can be determined. The survey shows a number of the large 
users in the dense area would be interested if the payback to them was reasonable, i.e., three to five years.

For the initial iteration 70 percent connection in the central zone and 50 percent in the less dense regions will be assumed. This totals $360 \mathrm{MW}$, sum of the peak loads, but not necessarily the peak coinciding loads. Diversity of peak loads may give approximately 300 MW peak demand.

The daily and seasonal demand for the climate in Panalville (Figure 6-1) is similar to that portrayed by Margen (1979b) for the Twin Cities in Minnesota. Figure 6-1 shows the monthly average, maximum and minimum, related to the annual average, 1.0 on the lefthand scale. Some idea of the daily swings is given by the shaded area. This much variation of demand could be mitigated by daily storage instead of or in addition to ATES, if economically desirable.

ELECTRIC. The electric load demands of the United Electric Co. system are of peripheral interest in indicating the load patterns, seasonal and daily, which determine the dispatching requirements on the utility and its needs for mid-range and peaking capacity as well as baseload capacity. It also indicates the mismatch between district heating and electric loads, which may affect the benefits from ATES.

Figures 6-2 to 6-7 show the weekly pattern of electric demand in the spring/fall, the summer, and the winter seasons. Table 6-1 illustrates the type of data accumulated that is plotted as the hourly variation of load over a week, and the condensation of the data into a load-duration curve, which indicates the fraction of the time that any particular load demand is exceeded during the quarter. The load demands are normalized to the peak demand within the quarter. Table 6-2 shows the monthly peaks in terms of the annual peaks - a multiplier to the scales on Figures $6-2$ to $6-7$ before combining them into an annual load duration curve. 


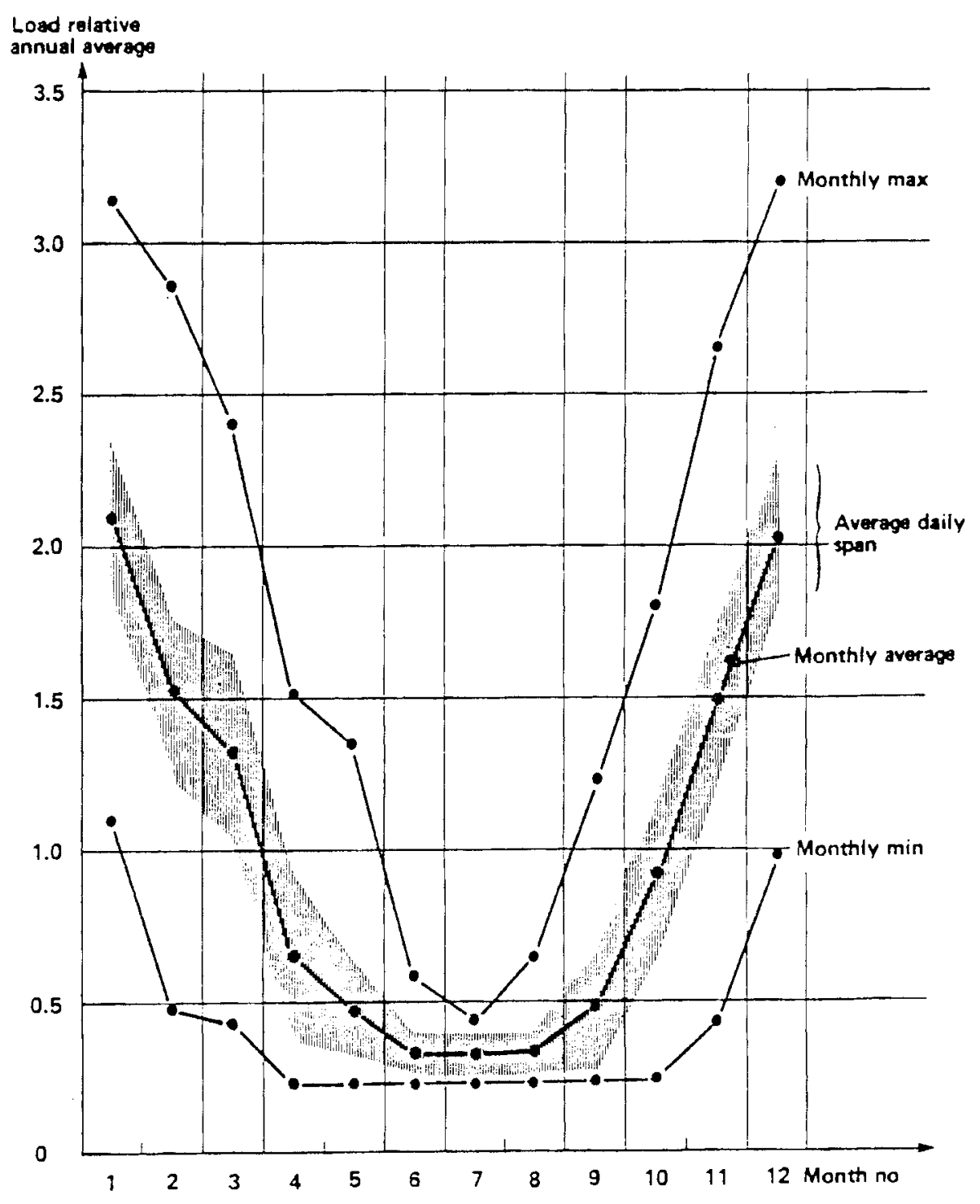

Figure 6-1. Load fluctuations for district heating system. (Source: Studsvik Energiteknik AB) 


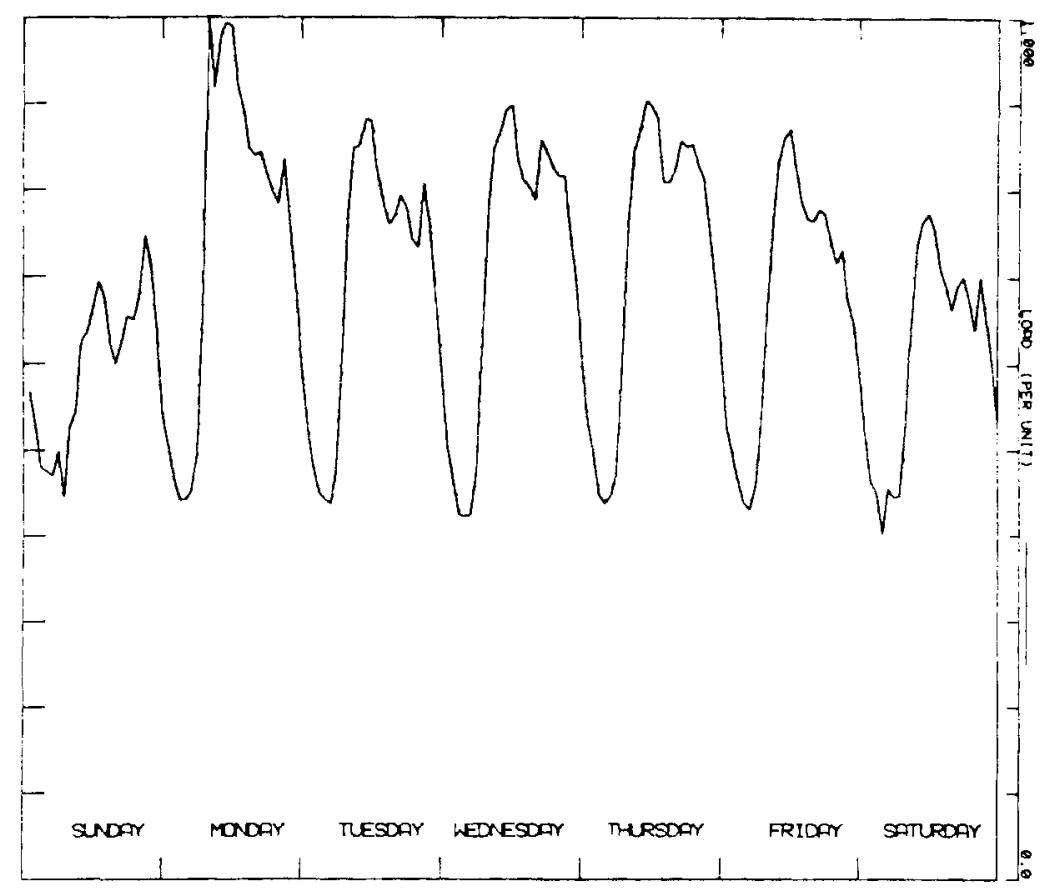

Figure 6-2. Scenario C - spring/fall weekly load cycle plot. (Source: Zaininger, 1977)

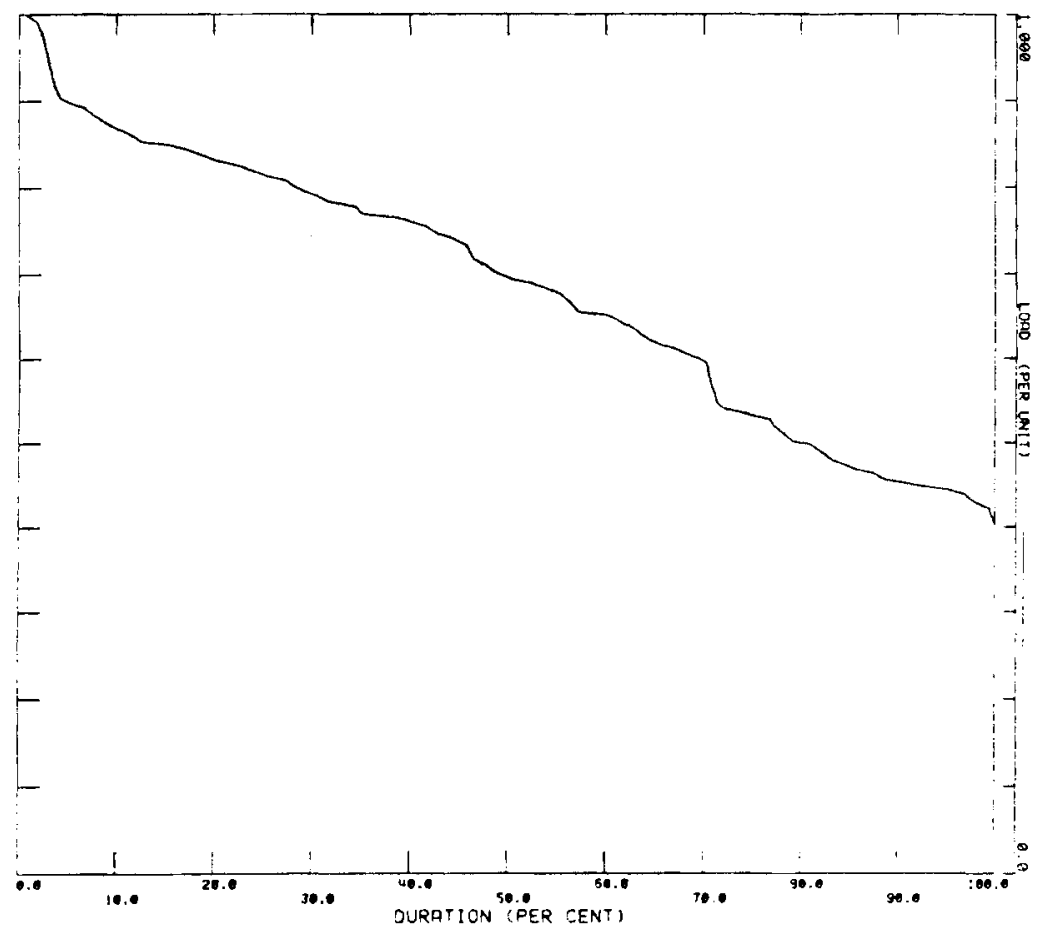

Figure 6-3. Scenario C - spring/fall load duration curve. (Source: Zaininger, 1977) 


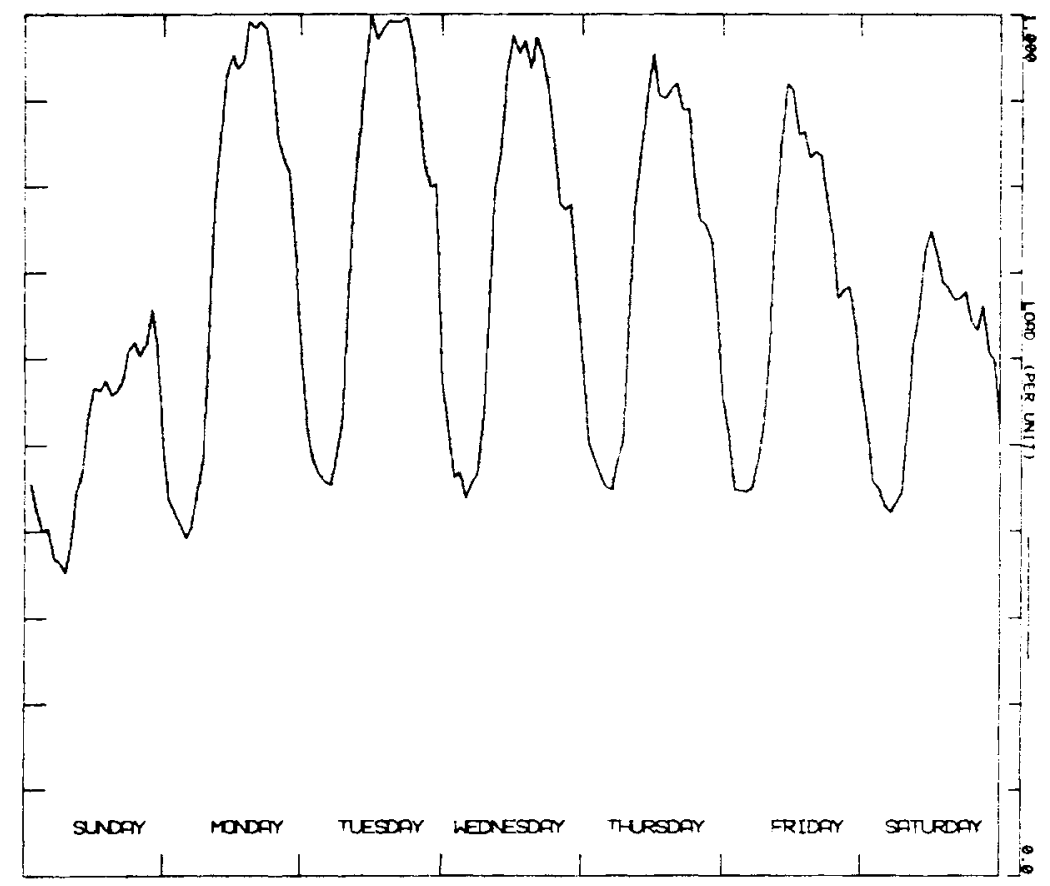

Figure 6-4. Scenario C - summer weekly load cycle plot. (Source: Zaininger, 1977)

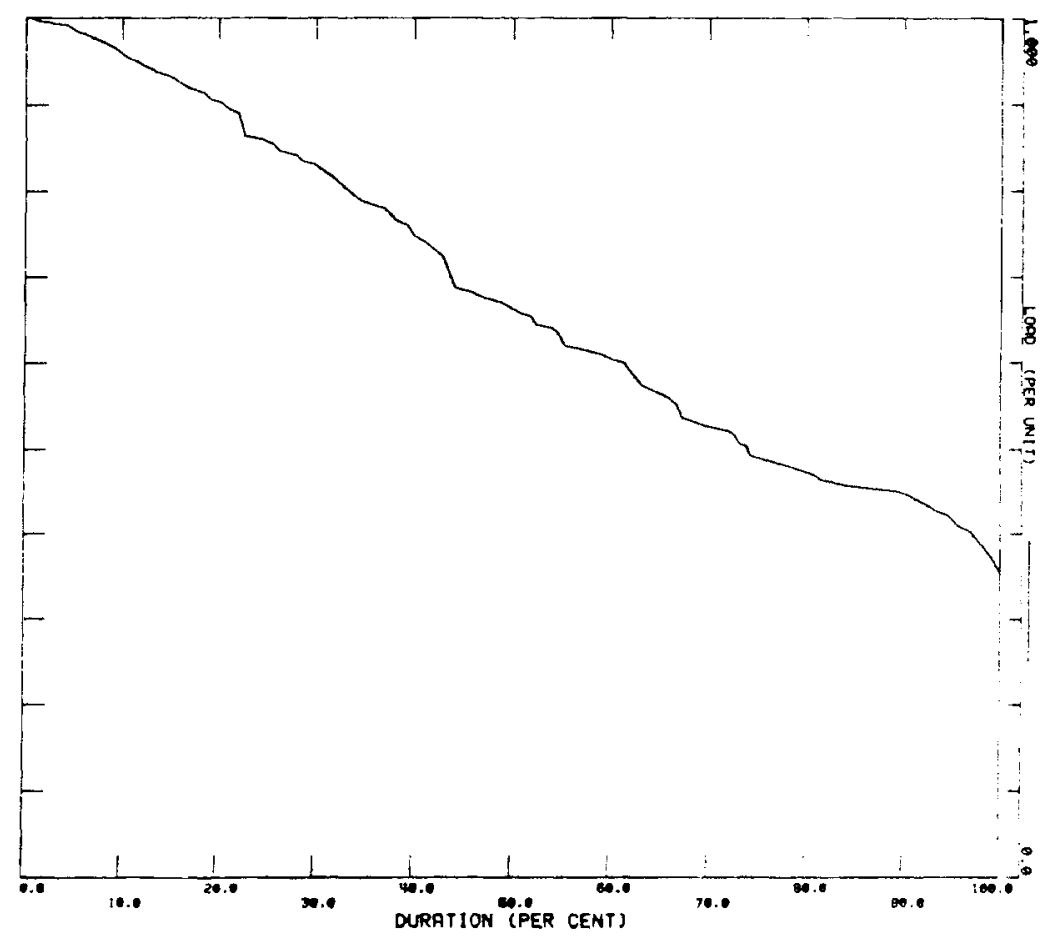

Figure 6-5. Scenario C - summer load duration curve. (Source: Zaininger, 1977) 


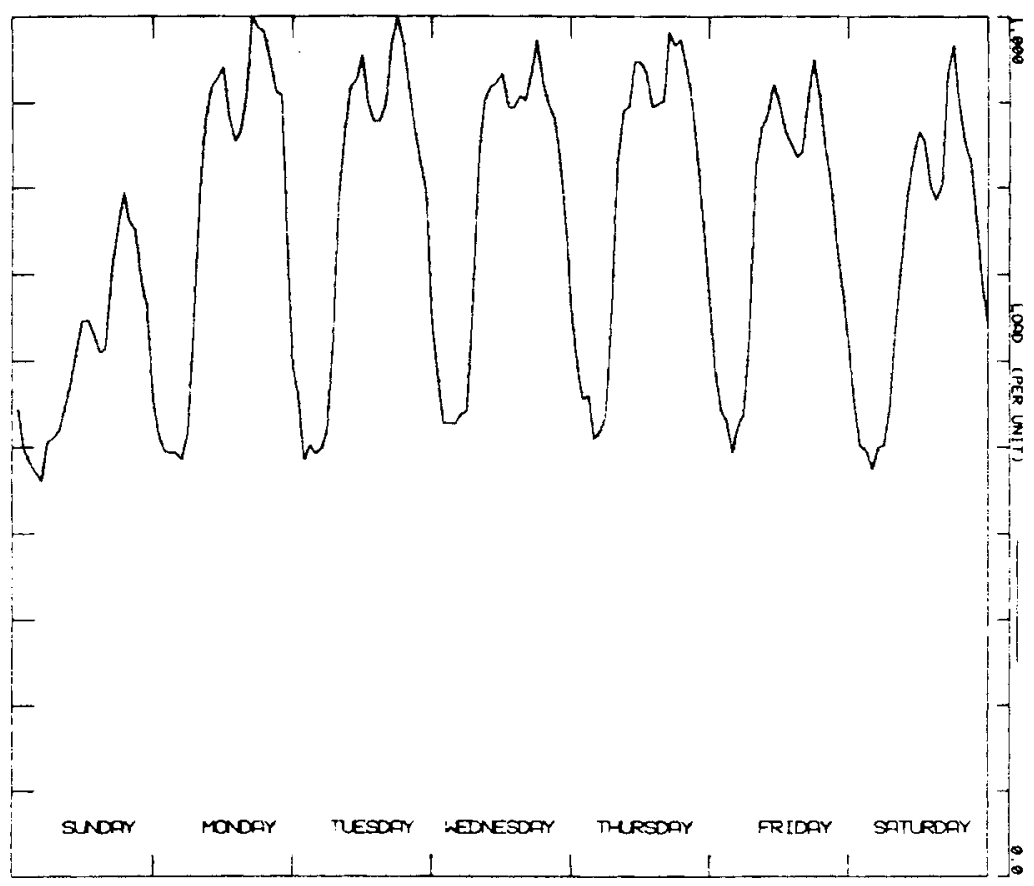

Figure 6-6. Scenario C - winter weekly load cycle plot. (Source: Zaininger, 1977)

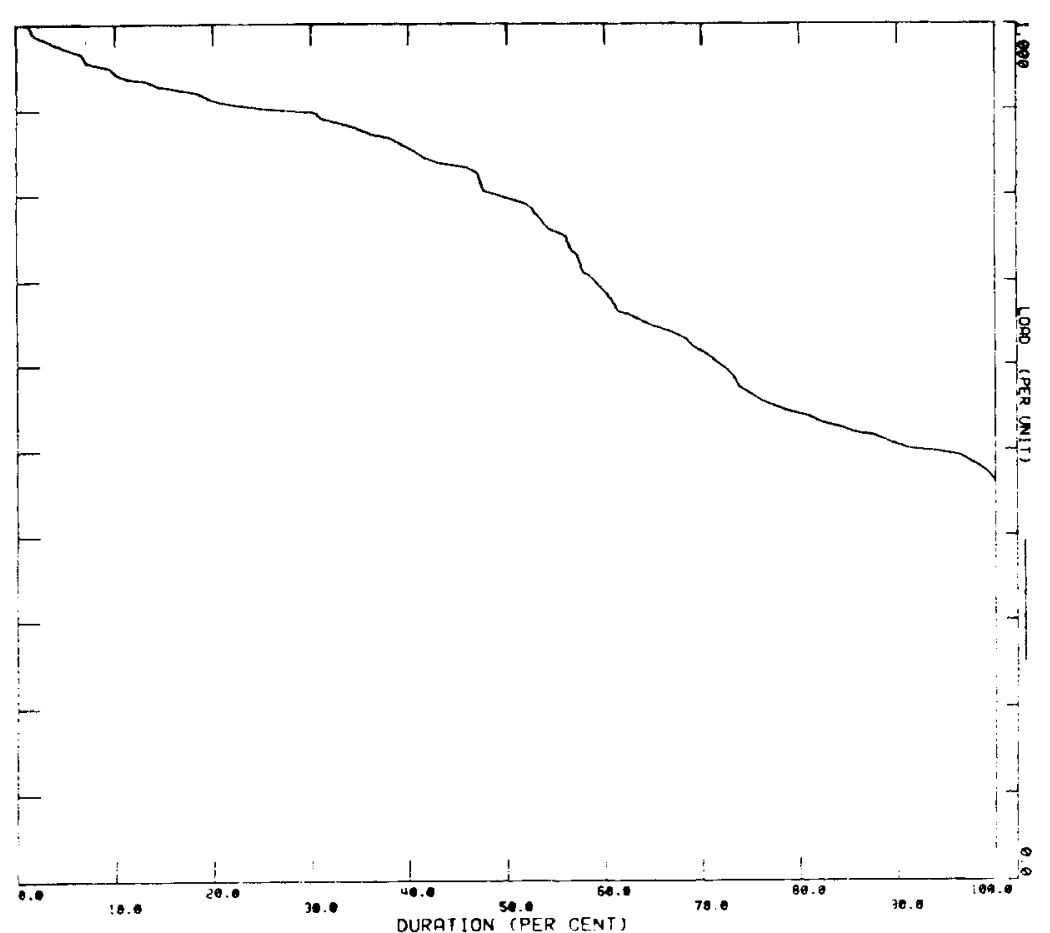

Figure 6-7. Scenario C - winter load duration curve. (Source: Zaininger, 1977) 
Tabie 6-1. Scenario C - winter weekly load cycle and load duration data tabulation.

\begin{tabular}{|c|c|c|c|c|c|c|c|}
\hline TIME & SUTNDAY & $\begin{array}{l}\text { TYP ICA } \\
\text { MONDAY }\end{array}$ & $\begin{array}{l}\text { WEEK - } \\
\text { TUESDAY }\end{array}$ & $\begin{array}{l}\text { IOURLY LOADS } \\
\text { KEDNESDAY }\end{array}$ & $\begin{array}{l}\text { IN PU } \\
\text { THURSDAY }\end{array}$ & FRIDAY & SATURDAY \\
\hline $\begin{array}{l}100 \\
200 \\
300 \\
400 \\
500 \\
600 \\
700 \\
300 \\
900 \\
1600 \\
1100 \\
1200 \\
1300 \\
1400 \\
1500 \\
1600 \\
1700 \\
1800 \\
1930 \\
2000 \\
2100 \\
2200 \\
2300 \\
2400\end{array}$ & $\begin{array}{l}0.5443 \\
0.4988 \\
0.4320 \\
0.4709 \\
0.4613 \\
0.5060 \\
0.5108 \\
0.5188 \\
0.5467 \\
0.5746 \\
0.6145 \\
0.6464 \\
0.6464 \\
0.6305 \\
0.6089 \\
0.6145 \\
0.7063 \\
0.7502 \\
0.7941 \\
0.7606 \\
0.7502 \\
0.6927 \\
0.6632 \\
0.5571\end{array}$ & $\begin{array}{l}0.5172 \\
0.4956 \\
0.5932 \\
0.4932 \\
0.4352 \\
0.5172 \\
0.6305 \\
0.7901 \\
0.8779 \\
0.9178 \\
0.9282 \\
0.9417 \\
0.8367 \\
0.8547 \\
0.8543 \\
0.9122 \\
1.0906 \\
0.9372 \\
0.9816 \\
0.9497 \\
0.9122 \\
0.9090 \\
0.7242 \\
0.5938\end{array}$ & $\begin{array}{l}0.5555 \\
0.4844 \\
0.5020 \\
0.4924 \\
0.4288 \\
0.5172 \\
0.6265 \\
0.7901 \\
0.8599 \\
0.9170 \\
0.9274 \\
0.9553 \\
0.0986 \\
0.8779 \\
0.8779 \\
0.8978 \\
0.9657 \\
0.9992 \\
0.9721 \\
0.9178 \\
0.8599 \\
0.8284 \\
0.7957 \\
0.6504\end{array}$ & $\begin{array}{l}0.5366 \\
0.5267 \\
0.5275 \\
0.5267 \\
0.5371 \\
0.5411 \\
0.6544 \\
0.8380 \\
0.9018 \\
0.9178 \\
0.9226 \\
0.9338 \\
0.8939 \\
0.8939 \\
0.9374 \\
0.9018 \\
0.9338 \\
0.9737 \\
0.9218 \\
0.8978 \\
0.8393 \\
0.3316 \\
0.7534 \\
0.6584\end{array}$ & $\begin{array}{l}9.5946 \\
0.5547 \\
0.5587 \\
0.5692 \\
0.5188 \\
0.5339 \\
0.6600 \\
0.6324 \\
0.8591 \\
0.8947 \\
0.9481 \\
0.9465 \\
0.9346 \\
0.8939 \\
0.5978 \\
0.9018 \\
0.9816 \\
0.9657 \\
0.9737 \\
0.9377 \\
0.6978 \\
0.8260 \\
0.7574 \\
0.6768\end{array}$ & $\begin{array}{l}0.5898 \\
0.5435 \\
0.5307 \\
0.4932 \\
0.5227 \\
0.5387 \\
0.6335 \\
0.8244 \\
0.8599 \\
0.8343 \\
0.9210 \\
0.9010 \\
0.8559 \\
0.8532 \\
0.8356 \\
0.8412 \\
0.9058 \\
0.9497 \\
0.9018 \\
0.8436 \\
0.7965 \\
0.7302 \\
0.6784 \\
0.6209\end{array}$ & $\begin{array}{l}0.5459 \\
0.5012 \\
0.4948 \\
0.4741 \\
0.4996 \\
0.5020 \\
0.5427 \\
0.6355 \\
0.7087 \\
0.7835 \\
0.6324 \\
0.6659 \\
0.8540 \\
0.6021 \\
0.7053 \\
0.6037 \\
0.9322 \\
0.9665 \\
0.6994 \\
0.8508 \\
0.8316 \\
0.7614 \\
0.6935 \\
0.6449\end{array}$ \\
\hline & & & $\begin{array}{l}\text { PICAL LOA } \\
\text { OAD (PU) } \\
1.0000 \\
0.9874 \\
0.9695 \\
0.9485 \\
0.9293 \\
0.9690 \\
0.8933 \\
0.8711 \\
0.8496 \\
0.8312 \\
0.8029 \\
0.7915 \\
0.7610 \\
0.7528 \\
0.7322 \\
0.7075 \\
0.6931 \\
0.6696 \\
0.6495 \\
0.6509 \\
0.6127 \\
0.5912 \\
0.5746 \\
0.5430 \\
0.5305 \\
0.5109 \\
0.4926 \\
0.4687\end{array}$ & $\begin{array}{r}\text { D DURATIO C } \\
\text { DURATION } \\
0.60 \\
2.38 \\
3.57 \\
3.57 \\
5.95 \\
\mathbf{8 . 3 3} \\
\mathbf{8 . 3 3} \\
\mathbf{5 . 3 6} \\
\mathbf{3 . 5 7} \\
\mathbf{5 . 3 6} \\
1.19 \\
\mathbf{4 . 1 7} \\
1.19 \\
2.38 \\
1.19 \\
1.19 \\
1.19 \\
\mathbf{2} .38 \\
3.57 \\
3.57 \\
1.79 \\
2.38 \\
\mathbf{6 . 6 0} \\
\mathbf{5 . 9 5} \\
\mathbf{4 . 7 6} \\
\mathbf{6 . 5 5} \\
\mathbf{7 . 1 4} \\
1.79\end{array}$ & $\begin{array}{l}\text { TIME } \\
\text { TIME) } \\
3 \\
3 \\
3 \\
3 \\
3 \\
3 \\
3 \\
3 \\
3 \\
3 \\
3\end{array}$ & & \\
\hline
\end{tabular}

(Source: Zaininger, 1977) 
Table 6-2. Scenario C - monthly peak data.

\begin{tabular}{|c|c|c|c|}
\hline \multirow[b]{2}{*}{ Month } & \multirow{2}{*}{$\begin{array}{l}\text { Monthly Peak } \\
\text { (P.U. Annual Peak) } \\
\end{array}$} & \multicolumn{2}{|c|}{ Corresponding Load Duration Curve } \\
\hline & & Season & Load Factor (\%) \\
\hline January & 0.84 & Winter & 68 \\
\hline February & 0.81 & Winter & 68 \\
\hline March & 0.75 & Spring/Fall & 70 \\
\hline April & 0.72 & Spring/Fal1 & 70 \\
\hline May & 0.77 & Spring/Fall & 70 \\
\hline June & 0.91 & Summer & 67 \\
\hline July & 0.99 & Summer & 67 \\
\hline August & 1.00 & Summer & 67 \\
\hline September & 0.86 & Spring/Fall & 70 \\
\hline October & 0.78 & Spring/Fall & 70 \\
\hline November & 0.83 & Spring/Fall & 70 \\
\hline December & 0.88 & Winter & 68 \\
\hline
\end{tabular}

United Electric Co. is a summer peaking utility with an annual load factor of 57 percent. Its generation plant description includes five coal-fired plants of 1241, 1241, 1241, 1100, and $923 \mathrm{MW}_{e}$; three oil- and gas-fired steam plants of 474, 70, and $55 \mathrm{MW} ; 700$ MW hydroelectric capacity (with capability of pumped storage); and a $75 \mathrm{MW}$ gas turbine. One of the $1241 \mathrm{MW}$ plants is collocated with the 70 and $55 \mathrm{MW}$ plants, at the desired site for the new $300 \mathrm{MW}$ unit.

TRANSPORT. There is a transmission (electric) right of way from the site to a substation near Panalville; the terrain is principally flat and agricultural, with suburban residential for the last $2 \mathrm{~km}$. This corridor is the preferred route for a dual-pipeline for HTW sendout and return. A $1 \mathrm{~km}$ stub is needed to a distribution network branching into Panalville. The transmission corridor continues to within $3 \mathrm{~km}$ of the downtown area, but is more densely populated. This consideration applies only to future expansion to serve the downtown area.

AQUIFER AVAILABILITY. In the United Electric Co.'s service area, and particularly near Panalville, there is evidence that there are numerous confined aquifer layers down to 400 meters, but data on 
their properties is sparse below 150 meters. The water table is at about $20 \mathrm{~m}$ depth and the upper unconfined aquifer (Alpha) extends down to $60 \mathrm{~m}$. At least four distinct aquifers below this alternate with confining layers of siltstone and shale. Their tops are roughly: Beta, $70 \mathrm{~m}$; Gamma, $120 \mathrm{~m}$; Delta, $180 \mathrm{~m}$; and Epsilon, $220 \mathrm{~m}$ depth.

The Alpha and Beta aquifers are widely used for irrigation and community water supply. The Gamma aquifer is sparsely used as yet within a $20 \mathrm{~km}$ radius of the site. The Delta and Epsilon are brackish, too saline for potable water, so are little explored except for a few USGS test holes.

The Gamma aquifer would be the preferred aquifer, with those below as backup if aquifer conditions are not suitable or permits cannot be obtained for the Gamma aquifer.

Estimated properties from best available information from the nearest several wells in this aquifer are that the aquitard above it is 10 meters thick and the thickness of the Gamma aquifer is 40 to 45 meters. The static water level is at $30 \mathrm{~m}$ depth, providing $90 \mathrm{~m}$ head in the aquifer. Water quality is good, ranging from 250 to 350 $\mathrm{mg} / 1$ iter of dissolved solids, hardness $200-300 \mathrm{mg} / 1$ iter, $\mathrm{pH}=7.0$ to 7.5. Estimated natural pore velocity (regional flow) is $0.06 \mathrm{~m} /$ day.

Although it may vary from point to point the hydraulic conductivity is estimated as 6 to $8 \mathrm{~m} /$ day $\left(150\right.$ to $\left.200 \mathrm{gpd} / \mathrm{ft}^{2}\right)$. The ambient water temperature is about $13^{\circ} \mathrm{C}\left(55^{\circ} \mathrm{F}\right)$. The specific permeability of the sandstone is about three darcys and its porosity about 0.26.

\section{CONCEPT DEFINITION}

Comparison is required of systems with and without ATES which deliver heat from a $300 \mathrm{MW}$ (electric) coal-fired cogeneration plant to a new area. The system without ATES is the reference case, identified as Concept A. The system with ATES is Concept B. Also required is a description of the existing situation - the current usage of gas and oil fuel in dispersed individual furnaces and heaters for space- and water-heating in the selected district-heating area, Panalville. This description is Concept C. 
Diagrammatically, the three concepts can be represented as shown in $A, B$, and $C$ in Figure 6-8. The balance of the United Electric Co.'s electric generation and transmission system other than that at the site of the new $300 \mathrm{MW}$ plant is of interest only as a user or receiver of the electricity generated at the site. The 55 and $70 \mathrm{MW}$ plants are already there, and the basic equipment of the new 300 MW plant is assumed in all three concepts. It is only necessary to consider incremental changes in equipment and operation to compare concepts.

For the level of connection assumed, the peak heat load delivered to end users was taken as $300 \mathrm{MW}$. Using the monthly load data of Figure 6-1, the average annual load is about $95 \mathrm{MW}$; the capacity factor is about 0.31; and the annual load demand is $3.0 \mathrm{PJ}$ ( $830 \mathrm{GWh}$ ) corresponding to $95 \mathrm{MW}$ average rate.

For a first iteration at least, a thermal energy loss of 11 percent will be assumed; about 4 percent in the $10 \mathrm{~km}$ transport pipe1 ine, from plant to substation plus a $1-\mathrm{km}$ stub to Panalville, and 7 percent in the local distribution. About $105 \mathrm{MW}$ is required at the sendout as an average; the peak will not rise 11 percent, but only $10 \mathrm{MW}$ because the loss rate is constant over the year if the temperatures of sendout and return are constant. The transport pipeline must be rated for $310 \mathrm{MW}$ sendout (concept $A$ ), and the cumulative capacity of the distribution network must similarly carry $306 \mathrm{MW}$ (less by the transport losses).

The monthly energy demands at various points, for Concepts $A$ and $B$, are shown in Table 6-3. The average monthly demand in MW is derived from the average annual demand of $95 \mathrm{MW}$ and the data of Figure 6-1. Al1 months are considered equal (30.44 days) for convenience. For Concept $A$ the transport pipeline, and the cogeneration source, must be designed for an annual peak of $310 \mathrm{MW}$ and an average sendout of 105 MW to take care of transport and distribution losses. This is shown in column 2. Annual energy delivered to the transport pipeline is $3.31 \mathrm{PJ}$. 


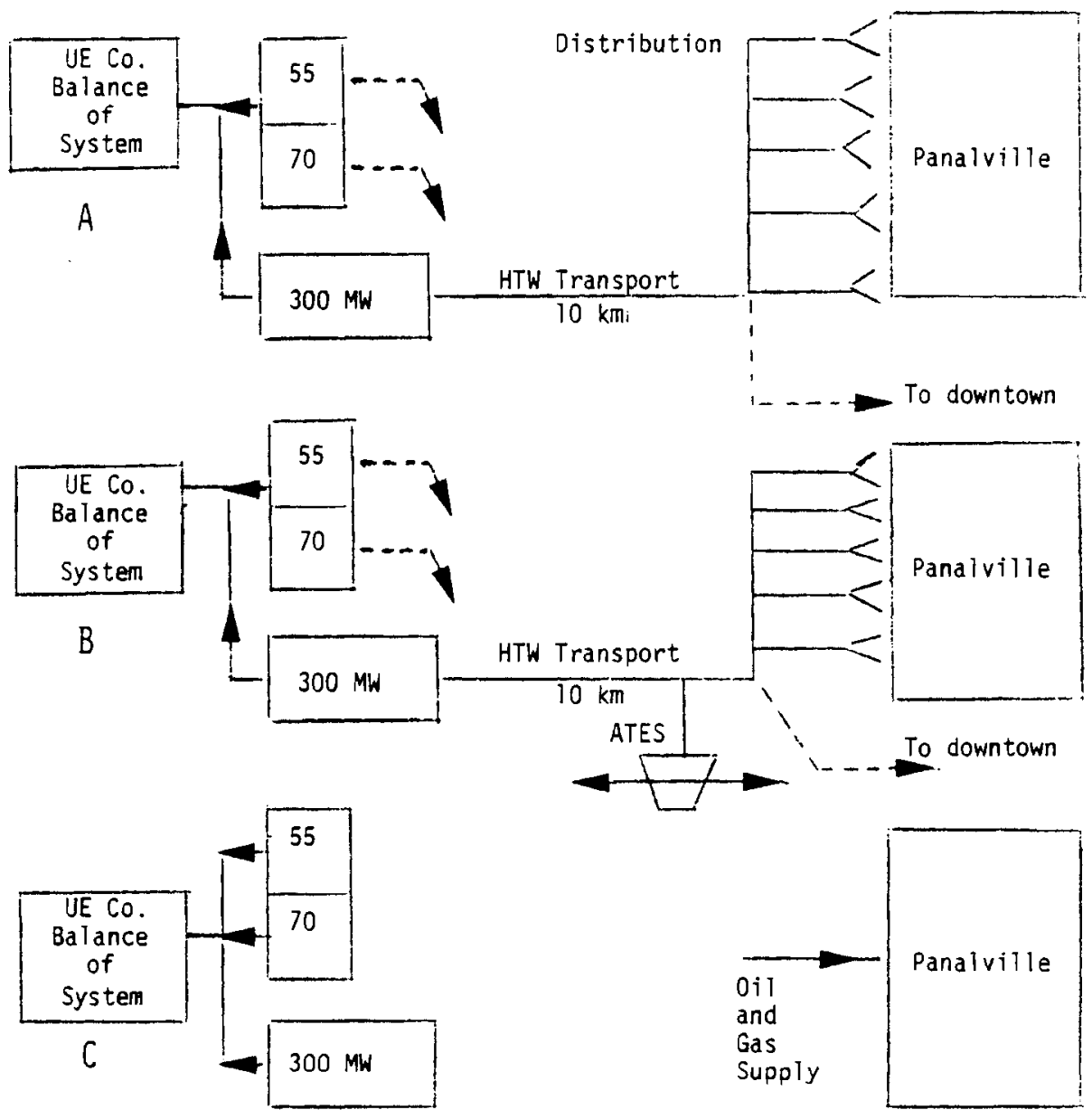

Figure 6-8. Alternative concepts defined. 
Table 6-3. Demand scheduling for Concepts A and B.

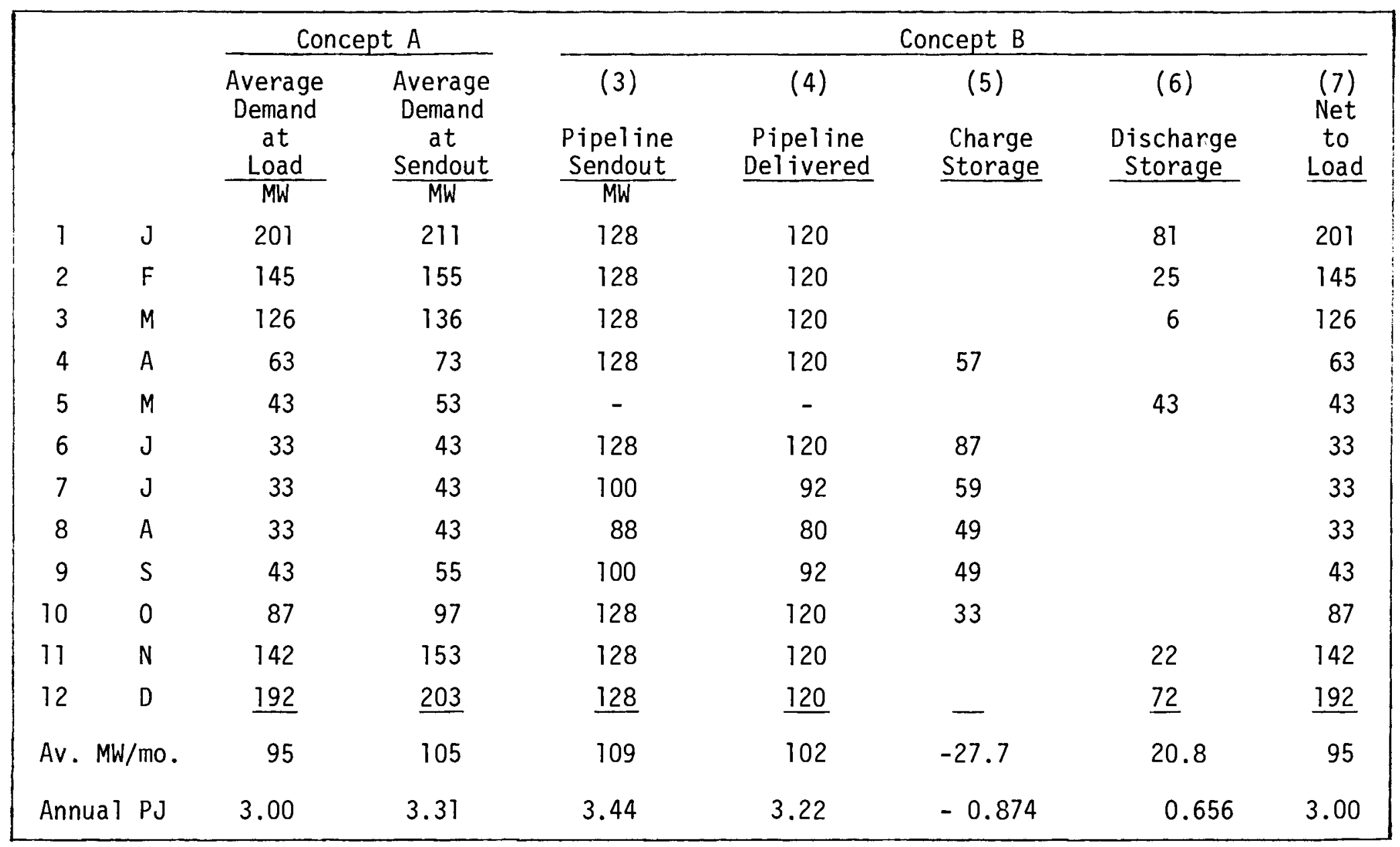


Describing the annual cycle for Concept $B$ requires some iteration; one consistent plan to deliver the same net energy to the load is shown in columns 3 through 6 . Starting with column 4 , the use of ATES storage permits the pipeline to deliver a fairly uniform $120 \mathrm{MW}$ through most of the year. While distribution losses will be the same as in Concept $A$, transmission losses will be less, say only 2 percent, since a smaller pipeline, peak rated 128 or $130 \mathrm{MW}$ can be used, operated at a much higher capacity factor. While in theory storage would permit the pipeline to operate at $C F=1.0$, uniform output all year, provision for maintenance and forced outages of the source and pipeline should be made, and consideration given to the need for maximum electric output in mid-summer peak hours. In the iteration shown, for one low-demand month (May) the pipeline and source may be shut down completely. Further, in the months July, August, and September, pipeline transport is reduced to zero for six to eight hours a day to provide more electric output during peak hours. These choices are only meant to be illustrative of the flexibility provided by storage.

During months when the pipeline capacity exceeds the demand, energy is charged into storage. During months when the demand exceeds the pipeline delivered energy, energy is discharged from storage. A storage efficiency of 0.75 is assumed as the total energy recovered; 0.656 PJ in column 6 is 25 percent less than the $0.874 \mathrm{PJ}$ charged into storage. After a number of cycles, the energy recovery efficiency is expected to be greater than this.

For Concept $C$ of course, the same average energy per month and annual total of $3.00 \mathrm{PJ}$ are required as are shown in columns 1 and 7 . However, the efficiency of the furnaces/heaters used to provide this energy is not unity. Fuel distribution of one-third gas and twothirds oil was indicated earlier. Assuming that oil is used in the larger installations at 70 percent efficiency, and gas in residential and small commercial installation at 50 percent efficiency, the $3.00 \mathrm{PJ}$ demand will require 1.6 PJ of gas and $3.2 \mathrm{PJ}$ of 011 , totaling 4.8 PJ (Meyer, Hausz, et al, 1976). 
ECONOMIC ANALYSIS

Concept C (Existing Situation)

To use Concept $C$ as a starting point, its fixed and variable costs must be estimated. The inflation and escalation scenario described in Chapter 5 will be used. One remaining important parameter is the year of initial operation of the concepts to be compared. While Concept $C$ is already in operation, Concepts A or B would take some years to implement. For this example, base-year 1985 will be assumed for all three concepts, and a system life, $\mathrm{N}$, of 30 years.

Mid-1980 dollars will be used. For items that escalate at the general inflation rate, de-escalation of costs at 6 percent back to 1980 will give the same cost as in 1980. For items with a net escalation of say 2 percent a year, de-escalation from 1985 to 1980 gives a cost 10.4 percent $\left(1.02^{5}\right)$ higher than in 1980 .

FUEL COSTS. Fuel costs are found as:

$0 \mathrm{il}: 3.2 \mathrm{PJ} \times 6 \$ / \mathrm{GJ} \times 10^{6} \times 1.02^{5} \times 2.46=52.14 \mathrm{million} \$ / \mathrm{yr}$ where 2.46 is the levelizing factor $\operatorname{LF}(30,2.0,10)$. (Table 5-4.) Gas: 1.6 PJ $\times 2.50 \$ / G J \times 10^{6} \times 1.05^{5} \times 3.84=19.60 \mathrm{mill} 1$ ion $\$ / \mathrm{yr}$ where 3.84 is the levelizing factor.

These total $\$ 71.74$ million/year. The large-quantity or industrial price of fuels was used; many of the consumers would pay considerably more. It is difficult to estimate annual operating and maintenance costs on the complex of large and sma11 space heating and water heating equipment. These omissions can be traded off against comparable omissions in the other concepts.

FIXED COSTS. While the area of Panalville already has heaters and furnaces in place, they have been in operation for various periods of time, and some must be replaced each year. The total peak demand is $360 \mathrm{MW}$; if the average life for complete replacement or its equivalent in major repairs is 15 years, the replacement rate is $24 \mathrm{MW} /$ year. A mid-1980 installed cost of $30 \$ / \mathrm{kW}$ is estimated, and 
is assumed to have no net escalation. The stream of annual replacement costs can be levelized by using $\operatorname{LF}(30,0,10)=1.89$.

Capital Replacement: $24 \times 10^{3} \times 30 \$ / \mathrm{kW} \times 1.89=\$ 1.36 \mathrm{mi} 11 \mathrm{ion} / \mathrm{yr}$.

With this small addition, the total annual costs for Concept $C$ are $\$ 73.10$ million.

Concept A (Reference Case)

In treating Concepts $A, B$, and $C$ it is assumed that the $300 \mathrm{MW}$ (electric) coal plant is built, is common to all three concepts, and goes on line in 1985. In Concept $C$ it generates electricity only; in Concepts $A$ and $B$ it cogenerates heat and electricity. Only the incremental fixed and variable costs need be considered.

HEAT EXTRACTION. For extraction of thermal energy from the turbogenerator, and for transport of the energy, a sendout and return temperature must be selected. As a first iteration, $150^{\circ} \mathrm{C}\left(300^{\circ} \mathrm{F}\right)$ sendout and $80^{\circ} \mathrm{C}\left(176^{\circ} \mathrm{F}\right)$ are chosen. It was indicated on page $6-3$ that $200 \mathrm{MW}$ thermal may be the maximum allowable, from turbine constraints, at this temperature and at the equivalence factor of 0.15 shown in Figure $5-1$. (More can be extracted at a penalty in equivalence factor.) In this example, $200 \mathrm{MW}$ of extraction capacity will be provided, and use of the existing oil-fired boilers assumed to supply the required peak output, as well as reserve capacity.

The multiple stages of steam extraction for HTW heating require heat exchangers similar to the condenser and to the lower temperature feedwater heaters. Estimating the average cost in mid-1980 dollars from 1976-dollar data used in earlier studies (United Engineers, 1977; Hall, Hausz, et al, 1979) gives $30 \$ / \mathrm{kW}$, conservatively.

The investment cost, and the annual fixed cost at 0.18 FCR are respectively $\$ 6$ million and $\$ 1.08$ million.

TRANSPORT. For a $10 \mathrm{~km}$ pipeline at this sendout and return temperature, using Figure 3-16and the related text gives an estimate of:

Pipeline: $(10.1 \sqrt{310}+22) \times(170 / 141)=240 \mathrm{k} \$ / \mathrm{km} \cdot \mathrm{yr}$

or $\$ 2.4 \mathrm{million} /$ year for $10 \mathrm{~km}$. 
DISTRIBUTION. The investment cost of the distribution network including connections to consumers may be only roughly estimated without a detailed map showing pipelines of decreasing size fanning out to a street-by-street network, plus data on the other utilities also using these streets. Margen (1979) estimated a network of $58 \mathrm{~km}^{2}$ to cost $\$ 224$ million in 1978 dollars (roughly $\$ 4.8 \mathrm{million} / \mathrm{km}^{2}$ in mid-1980 dollars). The density in his example was about $29 \mathrm{MW} / \mathrm{km}^{2}$; our example is about $15 \mathrm{MW} / \mathrm{km}^{2}$. With the lesser density the cost would be more per MW but less per $\mathrm{km}^{2}$; it would be conservative to estimate $\$ 4$ million $/ \mathrm{km}^{2}$ or $\$ 82$ million for the $20.5 \mathrm{~km}^{2}$ assumed at Panalville. This is an annual fixed cost of $\$ 14.8$ million.

VARIABLE COSTS. The cost of fuel to supply the extracted heat in HTW can be estimated in various ways. The simplest and most direct is use of the equivalence factor, $F_{e}$, to convert the unit cost of electricity lost into unit cost of heat extracted. The most complete and accurate way would be a complete simulation of the whole utility: load simulation, dispatch procedures for meeting load through one or more annual cycles, for alternative cases with and without the district heating system in operation. The comparison would indicate how much of each fuel type was used in each case, and what allowance was necessary in reserve capacity to keep the system reliability the same in both cases. For this example the simpler approach will be used.

With a maximum limit of 200 MW HTW extraction set on the 300 MW cogeneration unit, peak demand must be met by the boilers for the 55 or $70 \mathrm{MW}$ units. It is assumed that no additional equipment is necessary, although the production of HTW at the desired temperature in the economizer and steam generating tubes in these boilers, or the generation of steam subsequently condensed by their feedwater heating train would require pipe, valve, and control modification, perhaps extensive.

The annual load cycle, Figure 6-1, indicates that $200 \mathrm{MW}$ is exceeded by the peak in five months and by the average in two months, 
normalizing to the required average annual demand of $105 \mathrm{MW}$. While monthly load duration curves (cf Figures 6-2, 6-5, 6-7) or an annual load duration curve would be desirable to determine the peaking energy required, it can be noted that the above mentioned figures are reasonably linear from maximum to minimum. On this basis a triangular area represents the energy (MW $x$ time) required each month. As the peak requirement approaches $200 \mathrm{MW}$, both the monthly peak required from the peaking boiler, and the duration that the peak is exceeded decline. The monthly average power required for peaking can be expressed as

$$
P_{p b}=0.25\left(P_{p}-P_{c g}\right)^{2} /\left(P_{p}-P_{a v}\right)
$$

where

$P_{p b}$ is the average power demand on the peaking boiler

$P_{p}$ is the monthly peak demand

$P_{c g}$ is the maximum allowable cogeneration output

$P_{a v}$ is the average power demand for the month (as shown in Figure 6-3).

The computation for the average MW per month, corresponding to the bottom lines in the second column of Table 6-3 is shown in Table $6-4$. The peaking boiler must supply 6.3 percent of the annual energy, or $58 \mathrm{GWh}(0.20 \mathrm{PJ})$ while the cogeneration plant supplies the remaining $862 \mathrm{GWh}(3.10 \mathrm{PJ})$.

Table 6-4. Determination of peaking energy demand.

\begin{tabular}{|c|c|c|c|c|c|c|c|c|c|c|c|c|c|}
\hline Month: & 1 & 2 & 3 & 4 & 5 & 6 & 7 & 8 & 9 & 10 & 11 & 12 & Avg \\
\hline$P_{\partial v}$ & 211 & 155 & 136 & 73 & 53 & 43 & 42 & 43 & 55 & 97 & 153 & 203 & 105 \\
\hline$P_{p}$ & 300 & 275 & 235 & 150 & - & - & - & - & - & 170 & 260 & 310 & \\
\hline$\left(P_{p}-P_{c g}\right)$ & 100 & 75 & 35 & - & - & - & - & - & - & - & 60 & 110 & \\
\hline$P_{p b}$ & 28 & 12 & 3 & - & - & - & - & - & - & - & 8 & 28 & 6.6 \\
\hline
\end{tabular}


The levelized annual fuel cost of the peaking boiler fuel, assuming an 80 percent boiler efficiency for these older units, is

Peaking Fuel: $0.20 \times 10^{6} \times 5.52 \$ / \mathrm{GJ} \times 2.46=\$ 2.72 \mathrm{mill}$ ion $/ \mathrm{yr}$

The fuel cost for the 862 GWh (3.10 PJ) supplied by the cogeneration source involves the multiple products, electricity and heat. If on the one extreme, electricity takes the benefit of cogeneration efficiency, and the cost of fuel for HTW is charged at full cost including a boiler efficiency of 0.88 , the cost is

(1) Cogeneration Fuel: $3.10 \times 10^{6} \times 1.62 \$ / \mathrm{GJ} \times 2.15=\$ 10.8 \mathrm{mi} 11$ ion $/ \mathrm{yr}$

If on the other hand the equivalence factor is 0.15 (page 6-3) and electricity is given none of the credit for cogeneration, the production of 862 GWh of heat will cause an electricity loss of $129 \mathrm{GWh}$, which at a heat rate of $3.03 \mathrm{~J}_{\mathrm{t}} / \mathrm{J}$ e requires $391 \mathrm{GWh}(1.41 \mathrm{PJ})$. This would reduce the cogeneration fuel cost to

(2) Cogeneration Fuel: $\$ 10.8 \times 10^{6} \times 1.41 / 3.10=\$ 4.91 \mathrm{million} / \mathrm{yr}$

As discussed in Chapter 5 , the allocation of costs to multiple products is a complex subject. The more favorable of the above will be used in this example.

Table 6-5. Comparison of Concepts A and C.

\begin{tabular}{|c|c|c|}
\hline & $\begin{array}{c}\text { Concept A } \\
M \$ / y r \\
\end{array}$ & $\begin{array}{c}\text { Concept C } \\
\mathrm{M} \$ / \mathrm{yr}\end{array}$ \\
\hline \multicolumn{3}{|l|}{ Fixed Costs } \\
\hline \multirow[t]{2}{*}{$\begin{array}{l}\text { Heat Exchangers } \\
\text { Transport } \\
\text { Distribution }\end{array}$} & $\begin{array}{r}1.08 \\
2.40 \\
14.80 \\
\end{array}$ & \\
\hline & 18.38 & 1.36 \\
\hline \multicolumn{3}{|l|}{ Variable Costs } \\
\hline \multirow[t]{3}{*}{$\begin{array}{l}\text { Peaking Fuel } \\
\text { Baseload Fuel }\end{array}$} & $\begin{array}{l}2.72 \\
4.91 \\
\end{array}$ & \\
\hline & 7.63 & 71.74 \\
\hline & 25.91 & 73.10 \\
\hline
\end{tabular}


Concept B (ATES Case)

Most of the assumptions in this concept will be the same as for Concept A. The principal difference is the inclusion of ATES to better match the source to the load.

Referring to Table 6-3, the maximum sendout energy required is $128 \mathrm{MW}$. This is the maximum hourly output as well as the average for peak months so no energy will be required from peaking boilers. The required capacity of heat exchangers is reduced from $200 \mathrm{MW}$ to $130 \mathrm{MW}$, which will have an annual cost of $\$ 0.70$ million.

The transport system can be scaled down from $310 \mathrm{MW}$ to $128 \mathrm{MW}$, or will cost $\$ 1.64 \mathrm{million} /$ year for $10 \mathrm{~km}$. The distribution system is unchanged.

The new item is the cost of ATES storage. While in Table 6-3 the highest average monthly demand on the storage system is $87 \mathrm{MW}$, the peak hourly rate will be $310 \mathrm{MW}$ less $120 \mathrm{MW}$ pipeline delivery. The storage system must be peak rated for $190 \mathrm{MW}$ on discharge; on charge the maximum is clearly $120 \mathrm{MW}$, the pipeline capacity, so a somewhat smaller pump capacity can be used in the warm well than in the hot well. As the lower viscosity in the hot well facilitates withdrawal, both pumps may be similar in horsepower rating.

The cost of wells is likely to be quite site-specific; it may vary by as much as three-to-one. As indicated earlier, a local well driller may be able to narrow this range from local experience. Other parameter decisions to be made include the merit of reaming the well to a gravel pack of iarger diameter than the bore hole (e.g., a meter or more), choice of more well doublets with smaller injection and extraction rates versus fewer large capacity wells, and choice of heat exchanger parameters that determine the temperature drops into and out of storage. For an initial iteration $55 \$ / \mathrm{kW}$ will be assumed; this is roughly $40 \$ / \mathrm{kW}$ for the heat exchanger and $15 \$ / \mathrm{kW}$ for the well doublets, although the relative shares may differ. For $190 \mathrm{MW}$ maximum capacity the investment and the annual fixed costs are respectively $\$ 10.45 \mathrm{million}$ and $\$ 1.88 \mathrm{million} /$ year. 
The variable costs for concept $B$ require no peaking fuel. The fuel costs for the cogeneration plant, on the same basis used in Concept $A$ are

Baseload Fuel: $4.91 \mathrm{M} \$ / \mathrm{yr} \times 3.44 \mathrm{GJ} / 3.10 \mathrm{GJ}=\$ 5.45 \mathrm{mi} 11 \mathrm{ion} / \mathrm{yr}$.

Table 6-6 compares Concepts A and B. While the fixed costs are somewhat greater for $B$, the elimination of need for peaking boiler fuel more than compensates. The overall difference between the concepts appears small ( 6 percent) but the common cost of the distribution system dominates both concepts. The delivery system to the distribution system (subtracting 14.8 million from each) shows a 13 percent superiority for Concept $B$. Alternatively, the breakeven cost of the storage system (which would make $A$ and $B$ equal) is $97 \$ / \mathrm{kW}$.

Table 6-6. Comparison of Concepts A and B.

\begin{tabular}{|c|c|c|c|}
\hline & $\begin{array}{c}A \\
M \$ / y r\end{array}$ & $\begin{array}{c}B \\
M \$ / y r \\
\end{array}$ & C \\
\hline \multicolumn{4}{|l|}{ Fixed Costs } \\
\hline \multirow[t]{2}{*}{$\begin{array}{l}\text { Heat Exchangers } \\
\text { Transport } \\
\text { Distribution } \\
\text { Storage }\end{array}$} & $\begin{array}{r}1.08 \\
2.40 \\
14.80 \\
-\quad \\
\end{array}$ & $\begin{array}{r}0.70 \\
1.64 \\
14.80 \\
1.88 \\
\end{array}$ & \\
\hline & 18.28 & 19.02 & \\
\hline \multicolumn{4}{|l|}{ Variable Costs } \\
\hline \multirow[t]{2}{*}{$\begin{array}{l}\text { Peaking Fuel } \\
\text { Baseload Fuel }\end{array}$} & $\begin{array}{r}2.72 \\
4.91 \\
\end{array}$ & 5.45 & \\
\hline & 7.63 & 5.45 & $\begin{array}{l}\text { Existing } \\
\text { Situation: }\end{array}$ \\
\hline TOTAL & 25.91 & 24.47 & 73.10 \\
\hline
\end{tabular}

\section{DISCUSSION}

The preceding example illustrates a comparison procedure. No iterations or optimizations are shown; they of course could modify the results. Some cost elements, believed to be minor, were not included in each system. Some benefits were not credited to the system. A qualitative discussion can at least call attention to these items which would be included in an in-depth analysis. 
Variable 0\&M was not included in any of the concepts. While higher for high sulfur coal power plants than for oil-fired power plants, it may be relatively high for the small-scale dispersed heaters and furnaces of Concept $C$.

For 190 MW peak discharge rate from storage, multiple doublet wells must be assumed. Wells that can produce more than $160 \mathrm{~m}^{3} /$ hour ( 1 million gallons per day) are not common. Ten to $20 \mathrm{MW}$, depending on the $\Delta T\left(T_{3}-T_{4}\right)$ used in the wells is a reasonable well size so that 10 to 20 well doublets would be needed. While these could all be deployed in a pattern at the end of the transport line, a significant reduction in the distribution cost may be achieved by spotting doublets at the nodes in the distribution system, reducing the peak load demand, and the cost, of much of the intermediate size piping.

For a "first iteration" a sendout of $150^{\circ} \mathrm{C}$ and a return of $80^{\circ} \mathrm{C}$ were assumed at the cogeneration source, giving a $\Delta T$ of $70^{\circ} \mathrm{C}$. There will be a drop in this $\Delta T$ corresponding to the transmission and distribution losses assumed. For Concept $B$ the heat exchangers to the ATES will decrease the $\triangle T$ on both charge and discharge. If the heat exchangers are designed for a $10^{\circ} \mathrm{C}$ difference from primary to secondary, the ATES will be used at a $\triangle T$ of $50^{\circ} \mathrm{C}\left(140^{\circ}\right.$ to $\left.90^{\circ}\right)$ requiring more flow for the same energy storage. Cost of storage and of transmission and distribution could be decreased by using a higher $\Delta T$ at the source, either higher sendout or lower return temperature. One penalty of a higher sendout is a higher equivalence factor $\mathrm{F}_{e}$; a benefit is that a wider range of load requirements could be met. Using a lower return temperature may increase the required cost in the connected load equipments to insure that sufficient heat is extracted from the HTW.

If a higher temperature sendout is used so that safety questions would arise if the pressure were too high for residential/commercial connections, blending could be used. This is most easily done by providing pumps and thermostatic controls at the distribution nodes to bypass some return pipe water to the sendout pipe. Constant tem- 
perature could then be maintained despite storage and transmission loss seasonal variations.

The numbers in Table 6-6. are annual totals in millions of dollars. It gives perspective to translate these to the delivered cost of heat, in $\$ / G J$, first in levelized form, then reversing the levelizing process to give a current 1980 cost. In levelized, life-cycle terms, the unit fuel costs for $A, B$, and $C$ are $8.64,8.16$, and $24.4 \$ / G J$. Converted to current costs in 1980 dollars they are $3.92,3.84$, and $7.78 \$ / G J$. For cash flow, payback time considerations, which may be the principal basis on which the individual consumers decide to connect or not to connect to the system, these latter fuel costs may be the dominant factor. It would appear that the annual costs for space and water heating could be cut in half by either concept $A$ or $B$.

In Concept $B$, provision was made for shutting done the pipeline for a month for planned maintenance on the cogeneration plant and/or the pipeline. The capability can also provide for forced outages, except during the peak months. Concept A did not include such capability, so could properly be charged with the need for standby oilfired boilers in Panalville, and the oil fuel needed. Since the availability of a single plant may be about 80 percent, the replacement of coal by $0 i 1$ for 26 percent or more rather than 6 percent of the fuel could significantly degrade Concept $A$ in the comparison.

Also Concept $B$ provided for reducing transmitted heat during July, August, and September so that the cogeneration plant could provide its maximum electric output for eight to ten hours per weekday during these months of peak electric demand. This benefit is hard to evaluate without a full utility system simulation (Hausz, 1979a). Potentially, the 10.5 GWh of electric output gained could be replacing output from oil-fired peaking units at three times the fuel cost. This would further increase the benefits of Concept $B$ over Concept $A$. 
CONCLUSION

This example, it is repeated, is purely illustrative of methods and considerations to be remembered in analysis. While it showed a substantial economic advantage of cogeneration over separate production of heat and power, and an appreciable additional benefit when the system includes ATES, the results for other applications, other locations with less favorable aquifers, and other cost assumptions may be quite different. 


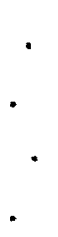




\section{APPENDIX A}

TECHNICAL ASPECTS OF THERMAL ENERGY STORAGE IN AQUIFERS

\section{CONTENTS}

\section{ILLUSTRATIONS}

Page

TABLES

$A-2$

Introduction

A-2

Principles of Fluid Flow and Heat Transfer

A-3

Fluid or Hydraulic Interface

A-3

Thermal Interface or Thermocline

Distance to the Thermocline

Thermocline Tilting During Injection

Thermocline Tilting During Shut-In Condition

Effect of Injection and Withdrawa1

Instabilities

Diffusion and Dispersion

Combined Effects

Energy Recovery

Multiple Cycles

Field Test Results

Factors Affecting Energy Recovery Fraction

Regional Flow

Interaction of Multiple Wells

Well Spacing for a Doublet

Flow Patterns for Arrays of Wells 


\section{ILLUSTRATIONS}

Figure

A-1 Heat Storage Well concept.

A-2 Thermocline tilting with time, due to buoyancy.

A-3 Modified thermocline shapes during storage charging and discharging.

A-4 Physical modeling of thermocline tilting.

A-5 Diffusion: relationship of dimensionless distance and concentration or temperature.

A-6 Synthesized isotherms at the end of the injection period (above) and the withdrawal period (below). Temperatures are in ${ }^{\circ} \mathrm{F}$.

A-7 Heat recovery versus cycle number for various cycles and different well penetrations.

A-8 Auburn production temperatures.

A-9 Heat recovery fraction versus distance from well to thermocline, for different aquifer thicknesses and injected volumes of hot water.

A-10 Heat recovery fraction effects of varying cycle lengths and ratios of injection, storage, and production periods, for various injected volumes and aquifer thicknesses.

A-11 Breakthrough tendency for doublet wells at various spacings.

A-12 Front patterns and flow lines for well doublet.

A-13 Front and flow patterns for five-spot we11 pattern (withdrawal).

A-14 Front and flow patterns for five-spot well pattern (injection).

\section{TABLES}

Table

$$
\text { Title }
$$

Page

A-1 First-cycle heat recovery fractions calculated for different temperatures and aquifer permeabilities.

A-2 Order-of-magnitude upper limit for intrinsic permeability ( $k$ ) of an aquifer in order to avoid large tilting of thermocline. 


\section{INTRODUCTION}

Designing an aquifer thermal energy storage (ATES) system requires enough understanding and information to analyze mass balance (fluid flow) and energy balance (heat flow) in aquifers. Until more data are at hand from field demonstrations and applications of ATES, a combination of basic principles and transfer of related experience in other fields - hydrology, petroleum engineering, geothermal development, and others - is the best guide. Some of these principles and experience are described in this appendix.

\section{PRINCIPLES OF FLUID FLOW AND HEAT TRANSFER}

Consider an aquifer of moderate thickness, say 30 meters, bounded both above and below by horizontal confining layers of very low permeability - clay or shale. The aquifer is homogeneous, of high to moderate porosity and relatively low permeability, and with zero or negligible regional flow. It need not be isotropic; in fact, it is desirable that vertical permeability be an order of magnitude less than horizontal permeability. The aquifer is fully penetrated by a well.

Injecting water of the same temperature and composition as the native groundwater will cause a flow of the injected water radially outward from the wel1 - an essentially two-dimensional situation, in cylindrical coordinates.

The injection requires a force exerted horizontally to move the water against the "resistance" (inversely related to permeability) of the aquifer. The force is created by injecting the water at a pressure greater than the natural artesian pressure in the aquifer. Within the undisturbed aquifer the fluid pressure increases from the top to the bottom at a rate of about $69 \mathrm{kPa}$ (10 psi) every $7 \mathrm{~m}(23$ $\mathrm{ft})$; this corresponds to the increase in the head, or weight of the column of fluid above each level in the aquifer. When the pressure at the top of the well is increased by $\Delta P$ the pressure at all levels in the well is increased by $\Delta P$, so all pressure gradients caused by injection are purely horizontal. 
The process of injection defines a set of flow lines and a set of equipotentials. In this idealized case the flow path followed by any volume of water of which we can keep track is radial. Equipotentials are circular cylinders surrounding the well; all points equidistant from the well have the same pressure difference from that of the undisturbed aquifer. With circular symmetry, the flow velocity and the potential gradient are greatest near the well and fall off inversely with radius $\left(r^{-1}\right)$. The equipotentials are spaced logarithmically (integral of $r^{-1}$ ). For a one-meter well radius there is as much pressure difference between the borehole perimeter and ten meters as there is between $10 \mathrm{~m}$ and $100 \mathrm{~m}$, and between $100 \mathrm{~m}$ and $1000 \mathrm{~m}$. Theoretically, neglecting the compressibility of water and rock, the integral of the pressure gradient from the well to an infinite radius is infinite; i.e., it would take an infinite pressure to inject water. Practically, the compressibility is finite, not zero, and the use of a second well that is discharging an amount equal to that being injected can reduce the injection pressure required. This is one reason for using a well doublet.

Other reasons for using a well doublet are:

- Environmental. There is no problem of disposal of the stored hot water after the thermal energy has been removed. There is no hot water resource problem of consumptive use of water to heat and inject. All water used is recycled.

- Water Quality. The native groundwater is basically compatible with itself and with the mineral matrix in which it resides. Only the effect of temperature changes need be considered. Foreign water can contain particles that produce plugging or ionic species that cause solution or precipitation when mixed with native groundwater; or it may produce swelling of the mineral matrix components, changing porosity and permeability.

Figure A-1 illustrates the basic configuration to be considered for an aquifer storage well doublet, or HSW. 


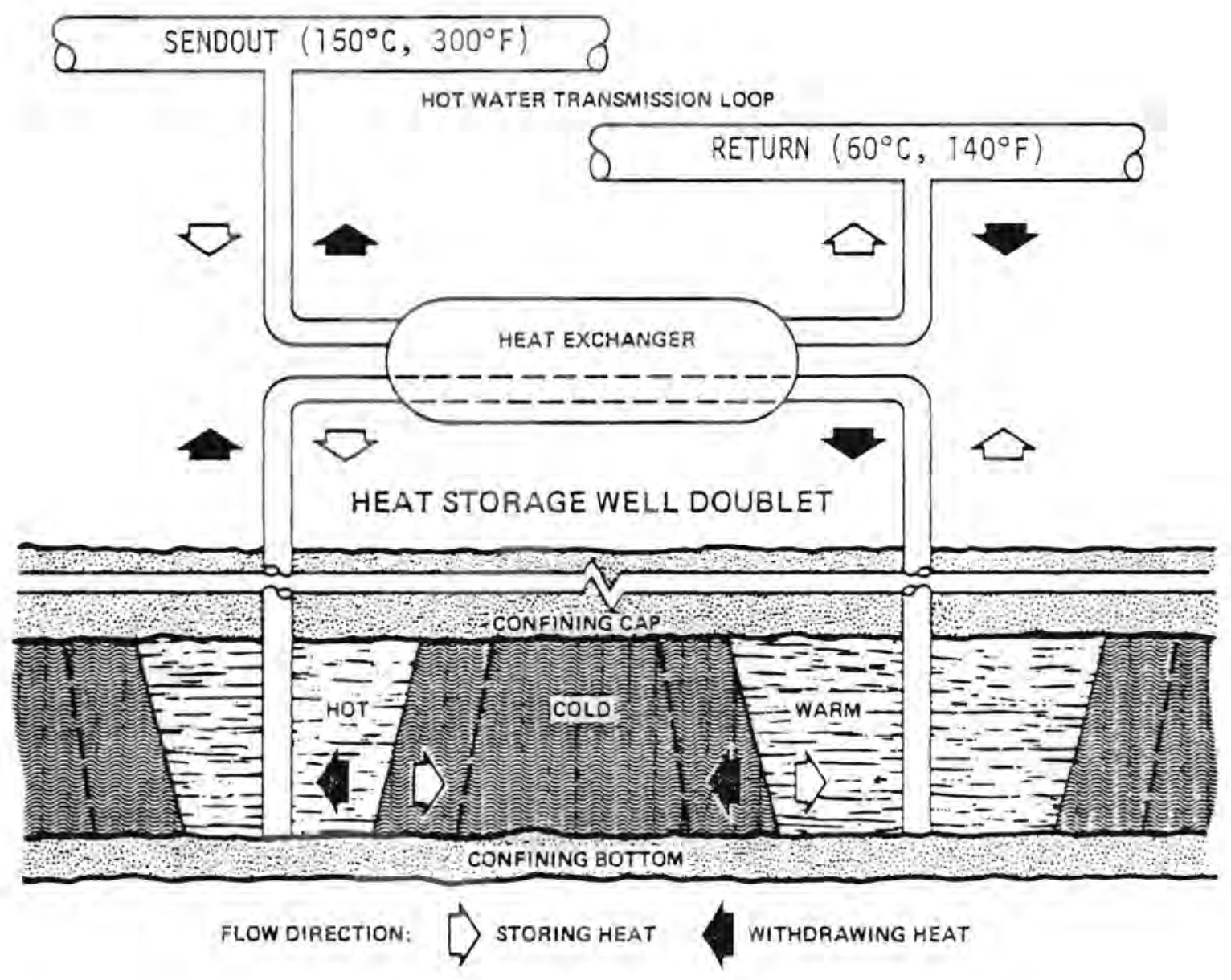

Figure A-1. Heat Storage Well concept.

\section{FLUID OR HYDRAULIC INTERFACE}

If the high-temperature water (HTW) that is injected and moves radially were tagged with a chemical or radioactive tracer, instrumentation recognizing the tracer would find that a fluid or hydraulic interface moves radially, separating the injected water, I, from the native water, N. Because the fluid only occupies the channels between the mineral granules, the hydraulic (darcian) interface I-N moves faster than the injected volume of HTW would indicate. That is, if the effective porosity is 0.25 , the volume inside the cylindrical interface I-N will be four times the injected volume.

The radial distance $r_{\text {hyd }}$ from the well to a hydraulic interface which is cylindrically symmetric about the well, in aquifer of effec- 
tive porosity $\phi_{e}$, will be determined by the injected water volume $V_{W}$ and the aquifer thickness $b$ :

$$
r_{\text {hyd }}=\left\{\frac{v_{w}}{\pi \phi_{e} b}\right\}^{1 / 2}
$$

THERMAL INTERFACE OR THERMOCLINE

As injected hot water moves away from the well through the porous rock of the matrix, heat exchange is rapid. The channels and the grains of rock are quite small, the area of contact between rock and water is large, and the required penetration depth to heat the center of the grains is small. A rule of thumb is that heat exchange is virtually complete for millimeter-size particles in seconds, for centimeter-size particles in minutes, and for decimeter-size particles in hours. Grains and pores in sandstone are typically less than 0.2 millimeter.

Heat exchange being quite rapid compared to darcian flow rate through the matrix, a sharp thermal gradient - a thermocline develops as injection of hot water continues. Outside the thermocline, the injected water which has given up its heat, and the matrix, are at native temperature. There is a thermal interface T-I, analogous to the hydraulic interface I-N and contained within it.

The matrix is composed of the aquifer rock and the water retained within it by surface tension and closed pores. Effective porosity denotes the fraction of a unit volume of rock through which water can flow. The density and heat capacity of the matrix are intermediate between those of water and of the rock.

Distance to the Thermocline

Because the behavior of the thermocline plays a critical role in the energy recovery efficiency of ATES, it is important to understand and be able to predict it. One parameter of importance is the radial distance to the thermocline from the injection well. 
The thermal energy in a volume $V_{W}$ of injected water is $\rho_{W} C_{W} V_{W}$, where $\rho_{w}=$ specific weight of water

$C_{W}=$ specific heat of water.

All of this energy will be contained in the volume $V_{t h}$ of matrix and water within the thermocline. The total pore space of the rock, $\phi$, is filled with water - some retained, some flowing.

Then

or

$$
\rho_{w} C_{w} V_{w}=\left\{(1-\phi) \rho_{r} C_{r}+\phi \rho_{w} C_{w}\right\} V_{t h}
$$

and

$$
=\left\{\left(1-\phi_{e}\right) \rho_{m} C_{m}+\phi_{e} \rho_{w} C_{w}\right\} V_{t h}
$$$$
\rho_{w} c_{w} \pi r_{w}^{2} b=\left\{(1-\phi) \rho_{r} c_{r}+\phi \rho_{w} c_{w}\right\} \pi r_{\text {th }}^{2} b \text {. }
$$

From which

$$
r_{\text {th }}=\left\{\frac{\rho_{w} c_{w} r_{w}^{2}}{\left\{(1-\phi) \rho_{r} c_{r}+\phi \rho_{w} c_{w}\right\}}\right\}^{1 / 2}
$$

where

$$
\begin{aligned}
& \rho_{m}=\text { specific weight of matrix } \\
& \rho_{r}=\text { specific weight of rock } \\
& c_{m}=\text { specific heat of matrix } \\
& c_{r}=\text { specific heat of rock } \\
& b=\text { aquifer thickness } \\
& r_{w}=\left\{\frac{v_{w}}{\pi b}\right\}^{1 / 2} \\
& r_{\text {th }}=\text { radius to thermocline }
\end{aligned}
$$

Thermocline Tilting During Injection

Consider first the effect of density and viscosity as injection of hot water begins. Hot water being less dense and less viscous than the native groundwater surrounding it, the flow patterns which develop will cause the thermocline to tilt away from the vertical, modifying the cylindrical symmetry assumed above.

Inside the thermocline, in hot, low-density water, the pressure gradient with depth will be less than in the ambient-temperature 
groundwater outside the thermocline. There will be a greater pressure gradient horizontally at the top of the aquifer than at the bottom. This buoyancy effect causes the thermocline to advance more rapidly at the top than at the bottom, producing a tilted interface: a truncated cone rather than a cylinder.

The lower viscosity of hot water, roughly one-fourth as much at $120^{\circ} \mathrm{C}\left(250^{\circ} \mathrm{F}\right)$ as at $15^{\circ} \mathrm{C}\left(60^{\circ} \mathrm{F}\right)$, augments the tilting effect. The horizontal pressure gradient is greatest near the well, where the radial velocity is greatest. With one-fourth the viscosity only 25 percent as much pressure gradient is needed for the same velocity. The equipotentials redistribute themselves; they spread out within the thermocline and are more closely spaced outside the thermocline, to support a new, higher velocity at the top of the aquifer for the same injection pressure.

The same effect, redistribution of equipotentials, occurs at the bottom of the aquifer and at intermediate levels, increasing the velocity for constant injection pressure. However, since buoyancy advances the thermocline at the top faster than at the bottom the magnitude of the viscosity effect is greater at the top than at the bottom.

If the injection is constrained to a constant flow rather than a constant pressure, the viscosity effect will increase the rate of advance of the thermocline at the top and reduce it at the bottom.

Even when injection stops, the tilt will continue to increase, because of the buoyancy effect.

Thermocline Tilting During Shut-In Condition

Tilting of the thermocline with time, due to the tendency of lowdensity hot water to float on top of cold water, is easy to understand in principle but difficult to determine or explain quantitatively. Three-dimensional computer codes which model both heat and water flow can be used, but the fine mesh sizes required to obtain desired detail can make the computation expensive. 
Some simplified analytic approaches can give perspective. Visualize a series of concentric circles as shown in Figure A-2. Consider that these circles are barriers to flow, that the space between them is filled with two immiscible fluids, say a red one initially to the left of the center line and a green one to the right. The red one is less dense (e.g., oil) and the green one more dense (e.g., water).

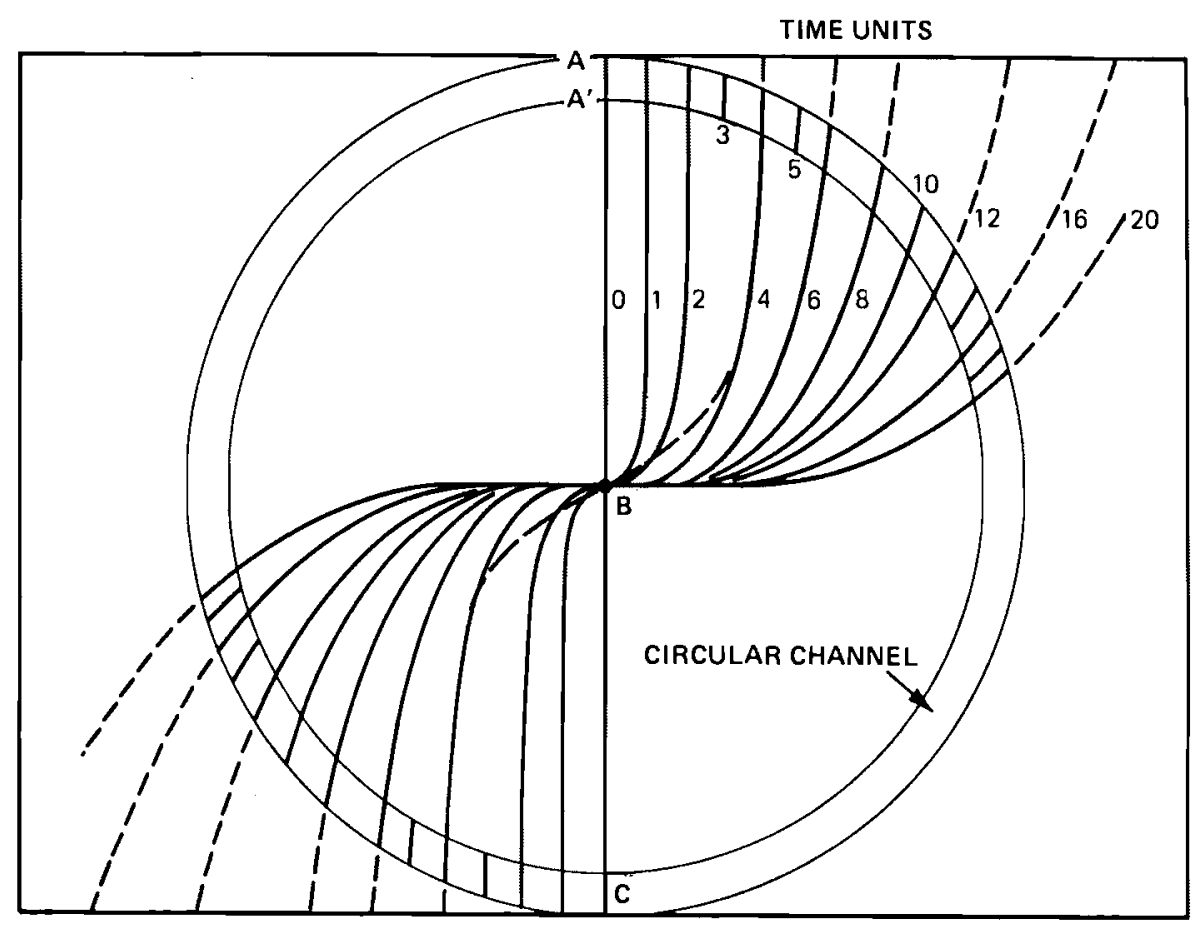

Figure A-2. Thermocline tilting with time, due to buoyancy.

Initially the interface A-C (modeling a thermocline) is vertical. In any circular channel, the weight of the fluid on the green side is greater than that on the red side, so the interface will move clockwise, green going downward and to the left, red upward and to the right, until the interface is horizontal. Assume the fluids are viscous and that, for example, the channels are filled with sand so the fluids move slowly. The resistance to flow is proportional to the length of the flow path, i.e., to the perimeter, hence to the radius. The driving force causing motion is the difference in weight between the fluids in the right half of the channel and the left half. This difference is also proportional to the radius when 
the interface is vertical at the initial moment. The ratio of driving force to resistance is a constant independent of radius, so the linear velocity in all channels is initially the same.

As, in each circular channel, the interface moves toward the horizontal, the differential driving force decreases, but the resistance to flow remains the same. The velocity of motion will decrease with time, in proportion to the sine of the angle of the interface with the horizontal, which will vary with the radius. The analysis of where the interface will be in each channel as a function of time is readily performed. These successive interface shapes are displayed in Figure A-2. At large radi $i$ the constant initial velocity resembles a vertical front advancing right at the top and left at the bottom. Near the center of the circle the interface has only a short distance to travel, and soon approaches the horizontal asymptotically. The S-shaped curve appears to be a fair approximation of what could be expected as the interface for shut-in wells - no injection or withdrawal. Very similar curve shapes are formed if elliptic or rectangular channels instead of the arbitrary circular channels are analyzed.

The next step of complexity is to consider miscible fluids such as hot and cold water. Diffusion or dispersion (to be discussed later) spreads the interface so it is no longer sharp. Over time, the spread between a point that is "almost hot" and one that is "almost cold" (say the 10 and 90 percent points in the total temperature difference) increases as the square root of time. The density between these points will also vary. Over the 10 to 90 percent range it will vary almost linearly between the hot and cold water density. At large radii this will have little effect; the driving force moving the interface is still proportional to the radius, as is the resistance of the path, so the thermocline moves as a vertical front at constant velocity. However, at radi i small compared to the above described thickness of the thermocline there will be an effect. The difference in temperature between the left and right half of the 
circular channel is less so the driving force is less and the interface rotates more slowly. If the initial vertical interface is a thermocline of finite thickness over which the temperature varies linearly, the initial velocity will be proportional to the radius within this thickness. This would lead to a constant slope near the midpoint as illustrated by the dashed line in Figure A-2, instead of the rapid approach to the horizontal.

\section{Effect of Injection and Withdrawal}

The picture is more complex when storage is being charged or discharged and there is net motion of the thermocline to the right or to the left. This changes the flow pattern; simple circular paths are no longer an adequate model. Asymmetric thermocline shapes such as shown in Figure A-3 could result from an initially vertical interface and simultaneous storage charging or discharging and tilting. A small lateral motion will say increase the velocity to the right at the top and decrease the velocity to the left at the bottom, so the point of zero lateral motion moves downward. Some combination of lateral motion and rate of tilt would move this point to the bottom of the aquifer. A greater lateral motion or lesser tilt rate would move this point outside the aquifer.

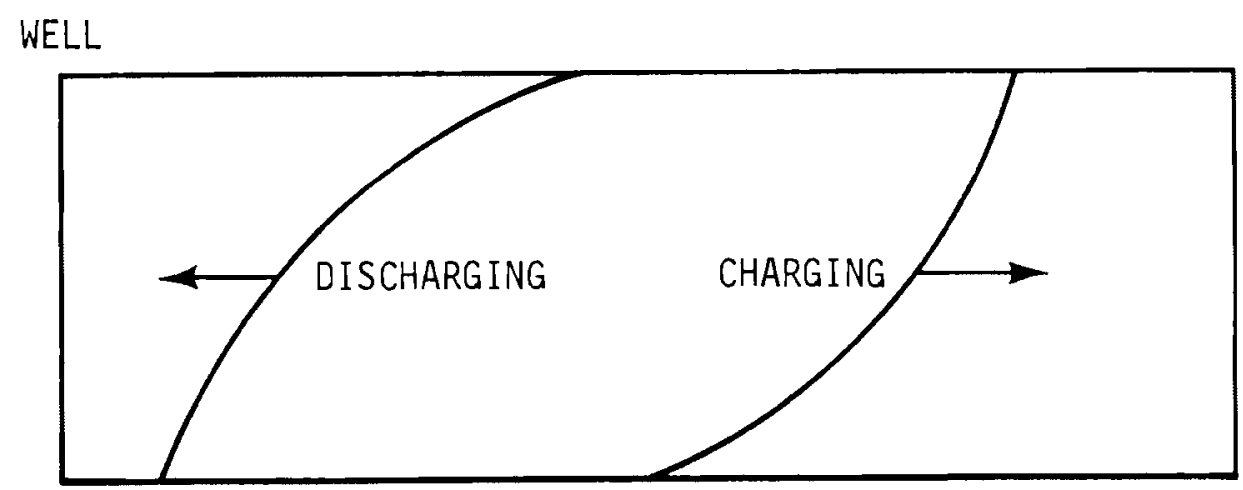

Figure A-3. Modified thermocline shapes during storage charging and discharging. 
When HTW is being withdrawn from storage, the viscosity effects on equipotential distribution will make the thermocline move inward more rapidly at the top of the aquifer than at the bottom, thus partially cancelling the tilt. However, the buoyancy effect of the difference in density is not reversible; it continues to act to increase tilt, even during withdrawal.

Next, of course, is the complexity added by the roughly circular symmetry of flow lines radially from the well. The thermocline is not a line but a conical surface. When a conical thermocline exists at some distance from the well, and injection (charging) is resumed, there are conflicting effects. Diffusion and the density difference between hot and cold water makes the thermocline thickness and tilt tend to increase with time. On the other hand, as the radius from the well, hence the perimeter of the thermocline, increases with time, a given volume requires less difference in radius. Therefore, the thermocline thickness may decrease with time, and the tilt angle may become more nearly vertical with time if the charging rate exceeds the thermal diffusion and the buoyancy effects. On discharging, decreasing radius from the well will correspondingly increase the rate of tilt and the growth of the thermocline in thickness.

\section{Instabilities}

The above, plus added effects from the lower viscosity of hot water compared to cold, deviations from circular symmetry around a doublet well, variations of permeability of the aquifer with depth, difference in vertical and horizontal permeability from thin layers of clay within the aquifer, and transient or permanent instabilities indicate a range of complexities that defy generalizations and require analysis and/or experimental data from each site. Permanent "instabilities" or fingering can result from fissures or high permeability inclusions. Transient instabilities, fingers which occur and disappear during tilting, may result from the difference in viscosity between two fluids. They are illustrated by the three photographs of a model using immiscible fluids, oil and air, shown in Figure A-4. 

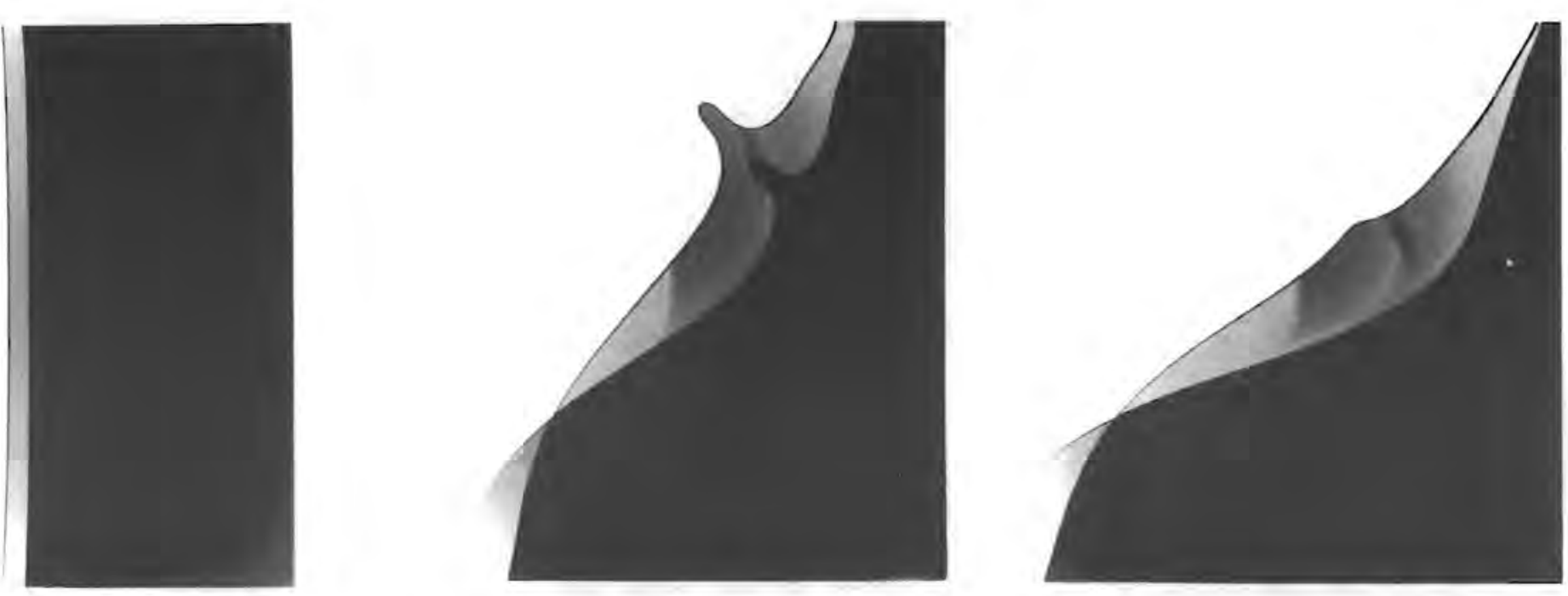

Figure A-4. Physical modeling of thermotine tilting.

(At left is the model just after it has been turned from the horizontal rest position to the vertical. Two separated oil layers with different viscosities are shown.

At the center is the position of each layer ten seconds later. Note the curvature similar to that in $\mathrm{A}-2$, and the transient instabilities shown as "fingers."

Another ten seconds gives the positions shown at the right. Surface tension has reduced or eliminated the fingers, and the curvature of the "thermocline" resembles a later time value in Figure A-2.) 
Diffusion and Dispersion

Diffusion and dispersion make the thermal and hydraulic interfaces less sharp with the passage of time.

For the fluid interface, marked by a sudden discontinuity in the concentration of a tracer in the injected water, the two effects that blur the discontinuity are molecular diffusion and hydrodynamic dispersion. The first, a small effect, arises from random thermal motion of all molecules including the additive tracer in the injected water. With time, some of the tracer molecules diffuse across the boundary, increasing the concentration on one side and decreasing it on the other. The concentration, as a function of distance from the original interface, has roughly the shape of the error function as shown in Figure A-5: the concentration is half the original value at the interface; the concentration gradient is roughly linear near the interface, and has a low concentration and high concentration tail at each end. The slope at the midpoint, initially very steep, decreases as the square root of elapsed time, and the radial extent of the diffusion similarly increases. The same function applies to thermal diffusion.

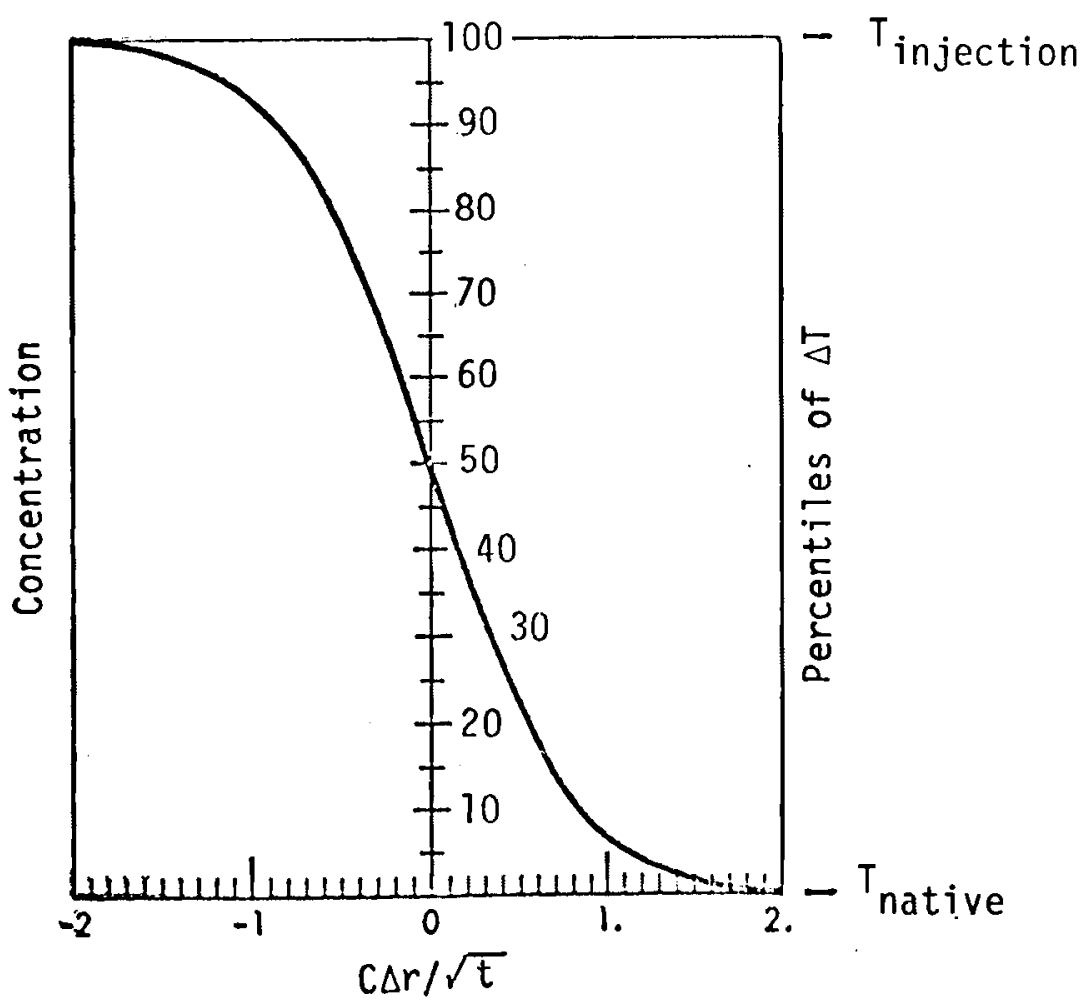

Figure A-5. Diffusion: relationship of dimensionless distance and concentration or temperature. 
For molecular diffusion or the other effects to be described, a diffusion coefficient $D$, dependent on aquifer parameters, defines the magnitude of the diffusion effect. This coefficient has the dimensions $L^{2} / t$ (e.g., meters ${ }^{2}$ per second). The spreading or blurring of the interface, as perhaps measured by the distance between the 0.2 and 0.8 concentration levels (with the original concentration level as 1.0), is proportional to the square root of this coefficient and of the elapsed time.

Hydrodynamic dispersion is a similar effect caused by the inhomogeneities of the aquifer. Water flows through the pore spaces in the mineral matrix, which are irregular. Some local paths are longer than others. As paths diverge and rejoin, water of differing concentrations is mixed, dispersing the concentration in the same functional pattern shown in Figure A-5. Also, in the narrow channels through the mineral matrix, viscosity effects make the water velocity zero at the interface with granules and maximum at the middle of the channel. Hydrodynamic dispersion is not directly a function of time, but rather of the distance traveled as well as the parameters of the aquifer. At zero velocity (resting between injection and withdrawal, wells shut in, no regional flow) there is no hydrodynamic dispersion. During charge or discharge, the rate of dispersion is proportional to the velocity.

When temperature rather than the concentration of an additive is the tag being measured, there are analogies to both molecular diffusion and to hydrodynamic dispersion, but the coefficients of diffusion and dispersion are not the same as those for the concentration tag. Thermal diffusion is a molecular effect. The average velocity of molecular motion is temperature dependent. Faster molecules from the hot water transfer their excess kinetic energy to slower molecules by impact and rebound. Since the energy can be passed on by a chain of successive collisions of different molecules, it can spread much more rapidly than molecular diffusion which requires the tag molecules themselves to advance. The coefficient of thermal diffu- 
sion is several orders of magnitude greater than the coefficient of molecular diffusion.

The analogue to hydrodynamic dispersion also exists. Water following different tortuous paths through the mineral matrix may recombine and mix with water at different temperatures, or from different parts of the "concentration" function of Figure A-5. Water in the middle of narrow channels through the matrix moves more rapidly than that adjacent to granule surfaces. Both of these cause spreading of the thermocline. The magnitude of the effect can be defined by a coefficient of thermal dispersion. However, at a microscopic level (granules of matrix smaller than $1 \mathrm{~mm}$ diameter), both of these effects will be mitigated by the rapid heat transfer to matrix particles. In the limit, with very small granules that have the same volumetric heat capacity as water, and low velocities so that heat transfer time delays to the granules can be neglected, the waterplus-matrix would be thermally homogeneous and only thermal diffusion would spread the thermocline. For practical granular structures and velocities it can be said that the thermal dispersion coefficient will be considerably smaller than the hydrodynamic dispersion coefficient.

Collins (1976, p 206) gives as the rule for combining the diffusion and dispersion effects the relation:

$$
K_{D}=D+\frac{C \times v^{2}}{D}
$$

Where $D$ is the molecular or thermal diffusion coefficient, $C$ is concentration, and the second term represents the hydrodynamic or thermal dispersion effect we have called the dispersion coefficient. The resultant may be called the total dispersion coefficient. Note that $K_{D}$ is independent of the sign of $v$ and reduces to just the diffusion coefficient if the flow velocity $v$ is zero. At some velocity $v^{\prime}$ the two terms are equal. Because of the exponent 2, the second term becomes negligible for values of $v / v^{\prime}$ much below 1 , and rapidly becomes dominant as $v / v^{\prime}$ exceeds 1 . 
VARIATIONS WITH TIME. Some effects follow naturally from the cylindrical symmetry around a single well and the close approximation to it in the regions near each well of a doublet. An injected volume of $3800 \mathrm{~m}^{3} /$ day ( $1 \mathrm{Mgd}$, occupying about 135,000 $\mathrm{ft}^{3}$ ) will occupy after the first day a cylinder say $32.8 \mathrm{~m}$ (100 feet) high and $8.3 \mathrm{~m}$ (25.3 feet) in radius (to the thermocline). The second day it occupies an annular volume from 8.3 to $11.7 \mathrm{~m}$ (25.3 to 35.8 feet), i.e., $3.44 \mathrm{~m}$ (10.5 feet) thick. By the one hundredth day it occupies an annular volume from 82.8 to $83.0 \mathrm{~m}$ (252.5 to 253.0 feet) in radius, i.e., $0.16 \mathrm{~m}$ (one-half foot) thick. Equal volumes have smaller thicknesses decreasing roughly as $t^{-1 / 2}$ after the first few days. This modifies some of the effects, or their appearance at least.

First, as the thermocline (and the fluid interface) spread by diffusion as $t^{1 / 2}$, the radial scale of the ring containing it is decreasing as $t^{-1 / 2}$ or as $r^{-1}$. These will partly cancel, giving a lesser spread in feet than expected for a stationary interface after 100 days. The very low velocity during the latter part of the charge cycle, i.e., one-half foot per day on the last day, will greatly decrease the effects of thermal and hydrodynamic dispersion. However, it should be noted that on withdrawal, the thickness of each annular volume will go through the reverse process, i.e., will expand as $r^{-1}$. At the same time diffusion and dispersion effects, not reversible, will be further spreading the thermocline.

\section{Combined Effects}

The alternation of charging, holding, and discharging storage for a number of cycles of course makes an accurate description of the thermocline very difficult to predict. A rough idea of the isothermal contours at the end of one cycle of injection and after the first withdrawal is shown in Figure A-6. This was arrived at as a synthesis of analytical estimates of the various effects, not as a complete solution of all effects simultaneously. To reduce clutter, only English units (feet, ${ }^{\circ} \mathrm{F}$ ) are shown in Figure $A-6$. 

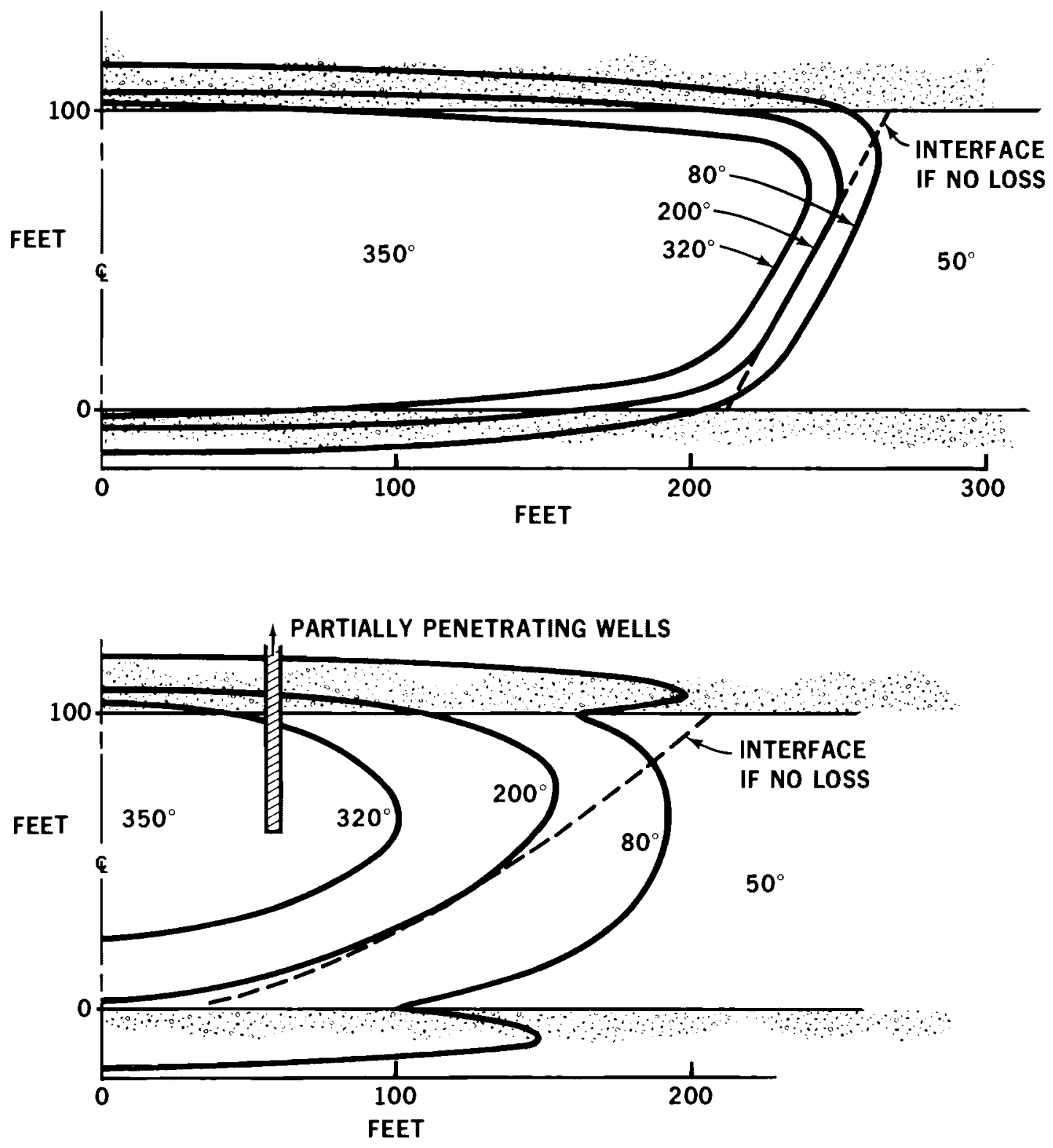

Figure A-6. Synthesized isotherms at the end of the injection period (above) and the withdrawal period (below). Temperatures are in ${ }^{\circ} \mathrm{F}$. 
Note that the retreating HTW leads to the confining cap and bottom being hotter than the adjacent aquifer, so some heat lost to these layers is returned to the aquifer as indicated by the isotherms.

Tilted thermoclines, diffused and dispersed, reduce the efficiency of energy recovery. All of the above complexity may result in a small or a large effect on the fraction of the energy charged into storage that is recovered before some tolerable threshold of temperature drop in the HTW withdrawn is reached. The effects can be partly mitigated by preferentially withdrawing from the top of the well when colder water begins to enter the bottom. Such means as packers and valves in the well, or a supplementary well partly penetrating the upper part of the aquifer, may be used if economically justified.

\section{ENERGY RECOVERY}

\section{Multiple Cycles}

GE-TEMPO and Lawrence Berkeley Laboratory have with computer models followed the injection and withdrawal process through multiple complete cycles. Although the models differed greatly in form and approach, and in the assumptions made such as the criterion for stopping withdrawa1, their results were in quite good agreement. After a first cycle energy recovery of 70-75 percent, the recovery improved by the fifth cycle to 85-90 percent.

Each cycle leaves energy behind, as an increasing buffer reducing the thermal gradients outside of the stored energy zone, and hence reducing the rate of heat loss.

In the limit, after a large number of cycles, the loss per cycle will approach steady-state conditions. The steady-state heat loss from a sphere in an infinite matrix of known "thermal diffusivity" (a function of thermal conductivity, density, and specific heat) is given in "Heat Transfer" by Rohsenow and Hartnett (1973). Steadystate loss, for a sphere equivalent to the maximum storage volume, is much less than 5 percent per year. It will take many cycles to approach this limit. 
The results of one simulation by TEMPO, shown in Figure 3-12 of this volume, were reported in 1972 by Meyer, Todd, and Hare, and in 1973 by Meyer and Todd. Injection of water at $170^{\circ} \mathrm{C}\left(340^{\circ} \mathrm{F}\right)$ at a rate of $3800 \mathrm{~m}^{3} /$ day $(1 \mathrm{mgd}$ ) for 90 days was simulated, followed by withdrawal of stored water until the production temperature dropped to $150^{\circ} \mathrm{C}\left(300^{\circ} \mathrm{F}\right)$. The heat recovery fraction ranged from 0.72 on the first cycle to 0.79 on the fifth cycle. In a second simulation, not shown in Figure 3-12 but reported in the references cited, injection of $99^{\circ} \mathrm{C}\left(210^{\circ} \mathrm{F}\right)$ water at the same rate for the same period of time was simulated, followed by withdrawal until the temperature dropped to $82^{\circ} \mathrm{C}\left(180^{\circ} \mathrm{F}\right)$. The fifth-cycle heat recovery fraction was found to be 0.86 .

LBL has reported the results of several multiple-cycle simulations, shown in Figure A-7. The very high recovery for a daily cycle is of particular interest because it illustrates the potential thermal efficiency of superimposing daily cycling on seasonal use of ATES.

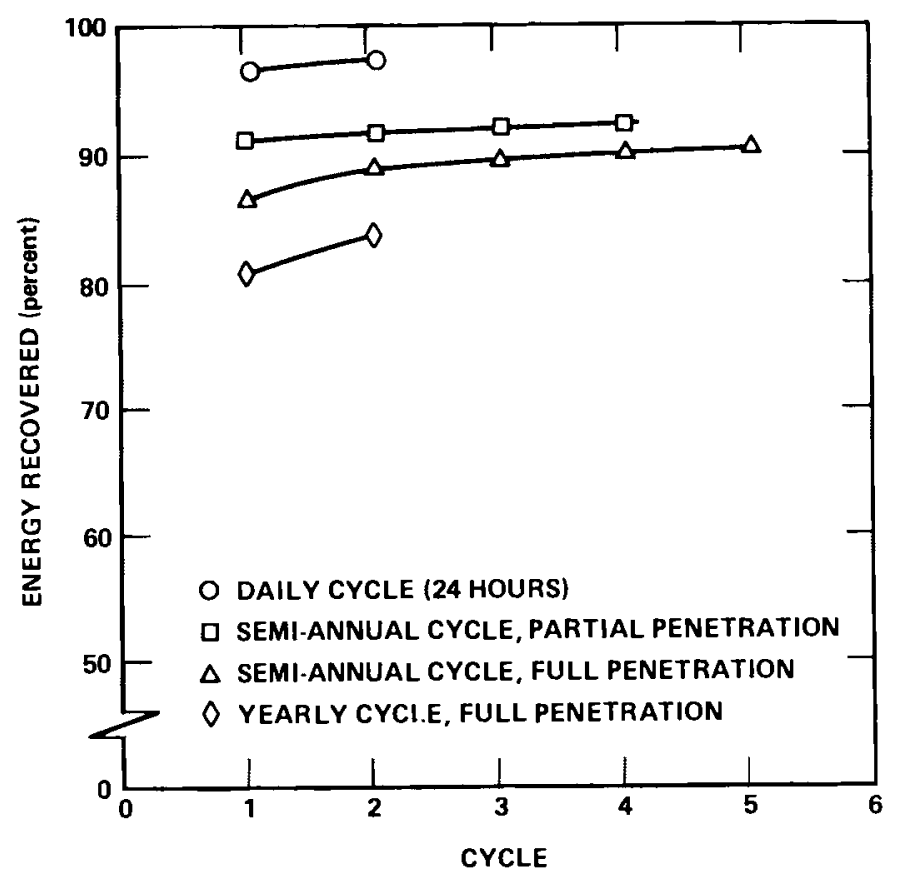

Figure A-7. Heat recovery versus cycle number for various cycles and different well penetrations. (After Tsang, 1977) 
Only a few such calculations of the heat recovery fraction for a series of cycles appear to have been reported, perhaps because they become quite specific to assumptions concerning schedules of injection, storage, and production, and to aboveground system parameters.

\section{Field Test Results}

AUBURN EXPERIMENT. Production temperature data from a field test by Auburn University, which has been successfully simulated by $L B L$, are shown in Figure $A-8$. The drop in $T_{\text {prod }}$, from $55^{\circ} \mathrm{C}$ to $33^{\circ} \mathrm{C}$ in 41 days, makes $\left(T_{\text {prod }}-T_{0}\right) /\left(T_{\text {in }}-T_{0}\right)$ less than 0.4 - a 63 percent drop. (Compare this to the 40 to 50 percent drop shown for the first cycle in Figure 3-13. Note that $T_{\text {prod }}$ follows a quite different curve in the two figures, illustrating the effect of buoyancy flow.)

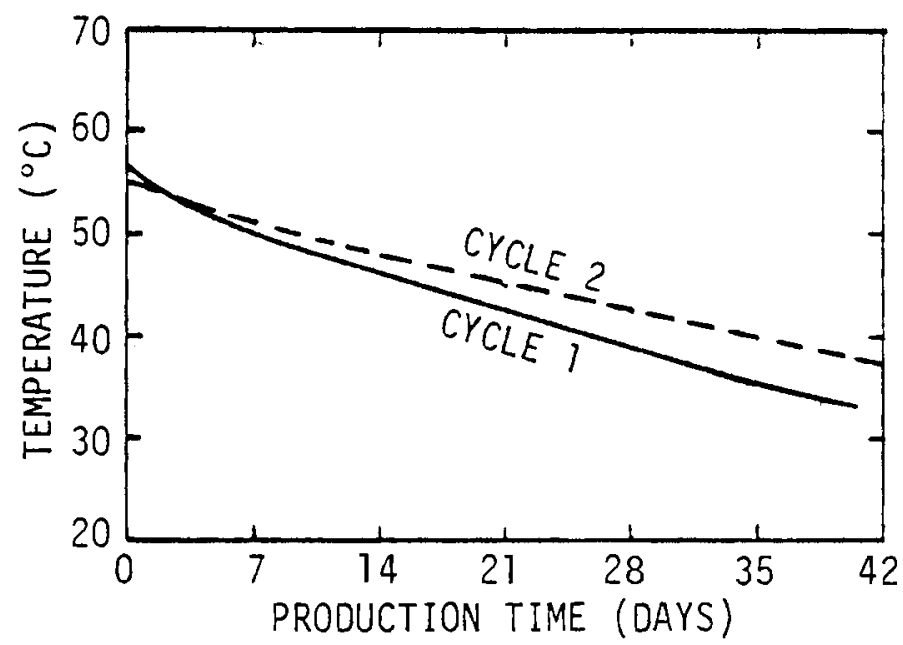

Figure A-8. Auburn production temperatures. (After Tsang, 1980a, p 587)

Conditions for the first cycle of the Auburn experiment were as follows: Water from an over?ying aquifer was heated to $55^{\circ} \mathrm{C}\left(130^{\circ} \mathrm{F}\right)$ and injected during a period of 70 days, at various rates, into an aquifer whose ambient temperature is $20^{\circ} \mathrm{C}\left(68^{\circ} \mathrm{F}\right)$. The storage well was then shut in and the hot water stored for 51 days before producing began. The amount of water injected and the amount pumped out were roughly equal, about $55,000 \mathrm{~m}^{3}\left(14.5 \times 10^{6} \mathrm{gal}\right)$. The heat 
recovery was 66 percent. The measured horizontal permeability of the aquifer is about $5 \times 10^{-7} \mathrm{~cm}^{2}$ (50 darcys). The vertical permeability was deduced to be about one-tenth the horizontal permeability, giving a value which is still 50 times greater than the low permeability example used in the earlier LBL simulation: $10^{-9} \mathrm{~cm}^{2}$ (0.1 darcy, $10^{-12} \mathrm{ft}^{2}$ ). (Molz, et al, 1980; Tsang, 1980a.)

Injection of hot water to begin the second cycle of the Auburn experiment commenced within less than one month after completion of the first cycle. Injection, storage, and production periods were somewhat longer than in the first cycle, and, by the time production temperature dropped to $33^{\circ} \mathrm{C}$, more water had been pumped out than was injected. Heat recovery was 76 percent. The second cycle of the experiment was completed in April 1979.

Further experimental work by Auburn University is planned. A true doublet system will be used, with two wells completed in the same aquifer - the two cycles described above utilized water withdrawn from an overlying aquifer. Plans call for injection of water at $55^{\circ} \mathrm{C}\left(130^{\circ} \mathrm{F}\right), 90^{\circ} \mathrm{C}\left(194^{\circ} \mathrm{F}\right)$, and $125^{\circ} \mathrm{C}\left(257^{\circ} \mathrm{F}\right)$, to verify computer projections of heat recovery efficiency at elevated temperatures.

TEXAS EXPERIMENT. A cold water storage experiment has been conducted by Texas A\&M University. During the first three months of 1979 about $31,000 \mathrm{~m}^{3}\left(8 \times 10^{6}\right.$ gallons $)$ of chilled water were injected at an average rate of $520 \mathrm{~m}^{3} / \mathrm{d}(95 \mathrm{gpm})$ into a highly permeable, shallow, unconfined aquifer. Water withdrawn from a well at $22^{\circ} \mathrm{C}$ was chilled to $4^{\circ} \mathrm{C}$ in a $450 \mathrm{~m}^{2}$ spray pond, passed through a sand filter, and chlorinated before injection. Aeration in the cooling pond of the well water, which had an iron content of $9.1 \mathrm{mg} / 1 \mathrm{iter}$, formed an iron precipitate which was completely removed by the sand filter.

Recovery of the chilled water began in July, after a 100-day storage period. By this time regional flow had moved the cold water zone approximately $30 \mathrm{~m}$ downgradient from the injection well. Recovery was halted in 60 days, when a volume of water equivalent to that 
injected had been recovered. The temperature of the water recovered was initially $17^{\circ} \mathrm{C}$ and increased to a final temperature of $19^{\circ} \mathrm{C}$. A total of $1.6 \mathrm{TJ}$ were injected and $0.36 \mathrm{TJ}$ were recovered, for 23 percent recovery efficiency. A recovery efficiency of 40 percent had been expected, but was not attained because of the exceptionally heavy rainfall and increased regional flow in the unconfined aquifer.

Viewed not as a demonstration of ATES but as the experiment it was, the Texas work was very productive. The cooling pond proved to be an exceptionally efficient and low-cost method of producing chilled water. The simple sand filter worked perfectly: there were no problems with well plugging from iron precipitates, aeration, or biological activity. (Reddel1, Davison, and Harris, 1980; Minor, 1980.)

\section{Factors Affecting Energy Recovery Fraction}

The factors affecting heat recovery fraction and their significance appear to have been fairly well identified by LBL simulations and others, with some validation from Auburn field test data. The factors are permeability, ratio of surface area to volume of injected water, temperature, cycle periods, and thermal properties of the aquifer and its confining layers. Regional flow, if present, can have a substantial effect as in the Texas experiment.

Table A-1 shows first-cycle heat recovery fractions after injection of water at four different temperatures into aquifers of three different permeabilities, for various cycles and for production from the entire 21-meter aquifer thickness, from the upper one-half, and from the upper one-third. The permeability of the confining layers is assumed to be less than the aquifer permeability by a factor of $10^{5}$. The injected volume is that of the first Auburn cycle, about $55,000 \mathrm{~m}^{3}\left(14.5 \times 10^{6}\right.$ gallons $)$, and the ambient temperature is $20^{\circ} \mathrm{C}$. (Tsang, 1980b.)

The most important reason for a decrease in heat recovery fraction as injection temperature and permeability increase is the 
Table A-2. Order-of-magnitude upper limit for intrinsic permeability (k) of an aquifer in order to avoid large tilting of thermocline. (Source: Hellström, et a1, 1979, p 60)

\begin{tabular}{|c|c|c|c|}
\hline \multirow{2}{*}{$\begin{array}{c}\text { Injection } \\
\text { Temperature } \\
T_{\text {in }}\left({ }^{\circ} \mathrm{C}\right) \\
\end{array}$} & \multicolumn{3}{|c|}{$\begin{array}{c}\text { Aquifer Thickness } \\
(\mathrm{m})\end{array}$} \\
\hline & 10 & 25 & 50 \\
\hline \multirow[t]{2}{*}{60} & 3 darcys & 8 & 15 darcys \\
\hline & $3 \times 10^{-8} \mathrm{~cm}^{2}$ & $8 \times 10^{-8}$ & $1.5 \times 10^{-7} \mathrm{~cm}^{2}$ \\
\hline \multirow[t]{2}{*}{90} & 1 & 3 & 6 \\
\hline & $1 \times 10^{-8}$ & $3 \times 10^{-8}$ & $6 \times 10^{-8}$ \\
\hline \multirow[t]{2}{*}{120} & 0.7 & 2 & 4 \\
\hline & $7 \times 10^{-9}$ & $2 \times 10^{-8}$ & $4 \times 10^{-8}$ \\
\hline
\end{tabular}

permeability, the geometric mean of the two permeability values $\left(\sqrt{\mathrm{kk}^{\prime}}\right)$ is given by the table.

Using a linear flow model developed by Lund University, LBL has recently studied the effect on recovery fraction of cycle periods, storage volume, aquifer thickness, and thermal properties. Results so far reported (Doughty and Tsang, 1980) do not include effects of gravity, dispersion, or finite caprock thickness. Neglecting gravity means that the effect of buoyant forces, particularly tilting of the thermocline, is not taken into account.

Figure A-9 illustrates the change in the first-cycle heat recovery fraction for variations in injected volume of water, height $\mathrm{H}$ (thickness) of the aquifer, and thermal radius (distance from the well to the cylindrical thermocline). Of principal interest is the initial sharp increase and the later slow changes in the heat recovery fraction as the thermal radius increases, corresponding to increases in injection volume. In other words, beyond a point increases in injection volume no longer significantly improve the recovery fraction; the optimal aspect ratio of thermal radius to aquifer thickness has been reached. 


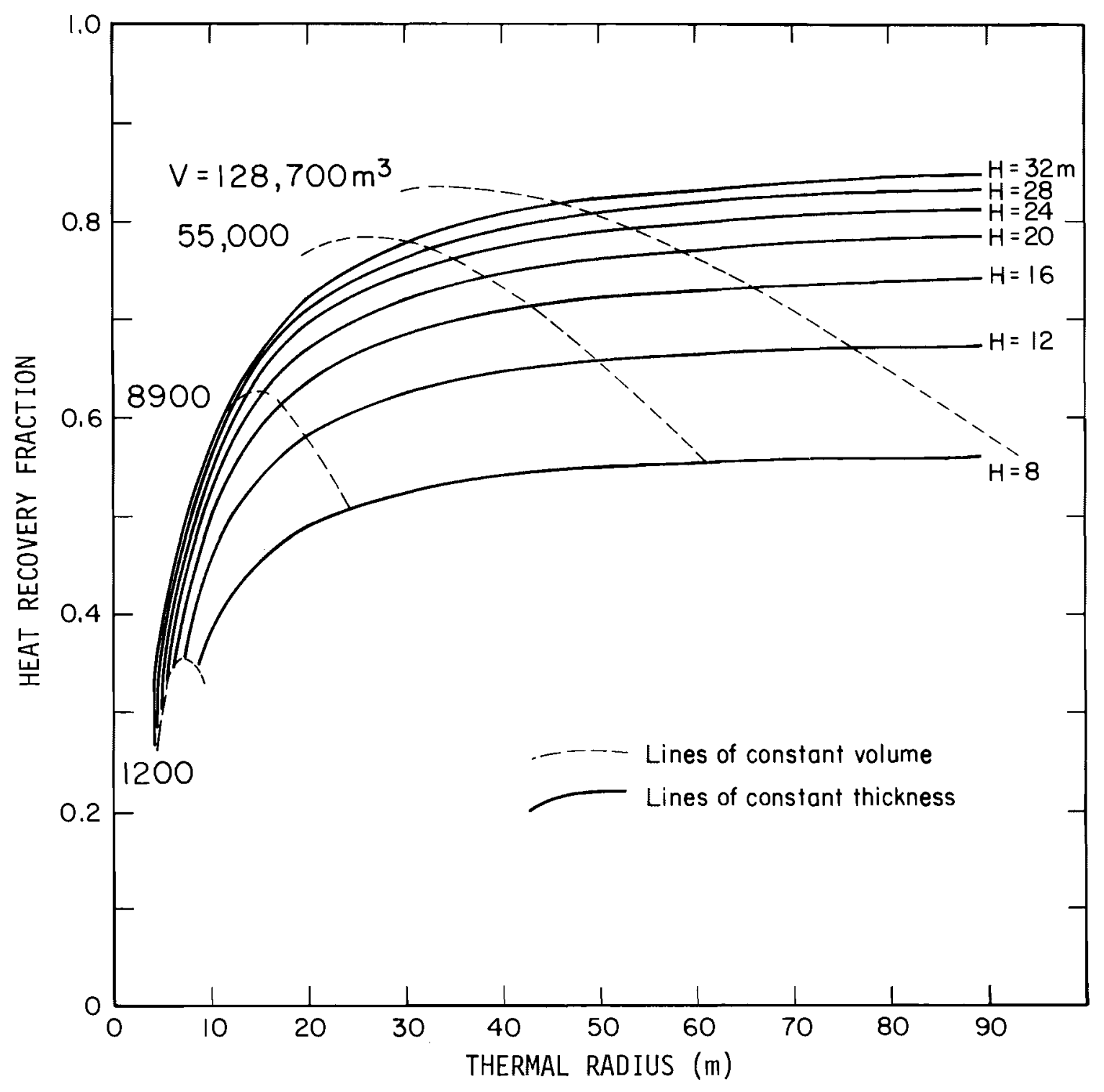

Figure A-9. Heat recovery fraction versus distance from well to thermocline, for different aquifer thicknesses and injected volumes of hot water. (Source: Doughty and Tsang, 1980) 
Figure A-10 shows energy recovery fraction as a function of the total length of a single injection-storage-production cycle for three different injected volumes. The aquifer thickness (H) for each volume is such that the aspect ratio $r_{t h} / H$ is optimal. Curves labeled "a" show the results for a cycle with no storage period - production begins as soon as injection ends, and the production and injection periods are equal. The curves labeled " $b$ " show the results for a cycle with equal injection, storage, and production periods. The curves labeled " $c$ " show the results for a hypothetical, lower-bound cycle that is entirely storage period, the hot water being instantly injected and, at the end of the storage period, instantly produced.

These results suggest the pronounced effect on energy recovery efficiency of storing large volumes of water in appropriately thick aquifers, and the effect of the length of the storage period on recovery efficiency. However, it should be kept in mind that thermocline tilting is not yet included in the analysis. Long storage periods would allow time for tilting from buoyancy forces to become important. (See Figure A-2.)

\section{REGIONAL FLOW}

Groundwater is constantly moving from a point of recharge toward a point of discharge; in general, from the highlands toward the lowlands. The rate of movement varies widely. Todd (1959) estimates the normal range as $150 \mathrm{~cm}(5 \mathrm{ft})$ per year to $150 \mathrm{~cm}(5 \mathrm{ft})$ per day. Deep aquifers generally have lower regional flow rates than shallow aquifers. Because it could carry away some of the valuable hot or cold water stored in an aquifer, the regional flow rate in an aquifer is an important consideration in deciding whether an aquifer is suitable for ATES. ("Lateral flow" and "groundwater drift" are other terms used with the same meaning as regional flow.)

Regional flow can be counteracted by neutralizing the hydraulic gradient which causes it, according to analyses reported by Moiz and Beli (1977) and Whitehead and Langhetee (1978). The approach involves drilling from three to eight small bounding wells, surround- 


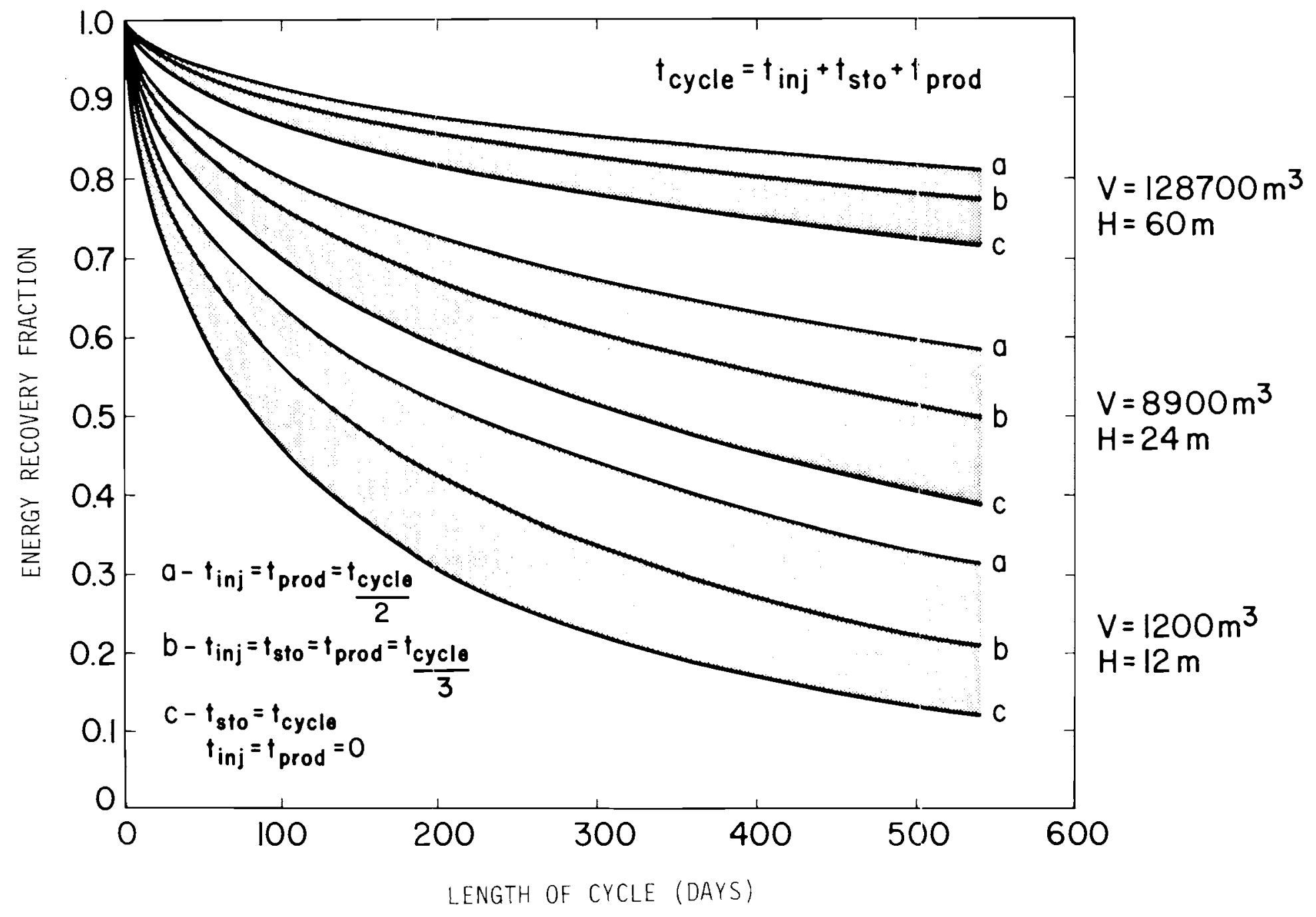

Figure A-10. Heat recovery fraction effects of varying cycle lengths and ratios of injection, storage, and production periods, for various injected volumes and aquifer thicknesses. (Source: Doughty and Tsang, 1980) 
ing the heat storage well doublet, pumping water from the upgradient direction, and injecting it into the downgradient flow, to produce an essentially zero gradient within the area enclosed by the wells. Relatively small amounts of water need be pumped from and injected into the bounding wells, but the amounts must be controlled according to the amount of gradient that is to be neutralized. No field applications of the technique are reported. Molz and Bell feel that buoyancy effects, if important, will require additional analysis.

\section{INTERACTION OF MULTIPLE WELLS}

\section{Well Spacing for a Doublet}

For pairs or arrays of wells, the required spacing between wells is determined by the allowance necessary for movement of thermoclines back and forth between the wells without breakthrough.

LBL simulated the breakthrough problem for doublet wells spaced at various distances as shown in Figure A-11, with $10^{6} \mathrm{~kg} /$ day $(180$ $\mathrm{gpm})$ of water at $220^{\circ} \mathrm{C}\left(430^{\circ} \mathrm{F}\right)$ injected into an aquifer $60 \mathrm{~m}$ thick whose ambient temperature is $20^{\circ} \mathrm{C}\left(68^{\circ} \mathrm{F}\right)$. After 90 days of injection, for $55 \mathrm{~m}$ spacing the thermal front is definitely distorted and extends toward the producing well. With as much as $100 \mathrm{~m}$ spacing, the distortion is hardly noticeable, nor is it after 45 days of injection for any of the spacings shown.

Note that the thermal front, or thermocline, is of principal interest in breakthrough. The fluid or hydraulic front will reach the producing well sooner than the thermal front. For example, the injected water volume, the volume bounded by the thermocline, and the volume bounded by the fluid interface might be in the ratios of $1: 1.49: 4$, the relative radii $1: 1.22: 2$, for cylindrical symmetry. (Equations A-1, A-5; Figure 3-10.) These ratios would change as distortion takes place, but they describe a reference case.

The term "breakthrough" is somewhat dramatic, suggesting a sudden and perhaps disastrous event. Actually, when breakthrough does occur, it will at first be hardly noticeable. Only a small fraction of the hot water will enter the producing well for some time - neglecting 
(a) $D=55 \mathrm{~m}$

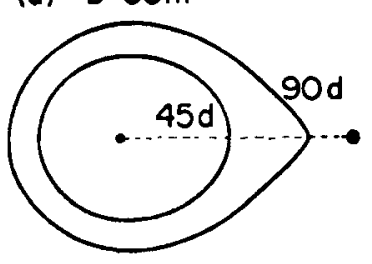

(b) $D=60 \mathrm{~m}$

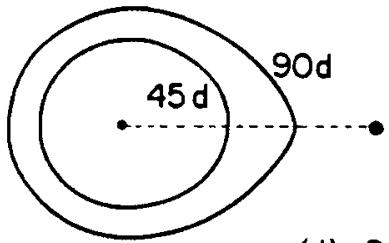

(c) $D=70 \mathrm{~m}$

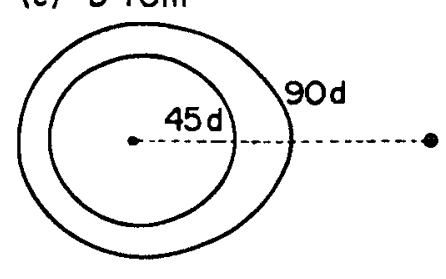

(d) $D=100 \mathrm{~m}$

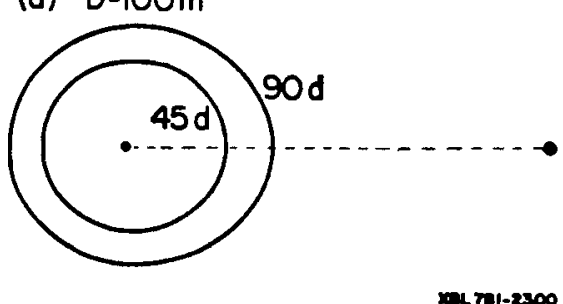

Figure A-11. Breakthrough tendency for doublet wells at various spacings. (Source: Tsang, et al, 1978)

the possibility of fissures or channeling of flow, of course. The reason is that flow lines emanate from the injection well in all directions, and converge toward the producing well rather slowly as a function of time.

Unless an abnormally thin aquifer is utilized, a spacing of $200 \mathrm{~m}$ between wells should be a reasonable conceptual-design assumption for protection against breakthrough. Closer spacing probably can be used. Only after the thermal characteristics of the aquifer and its other parameters are known can good calculations be made to predict thermal and fluid fronts; this should, of course, be done before actual system installations are undertaken.

Flow Patterns for Arrays of Wells

Various authors, including Collins (1976) describe the flow lines and hydraulic front patterns for multiple well configurations used by 
the petroleum industry and of interest for ATES purposes. A doublet has the pattern indicated in Figure A-12. The injection well is at the right, where $x=+1 / 2$; the withdrawal well at $x=-1 / 2$. For the indicated values of time in arbitrary units, the shape and size of the hydraulic interface, or front, is shown. The times given are roughly in the series $1,8,15,30,45,48$. The radi $i$ upwards, downwards, and to the right are quite nearly equivalent and in the series $4,9,12,16,20,21$. The circular fronts deviate increasingly from circular form to the right; at the time marked 0.650 the bulge is about 20 percent.

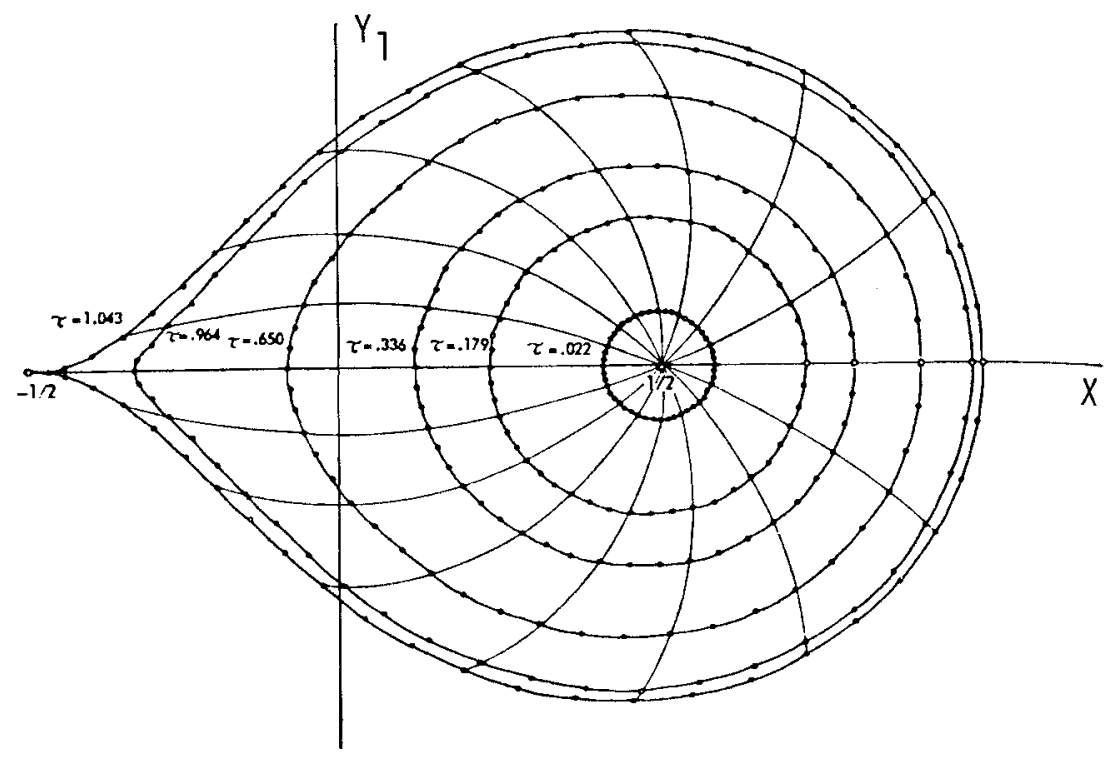

Figure A-12. Front patterns and flow lines for well doublet. (Source: Collins, 1976, p 182)

Eventually, hydraulic breakthrough occurs. The specific contour marked 1.043 is at the time of breakthrough. From this time onward some of the injected fluid as well as native groundwater is being withdrawn. The lines orthogonal to the fronts are the flow lines. For times after breakthrough an increasing fraction of the flow 1 ines will transport the injected fluid all the way to the withdrawal well.

Other well patterns of interest include two concentric circles with hot wells on the inner circle and cold wells outside; two paral- 
lel lines of wells; and a "five-spot" pattern. The latter has been frequently used in petroleum engineering. Collins (1976) gives the fronts and flow lines for a central withdrawal well surrounded by four injection wells, as shown in Figure A-13. In petroleum reservoirs, hot water, steam, or gas is injected into the outer wells to facilitate petroleum withdrawal.

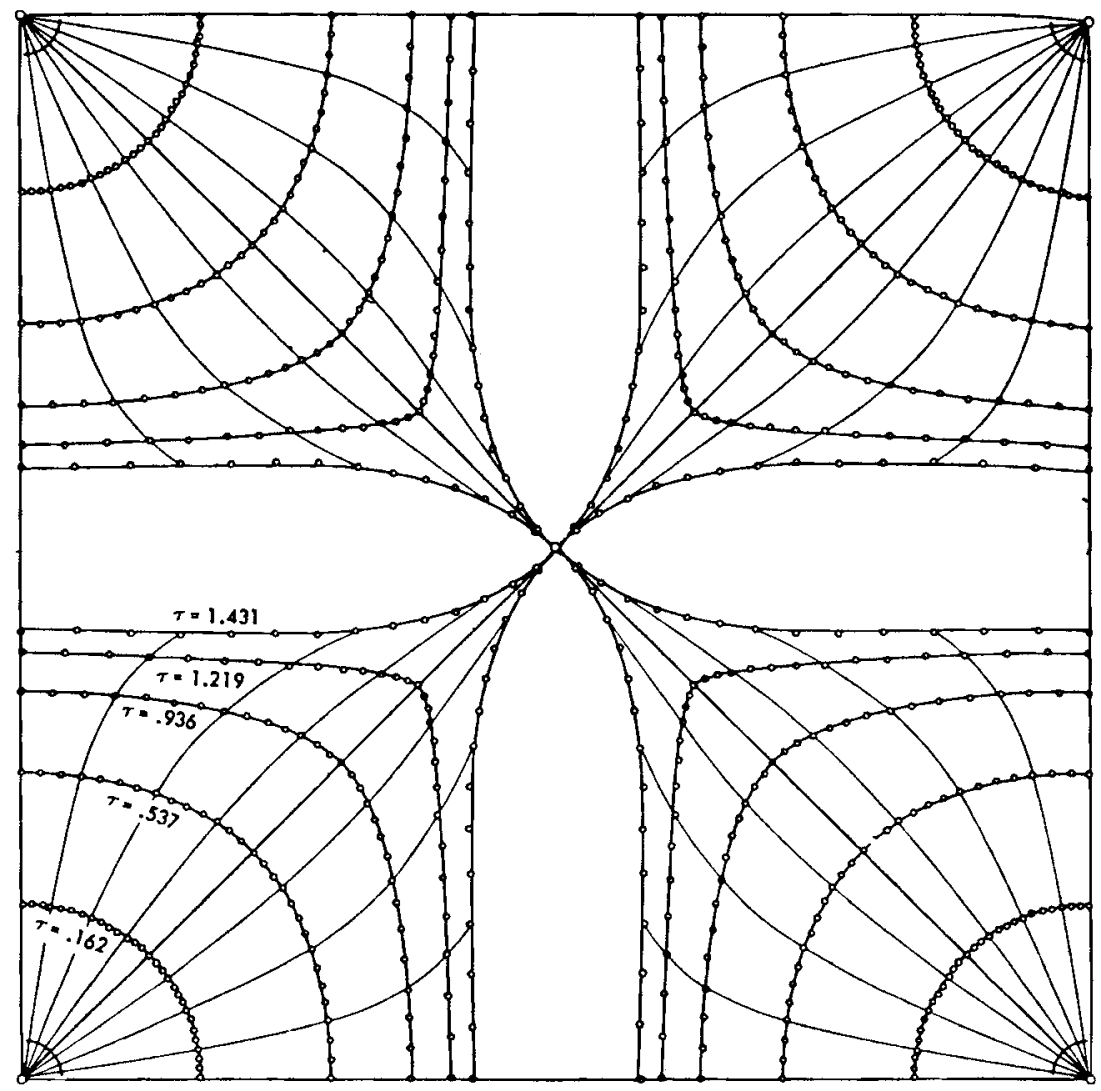

Figure A-13. Front and flow patterns for five-spot well pattern (withdrawa1). (Source: Collins, 1976)

As derived, the patterns are for an infinite array of wells extending in all directions, so the pattern shown would be repeated as similar squares surrounding the square shown. The shapes within the square should not differ much from that for a simple five-spot.

For ATES, both injection and withdrawal will occur at separate times in the central we11. The corresponding fronts and flow lines for central injection are shown in Figure A-14. 


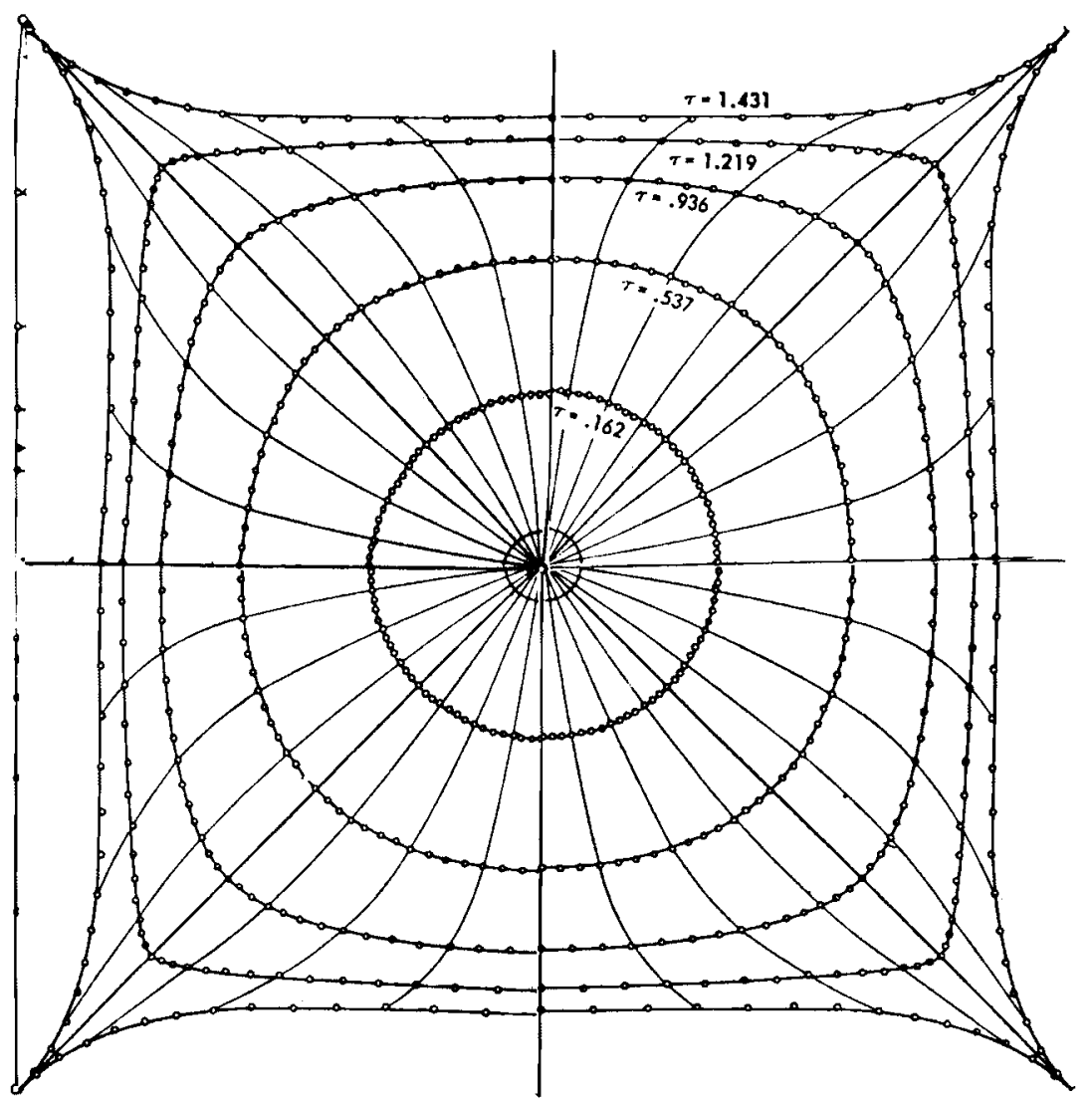

Figure A-14. Front and flow patterns for five-spot well pattern (injection). (Source: Collins, 1976)

It should be noted that various effects could facilitate breakthrough so the margin of safety in the well spacing should be liberal. Fissures, local variations of permeability or aquifer thickness, or other inhomogeneities may cause fingering in the breakthrough direction. As noted earlier, tilt in the thermocline caused by density differences will make the radius of the hot water volume greater at the top than at the bottom of the aquifer. The lower viscosity of hot water both exaggerates the tilt and facilitates fingering toward the withdrawal wells. 
for packers is an example of the possible applicability of this work. Hydrothermal cements for use in the completion of geothermal wells are described by Curtice and Mallow (1979) and Kukacka, et al (1977). R.L. Miller of Idaho National Engineering Laboratory has published information on chemistry and materials in geothermal systems, including reports on corrosion tests (1978, 1979a, 1979b).

The Environmental Protection Agency's Groundwater Research Branch has reported investigations of subsurface biota: Dunlap, et al, 1977; McNabb, Dunlap, and Keeley, 1977; Dunlap and McNabb, 1973.

Warner and Lehr (1977) prepared for EPA a definitive report on subsurface waste injection which covers not only chemical, physical, and biological compatibility of injected wastes but also geologic and hydrologic considerations and well construction information useful for ATES purposes. 
POTENTIAL GEOCHEMICAL PROBLEMS

A great deal is known about well plugging, corrosion, scaling, fouling, and biota as problems in industrial water treatment, petroleum engineering, geothermal development, and injection of waste materials into deep wells. All of these activities involve hot water, groundwater, aquifers, and wells. In addition, there is literature on wells supplying potable water which experience similar problems, but hot water is not involved. Such information is therefore fairly relevant (if somewhat discouraging) for ATES using non-potable aquifer water, but not very relevant for ATES in potable-water aquifers.

Without attempting to summarize the relevant knowledge, a few references will be suggested which are useful in themselves and also provide further references. The STES Program Office at Pacific Northwest Laboratory may be contacted for bibliographic lists.

The NALCO Water Handbook (1979) provides good descriptions of the nature and uses of water, water chemistry, and methods for water treatment.

Petroleum industry experience in water injection is extensive. Subcasky (1978) has summarized some of the relevant experience with particular regard to ATES.

Geochemical problems abound in geothermal development work. Some problems associated with injection wells are discussed in papers presented at Lawrence Berkeley Laboratory's Invitational Well Testing Symposium (LBL, 1978). Both LBL and the Pacific Northwest Laboratory (PNL) have computer codes to model geochemical interactions - water-rock, rock-water, and water-water. Stottlemyre and Cooley (1980), and Stottlemyre, et al (1979) have published results of research into geochemical aspects of ATES. Brookhaven National Laboratory and its contractors have published reports on use of alternate, nonmetallic materials for geothermal applications (Cabibbo, et a1, 1979; Kukacka, et a1, 1979a, 1979b) which describe corrosion resistance, high-temperature properties, scaling, and scale removal, among other topics. High-temperature sealing material 


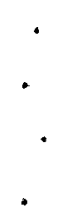

• 
APPENDIX B

AQQUIFER TYPES, AVAILABILITY, AND SUITABILITY FOR ATES

CONTENTS

Page

Summary

B-4

Introduction

B-4

Definition of Ground Water

B-4

The Occurrence of Ground Water

B-5

Major Types of Aquifers

$B-5$

Unconfined Aquifers

B-5

Confined Aquifers

B-7

Recharge and Discharge

$B-8$

Climatic Effects

B-10

Temperature

$B-12$

Water in the Unsaturated Zone

$B-13$

Topography

$B-13$

$B-15$

$B-15$

Clastics

$B-17$

Evaporites

$B-17$

Carbonates

$\mathrm{B}-17$

Igneous

B-18

Metamorphics

$\mathrm{B}-18$

Other Factors

$B-18$

B-18

Valley-Fil1 Aquifers

Sands and Gravels of the Coastal Plain

$\mathrm{B}-20$

Sands and Gravels of the Intermontane Valleys

$\mathrm{B}-22$

Alluvium of the High Plains

B-24

Glacial Drift

$\mathrm{B}-26$

Basalt Aquifers

$B-28$

Carbonate Aquifers

$\mathrm{B}-30$

Sandstone Aquifers

$\mathrm{B}-32$

Crystalline Rocks (Igneous and Metamorphic)

B-34

$B-36$

Natural Chemical Quality of Ground Water

B-40 


\section{APPENDIX B \\ AQUIFER TYPES, AVAILABILITY, AND SUITABILITY FOR ATES}

This appendix describes the different types of aquifers, the rock types comprising aquifers, where aquifers may be found in the United States, and their expected suitability for ATES purposes.

Readers already familiar with the hydrologic cycle, types of aquifers, and how water flows through them should skip the introductory material and proceed to "Rock Types Comprising Aquifers" (page B-15) or to "Principal Aquifers" (page B-18).

This appendix is basically a photographic reproduction of Section IV, "Nature and Extent of the Resource," from the U.S. Environmental Protection Agency's January 1977 Report to Congress: Waste Disposal Practices and Their Effects on Ground Water, edited by David W. Miller. The material is one of the better descriptions currently available of the various types of aquifers with maps showing where they occur in the United States.*

A regional aquifer assessment study is underway, funded by the U.S. Department of Energy through Battelle Pacific Northwest Laboratories. The goal of this study is to qualitatively describe the ATES potential of major aquifers throughout the United States. The regional aquifer assessment is expected to supersede the material presented in this Appendix.

\footnotetext{
“C.L. McGuinness' classic 1963 report, The Role of Ground Water in the National Water Situation (U.S. Geological Survey Water-Supply Paper 1800), provides a wealth of detailed information on State and local geology and on groundwater availability, use, and quality.
} 
The purpose of EPA's report was to discuss pollution of aquifers, not their availability or suitability for ATES. To make the material more directly applicable to ATES, portions of the EPA report dealing specifically with how waste materials may enter and pollute water-supply aquifers have been excised and replaced (in a different type face, the Letter Gothic used for this introductory material, and within brackets) with comments on the suitability for ATES of the various types of aquifers. 


\section{SUMMARY}

At almost any location, ground water may be tapped to provide a supply sufficient for single-family domestic use, and more than one third of the nation is underlain by aquifers generally capable of yielding at least $100,000 \mathrm{gpd}(380 \mathrm{cu}$ $\mathrm{m} /$ day) to an individual well. In many regions, ground water is the only economic and high quality water source available. In others, ground water can be developed at a fraction of the cost of surface water.

Ground water in aquifers across the nation is generally suitable for human consumption with little or no treatment necessary, except for disinfection where large, piped watersupply systems are involved. Salinities tend to be higher in arid regions and areas where drainage is poor.

\section{INTRODUCTION}

As discussed in the previous section, ground water presently supplies almost one quarter of the nation's total water supply. It provides the dry-season flow (base flow) of streams that otherwise might cease flowing part of the year. Some of the nation's largest cities and most of the rural population depend on ground water as a source of drinking water.

It has been estimated that total ground water in storage in the United states greatly exceeds the combined volume of all the Great Lakes, and that the amount of useable ground water is 150 times the amount of water presently used. At almost any location, ground water may be tapped to provide a supply sufficient for single-family domestic use. However, the distribution of ground-water reservoirs (aquifers) capable of supplying communities, towns, and cities is more limited.

DEFINITION OF GROUND WATER

In the hydrologic cycle, water is continually evaporated from the oceans, moves through the atmosphere, and eventually returns to the ocean through one or more paths. Of the water that precipitates, a portion infiltrates into the ground under the influence of gravity. It moves first through an unsaturated zone known as the "zone of aeration." Passing downward, the water arrives at the zone of saturation where the voids between the rock particles are complete- 
ly saturated. The water in the zone of saturation is called ground water. Figure 17 illustrates the relationships within the hydrologic system.

\section{THE OCCURRENCE OF GROUND WATER}

The ability of an aquifer to store and transmit water is a function of its porosity and permeability. Porosity reflects the volume of void space (pores) in a rock, and is an index of how much ground water can be stored in the saturated material. Porosity is usually expressed as a percent of the bulk volume of the material. Permeability is an index of how much ground water can be transmitted through a rock. The coefficient of permeability is expressed as the rate of flow of water (gallons per day) that will flow through a one-foot square area per unit of time under a hydraulic gradient of one, at a temperature of $60^{\circ} \mathrm{F}\left(16^{\circ} \mathrm{C}\right)$.

An index closely related to permeability is transmissivity. Transmissivity is simply permeability multiplied by aquifer thickness; it is indicative of the water-transmitting capacity of the entire aquifer thickness. Where the saturated rock is sufficiently permeable to store and transmit significant quantities of water, the rock is called an aquifer. Aquifers are defined by the ability to store and transmit water and not by rock type directly.

\section{Major Types of Aquifers}

The two major types of aquifers are: unconfined or watertable aquifers, and confined or artesian aquifers. Less permeable zones are called aquitards or confining layers. Figure 17 illustrates the major aquifer types.

\section{Unconfined Aguifers -}

When an aquifer is unconfined, the water is under atmospheric pressure. The upper surface of the aquifer is known as the water table and is free to rise and fall with changes in volume of stored water.

Under nonpumping conditions, the water level in a well and the adjacent water table are at the same elevation. The water table is responsive to changes in the amount of stored water, and fluctuates seasonally in response to variations in the rate of natural recharge. In the humid eastern states, for example, the water-table elevation is normally highest in spring and lowest in autumn.

The principal source of natural recharge to a water-table 


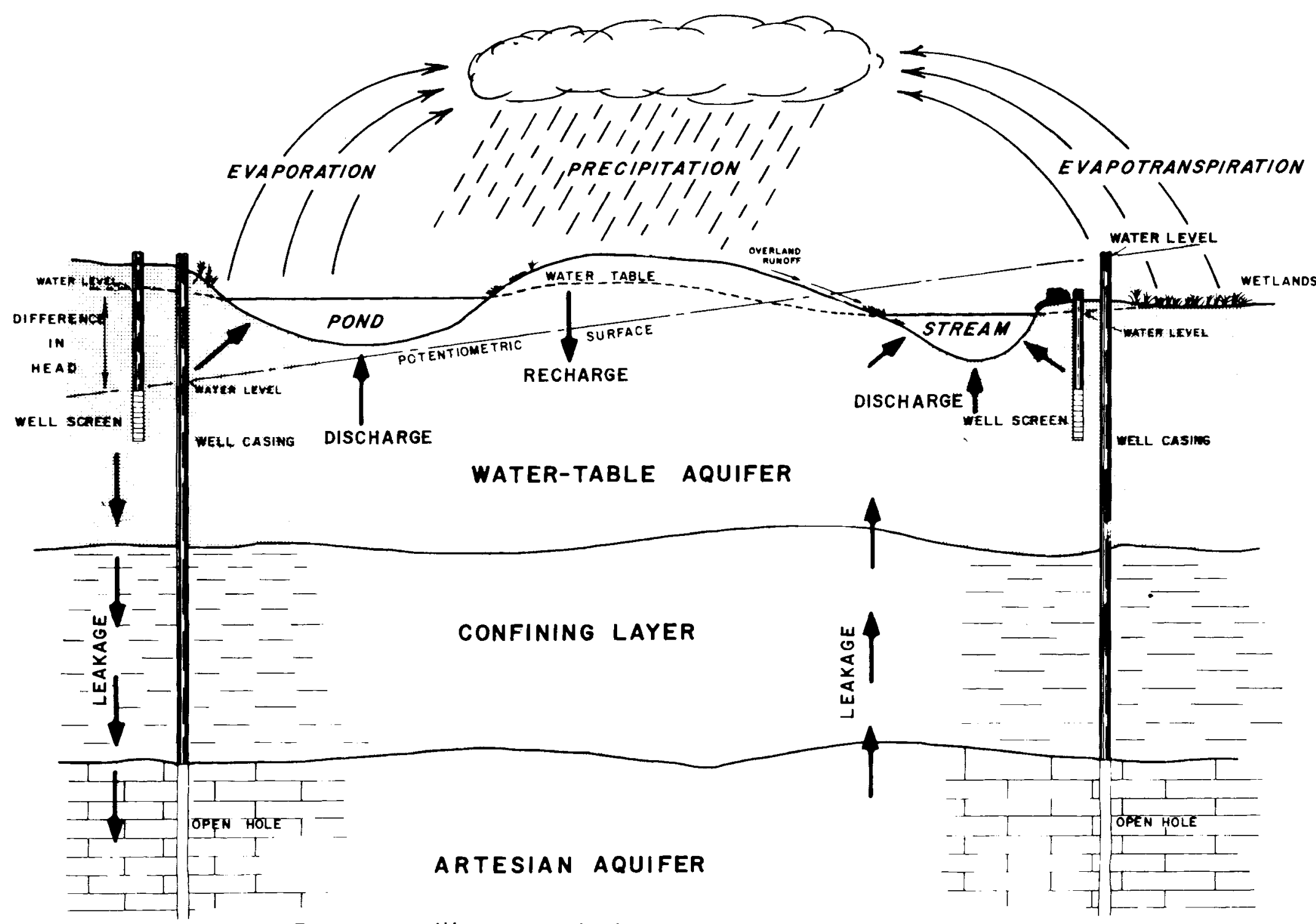

Figure 17. Illustration of relationships within the hydrologic system. 
aquifer is precipitation. In arid regions, because precipitation is infrequent, intermittent surface streams carrying runoff from other parts of the region may provide significant recharge. Perennial through-flowing streams of more humid regions can be areas of recharge to or discharge from water-table aquifers.

A variant type of water-table aquifer is a perched aquifer. occurring within the zone of aeration are beds of relatively low permeability, but of limited areal extent. Precipitation moving downward cannot pass easily through these beds, so a thin zone of saturation is created above the bed, forming a perched water body. Although perched aquifers are sometimes tapped by wells, they are usually not sufficiently thick or extensive to provide a significant supply of water. They do, however, restrict and control recharge to the underlying aquifer.

\section{Confined Aguifers -}

Confined or artesian aquifers are bounded below by geologic formations of relatively low permeability. In addition, an artesian aquifer is separated from the zone of aeration above or from shallow aquifers by geologic formations of low permeability. The aquifer is completely saturated with water, and the upper surface is defined and fixed by the lower limit of the overlying confining unit. Under nonpumping conditions, when a well is constructed and open only to an artesian aquifer, the water level in the well stands above the top of the aquifer at a height dependent upon the pressure in the confined aquifer (artesian pressure). Where sufficient pressure is encountered, the water level may stand above the top of the well casing, causing the well to flow. The hypothetical projection of the water levels is known as the potentiometric surface.

An artesian aquifer does not receive recharge everywhere uniformly. Most recharge is received in one or more general areas known as recharge areas. Rather than being sensitive to volumetric changes, the water levels in wells in artesian aquifers respond principally to changes in artesian pressure.

Rocks with identical characteristics may form an aquifer in one area, yet may act as a confining unit for a more permeable zone in another area. No confining unit is completely impermeable. Where an aquitard is sufficiently permeable to allow significant volumes of water to leak into or out of an aquifer, the aquifer is called semi-confined or leaky artesian. A water-table aquifer can overlie an artesian aquifer, separated by an aquitard. Two artesian aquifers can be sep- 
arated by a confining unit.

Recharge and Discharge

Ground water is constantly moving from a point of recharge toward a point of discharge. If a particular region is a recharge area, the recharging water exerts a stress on the aquifer in the form of increased hydrostatic head. This head seeks release in areas of low head, which are designated discharge areas. Thus, movement of ground water is from regions of high hydrostatic head toward those of low hydrostatic head. In practice, recharge and discharge areas of an aquifer are indicated by relative water levels. Within an aquifer, areas of high water-level elevations indicate higher hydrostatic head and areas of lower water-level elevations indicate lower hydrostatic head, so ground water moves from areas of high water-level elevations toward areas of low water-level elevations. The hydraulic head difference divided by the distance along the flow path is known as the hydraulic gradient.

Head differences can be induced artificially by pumping wells. As water is withdrawn from a well, a hydraulic gradient is produced, which causes water to move toward the well. A cone-shaped depression in the water table or potentiometric surface is produced (Figure 18). As more water is extracted, the depth and radius of the cone increase, blit at a decreasing rate, until the volume of water leaking into the aquifer exactly equals the withdrawal rate. At this point, the cone will stabilize (stop growing). Cones of depression from more than one well can overlap if leakage does not stabilize them first. In some cases, particularly in aquifers in arid western basins, the volume of water leaking to the cone (or cones) of depression never equals the total volume withdrawn. The cones continue to expand downward and laterally indefinitely. This activity is known as groundwater mining.

In addition to precipitation, a water-table aquifer can be recharged where it is hydraulically connected to a surfacewater source, such as a stream or a pond. A water-table aquifer can receive leakage through semi-permeable confining beds of an underlying artesian aquifer. Artesian aquifers can receive recharge from confining beds or from precipitation and surface-water bodies in the outcrop area of the aquifer.

Recharge locations can be points, lines, or areas. Natural point recharge locations are infrequent; individual sinkholes in limestone terrane are an example. Artificial point 


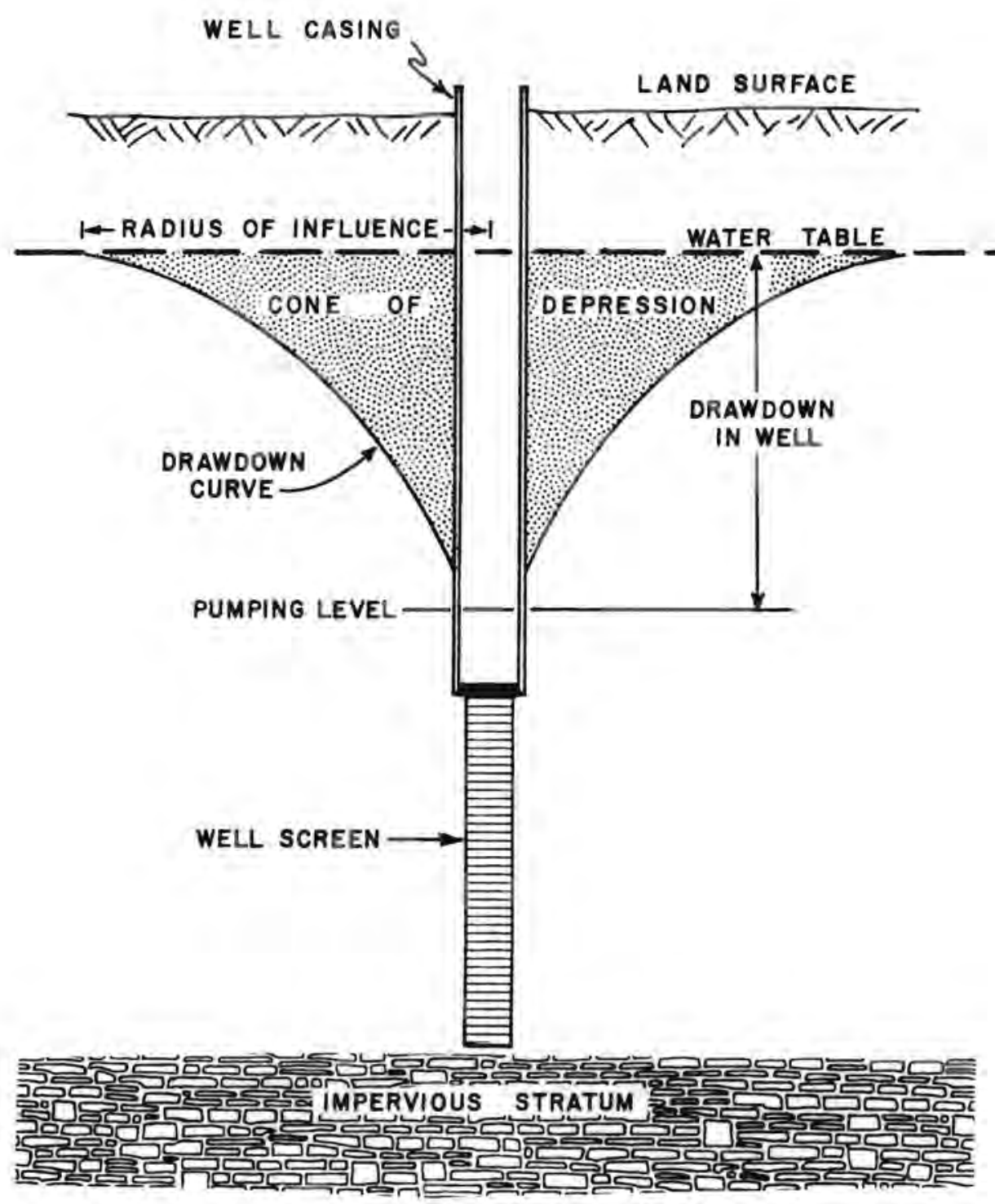

Figure 18. Cone of depression created by pumping in a water-table aquifer. 1) 
recharge locations are very common, and in fact are of major concern in a later section of this study. Examples include waste-disposal or recharge wells and individual septic tanks and cesspools. Natural line recharge is related to leakage from the beds of streams. This is a common situation in the western states where mountainous areas tend to capture precipitation, pass it to streams as runoff, and the streams carry it across valley-fill deposits where recharge to aquifers occurs. Natural line recharge also occurs along the edge of valley-fill deposits, the coarser layers of the fill receiving direct overland runoff from the adjacent mountains. Leaky sewage transmission pipes are an example of artificial line recharge. Most natural area recharge occurs across broad regions and is derived directly from precipitation. Artificial area recharge occurs where homes in subdivisions, as a group, each have septic tanks which recharge the aquifer. Reservoirs and large waste-water disposal ponds are also examples of artificial area recharge.

Discharge locations for aquifers can also be points, lines or areas. A spring is a natural point discharge location while a pumping well is an artificial point discharge location. Gaining streams can be line discharge areas. In this case, precipitation falling on adjacent upland areas infiltrates the water-table aquifer, and the ground water moves toward a nearby stream where it is discharged. Area discharge locations are swamps, ponds, lakes, and the sea. The volume of ground water naturally discharged to the ocean along the Atlantic coast is many times that discharged to wells, springs, and streams.

\section{Climatic Effects}

The amount of precipitation and the percent returned to the atmosphere (evapotranspiration) vary according to climatic conditions. Variations in the average precipitation in any region may create exceptional surpluses or deficits -- evidenced by floods or droughts -- during individual years. Figure 19 illustrates the average annual precipitation over the United States.

The processes which return water from the land surface to the atmosphere are evaporation and transpiration. The combined term evapotranspiration represents the amount of water lost to the atmosphere from the land surface. A distinction has been made between potential evapotranspiration and actual evapotranspiration in an area. Potential evapotranspiration represents the volume of water which would be lost from a completely vegetated area if there were no water deficiency at any time. On the other hand, actual evapotranspira- 


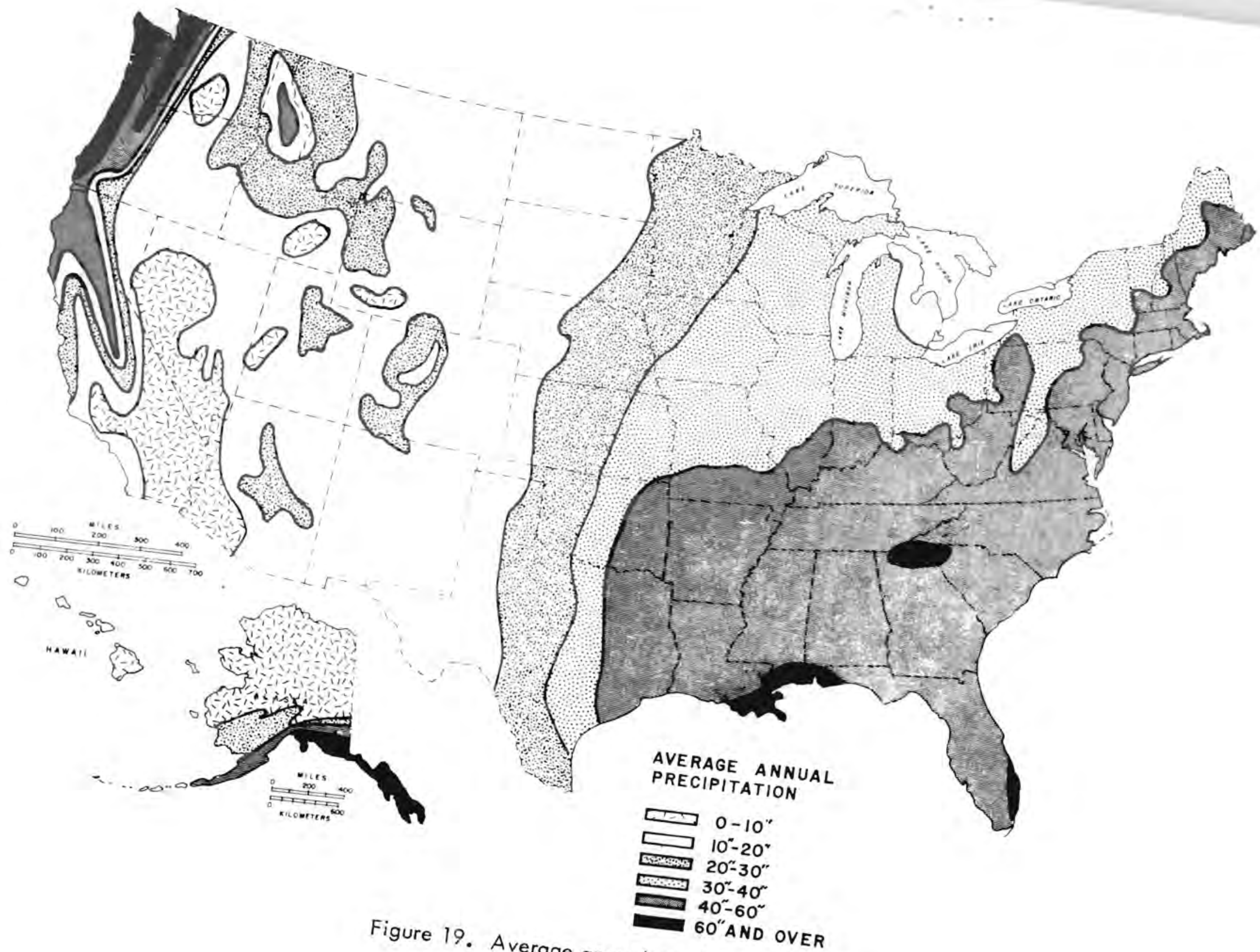

Figure 19. Average annug

$$
\text { annual precipitation. 2) }
$$


tion is the real volume of water lost under prevailing conditions. Except in rain forests, potential and actual evapotranspiration are seldom equal.

Wherever evapotranspiration is greater than the precipitation, ground-water recharge by downward percolation through the zone of aeration is minimized. Such water-deficient areas exist, especially in the desert lowlands of the southwest, where annual precipitation is less than 10 in. $(25 \mathrm{~cm})$, and potential evapotranspiration is 4 to 20 times greater.

In areas of prevailing water deficiency in the western states, ground-water recharge may result from abundant precipitation during "wet" years or multi-year cycles, rainy seasons, or prolonged storm periods. In many valleys that are practically rainless throughout the warmer half of the year, winter precipitation provides the major portion of recharge to shallow ground waters. In other valleys, there may be evidence of ground-water recharge only during years of greater than average precipitation.

In the eastern states, annual precipitation exceeds evapotranspiration, creating surpluses which discharge to and form the base flow of perennial streams and springs. But the locale of the water surpluses may vary from season to season. In the winter, with minimum evapotranspiration, water may accumulate in the soil and percolate downward. In the growing season, vegetation depletes the soil moisture and, even with frequent rains, may leave nothing for groundwater recharge.

\section{Temperature}

Temperature is also an important factor in ground-water recharge. In northern latitudes and western mountainous regions, floods have resulted from rain falling upon accumulated snow during unseasonably warm periods in winter or early spring. The flood runoff is increased if the underlying soil is frozen, thus preventing infiltration. The persistence of extremely low temperatures may cause unusual conditions which acutely affect the existence and flow of ground water. Permafrost, or permanently frozen ground, is common in Alaska, and exists over 60 percent of the state. Within these regions, the soil from a few feet to several hundred feet below the surface is continuously frozen with the exception of a relatively thin, seasonally-thawed surface layer.

Permafrost zones act as confining beds, and both their composition and distribution have a significant influence on 
patterns and rates of ground-water flow. In a number of basins, the artesian pressure of water confined below permafrost causes wells drilled through the permafrost to flow. Ground-water discharge may be restricted to the lower, central part of many river valleys where the permafrost is discontinuous. In the region of continuous permafrost, unfrozen zones penetrate the permafrost only where salinity of the ground water prevents freezing, or where heat transfer from a body of surface water or from discharging subpermafrost water is sufficient to maintain the unfrozen conditions.

Water in the Unsaturated Zone

The unsaturated zone occupies a critical position in the hydrologic cycle. The relationship between the unsaturated and saturated zones is shown in Figure 20 .

From land surface, the unsaturated zone receives water from precipitation to the limit of its infiltration capacity; the rest is left for surface storage, runoff, or evaporation. In most places, the upper part of the unsaturated zone is soil, which absorbs the infiltrating water, and retains much of it against the force of gravity until such time as the water is taken up by plant roots or otherwise returned to the atmosphere.

Some water, in excess of the retention capacity of the soil, percolates downward through the soil. In some places, the unsaturated zone is permeable enough to receive water rapidly and permit downward percolation with little retention. Under most of the land, the unsaturated zone extends below the soil and below plant roots to depths ranging from a few feet to hundreds of feet.

Topography

The amount of precipitation which recharges to ground water in any specific area depends, to some degree, upon topography. Rolling terrain, particularly when underlain by soils of low infiltration capacity, facilitates rapid runoff of precipitation to surface-water bodies. In valleys surrounded by mountains, the mountains tend to capture precipitation and direct it into the valleys, where it can recharge underlying aquifers. Spring runoff from snow melt in mountain areas is the principal source of recharge to many arid and semi-arid valleys in the western states. 


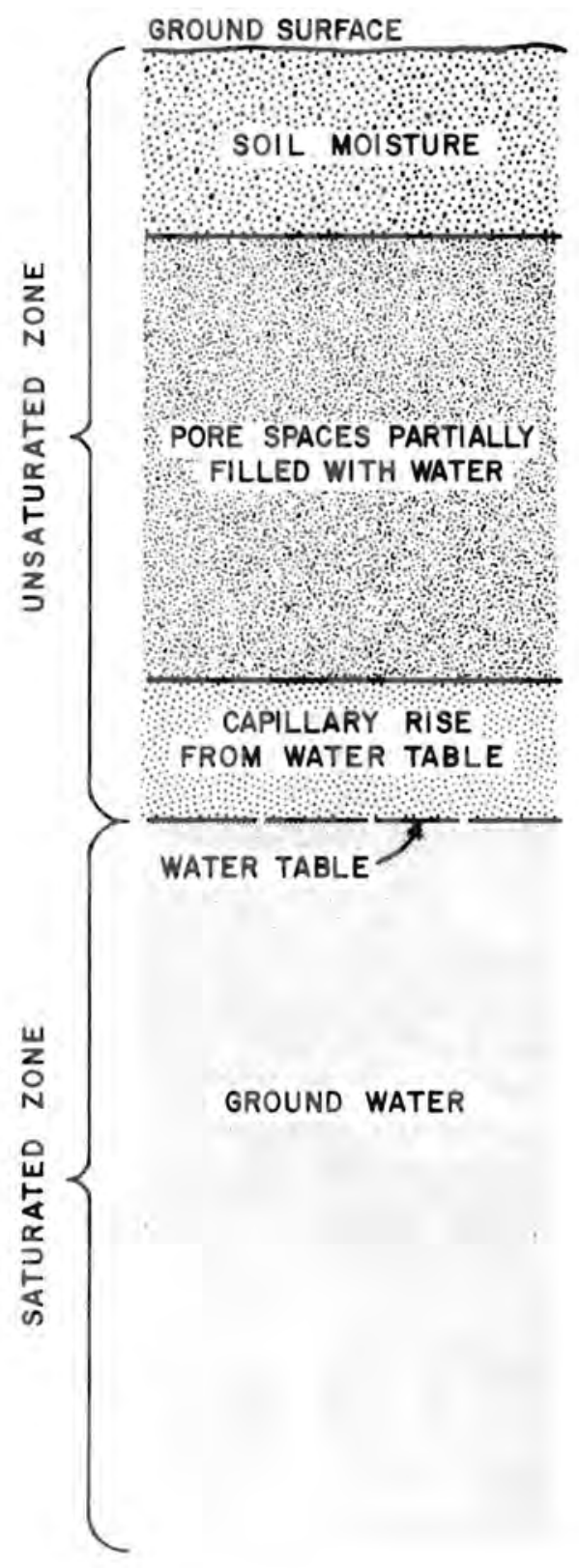

Figure 20. Relationship between unsaturated and saturated zones. 1) 


\section{ROCK TYPES COMPRISING AQUIFERS}

The principal aquifers in the United States consist of saturated sedimentary, igneous, and metamorphic rocks. Among the sedimentary rocks are clastics, evaporites, and carbonates. Clastics may be subdivided into consolidated and unconsolidated rocks. Igneous rocks also are divided into two classes: plutonics and volcanics. Volcanics are subdivided into flows and pyroclastics. Metamorphic rocks are not subdivided. Figure 21 shows several types of interstices (openings or void spaces) found in aquifers.

\section{Clastics}

Clastic sedimentary rocks are composed of fragments of other rocks transported from their sources and deposited by water or glacial ice. Clastics include both unconsolidated and consolidated rocks. Unconsolidated deposits are relatively uncemented and loosely compacted. The degree of consolidation is determined by the degree of cementation and compaction. In unconsolidated clastics such as gravel and sand, ground water is stored and transmitted in the interconnected voids which occur between individual grains.

Water availability in unconsolidated rocks is greatly affected by sorting and grain size. Deposits which are well sorted have many particles of the same or similar size. This assures that very little of the available pore space will be occupied by grains which are either overly large or overly small.

A high degree of sorting alone, however, does not insure high ground-water availability. Water moving through rock has a tendency to cling to the rock by capiliary and molecular attraction, forming a thin coating of water on the individual grains of rock. This water is unavailable to wells. Where grain sizes are small, as with silt and clay, even a well-sorted deposit will have a significant percentage of pore space occupied by retained water. Although the quantity of water in storage is great, that which is available is so small that clays and silts are normally considered to be confining beds. Well sorted sands and gravels, on the other hand, are considered aquifers.

As much as 30 percent of ar unconsolidated rock may consist of pore space. Where sedimentary rocks are partially consolidated, a precipitated substance like silica or calcium carbonate occupies some of the space and cements some of the individual grains together. As a result, the intergranular space available for ground-water storage is decreased, and 
SAND AND GRAVEL

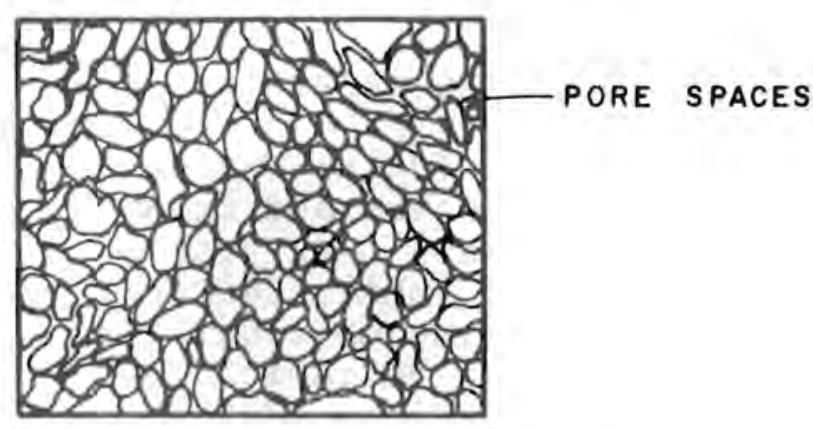

CONSOLIDATED ROCK:

IGNEOUS, METAMORPHIC, SEDIMENTARY

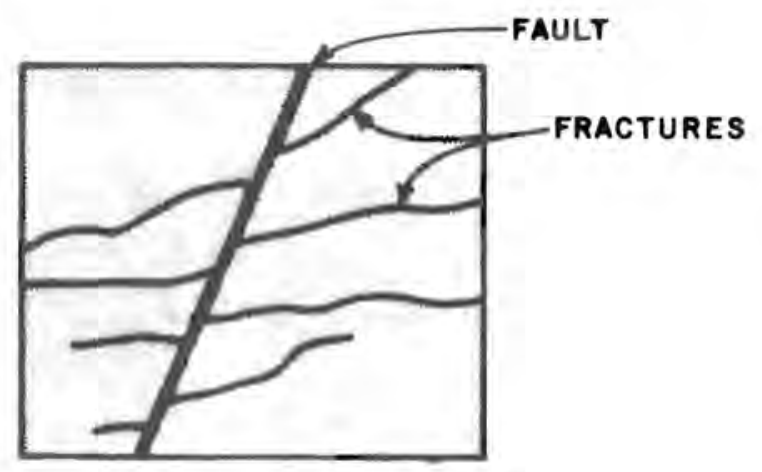

CARBONATE ROCK:

LIMESTONE, DOLOMITE

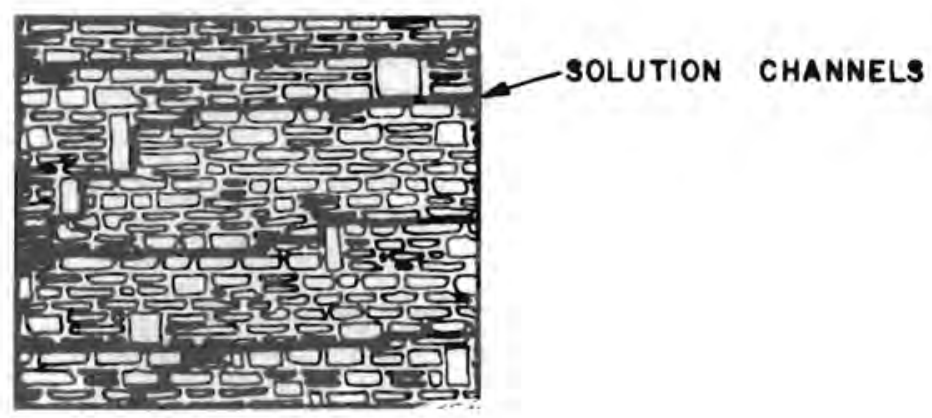

VOLCANIC ROCK:

LAVA FLOWS

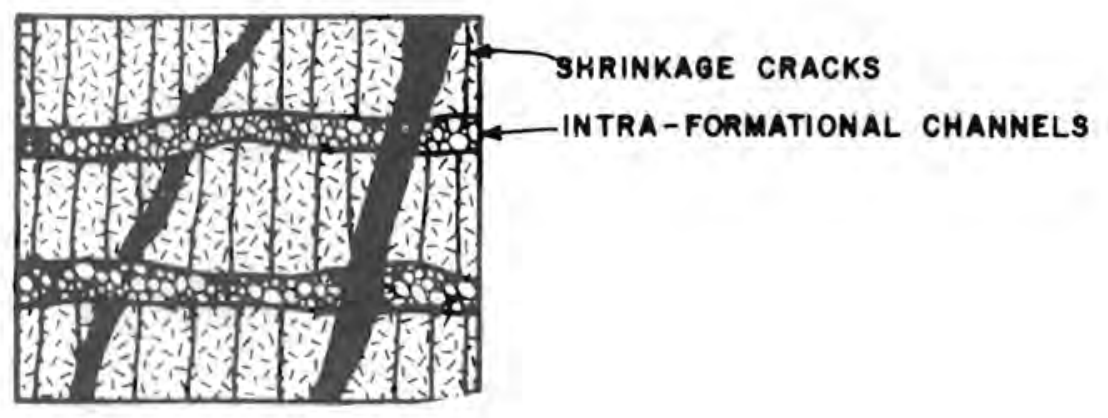

Figure 21. Rock texture in major aquifer types. ${ }^{3)}$ 
the available interconnected spaces needed for ground-water transmittal are also decreased. Where completely consolidated, a major portion of the available pore space has been decreased by cementation and/or compaction.

\section{Evaporites}

Sedimentary rocks which form by precipitation of dissolved minerals are called evaporites. When such deposits come into contact with fresh ground water, rapid dissolution occurs. Where other rocks are interbedded with evaporites, the voids produced by dissolution produce highly permeable aquifers. Unfortunately, ground water in these aquifers is normally so high in total dissolved solids that it is useless as a drinking-water source without costly treatment.

\section{Carbonates}

Rocks produced by secretions from organisms form a third class of sedimentary rocks known as carbonates. Shells and bones from aquatic animals collect on floors of seas, lakes, and streams. The matter is compacted and crystallized to form carbonate rock. Natural ground water, which is slightly acidic, can slowly dissolve carbonate rocks along joints and fractures. The resultant porosity and permeability may range from low values where the rock is slightly fractured to extremely high values where extensive fracturing and solution have taken place.

In some carbonate rocks, intergranular permeability is much more important than that attributable to fractures and solution openings. Some of the best aquifers of the southeastern coastal plain consist of soft coquinoid or bryozoan limestone or of slightly dolomitized limestone apparently owing most of its permeability to crystal-volume changes during dolomitization. In such aquifers, high permeability is so widespread that properly completed wells can obtain large yields almost everywhere.

Igneous

Igneous rocks form by crystallization of molten rock. Plutonic rocks cool and crystallize deep beneath the land sur- 
face, and volcanic rocks cool and crystallize on or near the surface. As with consolidated sedimentary rocks, ground water is available from fractures and joints, between layers, and along faults. A special class of volcanic rocks is known as pyroclastics -- unconsolidated to semi-consolidated deposits of fragmental material blown from volcanoes. However, pyroclastic deposits are rarely extensive. Groundwater availability in pyroclastics is variable but similar to that in semi-consolidated sedimentary rocks.

Metamorphics

Metamorphic rocks are recrystallized deposits of previously formed sedimentary and igneous rocks. No distinction is made here between metamorphic rocks of sedimentary origin and those of igneous origin. The listinction has little bearing from the standpoint of ground-water availability. Metamorphic rocks store and transmit water in a manner similar to plutonic rocks.

Other Factors

Other factors exert major influences on the availability of ground water from certain rock types. A principal factor is the variation in structure of geologic formations from one place to another. For example, in consolidated rock aquifers, a well drilled through a fault (a major break in the rocks) may be significantly more productive than a well in the same aquifer away from the fault. Faulting of the rocks produces more fractures along which ground water can move and be stored.

Weathering may also affect ground-water availability. In unconsolidated deposits, weathering of rock fragments may turn some of them to clay, thereby decreasing permeability. For consolidated rocks, weathering may enlarge or increase the number of joints and fractures, thereby improving the ability of the aquifer to yield water to wells.

\section{PRINCIPAL AQUIFERS}

\section{Valley-Fill Aquifers}

Valley-fill aquifers are composed of sand, gravel, and silt and generally lie along the course of present-day streams and rivers. Figure 22 indicates the locations of the major valley-fill aquifers. They are comprised of channel, floodplain, and terrace deposits, and are usually in direct hydraulic connection with surface streams. The deposits in each valley act as a single hydrologic unit, existing under 


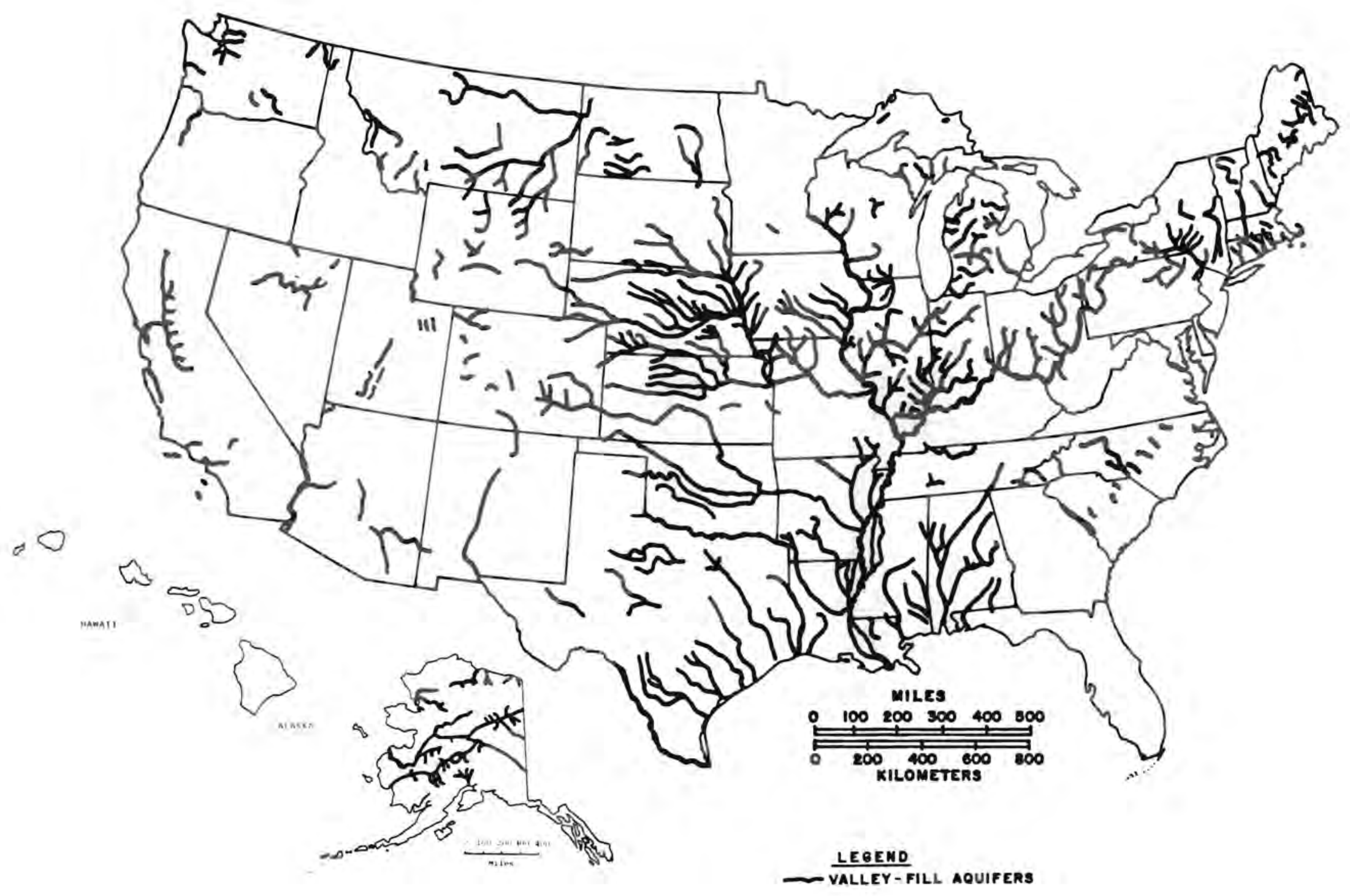


water-table or leaky artesian conditions. Where permeable valley-fill aquifers exist adjacent to perennial streams, large potential for ground-water development exists because of the opportunity to supplement natural recharge with infiltration of surface water.

The availability of potable water and the gentle topography of stream valleys has made them popular areas for urban development -- for example, the Ohio River valley and the Susquehanna River valley.

Because of the widespread distribution of valley-fill aquifers, no general statement can be made with regard to natural ground-water quality. However, the heavy use of these aquifers by industries and municipalities indicates the availability of generally good quality water.

[For ATES purposes, shallow valley-fill aquifers may be useful for storage of chilled water but are unlikely to be suitable for storing hot water. Deeper formations, confined or partially confined, are more likely to be suitable for ATES.

[Documented experience in large-scale aquifer storage of cold water in winter for use in summer dates back at least as far as World War II, when distilleries in Louisville, Kentucky, recharged cold municipal water into their own supply wells during the winter, to be withdrawn in summer for process cooling. A similar purpose was served by recharging aquifers near Peoria, Illinois, along the Illinois River, using cold river water drawn by gravity into a recharge pit. This project was conducted by the Illinois State Water Survey, beginning in 1951. (See D.K. Todd, Ground Water Hydrology, Wiley, 1959.) In a DOE-sponsored field test at Texas A\&M University, winter-chilled water was injected into a partially-confined aquifer during January, February, and March 1979. Because of unusually high regional flow in the aquifer, much of the cold water was swept away and only 23 percent of the injected chill was recovered by pumping during July, August, and September 1979.]

Sands and Gravels of the Coastal Plain

Extensive deposits of clastics are deposited seaward of ancient uplands from which they were eroded. The principal water-bearing units are sands and gravels, which are interbedded with silts and clays, and occasionally marls and limestones. The sediments were deposited on plains only slightly above sea level or in the shallow near-shore marine environment. Land emergence has since raised these sediments above sea level. The most extensive coastal plain in the United States (the Atlantic-Gulf Coastal Plain) extends from Cape Cod, Massachusetts, to Texas (Figure 23). 


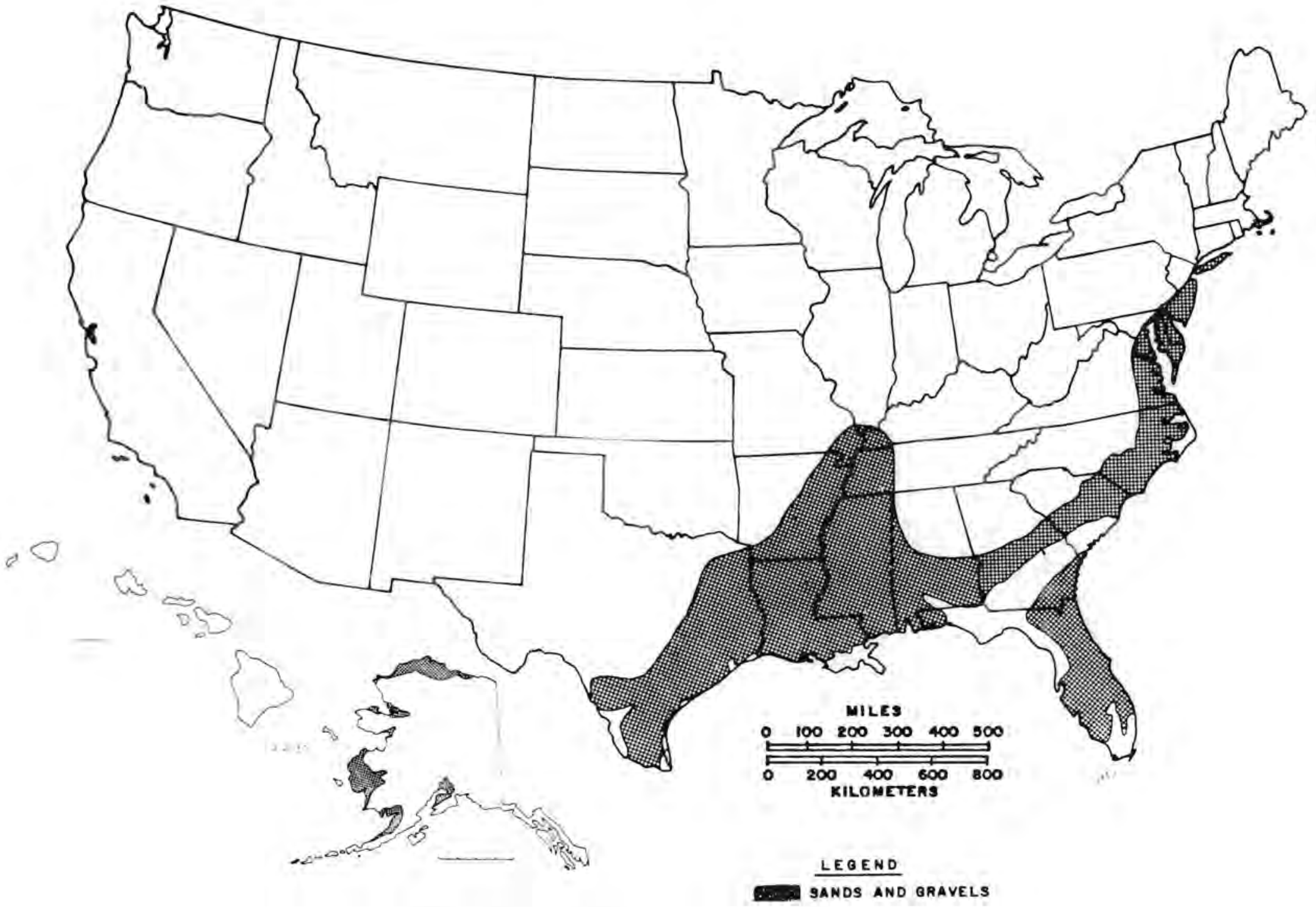

Figure 23. Sands and gravels of the coastal plain. 
Coastal plain sediments thicken seaward, and progressively younger geologic units outcrop in seaward direction. Although the outcrop areas of all units are under water-table conditions, the deeper sections are strictly artesian.

Where some confining units are thin or moderately permeable, leaky artesian conditions may allow ground-water flow between artesian aquifers.

The outcrop areas of coastal plain aquifers receive recharge by direct precipitation and leakage from surface-water bodies. This recharge is transmitted downgradient within the aquifer to replenish the artesian portion. An additional source of recharge, where artesian conditions prevail, is inter-aquifer flow. Natural discharge areas for coastal plain aquifers are near the present shorelines.

The natural water quality of coastal plain aquifers is generally good, particularly near outcrop areas. Problems do exist in some areas, however, principally related to low pH, high concentrations of iron, and the presence of connate saline water.

[Artesian aquifers of the Coastal Plain are extensive and of particular interest for ATES.]

Sands and Gravels of the Intermontane Valleys

Mountain building periods in the western states have created intermontane valleys (Figure 24 ). These valleys have filled with sediment eroded from the adjacent mountains. The sediments include rock detritus, alluvial sand and gravel, and silts and clays. The permeable alluvia constitute excellent aquifers, and the valleys contain enormous quantities of water in storage. Because the sediments were transported by surface runoff from adjacent mountains, the aquifers are generally coarse grained toward the edges of the valleys and finer toward the centers. Occasionally, extensive clay and silt deposits are encountered within the geologic sequence.

Water-table and leaky artesian conditions prevail except where the extensive silts and clays overlie water-bearing zones (producing tightly confined aquifers). Because the intermontane valleys occur in generally water-deficient areas, little recharge is received by direct, downward percolation. The major source of recharge is runoff from adjacent mountains -- particularly from snow melt and spring rains -- which flows down mountain canyons and percolates into the coarse deposits at the edges of the valleys. In many intermontane valleys, pumping from wells far exceeds annual recharge, seriously depleting the resource. 


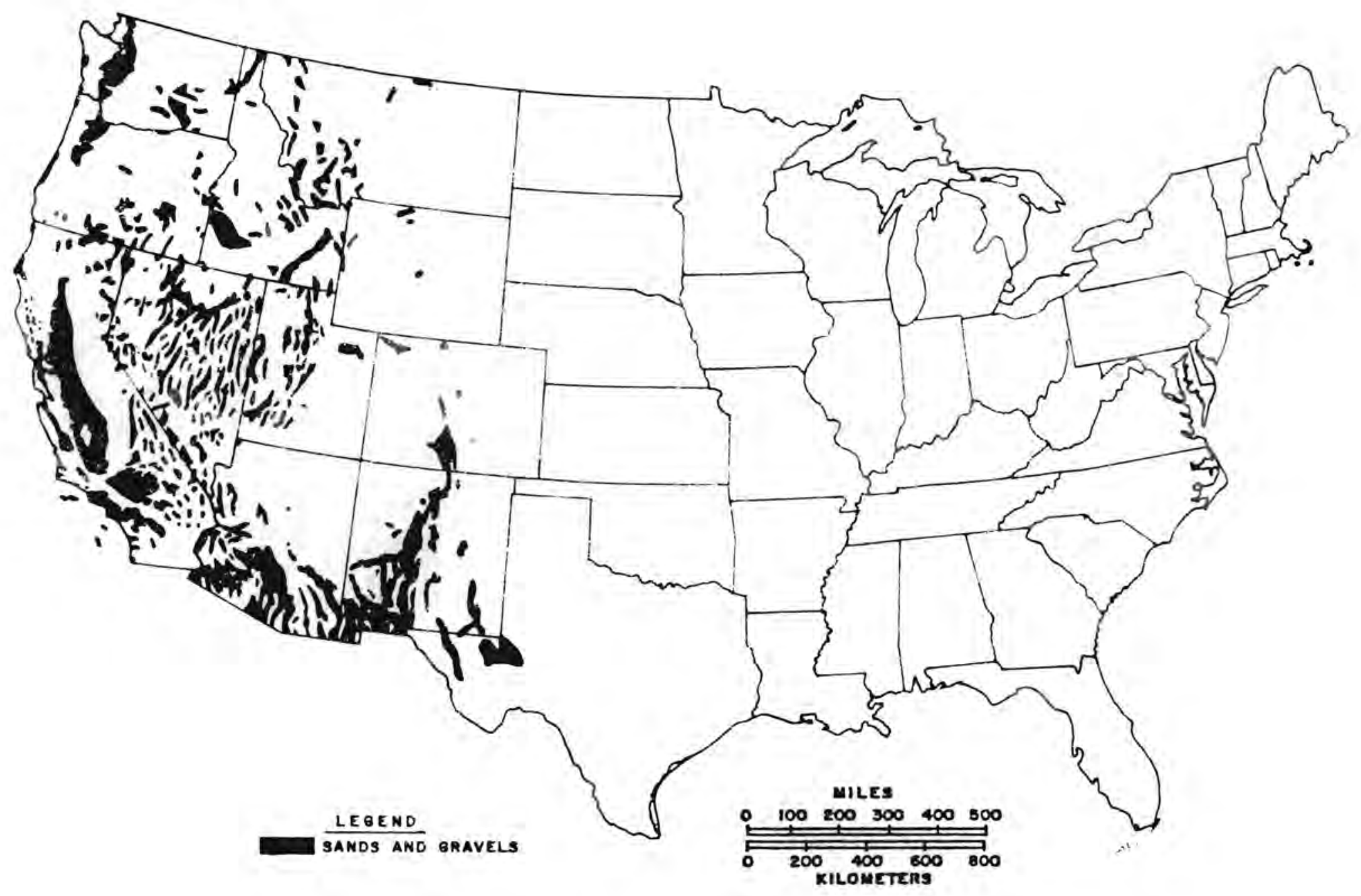

$\frac{\omega}{\omega}$

Figure 24. Sands and gravels of the intermontane valleys. 
[Particularly in the deeper aquifers of the intermontane valleys, tightly confined by impermeable layers of clay or silt, regional flow typically is low and artesian pressure is high. Such aquifers are of special interest for storing superheated water.]

\section{Alluvium of the High Plains}

Alluvium, derived from the Rocky Mountains and laid down by eastward flowing streams, was deposited on a vast plain stretching from Wyoming to Texas (Figure 25). A large part of the original plain has been eroded by streams along its margin, but the remnants exist as the High plains. The region is an important ground-water area because of the abundance of saturated sand and gravel, interbedded with silt and clay. The chief water-bearing unit is the Ogallala Formation.

Leaky artesian conditions prevail in the High plains. Recharge is chiefly by downward leakage of direction precipitation through water-table beds. The High plains lies completely within the water-deficient region of the United States, so recharge is variable. Generally, the southern part receives no recharge, and the northern part receives as much as 5 in. $(12.7 \mathrm{~cm})$ annually. Major streams can provide additional recharge where they have eroded into waterbearing zones. veal lly suins

The chemical quality of water in the High Plains is satisfactory for irrigation and generally meets the requirements for drinking water. Total hardness ranges from 200 to 600 ppm, although the average is less than $300 \mathrm{ppm}$. Excessive fluoride is a problem in some areas with local concentrations up to $5 \mathrm{ppm}$, and commonly exceeding $1.5 \mathrm{ppm}$. Silica may also be high, ranging up to $40 \mathrm{ppm}$. Total dissolved solids concentration averages less than $300 \mathrm{ppm}$, but may be as high as 1,000 ppm or greater. The quality of the water tends to deteriorate toward the southern end of the High Plains, and also tends to degrade with decreasing depth to the water table -- a condition produced by evapotranspiration, which has concentrated dissolved salts near the surface.

[Deeper formations in some locales are known to contain saline water because it sometimes has migrated upward into overpumped freshwater aquifers. While saline aquifers may be of interest for ATES purposes, the possibility that injection pressures may cause increased upward leakage will have to be taken into account. Yet to be explored is the feasibility of ATES in confined aquifers which have been overpumped, and are no longer pressurized because of dewatering.] 


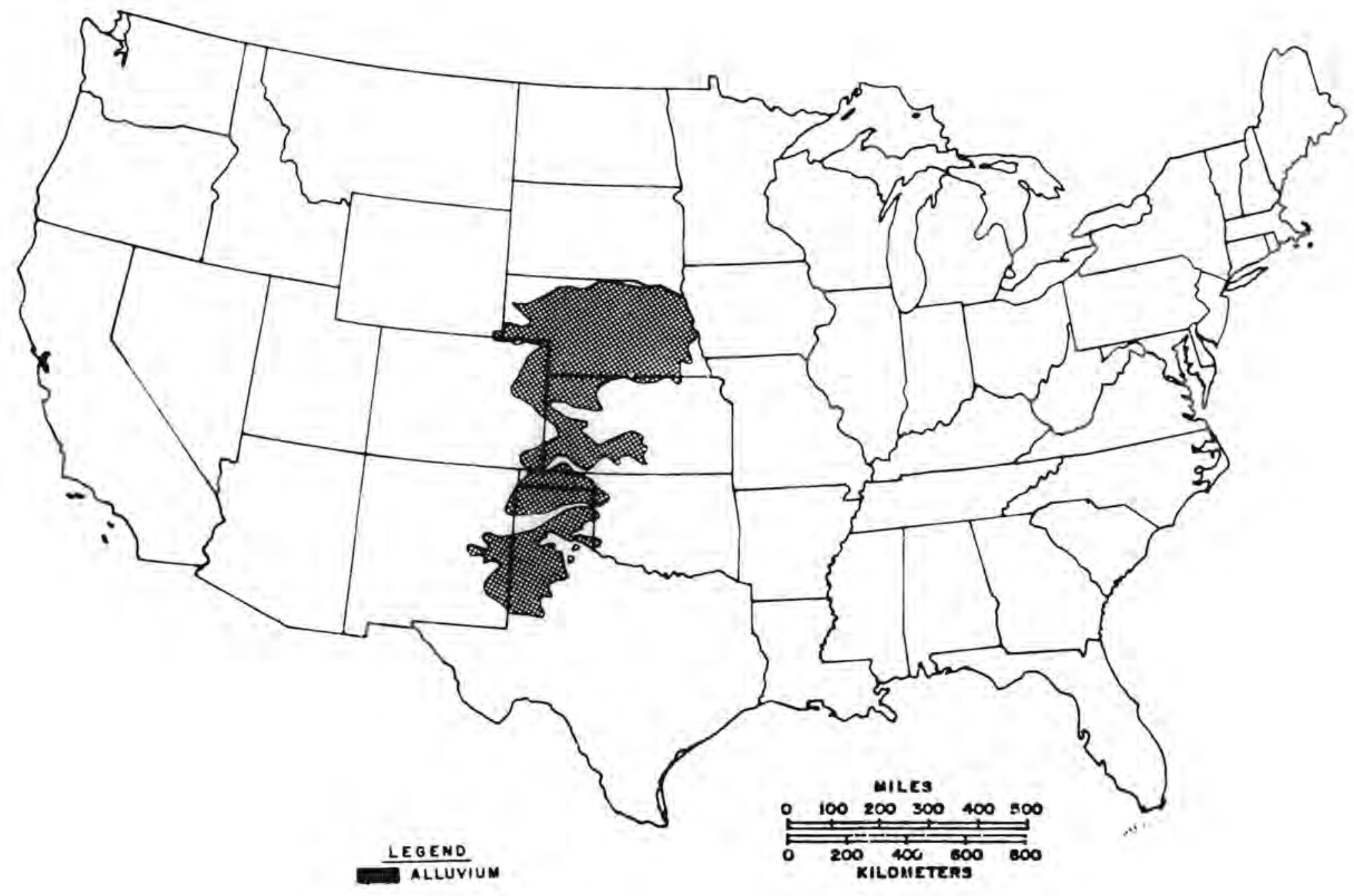

心̊

Figure 25. Alluvium of the High Plains. 


\section{Glacial Drift}

During the Ice Age, glacial ice (continental glaciation) covered northern portions of the country (Figure 26). Glaciers also occupied major river valleys. Repeated glacial advances eroded the soil and bedrock and incorporated the material in the ice. When the ice melted, these particles were left behind or were carried across the land surface by melt water. Glacial drift is composed of all particles carried by the ice, regardless of size. Those deposits left in place (tili) are unsorted; those sediments that were transported by water before deposition are generally better sorted. Where many small sediment-laden streams issued from the melting glaciers, broad extensive outwash deposits occurred, which are usually very productive water-table aquifers. Where fine grained glacial drift was deposited in standing bodies of water, like lakes in ice-dammed stream valleys, the resulting low permeability deposits constitute confining beds for underlying valley-fill aquifers.

The presence of low permeability till is much more common than that of more permeable water-borne deposits. Although till is tapped for small domestic supplies using dug wells, it more often acts as the confining bed for an underlying artesian sand and gravel aquifer.

The natural quality of water in the glacial drift reflects the regional geology. In New England, where much of the bedrock is crystalline, the ground water in the glacial drift is normally of good quality and low in mineral content, although high concentrations of iron and manganese are not uncommon. In the Ohio River basin, the water in glacial-drift aquifers is generally hard and can be high in mineral content, especially calcium bicarbonate and sulfate. Similarly, in the Upper Mississippi River basin, much of the ground water has a total dissolved solids content ranging from 300 to $1,000 \mathrm{ppm}$, with hardness from 120 to $700 \mathrm{ppm}$. Still farther west, in the semi-arid Dakotas, ground water in the glacial drift, although of better quality than in the underlying bedrock aquifers, may have a mineral content exceeding 1,000 ppm and may be locally brackish or even saline.

[Glacial drift aquifers commorily are under water-table conditions, highly permeable, and in regions of abundant precipitation. Downward percolation is therefore substantial and would dilute hot water stored in the aquifer - the hot water having a tendency to float to the top of the saturated zone, where it would be particularly subject to mixing with percolating water. Seasonal storage of chilled water in such aquifers could be attractive, if the local hydraulic gradient and regional flow are not too high or can be neutralized. 


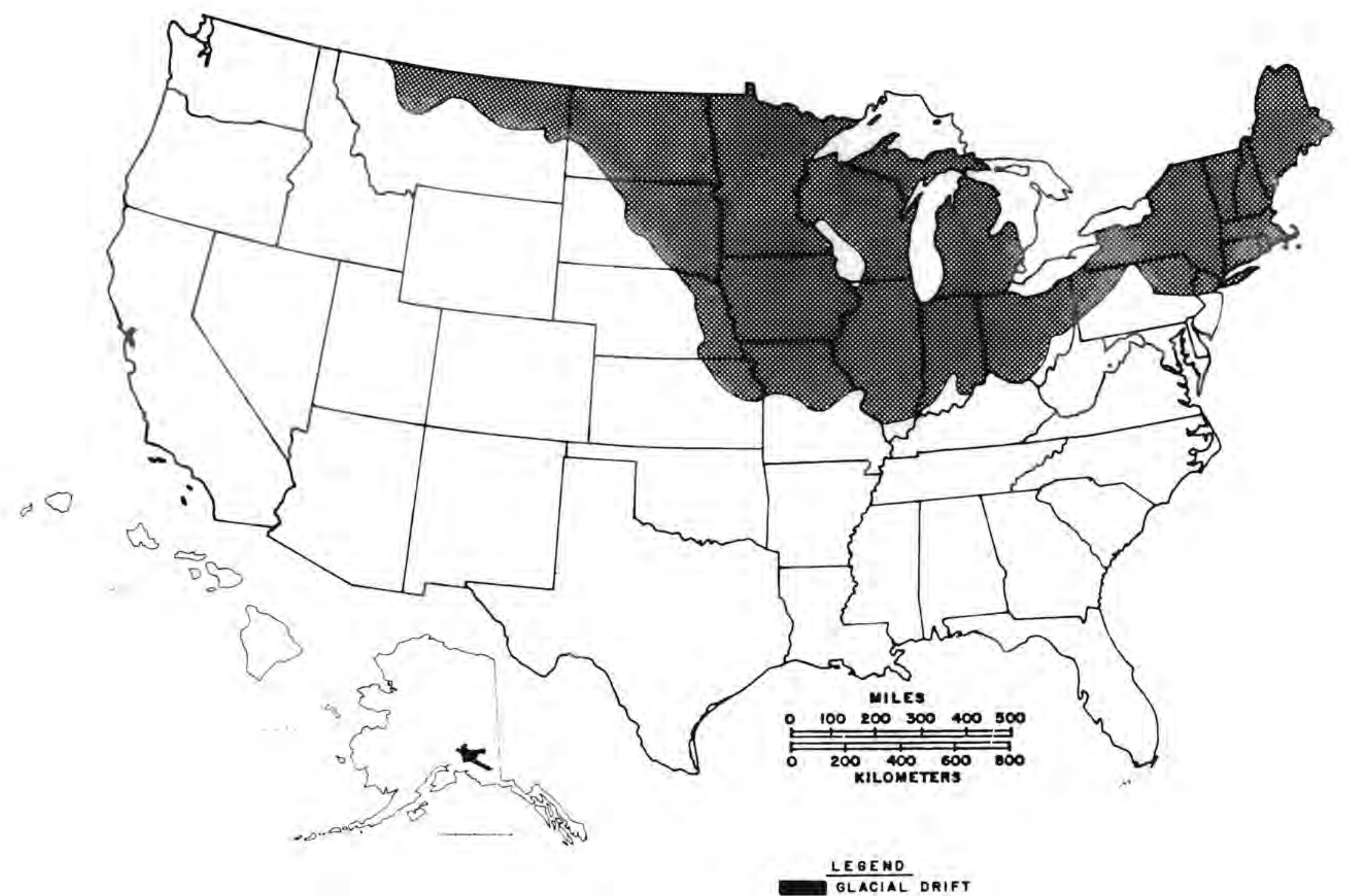

$\frac{1}{1}$

Figure 26. Glacial drift. 
[Storage of hot water in confined, shallow, high-permeability, glacioalluvial aquifers called eskers, which are common in Sweden, has been analyzed by $\mathrm{Claesson}$ and Hellström of the Lund Institute of Technology and Tsang of Lawrence Berkeley Laboratory. Because of the high permeability, buoyancy effects cause severe tilting of the thermal front, which is aggravated during the injection phase by the lower viscosity of hot water. The heat recovery efficiency may be quite low for permeabilities higher than one to ten darcys $\left(10^{-12}\right.$ to $\left.10^{-11} \mathrm{~m}^{2}\right)$.]

\section{Basalt Aquifers}

Basalt is volcanic rock which has flowed as lava across the land surface, or has intruded near the surface, and subsequently cooled. The basalt aquifers are thick, extensive sheets of rock piled in layer-cake fashion and interbedded with unconsolidated sediments. High capacity wells tap the natural openings between the basalt flows and depending upon their permeability, the interbedded sediments. Figure 27 shows the distribution of the principal basalt aquifers.

Ground water in the basalt aquifers occurs under artesian to leaky artesian conditions, produced by the varying permeabilities of individual beds in the aquifers. Recharge is almost exclusively by direct precipitation. Streams and rivers are incised deeply into the aquifers and serve to receive discharge from the aquifers rather than provide recharge to them.

In Hawaii, where basalt aquifers constitute most of the islands' ground-water reservoirs, water-bearing zones occur under both water-table and artesian conditions. Recharge is by both direct precipitation and stream flow. Hawaii's ground-water conditions are unusual because the basalt aquifer is sloping and is cross cut by many vertical dikes, most of which are impermeable and divide the aquifer into compartments. Individual compartments, if untapped, can fill and overflow to a compartment at a lower elevation through seeps and springs. A natural system of reservoirs is thus provided, which can be tapped by wells and tunnels for water supply.

The water in the basalt of the northwestern states typically has a total dissolved solids content in the range of 200 to $300 \mathrm{ppm}$. The best quality is found near recharge areas and in shallow aquifers. The waters are generally of a calciummagnesium bicarbonate type, with total hardness ranging from 50 to $250 \mathrm{ppm}$. In addition, the water in these aquifers generally contains 40 to $80 \mathrm{ppm}$ of silica, and locally, excessive iron. The qround water of Hawaii is of excellent quality with total dissolved solids concentrations in the range of 100 to $300 \mathrm{ppm}$. 


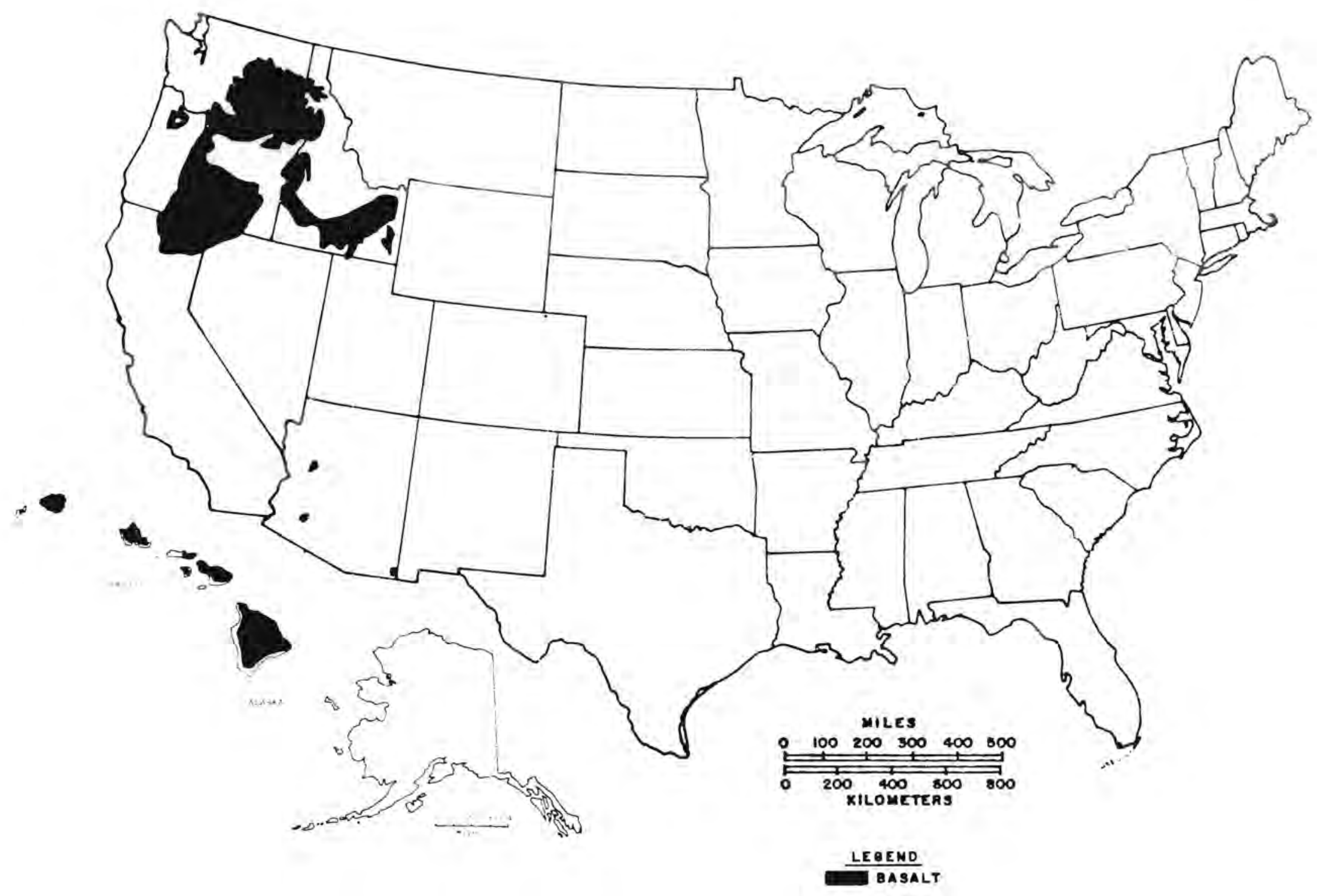

Figure 27. Basalt aquifers. 
[That basalt aquifers can produce large amounts of water into wells tapping the natural openings between basalt flows (sometimes, lava tubes) is not promising for ATES purposes: the hot or cold water would be quite likely to flow away from the injection well too readily, and be lost. Also, buoyancy effects in such high permeability formations can cause the same type of severe tilting of the thermal front mentioned earlier with regard to eskers. However, permeability within the Lower Yakima basalt flows and interbeds in Washington has been reported to vary by seven orders of magnitude. Since the average total thickness of the Columbia River Plateau exceeds 500 meters, stratigraphy and structure suitable for ATES very probably exist but may be difficult and expensive to locate and utilize.]

\section{Carbonate Aquifers}

Limestone and dolomite are relatively dense rocks composed of calcium and magnesium carbonate. However, in some places, ground water has partly dissolved the rock, increasing pore space and permeability. As a result, some carbonate rocks are among the world's most prolific aquifers.

Carbonate aquifers underlie large areas of the United States. The principal carbonate aquifers are shown in Figure 28. Carbonate aquifers may exist under either water-table or artesian conditions, but artesian conditions are most common, except where the aquifers outcrop at the surface. Recharge is by direct precipitation and leakage from surface-water bodies.

Karst topography is the ultimate development by erosion of a carbonate aquifer. In this situation, ground water has so dissolved the rock that extensive subterranean caverns and channels form. At the surface, karst topography is manifested by the lack of surface drainage, rivers that disappear underground and emerge at another location, and undrainea surface depressions.

Water from carbonate aquifers is typically hard (high in calcium bicarbonate content), and high in dissolved solids. Other ions, sulfate for example, are present in excessive concentrations in some regions.

[Inasmuch as neither analyses nor field tests of ATES in carbonate aquifers appear to have been reported, only speculation can be offered concerning the suitability of these aquifers for ATES.

[Where extensive solution caverns and channels exist in carbonate aquifers, the aquifers may be prolific sources of water but completely unsuitable for ATES purposes: injected hot or cold water would quickly flow away from the injection well. 


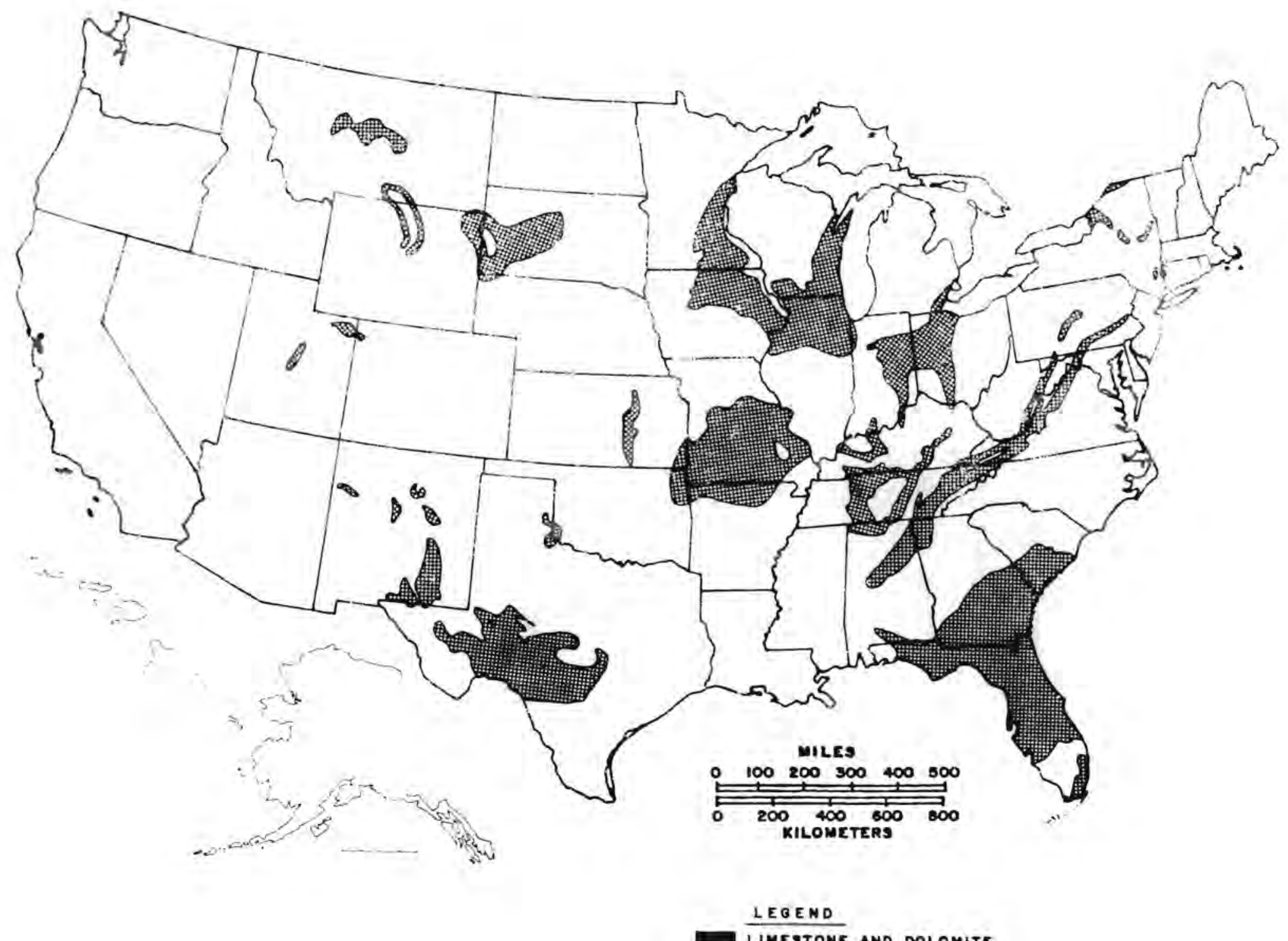

茪

Figure 28. Carbonate aquifers. 
[In the slightly dolomitized limestone rock aquifers of the southeastern coastal plain, which exhibit high permeability not attributable to fractures and solution openings, sites suitable for ATES may well be found to exist.

[Fractured and jointed carbonate aquifers may supply good yields to wells. Whether they might be suitable for ATES is a question involving the dimensions of flow channels, degree of fragmentation of the rock, tightness of confining layers, and regional flow.

[A question common to all carbonate aquifers which might be considered for ATES is the geochemistry. If the groundwater is saturated in calcite or dolomite, raising the temperature of the water will cause precipitation, since the solubility of these minerals decreases with increasing temperature. Scaling of heat exchanger surfaces and plugging of the injection well are among the possibilities to be evaluated.]

\section{Sandstone Aguifers}

Major sandstone aquifers occur in many states and constitute the principal water source of many urban and suburban areas (Figure 29). One important aquifer, the Dakota sandstone and its geologic equivalents, underlies all of the northcentral and western Great Lakes states. Other productive sandstone aquifers are found in New Jersey, Pennsylvania, Connecticut, Alabama, Georgia, South Carolina, Oklahoma, and Texas. These aquifers usually do not contain just sandstone but are commonly interbedded with shales.

Because of the interbedded shales, which are of low permeability, water in sandstone aquifers exists under artesian conditions except in the outcrop area. Artesian sandstone aquifers have been heavily pumped, particularly in the northcentral states. Withdrawals have not been balanced by natural recharge and serious water-level declines have resulted. When the northern Great Plains were settled, wells tapping the Dakota sandstone flowed naturally; now, they must be pumped.

Water quality in the outcrop and recharge areas of sandstone aquifers is typically good, but mineralization increases rapidly with depth and distance from recharge areas. High dissolved solids and excessive concentrations of iron and manganese occur in some regions, particularly where the interbedded shales comprise a considerable portion of the aquifer. 


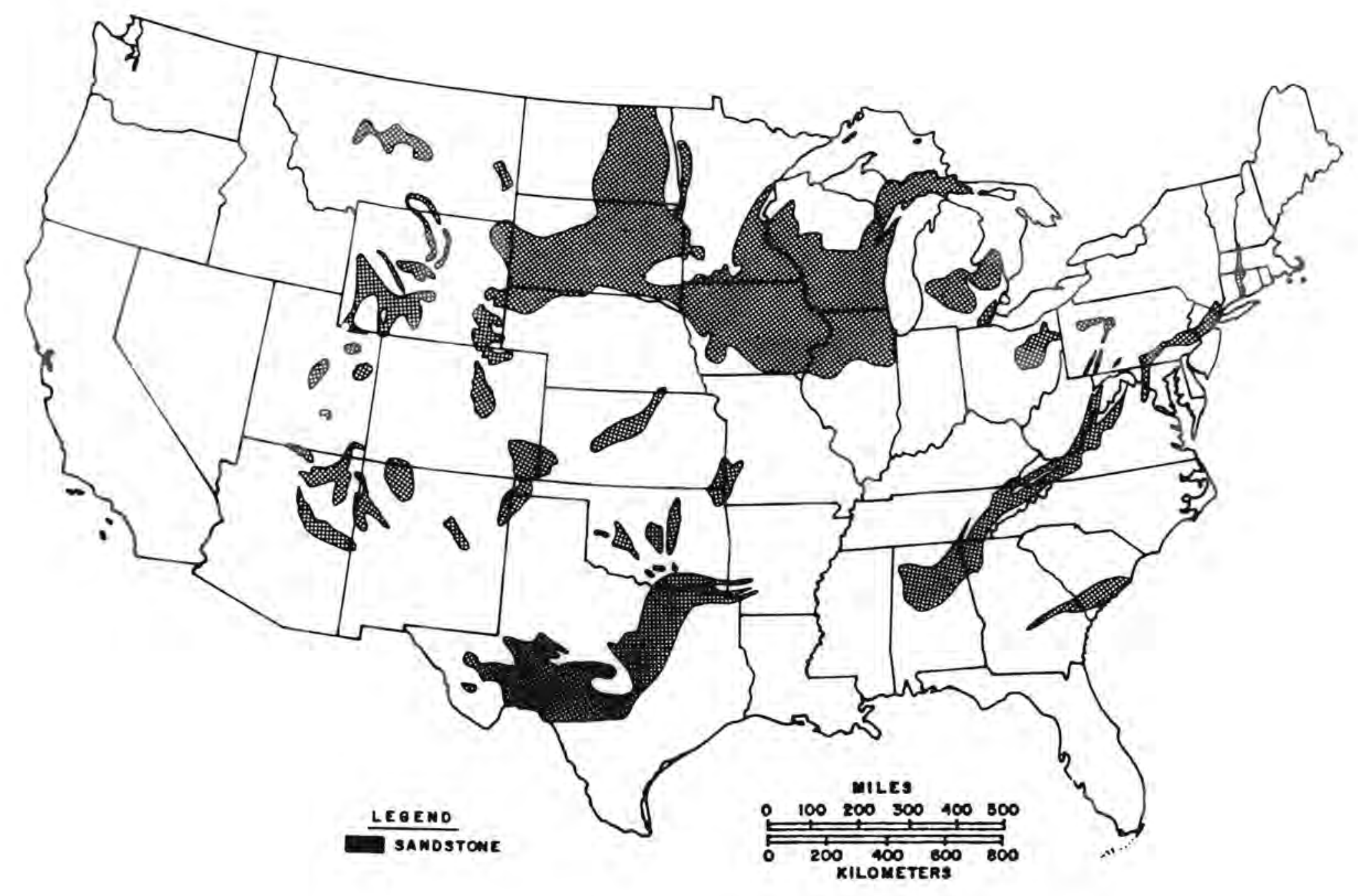

Figure 29. Sandstone aquifers. 
[Sandstone aquifers appear to offer the greatest promise for ATES. The intrinsic permeability of sandstones ranges from about $10^{-3}$ to about 10 darcys (hydraulic conductivity of about $10^{-8}$ to $10^{-4} \mathrm{~m} / \mathrm{s}$ ). The effective vertical permeability can be low even in zones where the horizontal permeability is quite high. Because permeability decreases with depth, tightly confined aquifers with optimum horizontal permeability, inherent limitation of buoyancy effects, and low regional flow velocity are likely to be available where sandstone sequences occur. However, mineralization may be high.]

\section{Crystalline Rocks (Igneous and Metamorphic)}

In the unglaciated areas (the Appalachian Piedmont and California, for example) and on the inter-stream uplands in the glaciated region (New England and the Adirondack Mountains of New York), crystalline rock aquifers are tapped for small ground-water supplies (Figure 30). Individual well yields average 2 to $10 \mathrm{gpm}(0.008$ to $0.04 \mathrm{cu} \mathrm{m} / \mathrm{min})$ and rarely exceed $50 \mathrm{gpm}(0.19 \mathrm{cu} \mathrm{m} / \mathrm{min})$.

Water from crystalline rock occurs principally in fractures and joints in the weathered zone; intergranular porosity is nil. Although wells in crystalline rock commonly are 165 to $330 \mathrm{ft}(50$ to $100 \mathrm{~m})$ deep, most of the water is derived from the upper $100 \mathrm{ft}(30 \mathrm{~m})$. An exception is when a well penetrates a deep fault zone in crystalline rock.

Ground water in crystalline rock is generally under watertable conditions because the network of joints and fractures in the weathered zone extends to the surface. Recharge is by direct precipitation, but where a fracture connects to an adjacent surface-water body, considerably more recharge may take place.

The water in crystalline rocks is generally soft and of excellent quality, reflecting the low solubilities of the major minerals in the rock. At isolated locations in some western states, however, highly mineralized water, often of high temperature, may discharge from springs fed by very deep fractures.

[Crystalline rock aquifers are considered to be the least promising among a11 types of aquifer for ATES purposes. Water flow is principally in shallow, unconfined zones. Yield is typically much lower than is considered necessary for ATES wells.] 


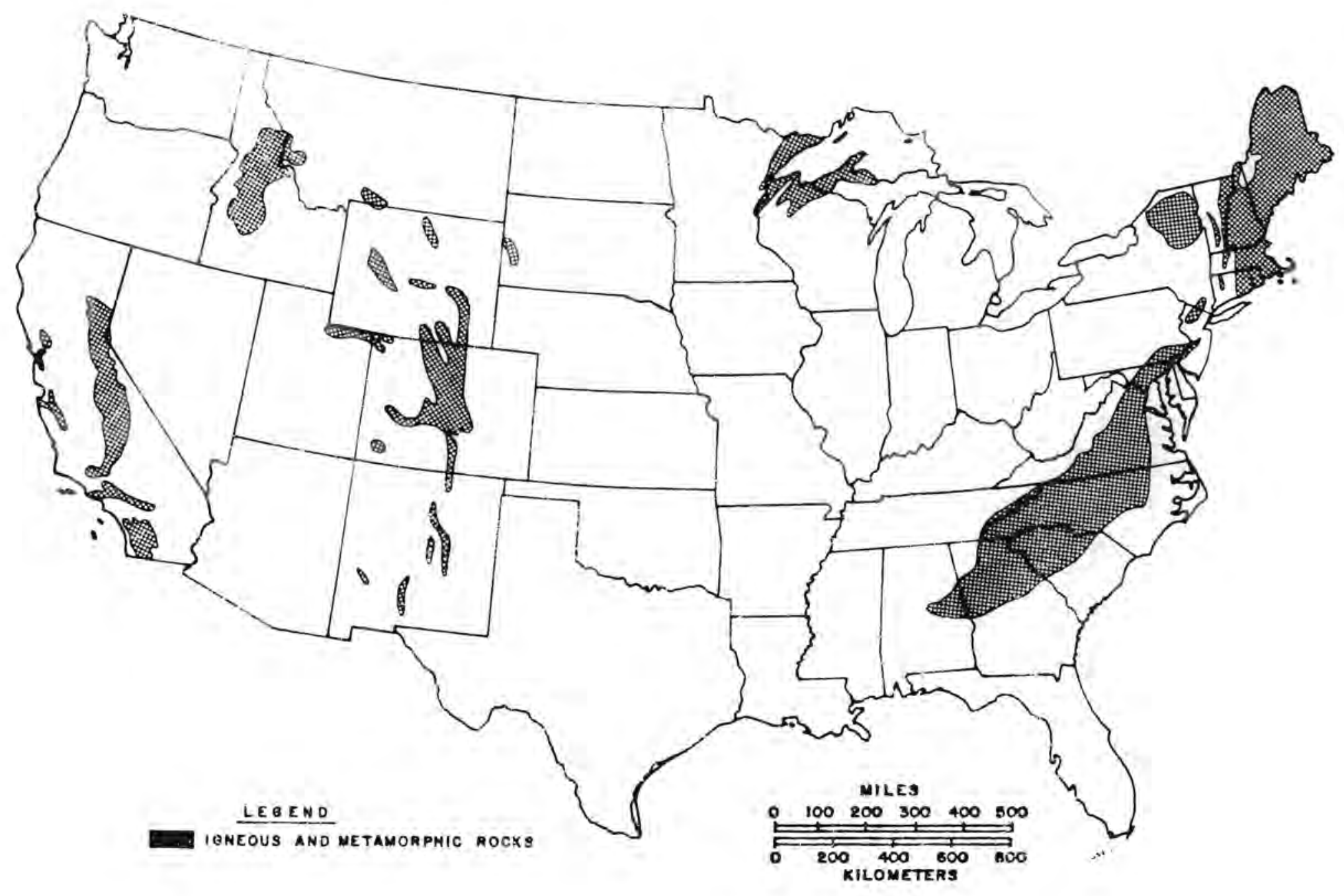

$\underset{\substack{\infty \\ \omega \\ \omega}}{\sigma}$

Figure 30. Crystalline rock aquifers. 


\section{NATURAL CHEMICAL QUALITY OF GROUND WATER}

All ground water contains chemical constituents in solution. The kinds and amounts of constituents depend upon the environment, movement, and source of the ground water. Typically, concentrations of dissolved constituents in ground water exceed those in surface waters. Salinity tends to be higher in arid regions and in areas where drainage is poor.

Chemical constituents originate primarily from solution of rock materials. Common chemical constituents of ground water include:

\begin{tabular}{lll} 
Cations & Anions & Undissociated \\
\hline Calcium & Carbonate & Silica \\
Magnesium & Bicarbonate & \\
Sodium & Sulfate & \\
Potassium & Chloride & \\
& Nitrate &
\end{tabular}

Within a large body of ground water, the natural chemical composition or type of water tends to be relatively consistent, although the concentrations of individual minerals in solution may be variable from place to place. Time variations of ground-water quality under natural conditions are minor in comparison with surface-water quality changes. In a few isolated cases, significant concentrations of such hazardous constituents as arsenic and radioactive elements have been found to occur naturally. These instances are related to the unique aquifer materials of the area.

The chemical quality of ground water is often conveniently described for domestic and industrial use in terms of its hardness and salinity. Hardness is a measure of the calcium and magnesium content and is usually expressed as the equivalent amount of calcium carbonate. Figure 31 shows ranges of hardness in ground water in the United States.

The definition of saline water varies somewhat depending on the intended use of the water. The recommended limit on total dissolved solids for drinking water established by the U. S. Public Health Service is $500 \mathrm{ppm}$. However, where such water is not available, water containing 1,000 ppm or more is used for drinking water purposes. The Safe Drinking Water Act of 1974 considers waters containing up to 10,000 ppm as "potential" sources of drinking water.

Naturally occurring saline ground water may be classified by origin into four types, all of which generally exceed 10,000 ppm total dissolved solids content: 


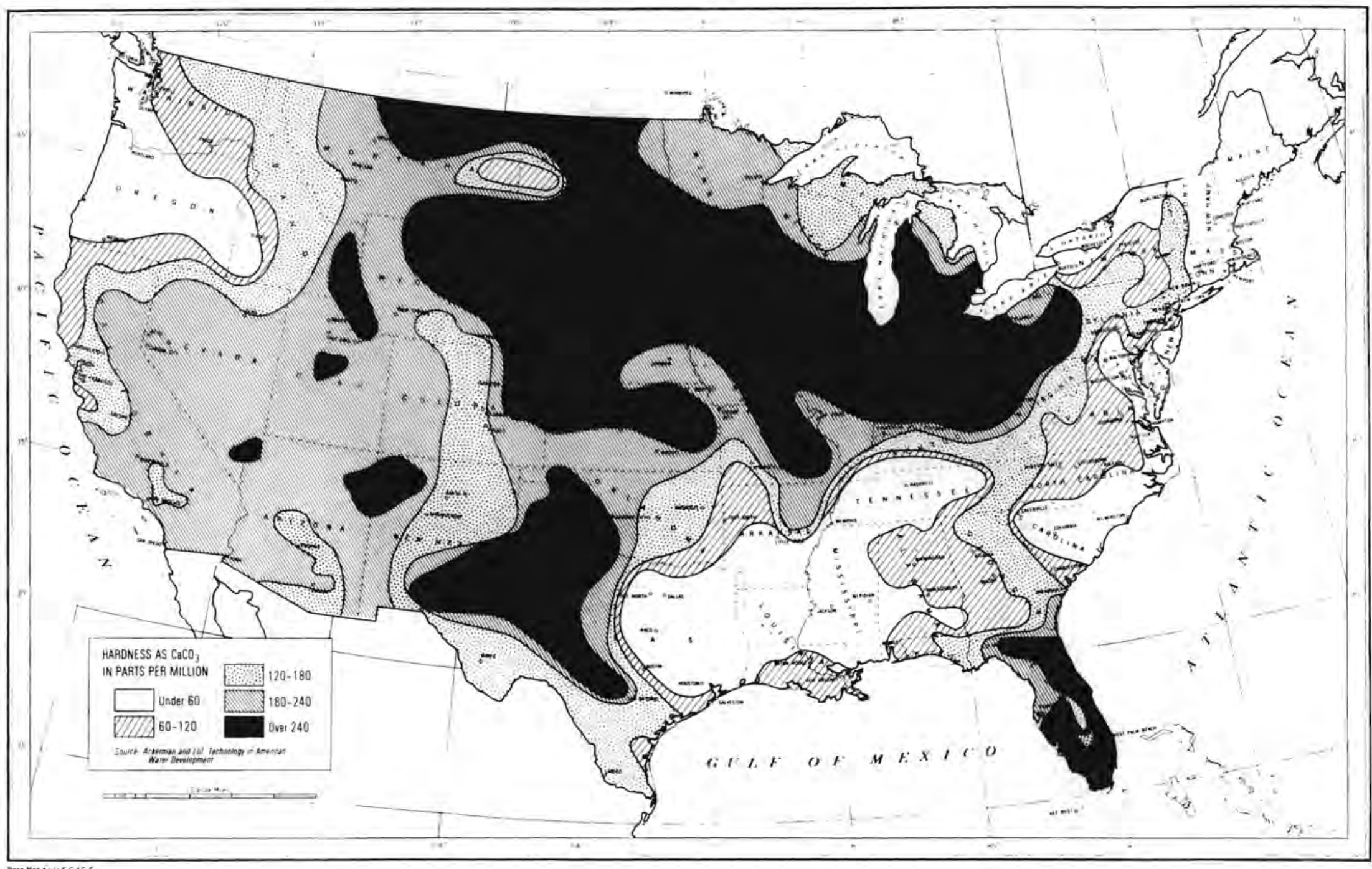

$\underset{\omega}{\omega}$

Figure 31. Hardness of ground water. 2) 
1. Connate water

2. Intruded sea water

3. Magmatic and geothermal water

4. Salt leaching and evapotranspiration products

Many sedimentary rock formations were originally deposited in a marine environment. Saline water may have remained trapped in the material throughout geologic history until the present. Such water is termed connate water. In many aquifers, infiltration and subsurface flow have flushed the connate water from the aquifers and replaced it entirely with fresh water. In other areas, for example in western Washington, such flushing is incomplete, and connate water is stili present.

Sea-water intrusion has occurred in several coastal groundwater basins hydraulically connected to the sea where, as a result of pumping, the head of fresh water has been lowered relative to that of sea water. This lowering has resulted in landward movement of sea water in the aquifer.

Magmatic water is water derived from molten igneous rock or magma. It is also called juvenile water. Geothermal water is water of any origin, including precipitation, which has been heated by a geothermal source. These mineralized waters may issue forth as hot springs. The concentrations of some constituents, particularly sodium, potassium, calcium, and chloride, may be very high, ranging in some cases up to many tens of thousands of ppm. Various heavy metals are also commonly present. Most of these types of saline water occurrences are concentrated in the arid states, in areas of relatively recent volcanic and intrusive activity.

Evapotranspiration and accumulation of residual salts may produce relatively large bodies of shallow saline water. Precipitation, percolating through the unsaturated zone, continually dissolves various soluble salts and flushes them through to ground water. This action produces a large portion of the total dissolved solids found in subsurface water. Ground water also is changed in composition as it moves through an aquifer because of contact with the rock materials.

Vegetation tends to absort relatively pure water through its root systems leaving behind dissolved salts. In areas where precipitation is insufficient to provide flushing to the water table (notably the arid regions of the west), salts may accumulate in the unsaturated zone. The natural accumulation of salts is greatest in the areas of lowest precipitation and areas where natural drainage is restricted. During times of unusually heavy precipitation, these minerals may be leached from the unsaturated zone and carried to ground water. 


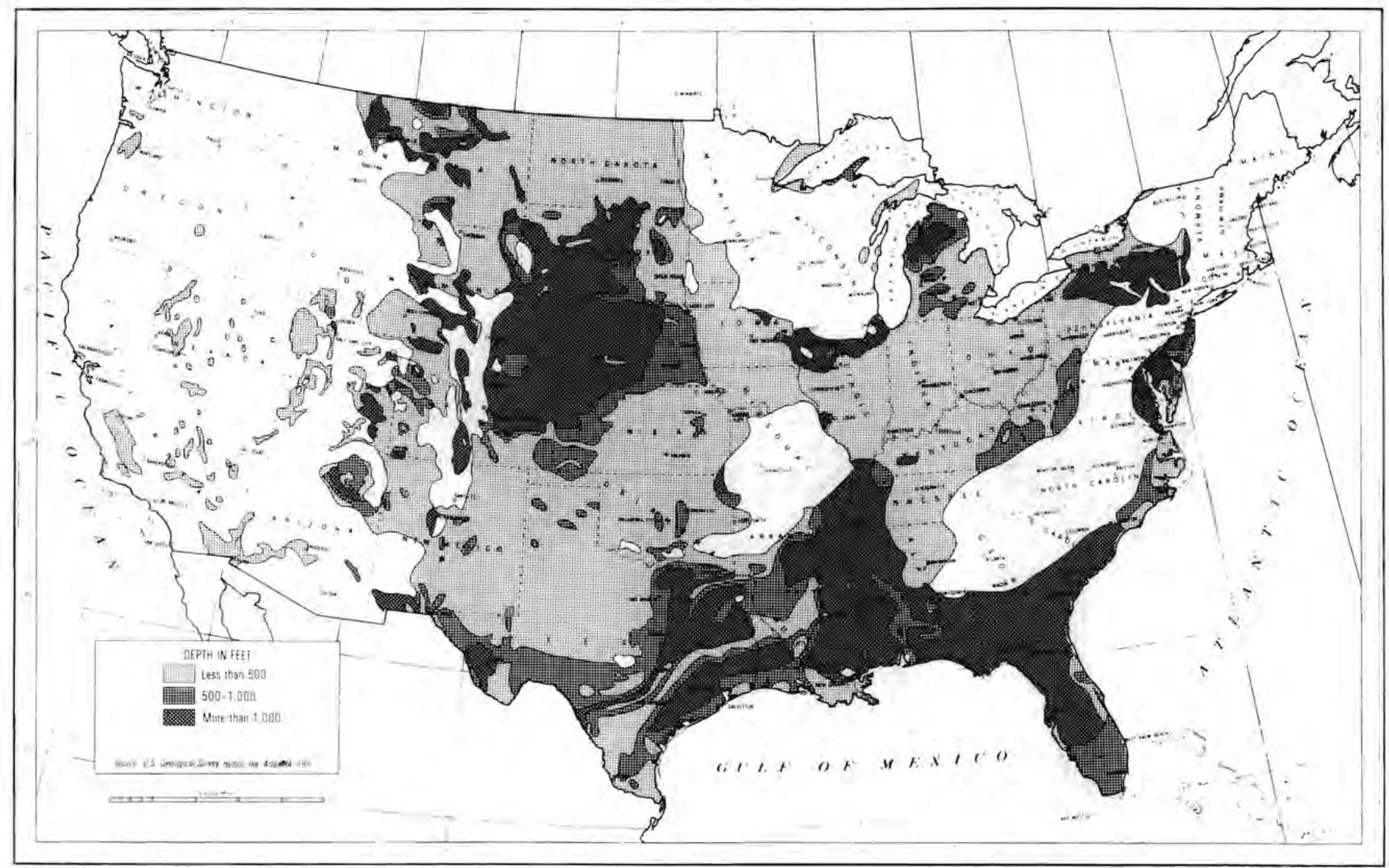


Most of the geologic formations containing fresh ground water are underlain by waters varying from brackish to highly saline. Approximately two thirds of the United States is underlain by aquifers containing at least 1,000 ppm of dissolved solids. These aquifers may occur very close to the surface or at depths of many thousands of feet. As a general rule, the salinity of ground water increases with depth. Figure 32 shows the distribution of depth to shallowest saline ground water, with saline water defined as that containing 1,000 ppm or more total dissolved solids. It should be noted that in much of the shaded area on the figure, ground water exceeds 10,000 ppm total dissolved solids. The blank areas on the map denote either a lack of information or geologic and hydrologic conditions that rule out the presence of saline ground water at depths within $1,000 \mathrm{ft}(300 \mathrm{~m})$ of land surface.

[In situations where groundwater is heavily mineralized in the only aquifers available for ATES purposes (e.g., confined and pressurized for storage of superheated water), and the economics of the proposed ATES application otherwise appear sufficiently favorable, it will be worthwhile to evaluate the cost of wells and related equipment made of noncorrosive materials and capable of dealing with scaling, precipitation, and plugging effects which may be encountered.]

\section{REFERENCES CITED}

1. Edward E. Johnson, Inc. 1966. Ground water and wells. St. Paul, Minnesota.

2. Geraghty, J. J., and others. 1973. Water atlas of the United States. Water Information Center, Port Washington, New York.

3. Walton, W. C. 1970. Groundwater resource evaluation. McGraw-Hill Book Co., New York. 


\section{APPENDIX C \\ ECONOMIC ANALYSIS}

\section{CONTENTS}

Page

Conversions Relevant to Present Worth Calculations

$\mathrm{C}-2$

EPRI Technical Assessment Guide Methodology

$C-10$

$\underline{\text { Table }}$

Page

C-1 Compound interest factors.

$\mathrm{C}-3$

C-2 Assumptions for weighted cost of capital.

C- 10

C-3 Components for levelized fixed charge rates.

$C-10$

C-4 Levelized annual fixed charge rates.

$\mathrm{C}-11$

C-5 Sample levelized busbar cost calculation.

$\mathrm{C}-12$ 


\section{APPENDIX C \\ ECONOMIC ANALYSIS}

This appendix supplements Chapter 5 with selected and edited excerpts from other sources which may be helpful. Explanation is held to a minimum where sources are given.

CONVERSIONS RELEVANT TO PRESENT WORTH CALCULATIONS

The tables following this brief description are from Waste Heat Management Guidebook (NBS Handbook 121, 1977).

The worth of something at present, $P$, its worth in a future year, $F$, and its equivalent as a levelized, uniform annual stream of $n$ payments can be related in all combinations:

- $P / F: \quad$ the present worth factor

- $F / P$ (its reciprocal): the compound amount factor

- $A / F$ : the sinking fund factor

- F/A (its reciprocal): the compound amount factor

- A/P: $\quad$ the capital recovery factor

- $P / A$ (its reciprocal): the annuity present worth factor

The mathematical formulae for these are, using $r$ and $N$ as in Chapter 5:

$$
\begin{aligned}
& P / F=(1+r)^{-N} \\
& A / F=r /\left((1+r)^{N}-1\right) \\
& A / P=A / F+r
\end{aligned}
$$


Table G-1. Compound interest factors. ${ }^{a}$

(Source: NBS Handbook 121, 1977)

\begin{tabular}{|c|c|c|c|c|c|c|c|}
\hline \multicolumn{8}{|c|}{$6 \%$ Compound interest factors } \\
\hline \multicolumn{4}{|c|}{ Single payment } & \multicolumn{4}{|c|}{ Uniform series } \\
\hline$n$ & $\begin{array}{l}\text { Compound } \\
\text { amount } \\
\text { factor } \\
F / P\end{array}$ & $\begin{array}{c}\text { Present } \\
\text { worth } \\
\text { factor } \\
P / F\end{array}$ & $\begin{array}{l}\text { Sinking } \\
\text { fund } \\
\text { factor } \\
A / F\end{array}$ & $\begin{array}{c}\text { Capital } \\
\text { recovery } \\
\text { factor } \\
A / P\end{array}$ & $\begin{array}{l}\text { Compound } \\
\text { amount } \\
\text { factor } \\
F / A\end{array}$ & $\begin{array}{c}\text { Present } \\
\text { worth } \\
\text { factor } \\
P / A\end{array}$ & $n$ \\
\hline $\begin{array}{l}1 \\
2 \\
3 \\
4 \\
5\end{array}$ & $\begin{array}{l}1.0600 \\
1.1236 \\
1.1910 \\
1.2625 \\
1.3382\end{array}$ & $\begin{array}{l}0.9434 \\
.8900 \\
.8396 \\
.7921 \\
.7473\end{array}$ & $\begin{array}{r}1.00000 \\
0.48544 \\
.31411 \\
.22859 \\
.17740\end{array}$ & $\begin{array}{r}1.06000 \\
0.54544 \\
.37411 \\
.22859 \\
.27340\end{array}$ & $\begin{array}{l}1.000 \\
2.060 \\
3.184 \\
4.375 \\
5.637\end{array}$ & $\begin{array}{l}0.943 \\
1.833 \\
2.673 \\
3.465 \\
4.212\end{array}$ & $\begin{array}{l}1 \\
2 \\
3 \\
4 \\
5\end{array}$ \\
\hline $\begin{array}{r}6 \\
7 \\
8 \\
9 \\
10\end{array}$ & $\begin{array}{l}1.4185 \\
1.5036 \\
1.5938 \\
1.6895 \\
1.7908\end{array}$ & $\begin{array}{l}.7050 \\
.6651 \\
.6274 \\
.5919 \\
.5584\end{array}$ & $\begin{array}{l}.14336 \\
.11914 \\
.10104 \\
.08702 \\
.07587\end{array}$ & $\begin{array}{l}.20336 \\
.17914 \\
.16104 \\
.14702 \\
.13587\end{array}$ & $\begin{array}{r}6.975 \\
8.394 \\
9.897 \\
11.491 \\
13.181\end{array}$ & $\begin{array}{l}4.917 \\
5.582 \\
6.210 \\
6.802 \\
7.360\end{array}$ & $\begin{array}{r}6 \\
7 \\
8 \\
9 \\
10\end{array}$ \\
\hline $\begin{array}{l}11 \\
12 \\
13 \\
14 \\
15\end{array}$ & $\begin{array}{l}1.8983 \\
2.0122 \\
2.1329 \\
2.2609 \\
2.3966\end{array}$ & $\begin{array}{l}.5268 \\
.4970 \\
.4688 \\
.4423 \\
.4173\end{array}$ & $\begin{array}{l}.06679 \\
.05928 \\
.05296 \\
.04758 \\
.04296\end{array}$ & $\begin{array}{l}.12679 \\
.11928 \\
.11296 \\
.10758 \\
.10296\end{array}$ & $\begin{array}{l}14.972 \\
16.870 \\
18.882 \\
21.015 \\
23.276\end{array}$ & $\begin{array}{l}7.887 \\
8.384 \\
8.853 \\
9.295 \\
9.712\end{array}$ & $\begin{array}{l}11 \\
12 \\
13 \\
14 \\
15\end{array}$ \\
\hline $\begin{array}{l}16 \\
17 \\
18 \\
19 \\
20\end{array}$ & $\begin{array}{l}2.5404 \\
2.6928 \\
2.8543 \\
3.0256 \\
3.2071\end{array}$ & $\begin{array}{l}.3936 \\
.3714 \\
.3503 \\
.3305 \\
.3118\end{array}$ & $\begin{array}{l}.03895 \\
.03544 \\
.03236 \\
.02962 \\
.02718\end{array}$ & $\begin{array}{l}.09895 \\
.09544 \\
.09236 \\
.08962 \\
.08718\end{array}$ & $\begin{array}{l}25.673 \\
28.213 \\
30.906 \\
33.760 \\
36.786\end{array}$ & $\begin{array}{l}10.106 \\
10.477 \\
10.828 \\
11.158 \\
11.470\end{array}$ & $\begin{array}{l}16 \\
17 \\
18 \\
19 \\
20\end{array}$ \\
\hline $\begin{array}{l}21 \\
22 \\
23 \\
24 \\
25\end{array}$ & $\begin{array}{l}3.3996 \\
3.6035 \\
3.8197 \\
4.0489 \\
4.2919\end{array}$ & $\begin{array}{l}.2942 \\
.2775 \\
.2618 \\
.2470 \\
.2330\end{array}$ & $\begin{array}{l}.02500 \\
.02305 \\
.02128 \\
.01968 \\
.01823\end{array}$ & $\begin{array}{l}.08500 \\
.08305 \\
.08128 \\
.07968 \\
.07823\end{array}$ & $\begin{array}{l}39.993 \\
43.392 \\
46.996 \\
50.816 \\
54.865\end{array}$ & $\begin{array}{l}11.764 \\
12.042 \\
12.303 \\
12.550 \\
12.783\end{array}$ & $\begin{array}{l}21 \\
22 \\
23 \\
24 \\
25\end{array}$ \\
\hline $\begin{array}{l}26 \\
27 \\
28 \\
29 \\
30\end{array}$ & $\begin{array}{l}4.5494 \\
4.8223 \\
5.1117 \\
5.4184 \\
5.7435\end{array}$ & $\begin{array}{l}.2198 \\
.2074 \\
.1956 \\
.1846 \\
.1741\end{array}$ & $\begin{array}{l}.01690 \\
.01570 \\
.01459 \\
.01358 \\
.01265\end{array}$ & $\begin{array}{l}.07690 \\
.07570 \\
.07459 \\
.07358 \\
.07265\end{array}$ & $\begin{array}{l}59.156 \\
63.706 \\
68.528 \\
73.640 \\
79.058\end{array}$ & $\begin{array}{l}13.003 \\
13.211 \\
13.406 \\
13.591 \\
13.765\end{array}$ & $\begin{array}{l}26 \\
27 \\
28 \\
29 \\
30\end{array}$ \\
\hline $\begin{array}{l}31 \\
32 \\
33 \\
34 \\
35\end{array}$ & $\begin{array}{l}6.0881 \\
6.4534 \\
6.8406 \\
7.2510 \\
7.6861\end{array}$ & $\begin{array}{l}.1643 \\
.1550 \\
.1462 \\
.1379 \\
.1301\end{array}$ & $\begin{array}{l}.01179 \\
.01100 \\
.01027 \\
.00960 \\
.00897\end{array}$ & $\begin{array}{l}.07179 \\
.07100 \\
.07027 \\
.06960 \\
.06897\end{array}$ & $\begin{array}{r}84.802 \\
90.890 \\
97.343 \\
104.184 \\
111.435\end{array}$ & $\begin{array}{l}13.929 \\
14.084 \\
14.230 \\
14.368 \\
14.498\end{array}$ & $\begin{array}{l}31 \\
32 \\
33 \\
34 \\
35\end{array}$ \\
\hline $\begin{array}{l}40 \\
45 \\
50 \\
55 \\
60\end{array}$ & $\begin{array}{l}10.2857 \\
13.7646 \\
18.4202 \\
24.6503 \\
32.9877\end{array}$ & $\begin{array}{l}.0972 \\
.0727 \\
.0543 \\
.0406 \\
.0303\end{array}$ & $\begin{array}{l}.00646 \\
.00470 \\
.00344 \\
.00254 \\
.00188\end{array}$ & $\begin{array}{l}.06646 \\
.06470 \\
.06344 \\
.06254 \\
.06188\end{array}$ & $\begin{array}{l}154.762 \\
212.744 \\
290.336 \\
394.172 \\
533.128\end{array}$ & $\begin{array}{l}15.046 \\
15.456 \\
15.762 \\
15.991 \\
16.161\end{array}$ & $\begin{array}{l}40 \\
45 \\
50 \\
55 \\
60\end{array}$ \\
\hline $\begin{array}{l}65 \\
70 \\
75 \\
80 \\
85\end{array}$ & $\begin{array}{r}44.1450 \\
59.0759 \\
79.0569 \\
105.7960 \\
141.5789\end{array}$ & $\begin{array}{l}.0227 \\
.0169 \\
.0126 \\
.0095 \\
.0071\end{array}$ & $\begin{array}{l}.00139 \\
.00103 \\
.00077 \\
.00057 \\
.00043\end{array}$ & $\begin{array}{l}.06139 \\
.06103 \\
.06077 \\
.06057 \\
.06043\end{array}$ & $\begin{array}{r}719.083 \\
967.932 \\
1300.949 \\
1746.600 \\
2342.982\end{array}$ & $\begin{array}{l}16.289 \\
16.385 \\
16.456 \\
16.509 \\
16.549\end{array}$ & $\begin{array}{l}65 \\
70 \\
75 \\
80 \\
85\end{array}$ \\
\hline $\begin{array}{r}90 \\
95 \\
100\end{array}$ & $\begin{array}{l}189.4645 \\
253.5463 \\
339.3021\end{array}$ & $\begin{array}{l}.0053 \\
.0039 \\
.0029\end{array}$ & $\begin{array}{l}.00032 \\
.00024 \\
.00018\end{array}$ & $\begin{array}{l}.06032 \\
.06024 \\
.06018\end{array}$ & $\begin{array}{l}3141.075 \\
4209.104 \\
5638.368\end{array}$ & $\begin{array}{l}16.579 \\
16.601 \\
16.618\end{array}$ & $\begin{array}{r}90 \\
95 \\
100\end{array}$ \\
\hline
\end{tabular}

a

The letter notations in the column headings, e.g.,F/P, $P / F$, etc., indicate the operation to be performed with the factors in that column. For exaniple, $F / P$ indicates that the single compound amount factors are used to find the future value of a given present amount. 
Table C-1 (continued).

\begin{tabular}{|c|c|c|c|c|c|c|c|}
\hline \multicolumn{8}{|c|}{$8 \%$ Compound interest factors } \\
\hline \multicolumn{4}{|c|}{ Single payment } & \multicolumn{4}{|c|}{ Uniform series } \\
\hline n & $\begin{array}{l}\text { Jompound } \\
\text { amount } \\
\text { factor } \\
F / P\end{array}$ & $\begin{array}{c}\text { Present } \\
\text { worth } \\
\text { factor } \\
P / F\end{array}$ & $\begin{array}{c}\text { Sinking } \\
\text { fund } \\
\text { factor } \\
A / F\end{array}$ & $\begin{array}{c}\text { Capital } \\
\text { recovery } \\
\text { factor } \\
A / P\end{array}$ & $\begin{array}{c}\text { Compound } \\
\text { amount } \\
\text { factor } \\
F / A\end{array}$ & $\begin{array}{c}\text { Present } \\
\text { worth } \\
\text { factor } \\
P / A\end{array}$ & $n$ \\
\hline $\begin{array}{l}1 \\
2 \\
3 \\
4 \\
5\end{array}$ & $\begin{array}{r}1.0800 \\
1.664 \\
1.2597 \\
1.3605 \\
1.4693\end{array}$ & $\begin{array}{r}0.9259 \\
.8573 \\
.7938 \\
.7350 \\
.6806\end{array}$ & $\begin{array}{r}1.00000 \\
0.48077 \\
.30803 \\
.22192 \\
.17046\end{array}$ & $\begin{array}{r}1.08000 \\
0.56077 \\
.38803 \\
.30192 \\
.25046\end{array}$ & $\begin{array}{l}1.000 \\
2.080 \\
3.246 \\
4.506 \\
5.867\end{array}$ & $\begin{array}{l}0.926 \\
1.783 \\
2.577 \\
3.312 \\
3.993\end{array}$ & $\begin{array}{l}1 \\
2 \\
3 \\
4 \\
5\end{array}$ \\
\hline $\begin{array}{r}6 \\
7 \\
8 \\
9 \\
10\end{array}$ & $\begin{array}{l}1.5869 \\
1.7138 \\
1.8509 \\
1.9990 \\
2.1589\end{array}$ & $\begin{array}{l}.6302 \\
.5835 \\
.5403 \\
.5002 \\
.4632\end{array}$ & $\begin{array}{l}.13632 \\
.11207 \\
.09401 \\
.08008 \\
.06903\end{array}$ & $\begin{array}{l}.21632 \\
.19207 \\
.17401 \\
.16008 \\
.14903\end{array}$ & $\begin{array}{r}7.336 \\
8.923 \\
10.637 \\
12.488 \\
14.487\end{array}$ & $\begin{array}{l}4.623 \\
5.206 \\
5.747 \\
6.247 \\
6.710\end{array}$ & $\begin{array}{r}6 \\
7 \\
8 \\
9 \\
10\end{array}$ \\
\hline $\begin{array}{l}11 \\
12 \\
13 \\
14 \\
15\end{array}$ & $\begin{array}{l}2.3316 \\
2.5182 \\
2.7196 \\
2.9372 \\
3.1722\end{array}$ & $\begin{array}{l}.4289 \\
.3971 \\
.3677 \\
.3405 \\
.3152\end{array}$ & $\begin{array}{l}.06008 \\
.05270 \\
.04652 \\
.04130 \\
.03683\end{array}$ & $\begin{array}{l}.14008 \\
.13270 \\
.12652 \\
.12130 \\
.11683\end{array}$ & $\begin{array}{l}16.645 \\
18.977 \\
21.495 \\
24.215 \\
27.152\end{array}$ & $\begin{array}{l}7.139 \\
7.536 \\
7.904 \\
8.244 \\
8.559\end{array}$ & $\begin{array}{l}11 \\
12 \\
13 \\
14 \\
15\end{array}$ \\
\hline $\begin{array}{l}16 \\
17 \\
18 \\
19 \\
20\end{array}$ & $\begin{array}{l}3.4259 \\
3.7000 \\
3.9960 \\
4.3157 \\
4.6610\end{array}$ & $\begin{array}{l}.2919 \\
.2703 \\
.2502 \\
.2317 \\
.2145\end{array}$ & $\begin{array}{l}.03298 \\
.02963 \\
.02670 \\
.02413 \\
.02185\end{array}$ & $\begin{array}{l}.11298 \\
.10963 \\
.10670 \\
.10413 \\
.10185\end{array}$ & $\begin{array}{l}30.324 \\
33.750 \\
37.450 \\
41.446 \\
45.762\end{array}$ & $\begin{array}{l}8.851 \\
9.122 \\
9.372 \\
9.604 \\
9.818\end{array}$ & $\begin{array}{l}16 \\
17 \\
18 \\
19 \\
20\end{array}$ \\
\hline $\begin{array}{l}21 \\
22 \\
23 \\
24 \\
25\end{array}$ & $\begin{array}{l}5.0338 \\
5.4365 \\
5.8715 \\
6.3412 \\
6.8485\end{array}$ & $\begin{array}{l}.1987 \\
.1839 \\
.1703 \\
.1577 \\
.1460\end{array}$ & $\begin{array}{l}.01983 \\
.01803 \\
.01642 \\
.01498 \\
.01368\end{array}$ & $\begin{array}{l}.09983 \\
.09803 \\
.09642 \\
.09498 \\
.09368\end{array}$ & $\begin{array}{l}50.423 \\
55.457 \\
60.893 \\
66.765 \\
73.106\end{array}$ & $\begin{array}{l}10.017 \\
10.201 \\
10.371 \\
10.529 \\
10.675\end{array}$ & $\begin{array}{l}21 \\
22 \\
23 \\
24 \\
25\end{array}$ \\
\hline $\begin{array}{l}26 \\
27 \\
28 \\
29 \\
30\end{array}$ & $\begin{array}{r}7.3964 \\
7.9881 \\
8.6271 \\
9.3173 \\
10.0627\end{array}$ & $\begin{array}{l}.1352 \\
.1252 \\
.1159 \\
.1073 \\
.0994\end{array}$ & $\begin{array}{l}.01251 \\
.01145 \\
.01049 \\
.00962 \\
.00883\end{array}$ & $\begin{array}{l}.09251 \\
.09145 \\
.09049 \\
.08962 \\
.08883\end{array}$ & $\begin{array}{r}79.954 \\
87.351 \\
95.339 \\
103.966 \\
113.283\end{array}$ & $\begin{array}{l}10.810 \\
10.935 \\
11.051 \\
11.158 \\
11.258\end{array}$ & $\begin{array}{l}26 \\
27 \\
28 \\
29 \\
30\end{array}$ \\
\hline $\begin{array}{l}31 \\
32 \\
33 \\
34 \\
35\end{array}$ & $\begin{array}{l}10.8677 \\
11.7371 \\
12.6760 \\
13.6901 \\
14.7853\end{array}$ & $\begin{array}{l}.0920 \\
.0852 \\
.0789 \\
.0730 \\
.0676\end{array}$ & $\begin{array}{l}.00811 \\
.00745 \\
.00685 \\
.00630 \\
.00580\end{array}$ & $\begin{array}{l}.08811 \\
.08745 \\
.08685 \\
.08630 \\
.08580\end{array}$ & $\begin{array}{l}123.346 \\
134.214 \\
145.951 \\
158.627 \\
172.317\end{array}$ & $\begin{array}{l}11.350 \\
11.435 \\
11.514 \\
11.587 \\
11.655\end{array}$ & $\begin{array}{l}31 \\
32 \\
33 \\
34 \\
35\end{array}$ \\
\hline $\begin{array}{l}40 \\
45 \\
50 \\
55 \\
60\end{array}$ & $\begin{array}{r}21.7245 \\
31.9204 \\
46.9016 \\
68.9139 \\
101.2571\end{array}$ & $\begin{array}{l}.0460 \\
.0313 \\
.0213 \\
.0145 \\
.0099\end{array}$ & $\begin{array}{l}.00386 \\
.00259 \\
.00174 \\
.00118 \\
.00080\end{array}$ & $\begin{array}{l}.08386 \\
.08259 \\
.08174 \\
.08118 \\
.08080\end{array}$ & $\begin{array}{r}259.057 \\
386.506 \\
573.770 \\
848.923 \\
1253.213\end{array}$ & $\begin{array}{l}11.925 \\
12.108 \\
12.233 \\
12.319 \\
12.377\end{array}$ & $\begin{array}{l}40 \\
45 \\
50 \\
55 \\
60\end{array}$ \\
\hline $\begin{array}{l}65 \\
70 \\
75 \\
80 \\
85\end{array}$ & $\begin{array}{l}148.7798 \\
218.6064 \\
321.2045 \\
471.9548 \\
693.4565\end{array}$ & $\begin{array}{l}.0067 \\
.0046 \\
.0031 \\
.0021 \\
.0014\end{array}$ & $\begin{array}{l}.00054 \\
.00037 \\
.00025 \\
.00017 \\
.00012\end{array}$ & $\begin{array}{l}.08054 \\
.08037 \\
.08025 \\
.08017 \\
.08012\end{array}$ & $\begin{array}{l}1847.248 \\
2720.080 \\
4002.557 \\
5886.935 \\
8655.706\end{array}$ & $\begin{array}{l}12.416 \\
12.443 \\
12.461 \\
12.474 \\
12.482\end{array}$ & $\begin{array}{l}65 \\
70 \\
75 \\
80 \\
85\end{array}$ \\
\hline $\begin{array}{r}90 \\
95 \\
100\end{array}$ & $\begin{array}{l}1018.9151 \\
1497.1205 \\
2199.7613\end{array}$ & $\begin{array}{l}.0010 \\
.0007 \\
.0005\end{array}$ & $\begin{array}{l}.00008 \\
.00005 \\
.00004\end{array}$ & $\begin{array}{l}.08008 \\
.08005 \\
.08004\end{array}$ & $\begin{array}{l}12723.939 \\
18701.507 \\
27484.516\end{array}$ & $\begin{array}{l}12.488 \\
12.492 \\
12.494\end{array}$ & $\begin{array}{r}90 \\
95 \\
100\end{array}$ \\
\hline
\end{tabular}


Table C-1 (continued).

$10 \%$ (inmpound interest factors

\begin{tabular}{|c|c|c|c|c|c|c|c|}
\hline \multicolumn{3}{|c|}{ Single payment } & \multicolumn{5}{|c|}{ Uniform series } \\
\hline$n$ & $\begin{array}{c}\text { Compound } \\
\text { smount } \\
\text { factor } \\
F / P\end{array}$ & $\begin{array}{c}\text { Present } \\
\text { worth } \\
\text { factor } \\
P / F\end{array}$ & $\begin{array}{c}\text { Sinking } \\
\text { fund } \\
\text { factor } \\
A / F\end{array}$ & $\begin{array}{c}\text { Capital } \\
\text { recovery } \\
\text { factor } \\
A / P\end{array}$ & $\begin{array}{l}\text { Compound } \\
\text { amount } \\
\text { factor } \\
F / A\end{array}$ & $\begin{array}{c}\text { Present } \\
\text { worth } \\
\text { factor } \\
P / A\end{array}$ & \\
\hline $\begin{array}{l}1 \\
2 \\
3 \\
4 \\
5\end{array}$ & $\begin{array}{l}1.1000 \\
1.2100 \\
1.3310 \\
1.4641 \\
1.6105\end{array}$ & $\begin{array}{r}0.9091 \\
.8264 \\
.7513 \\
.6830 \\
.6209\end{array}$ & $\begin{array}{r}1.00000 \\
0.47619 \\
.30211 \\
.21547 \\
.16380\end{array}$ & $\begin{array}{r}1.10000 \\
0.57619 \\
.40211 \\
.31547 \\
.26380\end{array}$ & $\begin{array}{l}1.000 \\
2.100 \\
3.310 \\
4.641 \\
6.105\end{array}$ & $\begin{array}{l}0.909 \\
1.736 \\
2.487 \\
3.170 \\
3.791\end{array}$ & $\begin{array}{l}1 \\
2 \\
3 \\
4 \\
5\end{array}$ \\
\hline $\begin{array}{r}6 \\
7 \\
8 \\
9 \\
10\end{array}$ & $\begin{array}{l}1.7716 \\
1.9487 \\
2.1436 \\
2.3579 \\
2.5937\end{array}$ & $\begin{array}{l}.5645 \\
.5132 \\
.4665 \\
.4241 \\
.3855\end{array}$ & $\begin{array}{l}.12961 \\
.10541 \\
.08744 \\
.07364 \\
.06275\end{array}$ & $\begin{array}{l}.22961 \\
.20541 \\
.18744 \\
.17364 \\
.16275\end{array}$ & $\begin{array}{r}7.716 \\
9.487 \\
11.436 \\
13.579 \\
15.937\end{array}$ & $\begin{array}{l}4.355 \\
4.868 \\
5.335 \\
5.759 \\
6.144\end{array}$ & $\begin{array}{r}6 \\
7 \\
8 \\
9 \\
10\end{array}$ \\
\hline $\begin{array}{l}11 \\
12 \\
13 \\
14 \\
15\end{array}$ & $\begin{array}{l}2.8531 \\
3.1384 \\
3.4523 \\
3.7975 \\
4.1772\end{array}$ & $\begin{array}{l}.3505 \\
.3186 \\
.2897 \\
.2633 \\
.2394\end{array}$ & $\begin{array}{l}.05396 \\
.04676 \\
.04078 \\
.03575 \\
.03147\end{array}$ & $\begin{array}{l}.15396 \\
.14676 \\
.14078 \\
.13575 \\
.13147\end{array}$ & $\begin{array}{l}18.531 \\
21.384 \\
24.523 \\
27.975 \\
31.772\end{array}$ & $\begin{array}{l}6.495 \\
6.814 \\
7.103 \\
7.367 \\
7.606\end{array}$ & $\begin{array}{l}11 \\
12 \\
13 \\
14 \\
15\end{array}$ \\
\hline $\begin{array}{l}16 \\
17 \\
18 \\
19 \\
20\end{array}$ & $\begin{array}{l}4.5950 \\
5.0545 \\
5.5599 \\
6.1159 \\
6.7275\end{array}$ & $\begin{array}{r}.2176 \\
.1978 \\
.1799 \\
.1635 \\
.1486\end{array}$ & $\begin{array}{l}.02782 \\
.02466 \\
.02193 \\
.01955 \\
.01746\end{array}$ & $\begin{array}{l}.12782 \\
.12466 \\
.12193 \\
.11955 \\
.11746\end{array}$ & $\begin{array}{l}35.950 \\
40.545 \\
45.599 \\
51.159 \\
57.275\end{array}$ & $\begin{array}{l}7.824 \\
8.022 \\
8.201 \\
8.365 \\
8.514\end{array}$ & $\begin{array}{l}16 \\
17 \\
18 \\
19 \\
20\end{array}$ \\
\hline $\begin{array}{l}21 \\
22 \\
23 \\
24 \\
25\end{array}$ & $\begin{array}{r}7.4002 \\
8.1403 \\
8.9543 \\
9.8497 \\
10.8347\end{array}$ & $\begin{array}{l}.1351 \\
.1228 \\
.1117 \\
.1015 \\
.0923\end{array}$ & $\begin{array}{l}.01562 \\
.01401 \\
.01257 \\
.01130 \\
.01017\end{array}$ & $\begin{array}{l}.11562 \\
.11401 \\
.11257 \\
.11130 \\
.11017\end{array}$ & $\begin{array}{l}64.002 \\
71.403 \\
79.543 \\
88.497 \\
98.347\end{array}$ & $\begin{array}{l}8.649 \\
8.772 \\
8.883 \\
8.985 \\
9.077\end{array}$ & $\begin{array}{l}21 \\
22 \\
23 \\
24 \\
25\end{array}$ \\
\hline $\begin{array}{l}26 \\
27 \\
28 \\
29 \\
30\end{array}$ & $\begin{array}{l}11.9182 \\
13.1100 \\
14.4210 \\
15.8631 \\
17.4494\end{array}$ & $\begin{array}{l}.0839 \\
.0763 \\
.0693 \\
.0630 \\
.0573\end{array}$ & $\begin{array}{l}.00916 \\
.00826 \\
.00745 \\
.00673 \\
.00608\end{array}$ & $\begin{array}{l}.10916 \\
.10826 \\
.10745 \\
.10673 \\
.10608\end{array}$ & $\begin{array}{l}109.182 \\
121.100 \\
134.210 \\
148.631 \\
164.494\end{array}$ & $\begin{array}{l}9.161 \\
9.237 \\
9.307 \\
9.370 \\
9.427\end{array}$ & $\begin{array}{l}26 \\
27 \\
28 \\
29 \\
30\end{array}$ \\
\hline $\begin{array}{l}\mathbf{3 1} \\
\mathbf{3 2} \\
\mathbf{3 3} \\
\mathbf{3 4} \\
\mathbf{3 5}\end{array}$ & $\begin{array}{l}19.1943 \\
21.1138 \\
23.2252 \\
25.5477 \\
28.1024\end{array}$ & $\begin{array}{l}.0521 \\
.0474 \\
.0431 \\
.0391 \\
.0356\end{array}$ & $\begin{array}{l}.00550 \\
.00497 \\
.00450 \\
.00407 \\
.03369\end{array}$ & $\begin{array}{l}.10550 \\
.10497 \\
.10450 \\
.10407 \\
.10369\end{array}$ & $\begin{array}{l}181.943 \\
201.138 \\
222.252 \\
245.477 \\
271.024\end{array}$ & $\begin{array}{l}9.479 \\
9.526 \\
9.569 \\
9.609 \\
9.644\end{array}$ & $\begin{array}{l}\mathbf{3 1} \\
\mathbf{3 2} \\
\mathbf{3 3} \\
\mathbf{3 4} \\
\mathbf{3 5}\end{array}$ \\
\hline $\begin{array}{l}40 \\
45 \\
50 \\
55 \\
60\end{array}$ & $\begin{array}{r}45.2593 \\
72.8905 \\
117.3909 \\
189.0591 \\
304.4816\end{array}$ & $\begin{array}{l}.0221 \\
.0137 \\
.0085 \\
.0053 \\
.0033\end{array}$ & $\begin{array}{l}.00226 \\
.00139 \\
.00086 \\
.00053 \\
.00033\end{array}$ & $\begin{array}{l}.10226 \\
.10139 \\
.10086 \\
.10053 \\
.10033\end{array}$ & $\begin{array}{r}442.593 \\
718.905 \\
1163.909 \\
1880.591 \\
3034.816\end{array}$ & $\begin{array}{l}9.779 \\
9.863 \\
9.915 \\
9.947 \\
9.967\end{array}$ & $\begin{array}{l}40 \\
45 \\
50 \\
55 \\
60\end{array}$ \\
\hline $\begin{array}{l}65 \\
70 \\
75 \\
80 \\
85\end{array}$ & $\begin{array}{r}490.3707 \\
789.7470 \\
1271.8952 \\
2048.4002 \\
3298.9690\end{array}$ & $\begin{array}{l}.0020 \\
.0013 \\
.0008 \\
.0005 \\
.0003\end{array}$ & $\begin{array}{l}.00020 \\
.00013 \\
.00008 \\
.00005 \\
.00003\end{array}$ & $\begin{array}{l}.10020 \\
.10013 \\
.10008 \\
.10005 \\
.10003\end{array}$ & $\begin{array}{r}4893,707 \\
7887.470 \\
12708.954 \\
20474.002 \\
32979.690\end{array}$ & $\begin{array}{l}9.980 \\
9.987 \\
9.992 \\
9.995 \\
9.997\end{array}$ & $\begin{array}{l}65 \\
70 \\
75 \\
80 \\
85\end{array}$ \\
\hline $\begin{array}{r}90 \\
95 \\
100 \\
\end{array}$ & $\begin{array}{r}5313.0226 \\
8556.6760 \\
13780.6123 \\
\end{array}$ & $\begin{array}{l}.0002 \\
.0001 \\
.0001\end{array}$ & $\begin{array}{l}.00002 \\
.00001 \\
.00001\end{array}$ & $\begin{array}{l}.10002 \\
.10001 \\
.10001\end{array}$ & $\begin{array}{r}53120.226 \\
85556.760 \\
137796.123\end{array}$ & $\begin{array}{l}9.998 \\
9.999 \\
9.999\end{array}$ & $\begin{array}{r}90 \\
95 \\
100\end{array}$ \\
\hline
\end{tabular}


Table C-1 (continued).

\begin{tabular}{|c|c|c|c|c|c|c|c|}
\hline \multicolumn{8}{|c|}{$12 \%$ Compound interest factors } \\
\hline \multicolumn{3}{|c|}{ Single payment } & \multicolumn{5}{|c|}{ Uniform series } \\
\hline$n$ & $\begin{array}{c}\text { Compound } \\
\text { amount } \\
\text { factor } \\
F / P\end{array}$ & $\begin{array}{c}\text { Present } \\
\text { worth } \\
\text { factor } \\
P / F\end{array}$ & $\begin{array}{c}\text { Sinking } \\
\text { fund } \\
\text { factor } \\
A / F\end{array}$ & $\begin{array}{c}\text { Capital } \\
\text { recovery } \\
\text { factor } \\
. / P\end{array}$ & $\begin{array}{c}\text { Compound } \\
\text { amount } \\
\text { factor } \\
F / A\end{array}$ & $\begin{array}{c}\text { Present } \\
\text { worth } \\
\text { factor } \\
P / A\end{array}$ & $n$ \\
\hline $\begin{array}{l}1 \\
2 \\
3 \\
4 \\
5\end{array}$ & $\begin{array}{l}1.1200 \\
1.2544 \\
1.4049 \\
1.5735 \\
1.7623\end{array}$ & $\begin{array}{r}0.8929 \\
.7972 \\
.7118 \\
.6355 \\
.5674\end{array}$ & $\begin{array}{r}1.00000 \\
0.47170 \\
.29635 \\
.20923 \\
.15741\end{array}$ & $\begin{array}{r}1.12000 \\
0.59170 \\
.41635 \\
.32923 \\
.27741\end{array}$ & $\begin{array}{l}1.000 \\
2.120 \\
3.374 \\
4.779 \\
6.353\end{array}$ & $\begin{array}{l}0.893 \\
1.690 \\
2.402 \\
3.037 \\
3.605\end{array}$ & $\begin{array}{l}1 \\
2 \\
3 \\
4 \\
5\end{array}$ \\
\hline $\begin{array}{r}6 \\
7 \\
8 \\
9 \\
10\end{array}$ & $\begin{array}{l}1.9738 \\
2.2107 \\
2.4760 \\
2.7731 \\
3.1058\end{array}$ & $\begin{array}{l}.5066 \\
.4523 \\
.4039 \\
.3606 \\
.3220\end{array}$ & $\begin{array}{l}.12323 \\
.09912 \\
.08130 \\
.06768 \\
.05698\end{array}$ & $\begin{array}{l}.24323 \\
.21912 \\
.20130 \\
.18768 \\
.17698\end{array}$ & $\begin{array}{r}8.115 \\
10.089 \\
12.300 \\
14.776 \\
17.549\end{array}$ & $\begin{array}{l}4.111 \\
4.564 \\
4.968 \\
5.328 \\
5.650\end{array}$ & $\begin{array}{r}6 \\
7 \\
8 \\
9 \\
10\end{array}$ \\
\hline $\begin{array}{l}11 \\
12 \\
13 \\
14 \\
15\end{array}$ & $\begin{array}{l}3.4785 \\
3.8960 \\
4.3635 \\
4.8871 \\
5.4736\end{array}$ & $\begin{array}{l}.2875 \\
.2567 \\
.2292 \\
.2046 \\
.1827\end{array}$ & $\begin{array}{l}.04842 \\
.04144 \\
.03568 \\
.03087 \\
.02682\end{array}$ & $\begin{array}{l}.16842 \\
.16144 \\
.15568 \\
.15087 \\
.14682\end{array}$ & $\begin{array}{l}20.655 \\
24.133 \\
28.029 \\
32.393 \\
37.280\end{array}$ & $\begin{array}{l}5.938 \\
6.194 \\
6.424 \\
6.628 \\
6.811\end{array}$ & $\begin{array}{l}11 \\
12 \\
13 \\
14 \\
15\end{array}$ \\
\hline $\begin{array}{l}16 \\
17 \\
18 \\
19 \\
20\end{array}$ & $\begin{array}{l}6.1304 \\
6.8660 \\
7.6900 \\
8.6128 \\
9.6463\end{array}$ & $\begin{array}{l}.1631 \\
.1456 \\
.1300 \\
.1161 \\
.1037\end{array}$ & $\begin{array}{l}.02339 \\
.02046 \\
.01794 \\
.01576 \\
.01388\end{array}$ & $\begin{array}{l}.14339 \\
.14046 \\
.13794 \\
.13576 \\
.13388\end{array}$ & $\begin{array}{l}42.753 \\
48.884 \\
55.750 \\
63.440 \\
72.052\end{array}$ & $\begin{array}{l}6.974 \\
7.120 \\
7.250 \\
7.366 \\
7.469\end{array}$ & $\begin{array}{l}16 \\
17 \\
18 \\
19 \\
20\end{array}$ \\
\hline $\begin{array}{l}21 \\
22 \\
23 \\
24 \\
25\end{array}$ & $\begin{array}{l}10.8038 \\
12.1003 \\
13.5523 \\
15.1786 \\
17.0001\end{array}$ & $\begin{array}{l}.0926 \\
.0826 \\
.0738 \\
.0659 \\
.0588\end{array}$ & $\begin{array}{l}.01224 \\
.01081 \\
.00956 \\
.00846 \\
.00750\end{array}$ & $\begin{array}{l}.13224 \\
.13081 \\
.12956 \\
.12846 \\
.12750\end{array}$ & $\begin{array}{r}81.699 \\
92.503 \\
104.603 \\
118.155 \\
133.334\end{array}$ & $\begin{array}{l}7.562 \\
7.645 \\
7.718 \\
7.784 \\
7.843\end{array}$ & $\begin{array}{l}21 \\
22 \\
23 \\
24 \\
25\end{array}$ \\
\hline $\begin{array}{l}26 \\
27 \\
28 \\
29 \\
30\end{array}$ & $\begin{array}{l}19.0401 \\
21.3249 \\
23.8839 \\
26.7499 \\
29.9599\end{array}$ & $\begin{array}{l}.0525 \\
.0469 \\
.0419 \\
.0374 \\
.0334\end{array}$ & $\begin{array}{l}.00665 \\
.00590 \\
.00524 \\
.00466 \\
.00414\end{array}$ & $\begin{array}{l}.12665 \\
.12590 \\
.12524 \\
.12466 \\
.12414\end{array}$ & $\begin{array}{l}150.334 \\
169.374 \\
190.699 \\
214.583 \\
241.333\end{array}$ & $\begin{array}{l}7.896 \\
7.943 \\
7.984 \\
8.022 \\
8.055\end{array}$ & $\begin{array}{l}26 \\
27 \\
28 \\
29 \\
30\end{array}$ \\
\hline $\begin{array}{l}31 \\
32 \\
33 \\
34 \\
35\end{array}$ & $\begin{array}{l}33.5551 \\
37.5817 \\
42.0915 \\
47.1425 \\
52.7996\end{array}$ & $\begin{array}{l}.0298 \\
.0266 \\
.0238 \\
.0212 \\
.0189\end{array}$ & $\begin{array}{l}.00369 \\
.00328 \\
.00292 \\
.00260 \\
.00232\end{array}$ & $\begin{array}{l}.12369 \\
.12328 \\
.12292 \\
.12260 \\
.12232\end{array}$ & $\begin{array}{l}271.292 \\
304.847 \\
342.429 \\
384.520 \\
431.663\end{array}$ & $\begin{array}{l}8.085 \\
8.112 \\
8.135 \\
8.157 \\
8.176\end{array}$ & $\begin{array}{l}31 \\
32 \\
33 \\
34 \\
35\end{array}$ \\
\hline $\begin{array}{l}40 \\
45 \\
50\end{array}$ & $\begin{array}{r}93.0510 \\
163.9876 \\
289.0022\end{array}$ & $\begin{array}{l}.0107 \\
.0061 \\
.0035\end{array}$ & $\begin{array}{l}.00130 \\
.00074 \\
.00042\end{array}$ & $\begin{array}{l}.12130 \\
.12074 \\
.12042 \\
.12000\end{array}$ & $\begin{array}{r}767.091 \\
1358.230 \\
2400.018\end{array}$ & $\begin{array}{l}8.244 \\
8.283 \\
8.305 \\
\\
8.333\end{array}$ & $\begin{array}{l}40 \\
45 \\
50 \\
\end{array}$ \\
\hline
\end{tabular}


Table C-1 (continued)

\begin{tabular}{|c|c|c|c|c|c|c|c|}
\hline \multicolumn{8}{|c|}{$15 \%$ Compound interest factors } \\
\hline \multicolumn{3}{|c|}{ Single payment } & \multicolumn{5}{|c|}{ Uniform series } \\
\hline$n$ & $\begin{array}{c}\text { Compound } \\
\text { amount } \\
\text { factor } \\
F / P\end{array}$ & $\begin{array}{c}\text { Present } \\
\text { worth } \\
\text { factor } \\
P / F\end{array}$ & $\begin{array}{c}\text { Sinking } \\
\text { fund } \\
\text { factor } \\
A / F\end{array}$ & $\begin{array}{c}\text { Capital } \\
\text { recovery } \\
\text { factor } \\
A / P\end{array}$ & $\begin{array}{c}\text { Compound } \\
\text { amount } \\
\text { factor } \\
F / A\end{array}$ & $\begin{array}{c}\text { Present } \\
\text { worth } \\
\text { fartor } \\
P / A\end{array}$ & $n$ \\
\hline $\begin{array}{l}1 \\
2 \\
3 \\
4 \\
5\end{array}$ & $\begin{array}{l}1.1500 \\
1.3225 \\
1.5209 \\
1.7490 \\
2.0114\end{array}$ & $\begin{array}{r}0.8696 \\
.7561 \\
.6575 \\
.5718 \\
.4972\end{array}$ & $\begin{array}{r}1.00000 \\
.46512 \\
.28798 \\
.20026 \\
.14832\end{array}$ & $\begin{array}{r}1.15000 \\
.61512 \\
.43798 \\
.35027 \\
.29832\end{array}$ & $\begin{array}{l}1.000 \\
2.150 \\
3.472 \\
4.993 \\
6.742\end{array}$ & $\begin{array}{l}0.870 \\
1.626 \\
2.283 \\
2.855 \\
3.352\end{array}$ & $\begin{array}{l}1 \\
2 \\
3 \\
4 \\
5\end{array}$ \\
\hline $\begin{array}{r}6 \\
7 \\
8 \\
9 \\
10\end{array}$ & $\begin{array}{l}2.3131 \\
2.6600 \\
3.0590 \\
3.5179 \\
4.0456\end{array}$ & $\begin{array}{l}.4323 \\
.3759 \\
.3269 \\
.2843 \\
.2472\end{array}$ & $\begin{array}{l}.11424 \\
.09036 \\
.07285 \\
.05957 \\
.04925\end{array}$ & $\begin{array}{l}.26424 \\
.24036 \\
.22285 \\
.29057 \\
.19925\end{array}$ & $\begin{array}{r}8.754 \\
11.067 \\
13.727 \\
16.786 \\
20.304\end{array}$ & $\begin{array}{l}3.784 \\
4.160 \\
4.487 \\
4.772 \\
5.019\end{array}$ & $\begin{array}{r}6 \\
7 \\
8 \\
9 \\
10\end{array}$ \\
\hline $\begin{array}{l}11 \\
12 \\
13 \\
14 \\
15\end{array}$ & $\begin{array}{l}4.6524 \\
5.3503 \\
6.1528 \\
7.0757 \\
8.1371\end{array}$ & $\begin{array}{l}.2149 \\
.1869 \\
.1625 \\
.1413 \\
.1229\end{array}$ & $\begin{array}{l}.04107 \\
.03448 \\
.02911 \\
.02469 \\
.02102\end{array}$ & $\begin{array}{l}.19107 \\
.18448 \\
.17911 \\
.17469 \\
.17102\end{array}$ & $\begin{array}{l}24.349 \\
29.002 \\
34.352 \\
40.505 \\
47.580\end{array}$ & $\begin{array}{l}5.234 \\
5.421 \\
5.583 \\
5.724 \\
5.847\end{array}$ & $\begin{array}{l}11 \\
12 \\
13 \\
14 \\
15\end{array}$ \\
\hline $\begin{array}{l}16 \\
17 \\
18 \\
19 \\
20\end{array}$ & $\begin{array}{r}9.3576 \\
10.7613 \\
12.3755 \\
14.2318 \\
16.3665\end{array}$ & $\begin{array}{l}.1069 \\
.0929 \\
.0808 \\
.0703 \\
.0611\end{array}$ & $\begin{array}{l}.01795 \\
.01537 \\
.01319 \\
.01134 \\
.00976\end{array}$ & $\begin{array}{l}.16795 \\
.16537 \\
.16319 \\
.16134 \\
.15976\end{array}$ & $\begin{array}{r}55.717 \\
65.075 \\
75.836 \\
88.212 \\
102.444\end{array}$ & $\begin{array}{l}5.954 \\
6.047 \\
6.128 \\
6.198 \\
6.259\end{array}$ & $\begin{array}{l}16 \\
17 \\
18 \\
19 \\
20\end{array}$ \\
\hline $\begin{array}{l}21 \\
22 \\
23 \\
24 \\
25\end{array}$ & $\begin{array}{l}18.8215 \\
21.6447 \\
24.8915 \\
28.6252 \\
32.9190\end{array}$ & $\begin{array}{l}.0531 \\
.0462 \\
.0402 \\
.0349 \\
.0304\end{array}$ & $\begin{array}{l}.00842 \\
.00727 \\
.00628 \\
.00543 \\
.00470\end{array}$ & $\begin{array}{l}.15842 \\
.15727 \\
.15628 \\
.15543 \\
.15470\end{array}$ & $\begin{array}{l}118.810 \\
137.632 \\
159.276 \\
184.168 \\
212.793\end{array}$ & $\begin{array}{l}6.312 \\
6.359 \\
6.399 \\
6.434 \\
6.464\end{array}$ & $\begin{array}{l}21 \\
22 \\
23 \\
24 \\
25\end{array}$ \\
\hline $\begin{array}{l}26 \\
27 \\
28 \\
29 \\
30\end{array}$ & $\begin{array}{l}37.8568 \\
45.5353 \\
50.0656 \\
57.5755 \\
66.2118\end{array}$ & $\begin{array}{l}.0264 \\
.0230 \\
.0200 \\
.0174 \\
.0151\end{array}$ & $\begin{array}{l}.00407 \\
.00353 \\
.00306 \\
.00265 \\
.00230\end{array}$ & $\begin{array}{l}.15407 \\
.15353 \\
.15306 \\
.15265 \\
.15230\end{array}$ & $\begin{array}{l}245.712 \\
283.569 \\
327.104 \\
377.170 \\
434.745\end{array}$ & $\begin{array}{l}6.491 \\
6.514 \\
6.534 \\
6.551 \\
6.566\end{array}$ & $\begin{array}{l}26 \\
27 \\
28 \\
29 \\
30\end{array}$ \\
\hline $\begin{array}{l}31 \\
32 \\
33 \\
34 \\
35\end{array}$ & $\begin{array}{r}76.1435 \\
87.5651 \\
190.6998 \\
115.8048 \\
133.1755\end{array}$ & $\begin{array}{l}.0131 \\
.0114 \\
.0099 \\
.0086 \\
.0075\end{array}$ & $\begin{array}{l}.00200 \\
.00173 \\
.00150 \\
.00131 \\
.00113\end{array}$ & $\begin{array}{l}.15200 \\
.15173 \\
.15150 \\
.15131 \\
.15113\end{array}$ & $\begin{array}{l}500.957 \\
577.100 \\
664.666 \\
765.365 \\
881.170\end{array}$ & $\begin{array}{l}6.579 \\
6.591 \\
6.600 \\
6.609 \\
6.617\end{array}$ & $\begin{array}{l}31 \\
32 \\
33 \\
34 \\
35\end{array}$ \\
\hline $\begin{array}{l}40 \\
45 \\
50 \\
-\end{array}$ & $\begin{array}{r}267.8635 \\
538.7693 \\
1083.6574\end{array}$ & $\begin{array}{l}.0037 \\
.0019 \\
.0009\end{array}$ & $\begin{array}{l}.0056 \\
.00028 \\
.00014\end{array}$ & $\begin{array}{l}.15056 \\
.15028 \\
.15014 \\
.15000 \\
\end{array}$ & $\begin{array}{l}1779.090 \\
3585.128 \\
7217.716\end{array}$ & $\begin{array}{l}6.642 \\
6.654 \\
6.661 \\
6.667 \\
\end{array}$ & $\begin{array}{r}40 \\
45 \\
50 \\
-\end{array}$ \\
\hline
\end{tabular}


Table C-1 (continued).

\begin{tabular}{|c|c|c|c|c|c|c|c|}
\hline \multicolumn{8}{|c|}{$25 \%$ Compound interest factors } \\
\hline \multicolumn{3}{|c|}{ Single payment } & \multicolumn{5}{|c|}{ Uniform series } \\
\hline$n$ & $\begin{array}{l}\text { Compound } \\
\text { amount } \\
\text { factor } \\
F / P\end{array}$ & $\begin{array}{c}\text { Present } \\
\text { worth } \\
\text { factor } \\
P / F\end{array}$ & $\begin{array}{c}\text { Sinking } \\
\text { fund } \\
\text { factor } \\
A / F\end{array}$ & $\begin{array}{c}\text { Cepital } \\
\text { recovery } \\
\text { factor } \\
A / P\end{array}$ & $\begin{array}{c}\text { Compound } \\
\text { amount } \\
\text { factor } \\
F / A\end{array}$ & $\begin{array}{c}\text { Present } \\
\text { worth } \\
\text { factor } \\
P / A\end{array}$ & $n$ \\
\hline $\begin{array}{l}1 \\
2 \\
3 \\
4 \\
5\end{array}$ & $\begin{array}{l}1.2500 \\
1.5625 \\
1.9531 \\
2.4414 \\
3.0518\end{array}$ & $\begin{array}{r}0.8000 \\
.6400 \\
.5120 \\
.4096 \\
.3277\end{array}$ & $\begin{array}{r}1.00000 \\
.44444 \\
.26230 \\
.17344 \\
.12185\end{array}$ & $\begin{array}{r}1.25000 \\
.69444 \\
.51230 \\
.42344 \\
.37185\end{array}$ & $\begin{array}{l}1.000 \\
2.250 \\
3.813 \\
5.766 \\
8.207\end{array}$ & $\begin{array}{l}0.800 \\
1.440 \\
1.952 \\
2.362 \\
2.689\end{array}$ & $\begin{array}{l}1 \\
2 \\
3 \\
4 \\
5\end{array}$ \\
\hline $\begin{array}{r}6 \\
7 \\
8 \\
9 \\
10\end{array}$ & $\begin{array}{l}3.8147 \\
4.7684 \\
5.9605 \\
7.4506 \\
9.3132\end{array}$ & $\begin{array}{l}.2621 \\
.2097 \\
.1678 \\
.1342 \\
.1074\end{array}$ & $\begin{array}{l}.08882 \\
.06634 \\
.05040 \\
.03876 \\
.03007\end{array}$ & $\begin{array}{l}.33882 \\
.31634 \\
.30040 \\
.28876 \\
.28007\end{array}$ & $\begin{array}{l}11.259 \\
15.073 \\
19.842 \\
25.802 \\
33.253\end{array}$ & $\begin{array}{l}2.951 \\
3.161 \\
3.329 \\
2.463 \\
3.571\end{array}$ & $\begin{array}{r}6 \\
7 \\
8 \\
9 \\
10\end{array}$ \\
\hline $\begin{array}{l}11 \\
12 \\
13 \\
14 \\
15\end{array}$ & $\begin{array}{l}11.6415 \\
14.5519 \\
18.1899 \\
22.7374 \\
28.4217\end{array}$ & $\begin{array}{l}.0859 \\
.0687 \\
.0550 \\
.0440 \\
.0352\end{array}$ & $\begin{array}{l}.02349 \\
.01845 \\
.01454 \\
.01150 \\
.00912\end{array}$ & $\begin{array}{l}.27349 \\
.26845 \\
.26454 \\
.26150 \\
.25912\end{array}$ & $\begin{array}{r}42.566 \\
54.208 \\
68.760 \\
86.949 \\
109.687\end{array}$ & $\begin{array}{l}3.656 \\
3.725 \\
3.780 \\
3.824 \\
3.859\end{array}$ & $\begin{array}{l}11 \\
12 \\
13 \\
14 \\
15\end{array}$ \\
\hline $\begin{array}{l}16 \\
17 \\
18 \\
19 \\
20\end{array}$ & $\begin{array}{l}35.5271 \\
44.4089 \\
55.5112 \\
69.3889 \\
86.7362\end{array}$ & $\begin{array}{l}.0281 \\
.0225 \\
.0180 \\
.0144 \\
.0115\end{array}$ & $\begin{array}{l}.00724 \\
.00576 \\
.00459 \\
.00366 \\
.00292\end{array}$ & $\begin{array}{l}.25724 \\
.25576 \\
.25459 \\
.25366 \\
.25292\end{array}$ & $\begin{array}{l}138.109 \\
173.636 \\
218.045 \\
273.556 \\
342.945\end{array}$ & $\begin{array}{l}3.887 \\
3,910 \\
3.928 \\
3.942 \\
3.954\end{array}$ & $\begin{array}{l}16 \\
17 \\
18 \\
19 \\
20\end{array}$ \\
\hline $\begin{array}{l}21 \\
22 \\
23 \\
24 \\
25\end{array}$ & $\begin{array}{l}108.4202 \\
135.5253 \\
169.4066 \\
211.7582 \\
264.6978\end{array}$ & $\begin{array}{l}.0092 \\
.0074 \\
.0059 \\
.0047 \\
.0038\end{array}$ & $\begin{array}{l}.00233 \\
.00186 \\
.00148 \\
.00119 \\
.00095\end{array}$ & $\begin{array}{l}.25233 \\
.25186 \\
.25148 \\
.25119 \\
.25095\end{array}$ & $\begin{array}{r}429.681 \\
538.101 \\
673.626 \\
843.033 \\
1054.791\end{array}$ & $\begin{array}{l}3.963 \\
3.970 \\
3.976 \\
3.981 \\
3.985\end{array}$ & $\begin{array}{l}21 \\
22 \\
23 \\
24 \\
25\end{array}$ \\
\hline $\begin{array}{l}26 \\
27 \\
28 \\
29 \\
30\end{array}$ & $\begin{array}{l}330.8722 \\
413.5903 \\
516.9879 \\
646.2349 \\
807.7936\end{array}$ & $\begin{array}{l}.0030 \\
.0024 \\
.0019 \\
.0015 \\
.0012\end{array}$ & $\begin{array}{l}.00076 \\
.00061 \\
.00048 \\
.00039 \\
.00031\end{array}$ & $\begin{array}{l}.25076 \\
.25061 \\
.25048 \\
.25039 \\
.25031\end{array}$ & $\begin{array}{l}1319.489 \\
1650.361 \\
2063.952 \\
2580.939 \\
3227.174\end{array}$ & $\begin{array}{l}3.988 \\
3.990 \\
3.992 \\
3.994 \\
3.995\end{array}$ & $\begin{array}{l}26 \\
27 \\
28 \\
29 \\
30\end{array}$ \\
\hline $\begin{array}{l}31 \\
32 \\
33 \\
34 \\
35\end{array}$ & $\begin{array}{l}1009.7420 \\
1262.1774 \\
1577.7218 \\
1972.1523 \\
2465.1903\end{array}$ & $\begin{array}{l}.0010 \\
.0008 \\
.0006 \\
.0005 \\
.0004\end{array}$ & $\begin{array}{l}.00025 \\
.00020 \\
.00016 \\
.00013 \\
.00010\end{array}$ & $\begin{array}{l}.25025 \\
.25020 \\
.25016 \\
.25013 \\
.25010\end{array}$ & $\begin{array}{l}4034.968 \\
5044.710 \\
6306.887 \\
7884.609 \\
9856.761\end{array}$ & $\begin{array}{l}3.996 \\
3.997 \\
3.997 \\
3.998 \\
3.998\end{array}$ & $\begin{array}{l}31 \\
32 \\
33 \\
34 \\
35\end{array}$ \\
\hline $\begin{array}{l}40 \\
45 \\
50 \\
-\end{array}$ & $\begin{array}{r}7523.1638 \\
22958.8740 \\
70064.9232\end{array}$ & $\begin{array}{l}.0001 \\
.0001 \\
.0000\end{array}$ & $\begin{array}{l}.00003 \\
.00001 \\
.00000\end{array}$ & $\begin{array}{l}.25003 \\
.25001 \\
.25000 \\
\\
25000\end{array}$ & $\begin{array}{r}30088.655 \\
91831.496 \\
280255.693\end{array}$ & $\begin{array}{l}3.999 \\
4.000 \\
4.000 \\
4.000 \\
\end{array}$ & $\begin{array}{l}40 \\
45 \\
50 \\
- \\
\end{array}$ \\
\hline
\end{tabular}


Table C-1 (continued).

\begin{tabular}{|c|c|c|c|c|c|c|c|}
\hline \multicolumn{8}{|c|}{$20 \%$ Compound interest factors } \\
\hline \multicolumn{3}{|c|}{ Single payment } & \multicolumn{5}{|c|}{ Uniform series } \\
\hline$n$ & $\begin{array}{c}\text { Compound } \\
\text { amount } \\
\text { factor } \\
F / P\end{array}$ & $\begin{array}{c}\text { Present } \\
\text { worth } \\
\text { factor } \\
P / F\end{array}$ & $\begin{array}{c}\text { Sinking } \\
\text { fund } \\
\text { factor } \\
A / F\end{array}$ & $\begin{array}{c}\text { Capital } \\
\text { recovery } \\
\text { factor } \\
A / P\end{array}$ & $\begin{array}{c}\text { Compound } \\
\text { amount } \\
\text { factor } \\
F / A\end{array}$ & $\begin{array}{c}\text { Present } \\
\text { worth } \\
\text { factor } \\
P / A\end{array}$ & $n$ \\
\hline $\begin{array}{l}1 \\
2 \\
3 \\
4 \\
5\end{array}$ & $\begin{array}{l}1.2000 \\
1.4400 \\
1.7280 \\
2.0736 \\
2.4883\end{array}$ & $\begin{array}{r}0.8333 \\
.6944 \\
.5787 \\
.4823 \\
.4019\end{array}$ & $\begin{array}{r}1.00000 \\
0.45455 \\
.27473 \\
.18629 \\
.13438\end{array}$ & $\begin{array}{r}1.20000 \\
0.65455 \\
.47473 \\
.38629 \\
.33438\end{array}$ & $\begin{array}{l}1.000 \\
2.200 \\
3.640 \\
5.368 \\
7.442\end{array}$ & $\begin{array}{l}0.833 \\
1.528 \\
2.106 \\
2.589 \\
2.991\end{array}$ & $\begin{array}{l}1 \\
2 \\
3 \\
4 \\
5\end{array}$ \\
\hline $\begin{array}{r}6 \\
7 \\
8 \\
9 \\
10\end{array}$ & $\begin{array}{l}2.9860 \\
3.5832 \\
4.2908 \\
5.1598 \\
6.1917\end{array}$ & $\begin{array}{l}.3349 \\
.2791 \\
.2326 \\
.1938 \\
.1615\end{array}$ & $\begin{array}{l}.10071 \\
.07742 \\
.06061 \\
.04808 \\
.03852\end{array}$ & $\begin{array}{l}.30071 \\
.27742 \\
.26061 \\
.24808 \\
.23852\end{array}$ & $\begin{array}{r}9.930 \\
12.916 \\
16.499 \\
20.799 \\
25.959\end{array}$ & $\begin{array}{l}3.326 \\
3.605 \\
3.837 \\
4.031 \\
4.192\end{array}$ & $\begin{array}{r}6 \\
7 \\
8 \\
9 \\
10\end{array}$ \\
\hline $\begin{array}{l}11 \\
12 \\
13 \\
14 \\
15\end{array}$ & $\begin{array}{r}7.4301 \\
8.9161 \\
10.6993 \\
12.8392 \\
15.4070\end{array}$ & $\begin{array}{l}.1346 \\
.1122 \\
.0935 \\
.0779 \\
.0649\end{array}$ & $\begin{array}{l}.03110 \\
.02526 \\
.02062 \\
.01689 \\
.01388\end{array}$ & $\begin{array}{l}.23110 \\
.22526 \\
.22062 \\
.21689 \\
.21388\end{array}$ & $\begin{array}{l}32.150 \\
39.581 \\
48.497 \\
59.196 \\
72.035\end{array}$ & $\begin{array}{l}4.327 \\
4.439 \\
4.533 \\
4.611 \\
4.675\end{array}$ & $\begin{array}{l}11 \\
12 \\
13 \\
14 \\
15\end{array}$ \\
\hline $\begin{array}{l}16 \\
17 \\
18 \\
19 \\
20\end{array}$ & $\begin{array}{l}18.4884 \\
22.1861 \\
26.6233 \\
31.9480 \\
38.3376\end{array}$ & $\begin{array}{l}.0541 \\
.0451 \\
.0376 \\
.0313 \\
.0261\end{array}$ & $\begin{array}{l}.01144 \\
.00944 \\
.00781 \\
.00646 \\
.00536\end{array}$ & $\begin{array}{l}.21144 \\
.20944 \\
.20781 \\
.20646 \\
.20536\end{array}$ & $\begin{array}{r}87.442 \\
105.931 \\
128.117 \\
154.740 \\
186.688\end{array}$ & $\begin{array}{l}4.730 \\
4.775 \\
4.812 \\
4.844 \\
4.870\end{array}$ & $\begin{array}{l}16 \\
17 \\
18 \\
19 \\
20\end{array}$ \\
\hline $\begin{array}{l}21 \\
22 \\
23 \\
24 \\
25\end{array}$ & $\begin{array}{l}46.0051 \\
55.2061 \\
66.2474 \\
79.4968 \\
95.3962\end{array}$ & $\begin{array}{l}.0217 \\
.0181 \\
.0151 \\
.0126 \\
.0105\end{array}$ & $\begin{array}{l}.00444 \\
.00369 \\
.00307 \\
.00255 \\
.00212\end{array}$ & $\begin{array}{l}.20444 \\
.20369 \\
.20307 \\
.20255 \\
.20212\end{array}$ & $\begin{array}{l}225.026 \\
271.031 \\
326.237 \\
392.484 \\
471.981\end{array}$ & $\begin{array}{l}4.891 \\
4.909 \\
4.925 \\
4.937 \\
4.948\end{array}$ & $\begin{array}{l}21 \\
22 \\
23 \\
24 \\
25\end{array}$ \\
\hline $\begin{array}{l}26 \\
27 \\
28 \\
29 \\
30\end{array}$ & $\begin{array}{l}114.4755 \\
137.3706 \\
164.8447 \\
197.8136 \\
237.3763\end{array}$ & $\begin{array}{l}.0087 \\
.0073 \\
.0061 \\
.0051 \\
.0042\end{array}$ & $\begin{array}{l}.00176 \\
.00147 \\
.00122 \\
.00102 \\
.00085\end{array}$ & $\begin{array}{l}.20176 \\
.20147 \\
.20122 \\
.20102 \\
.20085\end{array}$ & $\begin{array}{r}567.377 \\
681.853 \\
819.223 \\
984.068 \\
1181.882\end{array}$ & $\begin{array}{l}4.956 \\
4.964 \\
4.970 \\
4.975 \\
4.979\end{array}$ & $\begin{array}{l}26 \\
27 \\
28 \\
29 \\
30\end{array}$ \\
\hline $\begin{array}{l}31 \\
32 \\
33 \\
34 \\
35\end{array}$ & $\begin{array}{l}284.8516 \\
341.8219 \\
410.1863 \\
492.2235 \\
590.6682\end{array}$ & $\begin{array}{l}.0035 \\
.0029 \\
.0024 \\
.0020 \\
.0017\end{array}$ & $\begin{array}{l}.00070 \\
.00059 \\
.00049 \\
.00041 \\
.00034\end{array}$ & $\begin{array}{l}.20070 \\
.20059 \\
.20049 \\
.20041 \\
.20034\end{array}$ & $\begin{array}{l}1419.258 \\
1104.109 \\
2045.931 \\
2456.118 \\
2948.341\end{array}$ & $\begin{array}{l}4.982 \\
4.985 \\
4.988 \\
4.990 \\
4.992\end{array}$ & $\begin{array}{l}31 \\
32 \\
33 \\
34 \\
35\end{array}$ \\
\hline $\begin{array}{l}40 \\
45 \\
50\end{array}$ & $\begin{array}{l}1469.7716 \\
3657.2620 \\
9100.4382\end{array}$ & $\begin{array}{l}.0007 \\
.0003 \\
.0001\end{array}$ & $\begin{array}{l}.00014 \\
.00005 \\
.00002\end{array}$ & $\begin{array}{l}.20014 \\
.20005 \\
.20002 \\
.20000\end{array}$ & $\begin{array}{r}7343.858 \\
18281.310 \\
45497.191\end{array}$ & $\begin{array}{l}4.997 \\
4.999 \\
4.999 \\
\\
5.000\end{array}$ & $\begin{array}{l}40 \\
45 \\
50 \\
\end{array}$ \\
\hline
\end{tabular}


EPRI TECHNICAL ASSESSMENT GUIDE METHODOLOGY

The following excerpts from the TAG (EPRI, 1979) expand on the information in Chapter 5:

Table C-2. Assumptions for weighted cost of capital. (Source: EPRI, 1979)

\begin{tabular}{|lc|}
\hline Debt ratio & $50.0 \%$ \\
Debt cost & $8.0 \% / y r$ \\
Preferred stock ratio & $15.0 \%$ \\
Preferred stock cost & $8.5 \% / y r$ \\
Common stock ratio & $35.0 \%$ \\
Common stock cost & $13.5 \% / y r$ \\
Weighted cost of capital & $10.0 \%$ \\
Federal plus State income tax rate & $50.0 \%$ \\
Property taxes and insurance & $2.0 \%$ \\
Investment tax credit & $10.0 \%$ \\
. & \\
* Although income tax preference allowances (accelerated depreci- \\
ation and investment tax credit) are included in the current \\
income tax laws, these are often neglected in an analysis of \\
of investments to be made very far in the future because of \\
their history of frequent changes. For EPRI purposes, it is \\
recommended that income tax preference allowances be excluded \\
from long-term analyses, but may be appropriately included in \\
near-term studies. \\
\hline
\end{tabular}

Table C-3. Components for levelized fixed charge rates. (Source: EPRI, 1979)

Total return (weighted cost of capital)*

Depreciation (sinking fund) $)^{\star}$

Levelized annual income tax

4.70

Levelized annual accelerated depreciation factor

Levelized annual investment tax credit at 10\%

Property taxes, insurance, etc.

With tax preference allowances - TOTAL

Without tax preference allowances - TOTAL

* The total return plus sinking fund depreciation equals capital recovery factor for a life of 30 years and $10 \%$ interest $=10.61 \%$.

the use of book life does not provide sufficient depreciation reserve when there is retirement dispersion - i.e., when actual retirements are dispersed about the average 1 ife. 
Table C-4. Levelized annual fixed charge rates.

(Source: EPRI, 1979)

\begin{tabular}{|ccc|}
$\begin{array}{c}\text { Facility Life } \\
\text { Years }\end{array}$ & $\begin{array}{c}\text { No Tax } \\
\text { Preference } \\
(\%)\end{array}$ & $\begin{array}{c}\text { With Tax } \\
\text { Preference } \\
(\%)\end{array}$ \\
\cline { 2 - 2 } & 34 & 28 \\
10 & 23 & 18 \\
15 & 20 & 15 \\
20 & 19 & 14 \\
25 & 18 & 14 \\
30 & 18 & 14 \\
35 & 18 & 14 \\
40 & 18 & 14 \\
45 & 18 & 14 \\
50 & 18 & 14 \\
\hline
\end{tabular}

Levelizing costs that are escalating at a constant annual rate, as in the case with variable costs, is accomplished by multiplying the cost in the initial year by the appropriate levelizing factor, $\mathrm{L}_{f}$. The levelizing factor is calculated as follows: (EPRI, 1979)

$$
\begin{aligned}
& \mathrm{L}_{\mathrm{f}}=\operatorname{CRF}\left(\mathrm{k}+\mathrm{k}^{2}+\mathrm{k}^{3}+\cdot \cdot \cdot+\mathrm{k}^{\mathrm{N}}\right) \\
& =\operatorname{CRF}\left[\frac{k\left(1-k^{N}\right)}{1-k}\right] \\
& \text { Where } C \dot{C} F=\text { the capital recovery factor and } \\
& \operatorname{CRF}=\frac{(1+r)^{N}}{(1+r)^{N}-1} \\
& r=\text { discount rate } \\
& N=\text { book life } \\
& k=\frac{(1+e)}{(1+r)} \text { and } \\
& \text { e = the apparent escalation rate such that } \\
& (1+e)=(1+\text { real escalation })(1+\text { inflation rate })
\end{aligned}
$$




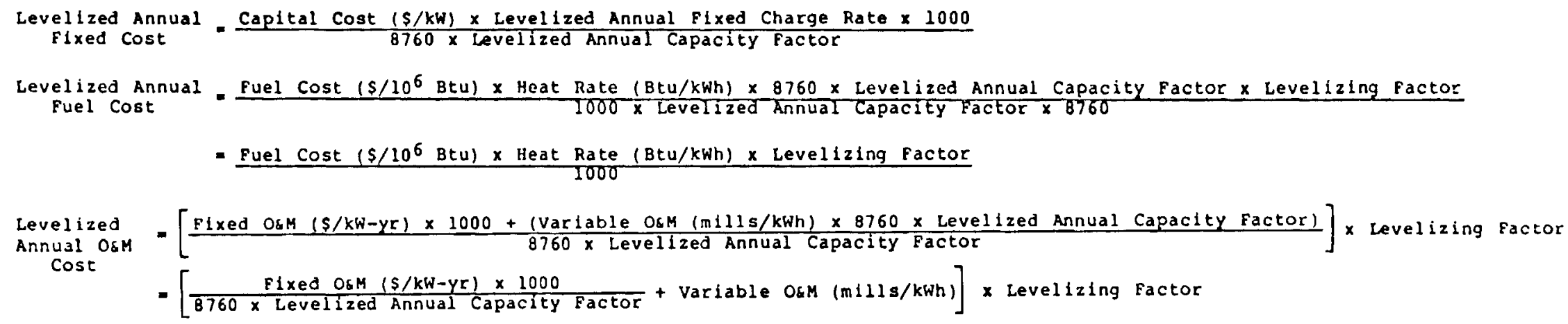

Levelized Annual Busbar Cost = Levelized Annual Capital Cost + Levelized Annual Fuel Cost + Levelized Annual Osm Cost

NOTES: The "levelizing factors" include the effect of inflation and any escalation relative to inflation. It is incorrect to include inflation in the cost of capital used to establish the fixed charge rate and not include this effect on the other components of cost. The capital, fuel, and 0\&M should be expressed in the same year's dollars.

All annual levelized costs are in mills/kWh. 
APPENDIX D

REFERENCES

Aamot, H.W.C., and G. Phetteplace, Long Distance Heat Transmission with Steam and Hot Water; Presented at the INTERNATIONAL TOTAL ENERGY CONGRESS, Copenhagen, Denmark, 4-8 0ctober 1976; Cold Regions Research and Engineering Laboratory (CRREL), U.S. Army Corps of Engineers, Hanover, New Hampshire, October 1976.

Ahern, John E., The Exergy Method of Energy Systems Analysis, John Wiley \& Sons, New York, New York, 1980.

Angus, S.G., and G.T. Williams, "Seasonal Thermal Energy Storage of Chilled Water in Aquifers," IECEC Paper 809247, "Energy to the 21st Century" - Proceedings of the 15th Intersociety Energy Conversion Engineering Conference, Seattle, Washington, August 1822, 1980; The American Institute of Aeronautics and Astronautics, New York, New York, Volume 2, pp 1249-1254, 1980.

ATES Newsletter (A Quarterly Review of Aquifer Thermal Energy Storage), Earth Sciences Division, Lawrence Berkeley Laboratory, University of California, Berkeley, California 94720.

Boyen, John L., Thermal Energy Recovery, John Wiley \& Sons, New York, New York, Second Edition, 1980.

Cabibbo, S.V., R.M. Costello, and T. Ammerlaan, Economic Assessment of Using Nonmetallic Materials in the Direct Utilization of Geothermal Energy, Final Report, BNL 51112; Prepared for the Process Sciences Division, Department of Energy and Environment, Brookhaven National Laboratory, under Contract No. 442252-S; Burns \& Roe Industrial Services Corporation, Paramus, New Jersey, February 1979.

Cole, L.T., and C.A. Allen, Liquid-Fluidized-Bed Heat Exchanger Flow Distribution ModeZs, ICP-1151; Prepared for the U.S. Department of Energy, under Contract 41-1570-I-598; Allied Chemical Corporation, Idaho Falls, Idaho, January 1979.

Collins, R.E., Flow of Fluids Through Porous Materials, The Petroleum Publishing Company, Tulsa, Oklahoma, 1976.

Curtice, David K., and William A. Mallow, Hydrothermal Cements for Use in the Completion of Geothermal WeIZs, BNL 51183; Final report prepared for the Brookhaven National Laboratory, Department of Energy and Environment, under Contract 427964-S; Southwest Research Institute, San Antonio, Texas, September 1979. 
Daniels, Farrington, Direct Use of the Sun's Energy, Yale University Press, New Haven, Connecticut, 1964.

Doughty, Christine, Donald McEdwards, and Chin Fu Tsang, Multiple We 21 Variable Rate Well Test Analysis of Data from the Auburm University Thermal Energy Storage Program, LBL-10194; Prepared for the U.S. Department of Energy, under Contract W-7405-ENG-48; Earth Sciences Division, Lawrence Berkeley Laboratory, Berkeley, California, November 1979.

, and Chin Fu Tsang, A Systematic Parometer Study of ATES Recovery Factor, LBL-11029, Earth Sciences Division, Lawrence Berkeley Laboratory, University of California, Berkeley, 1980.

Dunlap, William J., and James F. McNabb, Subsurface Biological Activity in Relation to Ground Water Polzution, EPA-660/2-73-014, Robert S. Kerr Environmental Research Laboratory, U.S. Environmental Protection Agency, Ada, Oklahoma, September 1973.

, et al, Sampling for Organic Chemicals and Microorganisms in the Subsurface, EPA-600/2-77-176, Robert S. Kerr Environmental Research Laboratory, U.S. Environmental Protection Agency, Ada, Oklahoma, August 1977.

(EPRI) Electric Power Research Institute, Technical Assessment Guide, Special Report EPRI PS-1201-SR, The Technical Assessment Group of The EPRI Planning Staff, Palo Alto, California, July 1979.

Ernst and Ernst, Development of a Joint Cost AZlocation Manual for Integrated Community Energy Systems (ICES), ANL/ICES-TM-20; Prepared for the Energy and Environmental Systems Division, Argonne National Laboratory under Contract No. 31-109-38-4458; September 1978.

Finn, Lennart, A Swedish Solar Heating Plant With Seasonal Storage: The Ingelstad Project - Design and Constmuction Stage, NTIS: PB80-131899, Swedish Council for Building Research (ISBN-91-5403119-2, D14:1979), Stockholm, Sweden, 1979.

Geraghty, James, David Miller, Frits van der Leeden, and Fred Troise, Water Atlas of the United States, Water Information Center, Port Washington, New York, 200 pp, 1973.

Glenn, D., et al, An Economic and Technical Feasibility Study of Thermal Energy Storage, C00-2558-1; Prepared for the U.S. Energy Research and Development Administration, Division of Conservation Research and Technology, under Contract No. AT(11-1)-2558; General Electric Co.-Space Division, Philadelphia, Pennsylvania, 1976.

Hausz, Walter, "Seasonal Storage in District Heating," (General Electric-TEMPO Paper P-760), District Heating, pp 5-11, Ju1yAugust-September 1977. 
- Combined Thermal Storage and Transport for Utility Applications, GE79TMP-26 (EPRI: EM-1175); Prepared for the Electric Power Research Institute; General Electric Co.-TEMP0, Santa Barbara, California, April 1979a.

- Thermal Energy Storage and Transport, P-835; Prepared for presentation at the 1979 ASME WINTER ANNUAL MEETING, New York, 3-7 December 1979; General Electric Co.-TEMP0, Santa Barbara, California, October 1979b.

Hellström, Göran, Chin Fu Tsang, and Johan Claesson, Heat Storage in Aquifers. Buoyancy Flow and Thermal Stratification Problems, Lund Institute of Technology, Department of Mathematical Physics, Lund, Sweden, October 1979.

Hotte1, H.C., and J.B. Howard, New Energy Technology - Some Facts and Assessments, The MIT Press, Cambridge, Massachusetts, 364 pp, 1971.

Katter, Lincoln B., and Randel L. Hoskins, Applications of Thermal Energy Storage to Process Heat and Waste Heat Recovery in the Primary AZuminum Industry, Final Report for September 1977September 1978, CONS-5080-1; Prepared for the U.S. Department of Energy under Contract No. W-7405-ENG-26; Rocket Research Company, Redmond, Washington, April 1979.

, and Daniel J. Peterson, Applications of Thermal Energy Storage to Process Heat and Waste Heat Recovery in the Iron and Steel Incustry, RRC-78-R-607; Prepared for the U.S. Department of Energy under Contract No. EC-77-C-01-5081 (CONS/5081-1; NASA: CR 159397); Rocket Research Company, Redmond, Washington, October 1978.

Kazmann, Raphael G., "Exotic Uses of Aquifers," ASCE Jourmal of the Irrigation and Drainage Division, Vo1. 97, No. IR3, Proceeding Paper 8352, pp 515-522, September 1971.

Keenan, Joseph H., Elias P. Gyftopoulos, and George N. Hatsopoulos, "The Fuel Shortage and Thermodynamics - The Entropy Crisis," Proceedings, Energy: Demand, Conservation, and Institutional Problems, Michael S. Macrakis (ed), The MIT Press, Cambridge, Massachusetts, pp 455-466, 12-14 February 1973.

Keller, Joseph G., Geothermal Direct Applications Hardware Systems DeveZopment and Testing - 1979 Summary Report, EGG-2013; Prepared for the U.S. Department of Energy, Idaho Operations Office, under Contract No. DE-AC07-76ID01579; EG\&G Idaho, Inc., Idaho Falls, Idaho, March 1980.

Kemmer, Frank N., 1979:

See NALCO Water Handbook, 1979. 
Kidder, Peabody \& Co., Financial Considerations Affecting Implementation of a Large Multiparty Cogeneration Project, ORNL/SUB-79/ $13521 / 1$; Prepared for the Gulf States Utilities Company under U.S. Department of Energy Contract No. W-7405-ENG-26; New York, New York, April 1979.

Koefoed, Jørgen, "Thermal Energy and Its Storage," Thermal Energy Storage (Eugene G. Kovach, ed); The Report of a NATO Science Committee Conference held at Turnberry, Scotland, 1st-5th March 1976; Scientific Affairs Division, North Atlantic Treaty Organization, Brussels, Belgium, pp 5-10, 1976.

Kovach, Eugene G. (ed), Thermal Energy Storage; The Report of a NATO Science Committee Conference held at Turnberry, Scotland, 1st5 th March 1976; Scientific Affairs Division, North Atlantic Treaty Organization, Brussels, Belgium, 1976.

Kovacik, J.M., "How to Evaluate the Effectiveness of Industrial Plant Energy Systems," Combustion, pp 21-38, December 1975.

Kreider and McNei1, 1977:

See USNBS \& FEA, 1977.

Kukacka, L.E., et al, Cementing of Geothermal Wells: Progress Report No. 6, July-September 1977, BNL 50738; Prepared for the Division of Geothermal Energy, U.S. Department of Energy; Process Sciences Division, Department of Energy and Environment, Brookhaven National Laboratory, Upton, New York, 1977.

, et al, Altemate Materials of Constmuction for Geothermal Applications: Progress Report No. 18, January-March 1979, BNL 51036; Prepared for the Division of Geothermal Energy, U.S. Department of Energy; Process Sciences Division, Department of Energy and Environment, Brookhaven National Laboratory, Upton, New York, 1979a.

, et al, Alternate Materials of Constmuction for Geothermal Applications: Progress Report No. 19, April-June 1979, BNL 51096; Prepared for the Division of Geothermal Energy, U.S. Department of Energy; Process Sciences Division, Department of Energy and Environment, Brookhaven National Laboratory, Upton, New York, 1979.

(LBL) Lawrence Berkeley Laboratory, Second Invitational Well-Testing Symposium: Proceedings, LBL (CONF-7810170); Prepared for the U.S. Department of Energy under Contract W-7405-ENG-48; Earth Sciences Division, LBL, University of California, Berkeley, October 25-27, 1978. 
Lundberg, Wayne L., and James A. Christenson, Applications of Thermal Energy Storage to Waste Heat Recovery in the Food Processing Industry, Final Report, ORNL/SUB-79/42532; Prepared for the Oak Ridge National Laboratory under Contract W-7405-eng-26; Westinghouse Electric Corporation, Advanced Energy Systems Division, Pittsburgh, Pennsylvania, July 1979.

McCabe, John E., and Douglas D. Huxtable, "District Heating for Bellingham, Washington: Using Waste Heat from an Aluminum Plant as the Energy Source," District Heating, Vo1. 65, No. 3, pp 14-21, January-February-March 1980.

McGuinness, C.L., The Role of Ground Water in the National Water Situation, Geological Survey Water-Supply Paper No. 1800, U.S. Department of the Interior, Washington, D.C., $1121 \mathrm{pp}, 1963$.

McNabb, James F., William J. Dunlap, and Jack W. Keeley, Nutrient, Bacterial, and Vimus Control as Related to Ground-water Contamination, EPA-600/8-77-010, Ground Water Research Branch, Robert S. Kerr Environmental Research Laboratory, U.S. Environmental Protection Agency, Ada, Oklahoma, July 1977.

Meyer, Charles F., David K. Todd, and Robert C. Hare, Thermal Storage for Eco-Energy Utilities, GE72TMP-56, General Electric Co.-TEMPO, Santa Barbara, California, December 1972.

, and David K. Todd, "Conserving Energy with Heat Storage Wells" (General Electric Co.-TEMPO Paper P-623), Environmental Science \& Technology, Vol. 7, No. 6, pp 512-516, June 1973.

- Walter Hausz, Bonnie L. Ayres, and Helen M. Ingram, Role of the Heat Storage Well in Future U.S. Energy Systems, GE76TMP-27 (NTIS: PB-263 480); Technical Completion Report prepared for the Office of Water Research and Technology, U.S. Department of the Interior; General Electric Co.-TEMPO, Santa Barbara, California, 186 pp, December 1976.

, Large-Scale Thermal Energy Storage for Cogeneration and Solar Systems, P-785; Prepared for the 5th Energy Technology Conference and Exposition, Washington, D.C., 27 February 1 March 1978; General Electric Co.-TEMPO, Santa Barbara, California, 24 February 1978.

- Potential Benefits of Thermal Energy Storage in the Proposed Twin Cities District Heating-Cogeneration System, GE79TMP-44 (ORNL/SUB-7604-2); Final report prepared for the Oak Ridge National Laboratory; General Electric Co.-TEMPO, Santa Barbara, California, July 1979.

Miller, R.L., "Results of Short-Term Corrosion Evaluation Tests at Raft River, Geothermal Resources Council, TRANSACTIONS, Vol. 2, pp 461-463, July 1978. 
, "Corrosion of Copper-Base Alloys in a Geothermal Brine," SPE 7881 , Proceedings, 1979 SPE of ATME International Symposium on Oilfield and Geothermal Chemistry, Houston, Texas, January 22-24, 1979, pp 195-200, 1979a.

, Chemistry and Materials in Geothermal Systems, CONF-790580-1; Presented as the Keynote Address to Symposium on Geothermal Corrosion and Scaling, ACS/CSJ Chemical Congress, Honolulu, Hawai, April 1-6, 1979; EG\&G Idaho, Inc., Idaho Falls, Idaho, $1979 b$.

Minor, J.E., Seasonal Thermal Energy Storage Program Progress Report, Apri 1979-December 1979, PNL-3322; Prepared for the U.S. Department of Energy, Office of Advanced Conservation Technologies, under Contract DE-AC06-76RL0 1830; Battelle Memorial Institute, Pacific Northwest Laboratory, Richland, Washington, March 1980.

Molz, Fred J., and Lansford C. Bell, "Heat Gradient Control in Aquifers Used for Fluid Storage," Paper 7W0075, Water Resources Research, Vol. 13, No. 4, pp 795-798, August 1977.

, James C. Warman, and Thomas E. Jones, "Aquifer Storage of Heated Water: Part I - A Field Experiment," Ground Water, Vol. 16, No. 4, pp 234-241, July-August 1978.

, A. David Parr, and Peter F. Andersen, Experimental Study of the Storage of Thermal Energy in Confined Aquifers, Final Report for the Period July 1, 1977 to December 31, 1979, ORNL/Sub7338/1; Prepared for the Oak Ridge National Laboratory; The Water Resources Research Institute, Auburn University, Auburn, Alabama, May 1980.

NALCO Water Handbook (The), Nalco Chemical Company, Frank N. Kemmer (ed), McGraw-Hi11 Book Company, New York, New York, 1979.

NBS Handbook 121, 1977:

See USNBS \& FEA, 1977.

0liker, I., Assessment of Existing and Prospective Piping Technology for District Heating Applications, ORNL/SUB-79/7672/1; Prepared for Engineering Technology Division, Oak Ridge National Laboratory; Burns and Roe, Inc., Orade11, New Jersey, September 1979.

Orchard, W.R.H., and P.J. Robinson, "Optimization of Combined Heat and Power Through Use of Heat Exchangers," Second International Total Energy Congress, Part 1: The Papers, Copenhagen, Denmark, October 8-12, 1979, Miller Freeman Publications, San Francisco, California, pp 3.73-3.97, 1979.

Papadopulos, S.S., and S.P. Larson, "Aquifer Storage of Heated Water: Part II - Numerical Simulation of Field Results," Ground Water, Vol. 16, No. 4, pp 242-248, July-August 1978. 
Park, William R., Cost Engineering Analysis: A Guide to the Economic Evaluation of Engineering Projects, A Wiley-Interscience Publication, John Wiley \& Sons, Inc., New York, New York, 1973.

Peters, Max S., and Klaus D. Timmerhaus, Plant Design and Economics for Chemical Engineers, McGraw-Hi11 Book Company, New York, New York, Second Edition, 1968.

Redde11, Donald L., Richard R. Davison, and William B. Harris, "Cold Water Aquifer Storage," Thermal Energy Storage, Fourth Annual Review Meeting, NASA CP-2125 (DOE: CONF-791232); A program review sponsored by the U.S. Department of Energy, organized by the NASA Lewis Research Center, held at Tysons Corner, Virginia, December 3-4, 1979; pp 591-599, 1980.

Reilly, R.W., A Descriptive Analysis of Aquifer Thermal Energy Storage Systems, PNL-3298; Prepared for the U.S. Department of Energy under Contract DE-AC06-76RLO 1830; Pacific Northwest Laboratory, Battelle Memorial Institute, Richland, Washington, June 1980.

, D.R. Brown, and H.D. Huber, "The Economics of Aquifer Storage of Chilled Water for Air Conditioning," IECEC Paper 809250, "Energy to the 21st Century" - Proceedings of the 15th Intersociety Energy Conversion Engineering Conference, Seattle, Washington, August 18-22, 1980; The American Institute of Aeronautics and Astronautics, New York, New York, Volume 2, pp 1265-1271, 1980.

Robsenow, Warren M., and James P. Hartnett (eds), Hondbook of Heat Transfer, McGraw-Hi11 Book Company, New York, New York, 1973.

Savitz, Maxine L., "Introduction and Overview: Cogeneration and Integrated Energy/Utility Seminar," Proceedings of the Energy Research and Development Administration Conference on: Cogeneration and Integrated Energy/Utility Systems, CONF-770632; Prepared by the National Consumer Research Institute for Argonne Nationa1 Laboratory under Contract No. 31-109-38-3972; Washington, D.C., pp 10-15, June 3, 1977.

Soderberg, Warren E., and James C. O'Gara, Grid Connected Integrated Communty Energy System, Phase II - Final Stage 2 Report: Executive Summary, C00-4210-3/1; Prepared for the U.S. Department of Energy under Contract No. EC-77-C-02-4210; University of Minnesota Physical Plant, Minneapolis, Minnesota, March 22, 1978.

Stottlemyre, J.A., R.P. Smith, and R.L. Erikson, Geochemical Equilibrium Modeling of the Auburn Thermal Energy Storage Field Test, PNL-3167; Prepared for the U.S. Department of Energy under Contract $86 \mathrm{X}-42534 \mathrm{~V}$; Pacific Northwest Laboratory, Battelle Memorial Institute, Richland, Washington, October 1979. 
, and C.H. Cooley, "Temperature-Induced Permeability Alterations in Unconsolidated and Consolidated Aquifer Media," IECEC Paper 809248, "Energy to the 21st Century" - Proceedings of the 15th Intersociety Energy Conversion Engineering Conference, Seattle, Washington, August 18-22, 1980; The American Institute of Aeronautics and Astronautics, New York, New York, Volume 2, pp 1255-1258, 1980.

Subcasky, Wayne J., "Petroleum Industry Experience in Water Injection," Thermal Energy Storage in Aquifers Workshop: Proceedings, Lawrence Berkeley Laboratory, May 10-12, 1978; Sponsored by U.S. Department of Energy through Oak Ridge National Laboratory; Report LBL-8431, Earth Sciences Division, Lawrence Berkeley Laboratory, University of California, Berkeley, pp 14-16, December 1978.

Sundberg, Ronald E., and Hans 0. Nyman, District Heating/Cogeneration Application Studies for the Minneapolis-St. Paul Area: Methods and Cost Estimates for Converting Existing Building to Hot Water District Heating, ORNL/TM-6830/P4; Prepared for the Oak Ridge National Laboratory under Contract No. W-7405-eng-26; Minnesota Energy Agency, St. Paul, Minnesota, December 1979.

Todd, David K., Ground Water Hydrology, John Wiley \& Sons, Inc., New York, New York, 336 pp, 1959.

Tsang, Chin Fu, "Thermal Energy Storage in Underground Aquifers," Proceedings of Second Annual Thermal Energy Storage Contractors' Information Exchange Meeting, CONF-770955; Gatlinburg, Tennessee, September 29-30, 1977; Oak Ridge National Laboratory, Oak Ridge, Tennessee, 1977.

, Thomas Buscheck, Donald Mangold, and Marcelo Lippmann, "Mathematical Modeling of Thermal Energy Storage in Aquifers," Thermal Energy Storage in Aquifers Workshop: Proceedings, May 1012, 1978; Sponsored by U.S. Department of Energy through Oak Ridge National Laboratory; Report LBL-8431, Earth Sciences Division, Lawrence Berkeley Laboratory, University of California, Berkeley, California, pp 37-45, December 1978.

, A Review of Current Aquifer Thermal Energy Storage Projects, LBL-9834; Paper presented at the INTERNATIONAL ASSEMBLY ON ENERGY STORAGE, Dubrovnik, Yugoslavia, May 27-June 1, 1979; Lawrence Berkeley Laboratory, University of California, Berkeley, May 1979.

"Seasonal Thermal Energy Storage in Aquifers - Mathematical Modeling Studies in 1979," Thermal Energy Storage, Fourth Annual Review Meeting, NASA CP-2125 (DOE: CONF-791232); A program review sponsored by the U.S. Department of Energy, organized by the NASA Lewis Research Center, held at Tysons Corner, Virginia, December 3-4, 1979; pp 581-589, 1980a. 
, "Thermohydraulics," Notes from Intermational Seminar on Heat Storage in Aquifers, Lund Institute of Technology, Lund, Sweden, Apri1 15-16, 1980b.

(UE\&C) United Engineers \& Constructors, Inc., AlZocation Method for the Separation of Electrical and Thermal Costs, High Bridge Generating Plant Cogeneration Retrofit Study, UE\&C-NSP-782811; Prepared for the Northern States Power Company; Philadelphia, Pennsylvania, November 1978, revised July 1979.

(USDOE) U.S. Department of Energy, Proceedings of Solar Energy Storage Options - Volume I-1, CONF-790328-P1, San Antonio, Texas, March 19-20, 1979a.

- Proceedings of Solar Energy Storage options - Volume I-2, CONF-790328-P2, San Antonio, Texas, March 19-20, $1979 \mathrm{~b}$.

, Proceedings of Solar Energy Storage Options - Volume II, CONF-790328-P3, San Antonio, Texas, March 19-20, 1979c.

- Multi-Year Plan for Thermal and Mechanical Energy Storage Program, DOE/ET-0109 (Draft), Division of Energy Storage Systems, Washington, D.C., June 1979d.

(USEPA) U.S. Environmental Protection Agency, Report to Congress: Waste Disposal Practices and Their Effects on Ground Water, EPA-570/9-77-001; Edited by David W. Miller, Geraghty \& Miller; Office of Water Supply and Office of Solid Waste Management Programs, Washington, D.C., 531 pp, January 1977.

(USGAO) U.S. General Accounting Office, Industrial Cogeneration What It Is, How It Works, Its Potential, EMD-80-7, Report to the Congress of the United States by the Comptroller General, Washington, D.C., Apri1 29, 1980.

(USGS) U.S. Geological Survey, Water of the World, Pamphlet GPO: 1972-472-417, Washington, D.C., 20 pp, 1972.

(USNBS \& FEA) U.S. National Bureau of Standards and Federal Energy Administration, NBS Handbook 121, Waste Heat Management Guidebook, Kenneth G. Kreider and Michael B. McNeil (eds), U.S. Government Printing Office (SD Catalog No. C13.11:121), Washington, D.C., February, 1977.

Van Note, Robert H., John L. Featherstone, and Bernard S. Pawlowski, "A Cost-Effective Treatment System for the Stabilization of Spent Geothermal Brines," Second Invitational Well-Testing Symposium: Proceedings, LBL-8883 (CONF-7810170); Prepared for the U.S. Department of Energy under Contract W-7405-ENG-48; Earth Sciences Division, Lawrence Berkeley Laboratory, University of California, Berkeley, California, pp 29-33, October 25-27, 1978. 
Warner, Don L., and Jay H. Lehr, An Introduction to the Technology of Subsurface Wastewater Injection, EPA-600/2-77-240; Prepared for the Robert S. Kerr Environmental Research Laboratory, U.S. Environmental Protection Agency, Ada, Oklahoma, under Grant No. R-803889; University of Missouri, Rolla, Missouri, December 1977.

, et al, Radius of Pressure Influence of Injection Wells, EPA-600/2-79-170; Prepared for the Robert S. Kerr Environmental Research Laboratory, U.S. Environmental Protection Agency, Ada, Oklahoma, under Grant No. R-805-29; University of Missouri, Rolla, Missouri, August 1979.

Werner, Dietrich, and Wolfram Kley, "Problems of Heat Storage in Aquifers," Joumal of Hydrology, Vol. 34, pp 35-43, 1977.

Whitehead, W.R., and E.J. Langhetee, "Use of Bounding Wells to Counteract the Effects of Preexisting Groundwater Movement," Paper 8W0064 (0043-1397/78/028W-006-4503.00), Water Resources Research, Vol. 14, No. 2, pp 273-280, April 1978.

Wilson, W.B., and W.J. Hefner, "The Role of Gas and Steam Turbines to Reduce Industrial Plant Energy Costs," Combustion, pp 32-41, November 1973.

Zaininger, H.W., et al, Synthetic Electric Utility Systems for Evaluating Advanced Technologies, Final Report EPRI EM-285; Prepared for the Electric Power Research Institute, Technology Planning Study 75-615; Power Technologies, Incorporated, Schenectady, New York, February 1977. 


\section{DISTRIBUTION}

No. of

Copies

OFFSITE

A. A. Churm

DOE Patent Division

9800 S. Cass Avenue

Argonne, IL 60439

John J. Brogan

DOE Office of Advanced Conservation Technologies

Washington, DC 20585

J. Gahimer

DOE Office of Advanced Conservation Technologies

Washington, DC 20585

B. J. Gallagher

DOE Office of Advanced Conservation Technologies

Washington, DC 20585

S. M. Hanson

DOE Office of Advanced Conservation Technologies

Washington, DC 20585

$R$. Jones

DOE Office of Advanced Conservation Technologies

Washington, DC 20585

G. F. Pezdirtz

DOE Office of Advanced Conservation Technologies

Washington, DC 20585

S. Strauch

DOE Office of Advanced Conservation Technologies

Washington, DC 20585
No. of

Copies

J. H. Swisher

DOE Office of Advanced Conservation Technologies

Washington, DC 20585

213 Technical Information Center

Fred J. Molz

School of Engineering

Auburn University

Auburn, AL 36830

Donald Langmuir

Department of Chemistry

and Geochemistry

Colorado School of Mines

Golden, CO 80401

Louis Stern

Dames \& Moore

6 Commerce Drive

Cranford, NJ 07016

Walter Hausz

GE-TEMPO

Center for Advanced Studies

816 State Street

P.0. Drawer QQ

Santa Barbara, CA 93102

50 Charles F. Meyer

GE-TEMPO

Center for Advanced Studies

816 State Street

P.0. Drawer QQ

Santa Barbara, CA 93102

Chin $\mathrm{Fu}$ Tsang

B1dg 90, Room 102-H

University of California

Lawrence Berkeley Laboratory

1 Cyclotron Road

Berkeley, CA 94720 
No. of

Copies

Victor E. Hampel

Integrated Information Systems

Computation Dept., L-275

University of California

Lawrence Livermore Laboratory

P.0. Box 808

Livermore, CA 94550

Charles H. Lee

Midwest Research Institute

425 Volker Blvd

Kansas City, MO 64110

Mat Walton

Minnesota Geological Survey

319 15th Avenue S.E.

Minneapolis, MN 55455

R. A. Duscha

NASA Lewis Research Center

21000 Brookpark Blvd

Cleveland, $\mathrm{OH} 44135$

E. R. Furman

NASA Lewis Research Center

21000 Brookpark Blvd

Cleveland, $\mathrm{OH} 44135$

A. William Nice

NASA Lewis Research Center

21000 Brookpark Blvd

Cleveland, $\mathrm{OH} 44135$

National Aeronautics and Space Adminstration Asst Adm for Energy Programs

Washington, DC 20546

National Science Foundation

Division of Advanced Energy

Research and Technology

Room 1140

1800 G Street, NW

Washington, DC 20550

L. Lorenz

Internorth

2223 Dodge St.

Omaha, NB 68102
No. of

Copies

Director

New York State Energy Research

\& Development Agency

Rockefeller Plaza

Albany, NY 12223

J. F. Martin

Oak Ridge National Laboratory

P.0. Box Y

Oak Ridge, TN 37830

Douglas D. Huxtable, Director

Energy R\&D

Rocket Research Company

York Center

Redmond, WA 98052

L. B. Katter

Rocket Research

York Center

Redmond, WA 98052

L. Radosevich

Sandia Laboratories, Livermore P.0. Box 969

Livermore, CA 94550

W. G. Wilson

Sandia Laboratories, Livermore

P.0. Box 969

Livermore, CA 94550

Sandia Laboratories

Technical Library Div. 3141

Albuquerque, NM 87185

Frank Baylin

Solar Energy Research Institute

1536 Cole Blvd

Golden, CO 80401

Charles Wyman

Solar Energy Research Institute

1536 Cole Blvd

Golden, CO 80401 
No. of

Copies

John F. Spencer

Department of Ecology

State of Washington

Olympia, WA 98504

J. M. Cherne

TRW

One Space Park

Redondo Beach, CA 90278

Jerry J. Phillips

Projects Manger

Tennessee Valley Authority

350 Commerce Union Bank Bldg

Chattanooga, TN 37401

William Waldrop

Assistant Branch Chief

Water Systems Development Branch

Division of Water Management

Tennessee Valley Authority

P.0. Drawer E

Norris, TN 37828

Craig Cooley

Terra Tek

University Research Park

400 Wakara Way

Salt Lake City, UT 84108

Donald L. Reddell

Agricultural Engineering Dept.

Texas A\&M University

College Station, TX 77843

U.S. Army Corps of Engineers

Attn: Library

P.0. Box 59

Louisville, KY 40202

U.S. Department of Energy

Attn: Chief, APMBR

Division of Energy Storage Systems

Washington, DC 20545
No. of

Copies

U.S. Department of Energy

Attn: Director, Policy and Planning

Office of Conservation and Solar Applications

Washington, DC 20545

U.S. Department of Interior

Attn: Natural Resources Library

Serials Branch (G/E)

Washington, DC 20240

Robert D. MacNish,

District Chief

Arizona District

U.S. Geological Survey

Federal Building

Tucson, AR 85718

Union Carbide Corporation

Nuclear Division

Attn. Library

$Y-12$ Plant

P.0. Box $Y$

Oak Ridge, TN 37830

Stanley N. Davis

Department of Hydrology and Water Research

University of Arizona

Tucson, AZ 85705

W. E. Soderberg

Program Director, ATES

University of Minnesota

Physical Plant Operations

200 Shops Bldg.

319 15th Avenue S.E.

Minneapolis, MN 55455

James W. Crosby II I

Geology Department

Washington State University

Pullman, WA 99164 
David L. Schreiber, Ph.D., P.E. Consulting Hydraulic Engineer

P.0. Box 1087

(c/o The Colony)

Coeur d'Alene, ID 83814

\section{ONSITE}

2 DOE Richland Operations Office

D. K. Jones

H. E. Ransom

82 Pacific Northwest Laboratory

M. A. Beckwith

D. Blahnik

C. H. Bloomster

S. M. Brown

D. B. Cear lock

R. N. Coy

D. E. Deonigi

T. J. Doherty

J. R. Eliason

J. D. Etchemendy

K. Fox

W. A. Frier

D. L. Gale

A. F. Gasperino

P. L. Hendrickson
R. K. Johnson

C. T. Kincaid

L. D. Kannberg

W. W. Laity

L. R. Lambert

W. V. Loscutoff

R. P. Marshall

J. E. Minor

D. A. Myers

M. E. Olson

J. R. Raymond

R. W. Reilly

W. D. Richmond

B. L. Scott

J. A. Stottlemyre

R. A. Walter

T. L. Willke

G. E. Wukelic

J. C. Zuck

STES Library (40)

Technical Information (5)

Publishing Coordination MI(2)

Program Office 